$\frac{127}{9-1 .-88} \mathrm{JT}$

UC-224

\title{
TFE VERIFICATION PROGRAM
}

\author{
SEMIANNUAL REPORT \\ FOR THE PERIOD ENDING APRIL 30, 1988
}

\author{
PREPARED UNDER \\ CONTRACT DE-AC03-86SF16298 \\ FOR THE SAN FRANCISCO OPERATIONS OFFICE \\ DEPARTMENT OF ENERGY
}

DATE PUBLISHED: JUNE 1988

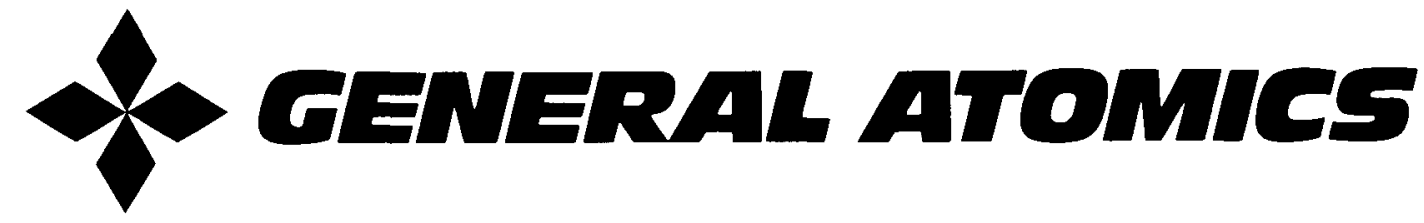




\section{DISCLAIMER}

This report was prepared as an account of work sponsored by an agency of the United States Government. Neither the United States Government nor any agency Thereof, nor any of their employees, makes any warranty, express or implied, or assumes any legal liability or responsibility for the accuracy, completeness, or usefulness of any information, apparatus, product, or process disclosed, or represents that its use would not infringe privately owned rights. Reference herein to any specific commercial product, process, or service by trade name, trademark, manufacturer, or otherwise does not necessarily constitute or imply its endorsement, recommendation, or favoring by the United States Government or any agency thereof. The views and opinions of authors expressed herein do not necessarily state or reflect those of the United States Government or any agency thereof. 


\section{DISCLAIMER}

Portions of this document may be illegible in electronic image products. Images are produced from the best available original document. 
This report was prepared as an account of work sponsored by an agency of the United States Government. Neither the United States Government nor any agency thereof, nor any of their employees, makes any warranty, express or implied, or assumes any legal liability or responsibility for the accuracy, completeness, or usefulness of any information, apparatus, product, or process disclosed, or represents that its use would not infringe privately owned rights. Reference herein to any specific commercial product, process, or service by trade name, trademark, manufacturer, or otherwise, does not necessarily constitute or imply its endorsement, recommendation, or favoring by the United States Government or any agency thereof. The views and opinions of authors expressed herein do not necessarily state or reflect those of the United States Government or any agency thereof.

Printed in the United States of America Available from

National Technical Information Service

U.S. Department of Commerce

P.O. Box 62

Oak Ridge, Tenn. 37831

Price Code: Printed Copy A10; Microfiche A01 
This report was prepared as an account of work sponsored by an agency of the United States Government. Neither the United States Government nor any agency thereof, nor any of their employees, makes any warranty, express or implied, or assumes any legal liability or responsibility for the accuracy, completeness, or usefulness of any information, apparatus, product, or process disclosed, or represents that its use would not infringe privately owned rights. Reference herein to any specific commercial product, process, or service by trade name, trademark, manufacturer, or otherwise does not necessarily constitute or imply its endorsement, recommendation, or favoring by the United States Government or any agency thereof. The views and opinions of authors expressed herein do not necessarily state or reflect those of the United States Government or any agency thereof.

\title{
TFE VERIFICATION PROGRAM
}

\author{
SEMIANNUAL REPORT \\ FOR THE PERIOD ENDING APRIL 30, 1988
}

\author{
PREPARED UNDER \\ CONTRACT DE-AC03-86SF16298 \\ FOR THE SAN FRANCISCO OPERATIONS OFFICE \\ DEPARTMENT OF ENERGY
}

\author{
GA PROJECT 3450 \\ DATE PUBLISHED: JUNE 1988
}

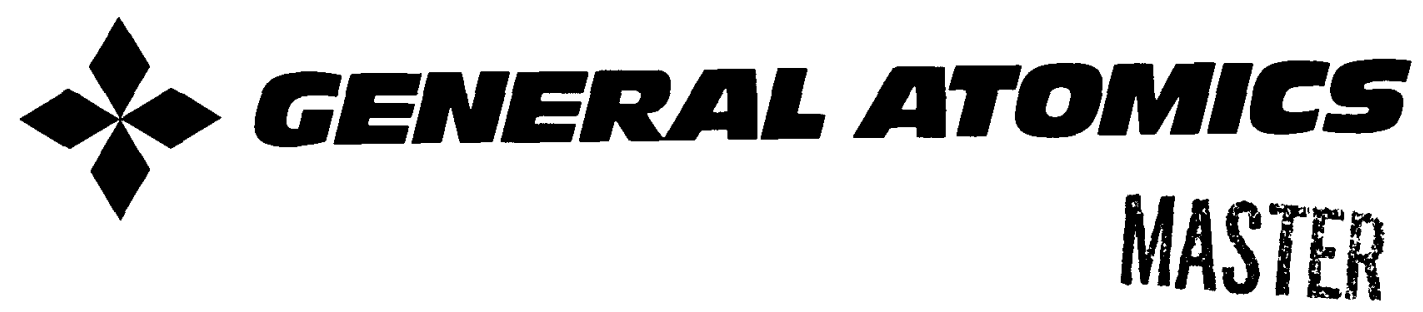


CONTENTS

Page

1. INTRODUCTION . . . . . . . . . . . . . . . . . . . . 1

1.1 Objective of Progress Report . . . . . . . . . . . . . . . 1

1.2 TFE Verification Program Goal . . . . . . . . . . . . . . 1

1.3 Technical Approach . . . . . . . . . . . . . . . . 1

2. CONCEPT DESIGN TASK ...................... . . 5

2.1 Objective . . . . . . . . . . . . . . . . 5

2.2 Technical Approach . . . . . . . . . . . . . . . 5

2.3 Results . . . . . . . . . . . . . . . . . 6

3. CONVERTER PERFORMANCE TASK . . . . . . . . . . . . . . . . . 9

3.1 Objective . . . . . . . . . . . . . . . . . . . . 9

3.2 Task Description . . . . . . . . . . . . . . . . . 9

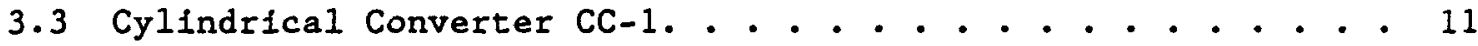

3.3.1 CC-1 Design and Fabrication. . . . . . . . . . . 11

3.3.2 Operational Checks ................ 11

3.3.3 Disassembly and Diagnostics . . . . . . . . . 13

3.3.4 Cesium Reservoir Analysis . . . . . . . . . . . . 17

3.3.5 Tantalum Foil Wrapped Around the Graphite Block . . . 19

3.4 CC-1X Design and Fabrication. . . . . . . . . . . . . . . . 24

3.5 1H1 Startup and Converter Diagnostic . . . . . . . . . . 24

3.5 .1 Project Goal . . . . . . . . . . . . . . . . . . 24

3.5.2 Status of Diagnostics and Computer Models . . . . 28

3.5 .3 Remalning Work . . . . . . . . . . . . . . 33

References................. 33

4. INSULATOR SEAL TASK . . . . . . . . . . . . . . . . . . 34

4.1 Objective. . . . . . . . . . . . . . . . . . . 34

4.2 Task Description . . . . . . . . . . . . . . . . . 34

4.3 Results-to-Date...................... 35

4.3.1 Fabrication Development ............ . 36

4.3.2 In-Reactor Testing . . . . . . . . . . . . 36

5. SHEATH INSULATOR TASK . . . . . . . . . . . . . . . . 46

5.1 Objective and Technical Approach . . . . . . . . . . . 46

5.2 Sheath Insulator Fabrication Development . . . . . . . . 47

5.2.1 Cermet Sheath Insulator Fabrication . . . . . . 47

5.2.2 Plasma Sprayed Sheath Insulator Fabrication . . . 55

5.3 Ex-Reactor Testing Program . . . . . . . . . . . . 57

5.3.1 Introduction ................ . 57

5.4 In-Reactor Testing Program . . . . . . . . . . . . . . 69

5.4.1 UCA Irradiation Testing . . . . . . . . . . . 69

References .................... 94

6. FUELED EMITTER TASK . . . . . . . . . . . . . . . 95

6.1 Objective and Technical Approach . . . . . . . . . . 95

6.2 Ex-Reactor Testing . . . . . . . . . . . . . 96

6.3 UFAC In-Reactor Testing . . . . . . . . . . . . . . . 97

6.3.1 UFAC Batch 1 Status . . . . . . . . . . 97 


\section{CONTENTS (Continued)}

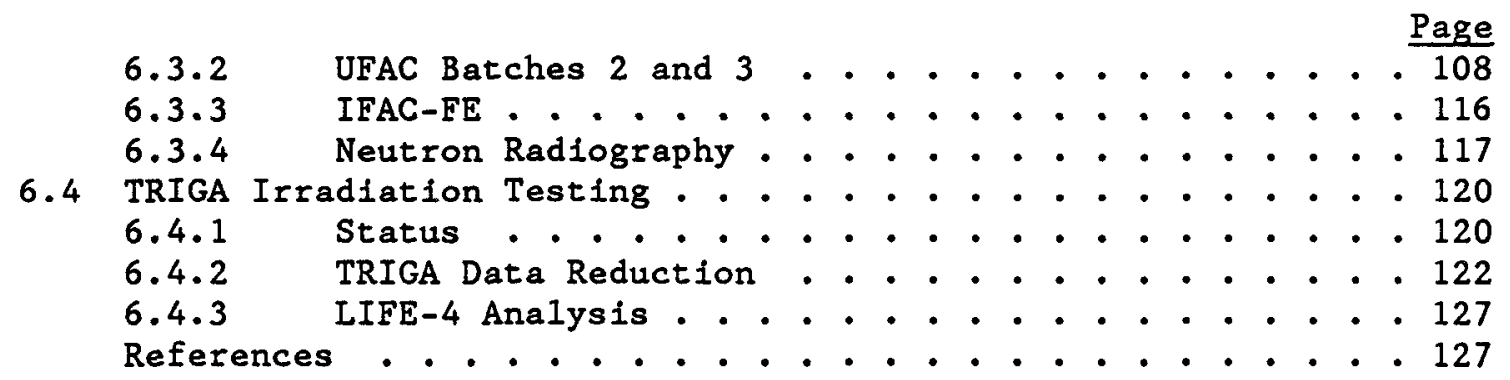

7. CESIUM RESERVOIR AND INTERCONNECTIVE TFE COMPONENTS • • . • • • 137

7.1 Objective . . . . . . . . . . . . . . . . . . . . 137

7.2 Task Description . . . . . . . . . . . . . . . . . 137

7.3 Progress During Present Reporting Period. . . . . . . . . . 138

7.3.1 Cesium Loading of HOPG . . . . . . . . . . . . . 138

7.3.2 POCO Outgassing . . . . . . . . . . . . . . 139

7.3.3 Alternate Reservoir Materials . . . . . . . . . 143

7.3.4 Impurities in Bulk Graph1te. . . . . . . . . . . . . . 145

7.3.5 Test Stand Modifications . . . . . . . . . . 145

7.3.6 PIE Test Stand................. 147

7.4 Cesium Reservoir Materlals Summary . . . . . . . . . 147

References 148

8. THERMIONIC FUEL ELEMENTS . . . . . . . . . . . . . . . 151

8.1 Objective . . . . . . . . . . . . . . . . . 151

8.2 Task Description . . . . . . . . . . . . . . 151

8.2.1 Testing Logic.................. 151

8.2.2 TRIGA Facility . . . . . . . . . . . . 152

8.2.3 Design Description . . . . . . . . . . . 155

8.3 Engineering and Hardware Design . . . . . . . . . . . . 176

8.3.1 Converter Design . . . . . . . . . . . . 180

8.3.2 Cesium Reservoir Design . . . . . . . . . . 181

8.3.3 TFE Assembly Design . . . . . . . . . . . 181

8.3.4 Test Vehicle Design ............. . 182

8.4 TFE Fabrication ..................... . . 187

8.4.1 Fabrication Process Development . . . . . . . 189

8.4.2 H-Series Fabrication . . . . . . . . . 193 


\section{FIGURES}

$\underline{\text { Page }}$

1-1 Logic to demonstrate technology readiness of megawatt class TFE . . . 2

3-1 CC-1 test configuration . . . . . . . . . . . . . . . . . . 12

3-2 Work function correlation . . . . . . . . . . . . . . . . . . . 14

3-3 Emitter work function test assembly . . . . . . . . . . . . . . . . 16

3-4 CC-1 reservoir tabulation . . . . . . . . . . . . . . . . . 18

3-5 Schematic of experimental setup for graphite reservoir evolved gas analysis ........... . . . . . . . . . . . . . . 18

3-6 Graphite reservoir evolved gas spectrum after 16 hours at $900 \mathrm{~K}$. . . 20

3-7 Graphite reservoir evolved gas spectrum after 4 hours at $1220 \mathrm{~K}$. . . 21

3-8 Photo of ring deposit on $\mathrm{Ta}$ foil wrapped around the graphite block 22

3-9 SEM and EDX pictures obtained outside the ring deposit . . . . . . . 23

3-10 SEM and EDX pictures obtained inside the ring deposit . . . . . . . . 25

3-11 Graphite reservolr outgassing and cesium loading assemb1y . . . . . . 26

3-12 CC-1X test configuration . . . . . . . . . . . . . . . . . 27

3-13 Effect of temperature profile and electrode resistance on ignited mode1 I-V curves . . . . . . . . . . . . . . . . . . . . . . . 29

3-14 Effect of temperature profile on unignited model I-V curves . . . . . 30

3-15 Comparison of ignited planar model with data . . . . . . . . . . . . 32

4-1 UCA-1 postirradiation examinations Litton tapered seal/AI $\mathrm{O}_{3} \cdot$. $\cdot$. $_{3} 39$

4-2 Thermionic fuel element insulator seal performance . . . ${ }^{2}{ }^{3}$. . . . . 40

4-3 UCA-1 postirradiation examinations gas pressure bonded insulator seal 41

4-4 Thermionic fuel element insulator seal performance . . . . . . . . . 42

4-5 UCA-1 postirradiation examinations yttria trilayer seal . . . . . . 44

4-6 Thermionfc fuel element insulator seal performance . . . . . . . . . 45

5-1 Biaxial strength test fixture schematic . . . . . . . . . . . . . . . 53

5-2 Sheath insulator/electrode configuration. Length $0.75 "$. . . . . . . 61

5-3 TFE verification sheath insulator data acquisition system . . . . . . 62

5-4 Sheath insulator test oven showing samples in place . . . . . . . . . 63

5-5 Detail of sample/spacer configuration . . . . . . . . . . . . 64

5-6 UCA-1 sheath insulator end configuration designs . . . . . . . . . . 72

5-7 UCA-1 test specimen location . . . . . . . . . . . . . . . . 73

5-8 Fast reactor irradiation testing UCA-1 PIE flow chart . . . . . . . . 74

5-9 Neutron radiographs of UCA-1 subcapsules from MOTA canisters $5 \mathrm{a} / 5 \mathrm{~b} .76$

5-10 Neutron radiographs of UCA-1 subcapsules from MOTA canisters $5 \mathrm{c} 5 \mathrm{~d} / 4 \mathrm{~b} \quad 77$

5-11 UCA-1 test content in canisfer $4 \mathrm{~B}$ and conditjons following irradiation

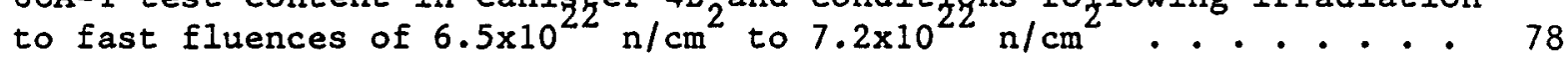

5-12 UCA-1 test content in canisfer $5 \mathrm{~A}$ and conditfons following irradiation to fast fluences of $2.5 \times 10^{22} \mathrm{n} / \mathrm{cm}^{2}$ to $4.1 \times 10^{22} \mathrm{n} / \mathrm{cm}^{2}$......... . 79

5-13 UCA-1 test content in $2 \xi^{a n i s t e} r$ 5B and cqpditions following irradiation to fluences of $2.5 \times 10^{22} \mathrm{n} / \mathrm{cm}^{2}$ to $4.1 \times 10^{22} \mathrm{n} / \mathrm{cm}^{2}$.......... 80

5-14 UCA-1 test content in ganister $5 \mathrm{C}$ and copditions following irradiation to fluences of $2.5 \times 10^{22} \mathrm{n} / \mathrm{cm}^{2}$ to $4.1 \times 10^{22} \mathrm{n} / \mathrm{cm}^{2}$.......... 81

5-15 UCA-1 test content in $\mathcal{F}^{\text {anister }} 5 \mathrm{D}$ and cphditigns following irradiation

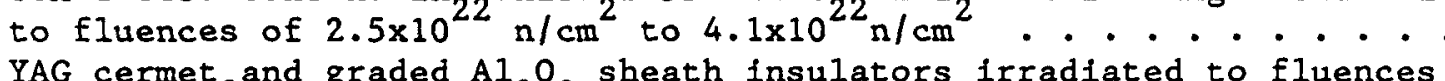

5-16 YAG cermet and $\mathrm{g} 5$ aded $\mathrm{Al}_{2} \mathrm{O}_{3}$ sheath insulators irradiated to fluences

5-17 UCA-2 sheath insulator end configurations . . . . . . . . . . . . 87

5-18 UCA-2 intercell insulation test specimen . . . . . . . . . . . . . . 88

5-19 UCA-2 TFE engineering restraint test specimen . . . . . . . . . . . . 89

5-20 UCA-2 test specimen location . . . . . . . . . . . . . . . . . . . . 90 
FIGURES (Continued)

$\underline{\text { Page }}$

5-21 Preirradiation condition and contents of the UCA-2 subcapsules in canister 1A . . . . . . . . . . . . . . . . . . . . . 91

5-22 Preirradiation condition and contents of the UCA-2 subcapsules in canister 1B............................ 92

5-23 Preirradiation condition and contents of the UCA-2 subcapsules in canister 4C . . . . . . . . . . . . . . . . . . . . 93

6-1 UFAC EBR-II testing schedule . . . . . . . . . . . . . . . . 98

6-2 TECO's UFAC batch 1 heat transfer test setup . . . . . . . . . . . . 99

6-3 EBR-II UFAC batch 1 fueled emitter SU1-4 . . . . . . . . . . . . . . 101

6-4 EBR-II UFAC batch 1 fueled emitter SU1-5 . . . . . . . . . . . . . 102

6-5 EBR-II UFAC batch 1 fueled emitter SU1-6 . . . . . . . . . . . . . 103

6-6 EBR-II UFAC batch 1 fueled emitter SU1-7 . . . . . . . . . . . . . . 104

6-7 EBR-II UFAC batch 1 fueled emitter SU1-8 . . . . . . . . . . . . . 105

6-8 EBR-II UFAC batch 1 fueled emitter SU1-9 . . . . . . . . . . . . . . 106

6-9 EBR-II UFAC batch 1 fueled emitter SU1-10 . . . . . . . . . . . . 107

6-10 EBR-II UFAC batch 1 fueled emitter SU1-4 ............... 108

6-11 EBR-II UFAC batch 1 fueled emitter SU1-5 . . . . . . . . . . . . . 109

6-12 EBR-II UFAC batch 1 fueled emitter SU1-6 . . . . . . . . . . . . . . 110

6-13 EBR-II UFAC batch 1 fueled emitter SU1-7 . . . . . . . . . . . . . . 111

6-14 EBR-II UFAC batch 1 fueled emitter SU1-8 . . . . . . . . . . . . . . 112

6-15 EBR-II UFAC batch 1 fueled emitter SU1-9 . . . . . . . . . . . . . . 113

6-16 EBR-II UFAC batch 1 fueled emitter SU1-10 . . . . . . . . . . . . . . 114

6-17 Photograph of $60^{\circ}$ NR film taken August 1987 by ANL-W . . . . . . . . 119

6-18 Deformation analysis capsule 1 cell 1 . . . . . . . . . . . . . . . . 128

6-19 Deformation analysis capsule 1 cell 2 . . . . . . . . . . . . . 129

6-20 Deformation analys is capsule 1 cell 3 . . . . . . . . . . . . . . 130

6-21 Deformation analysis capsule 2 cell 1 . . . . . . . . . . . . . . 131

6-22 Deformation analysis capsule 2 cell 1 . . . . . . . . . . . . . . . . 132

6-23 Deformation analys is capsule 2 cell 3 . . . . . . . . . . . . . . 133

6-24 Deformation analysis capsule 3 cell 1 . . . . . . . . . . . . . . . 134

6-25 Deformation analysis capsule 3 cell 2 . . . . . . . . . . . . . . . 135

6-26 Deformation analysis capsule 3 cell 3 . . . . . . . . . . . . . . . . 136

7-1 Cs pressure vs. Cs loading for HOPG-ZYH at $1000 \% \mathrm{~K}$. . . . . . . . . . . . . 140

7-2a Cs loading as a function of time at a Cs pressure of 3 torr (after equilibrium at $\sim 0.0$ torr) and graphite temp. of $1000^{\circ} \mathrm{K}$ for HOPG-ZYH .141

7-2b Cs unloading as a function of time at a Cs pressure of 3.8 torr (after equilibrium at 6 torr) and graphite temp. of $1000^{\circ} \mathrm{K}$ for HOPG-ZYH . . 142

8-1 H-series thermionic converter.................... 157

8-2 Converter to converter region. . . . . . . . . . . . . . . . 160

8-3 Converter-to-dumy region . . . . . . . . . . . . . . . 162

8-4 Bottom of TFE . . . . . . . . . . . . . . . . . . . . 163

8-5 Complete TFE . . . . . . . . . . . . . . . . . . . . 164

8-6 Converter-to-TFE lead region . . . . . . . . . . . . . . . . 166

8-7 Liquid cesium reservoir . . . . . . . . . . . . . . . . 167

8-8 Graphite cesium reservoir . . . . . . . . . . . . . . . . . . 168

8-9 Cesium and fission product plumbing . . . . . . . . . . . . . 170

8-10 1H1 TRIGA test capsule schematic . . . . . . . . . . . . . . . . 171

8-11 1H TFE electrical schematic . . . . . . . . . . . . . . . . 172

8-12 TFE $1 \mathrm{H} 1$ containment detalls . . . . . . . . . . . . . . . . . 174

8-13 TFE $1 \mathrm{H} 2$ containment details . . . . . . . . . . . . . . . 175 
8-14 Dummy converter changes . . . . . . . . . . . . . . . . . . . 183

8-15 Temperatures resulting from 0.1 in. disbond spot . . . . . . . . . . 184

8-16 Temperatures resulting from 0.2 in. disbond spot . . . . . . . . . 185

8-17 Effects of disbond spot size on trilayer and sheath temperatures . . 186

8-18 Final processing station . . . . . . . . . . . . . . . . . . . . . 190

8-19 Microstructure of flaw found at 1 Hl stem seal leak site . . . . . . . 192

8-20 Primary containment regassing setup . . . . . . . . . . . . . . . . . 194

8-21 Cesium reservoir, lead sheath and sheath tube weld setup for TFE 1 H1. 196

8-22 TFE 1H1 prepared for final processing . . . . . . . . . . . . . . . 197

8-23 View of $1 \mathrm{H} 1$ emitter potential-lead welded into a cesium reservoir with the cesium reservoir heater joined to the reservoir on the right . . 199 
2-1 2 MWe system parameters . . . . . . . . . . . . . . . 7

2-2 TFE design definition... . . . . . . . . . . . . . . . 8

3-1 Ex-reactor planar converter test program . . . . . . . . . . . . . 10

3-2 Ex-reactor cylindrical converter test program . . . . . . . . . . . . 10

4-1 Insulator seal - technology status . . . . . . . . . . . . . . . 37

5-1 Sheath insulator requirements . . . . . . . . . . . . . . . . 46

5-2 Sheath insulator fabrication development strategy . . . . . . . . . . 48

5-3 Sheath insulator fabrication development-experience . . . . . . . . . 49

5-4 Carbon content of purchased yttria powders . . . . . . . . . . . . 50

5-5 Ceramic mechanical properties (Ref. 6) . . . . . . . . . . . 55

5-6 Sheath insulator fabrication development matrix . . . . . . . . . 56

5-7 Plasma sprayed sheath insulator fabrication development matrix . . . 58

5-8 Metallographic examination of sheath insulators . . . . . . . . . 59

5-9 Final values of resistance for samples previously taken off-line . . 66

5-10 Resistance of samples currently in place in test apparatus . . . . 67

5-11 UCA-1 test matrix . . . . . . . . . . . . . . . . . . . 70

5-12 UCA-1 sheath insulator visual inspection . . . . . . . . . . . . . 84

5-13 UCA-2 test matrix ...................... 86

6-1 Fueled emitter design requirements . . . . . . . . . . . . . . 95

6-2 UFAC batch 1 irradiation history estimated for April 1, 1988 . . . . 100

6-3 UFAC batch 2 proposed test matrix .................. 116

6-4 TRIGA irradiation testing . . . . . . . . . . . . . . . . . . . . . . 121

6-5 TRIGA irradiation testing - capsule/diode status . . . . . . . . . 121

6-6 RSI Spread sheet - TRIGA data . . . . . . . . . . . . . . . . . . 123

7-1 Surface area and impurity content of alternate reservoir materials. . 144

7-2 Impurity levels (In ppm) of as-received starting graphites as specified by vendor and measured by General Atomics . . . . . . . . . . . . . . 146

7-3 Thermionic data: candidate reservolr materials . . . . . . . . . . . 149

7-4 Overall evaluation of candidate reservoir materials after down selection......................... 150

8-1 Comparison of TFE test requirements with system baseline design requirements . . . . . . . . . . . . . . . . . . . . 152

8-2 TFE in-reactor test matrix . . . . . . . . . . . . . . . . 153

8-3 Locations of thermocouples and probes - TFE $1 \mathrm{H} 1$. . . . . . . . . . 177

8-4 Locations of thermocouples and probes - TFE 1H2 . . . . . . . . . . . 178

8-5 Differences between converters . . . . . . . . . . . . . . . . . . . 180

8-6 Test vehicle differences . . . . . . . . . . . . . . . . . . . 187

8-7 Cell and TFE fabrication status summary through $2 / 29 / 88$. . . . . . 200 


\section{INTRODUCTION}

\subsection{OBJECTIVE OF PROGRESS REPORT}

The objective of the semiannual progress report is to summarize the technical results obtained during the latest reporting period. The information presented herein will include evaluated test data, design evaluations, the results of analyses and the significance of results.

\subsection{TFE VERIFICATION PROGRAM GOAL}

The program objective is to demonstrate the technology readiness of a TFE suitable for use as the basic element in a thermionic reactor with electric power output in the 0.5 to $5.0 \mathrm{MW}(e)$ range, and a full-power life of 7 years.

\subsection{TECHNICAL APPROACH}

The TFE Verification Program buflds directly on the technology and data base developed in the 1960s and early 1970s in an AEC/NASA program, and in the SP-100 program conducted in 1983, 1984 and 1985. In the SP-100 program, the attractive features of thermionic power conversion technology were recognized but concern was expressed over the lack of fast reactor irradiation data. The TFE Verification Program addresses this concern.

The general logic and strategy of the program to achieve its objectives is shown on Fig. 1-1. Five prior programs form the basis for the TFE Verification Program:

1) AEC/NASA program of the 1960s and early 1970s.

2) SP-100 concept development program.

3) SP-100 thermionfc technology program.

4) Thermionic frradiations program in TRIGA in FY-86.

5) Thermionic Technology Program in 1986 and 1987.

These programs provide both the systems and technology expertise necessary to design and demonstrate a megawat class TFE. 


\section{LOGIC TO DEMONSTRATE TECHNOLOGY READINESS OF MEGAWATT CLASS TFE}

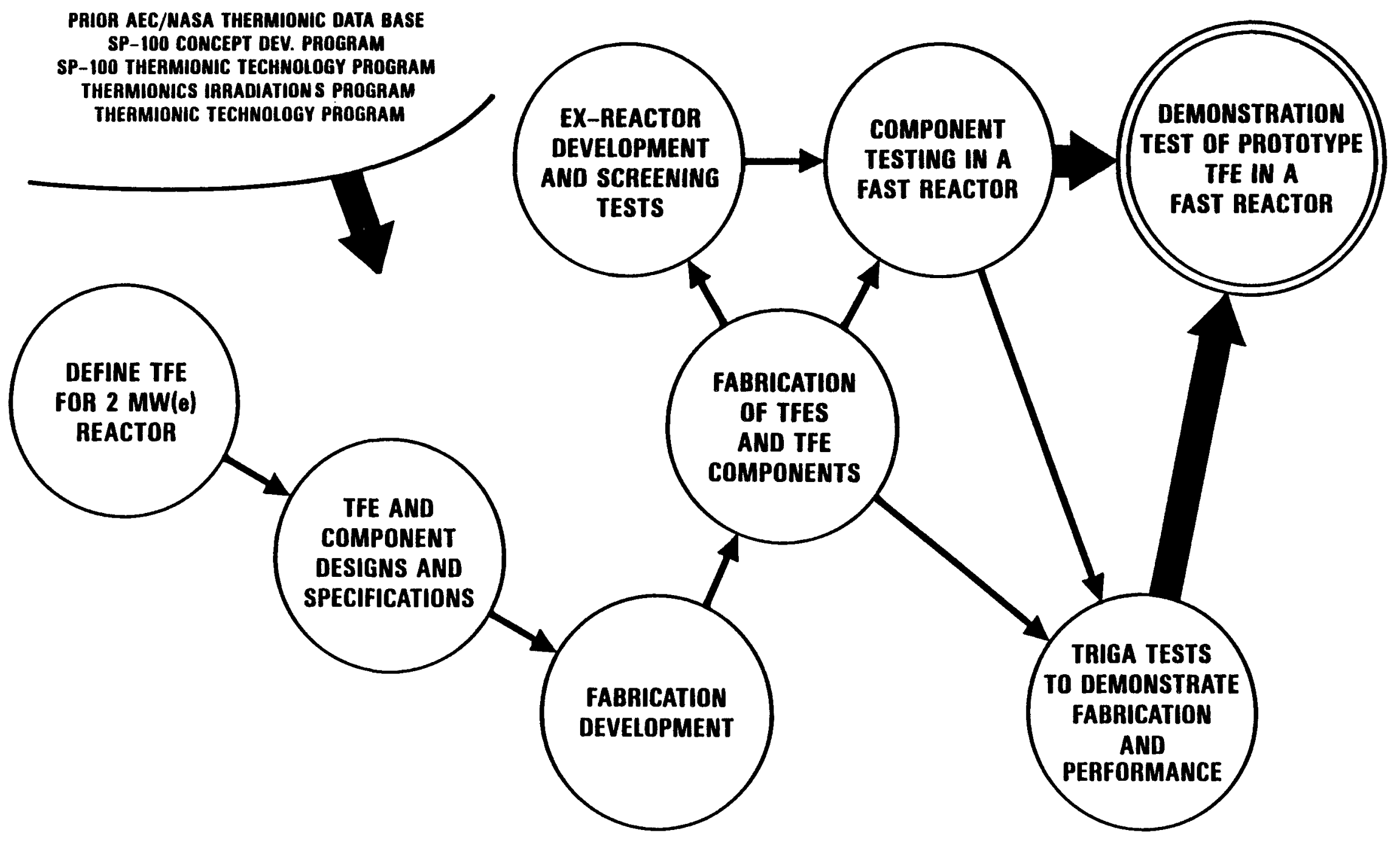


The approach to be followed is to design a TFE that will meet the reliability and lifetime requirements for the $2 \mathrm{MW}(e)$ conceptual reactor design, and initiate component testing in a fast reactor. The demonstration of a 7-year component lifetime capability will be through the combined use of analytical models and accelerated, confirmatory tests. Iterative testing will be performed where the results of one test series will lead to evolutionary improvements in the next test specimens.

The TFE components will undergo screening and inftial development testing in ex-reactor tests. Several design and materials options will be considered for each component. As screening tests permit, down selection will occur. It is necessary to rapidly make baseline design and materials selections to make optimum use of irradiation testing.

In parallel with ex-reactor testing, and fast reactor component testing, components will be integrated into a TFE and tested in the TRIGA. Real-time testing of partial length TFEs will be used to test support, alignment and interconnective TFE components, and to verify TFE performance in-reactor with integral cesium reservoirs. Real-time testing will also be used to verify the relation between TFE performance and fueled emitter swelling, to test the durability of intercell insulation, to check temperature distributions, and to verify the adequacy over time of the fission gas venting channels.

Predictions of TFE lifetime will rest primarily on the accelerated component testing results, as correlated and extended to real-time by the analytical models developed.

The fast reactor testing of fueled emitters will be calibrated by verifying the accuracy of emitter temperature predictions through complementary analysis and ex-reactor and in-reactor diagnostic tests. Instrumented sheath insulators will be tested in a fast reactor with an applied voltage. 
A test of prototypic TFEs will be run in a fast reactor as a verification of the basic TFE design. This design may be upgraded based on the final component testing results.

The deliverables of the program are:

1) Conceptual design of a megawatt class power system including component specifications and a system description.

2) Thermionic components with verified performance.

3) TFE demonstration in a fast reactor.

4) Fabrication process specifications.

5) Verifled performance models. 


\section{CONCEPT DESIGN TASK}

\subsection{OBJECTIVE}

Task 2 provides the design guidance for the TFE Verification Program. The primary goals of this task are:

1) Establish the conceptual design of an in-core thermionic reactor for a $2 \mathrm{MW}(e)$ space nuclear power system with a 7 year operating lifetime.

2) Demonstrate scalability of the above concept over the output power range of $500 \mathrm{~kW}(e)$ to $5 \mathrm{MW}(\mathrm{e})$.

3) Define the TFE which is the basis for the $2 \mathrm{MW}(\mathrm{e})$ reactor design. This TFE speciflcation will then be the basis for the test program.

\subsection{TECHNICAL APPROACH}

The technical approach being taken in the concept design effort can be characterized as follows:

1) Perform system-level tradeoffs to determine inftial TFE features and reactor scalability trends;

2) Refine these results and identify the $2 \mathrm{MW}(\mathrm{e})$ reactor general arrangement with primary emphasis on characterizing the features and performance of the TFE;

3) Enter this information into the program data base via two separate design description documents:

- Two MW(e) reactor-converter system description.

- TFE component specification. 


\subsection{RESULTS}

Current definition of the $2 \mathrm{MW}(e)$ system design and the relevant TFE are shown on Tables $2-1$ and 2-2, respectively. The basic system parameters are unchanged from the last semiannual report, but some minor revisions have been incorporated to make the data more readily understandable. Note that Table 2-2 now reflects gross electrical output power figures for the TFE and the individual converters. 
TABLE 2-1

\section{MWe SYSTEM PARAMETERS}

Net electrical power

System efficiency

Iifetime a full power

Shield cone half-angle

Reactor thermal power

Coolant

Number of TFEs

Heat rejection

Radiator temperature

Radiator area

System mass :

Reactor

Shield

Coolant loop

Main radiator

$P C$ and shielding

PC radiator

Cables

Structure and miscellaneous
$2010 \mathrm{kWe}$

$8.9 \%$

7 years

$12^{\circ}$

$22.5 \mathrm{MW}_{\mathrm{T}}$

Lithium

2849

$20.3 \mathrm{MW}_{\mathrm{T}}$ $1020 \mathrm{~K}$

$426 \mathrm{~m}^{2}$

$8720 \mathrm{Kg}$

2803

1788

6390

1230

262

506

791

Total $\overline{22,490 \mathrm{Kg}}$ 
TABLE 2-2

\section{TFE DESIGN DEFINITION}

PERFORMANCE

Overall TFE:

Output electrical power (We) 782

Efficiency 8.9

Maximum voltage

5.9 (15)

U-235 burnup (a/o)

4.1 avg., 5.3 peak

Fluence (nvt)

$2.7 \times 10^{22}$ avg., $3.5 \times 10^{22}$ peak

Converter:

Converter power (Wt/We)

$658 / 65.2$

Thermal power/length (wt $/ \mathrm{cm}$ )

Emitter power flux ( We $/ \mathrm{cm}^{2}$ )

129.5

Diode current density $\left(\mathrm{a} / \mathrm{cm}^{2}\right)$

3.22

Thermionic work function (eV)

7.0

Emitter temperature ( $K$ )

4.9

Collector temperature (K)

1800

Cesium pd (mil-torr)

1070

Converter output voltage

20

Converter current (amp)

0.49

140

CONFIGURATION

Overall TFE:

TFE length (active core) (in.) $\quad 39.6$

TFE length (overall)

TBD

Sheath tube o.d. (in.)

0.694

Lead o.d. (in.)

0.875

Lead length (in.)

4

Converters per TFE

12

\section{Converter:}

Emitter o.d. $x$ L $x \in$ (in.)

$0.5 \times 2.0 \times 0.040$

Emitter stem L $x \in$ (in.)

$0.45 \times 0.020$

Diode gap (in.)

0.010

Trilayer $t$ : collector

0.028 insulator (in.) outer cylinder

0.016

0.028

Fuel specification

93\% enriched $\mathrm{UO}_{2}$; variable

Intercell axial space (in.) volume fraction ${ }^{2}$

0.74 


\section{CONVERTER PERFORMANCE TASK}

\subsection{OBJECTIVE}

The objective of the converter performance task is to establish accurate converter performance models which have been correlated to observe test data. The data base will be developed from near prototypic converters using emitter and collector materials of interest over the full range of anticipated operating parameters. Part of the data base will include off-design and non-ideal operation of the converters. The resulting models will be used to determine the optimum converter configuration (materials, additives, spacing, etc.) for use in the prototypic TFE and reactor design.

A thermionic reactor is composed of a large array of thermionic cells, each of which has a unique input power, emitter temperature, and operating current density. In addition, individual cells will vary in performance over the system lifetime due to changing operating conditions caused by fuel burnup and variations in operating power requirement, or losses of some of the cells. Thus, the design and performance prediction of a thermionic reactor require an extensive data base on prototypical cell performance over a wide range of operating conditions.

The data and models will also be used in the startup of the TFEs in TRIGA and the FFTF and also in the startup of thermionic reactors. The observed current-voltage data during startup can be related to system temperatures through the ex-reactor correlations.

\subsection{TASK DESCRIPTION}

The test matrix was described in Ref. 3-1. The planned planar and cylindrical tests are shown on Tables $3-1$ and $3-2$, where the test rationale is also shown. 
TABLE 3-1

EX-REACTOR PLANAR CONVERTER TEST PROGRAM

Cs

Emitter Collector Reservolr Rationale for Test

\begin{tabular}{|c|c|c|c|c|}
\hline$P C-1$ & Duplex W & $\mathrm{Nb}$ & Graphite & $\begin{array}{l}\text { Early performance map with graphite } \\
\text {-cesium reservolr. }\end{array}$ \\
\hline PC -2 & Duplex W & $\begin{array}{c}\mathrm{Nb} \\
\text { Tilted }\end{array}$ & Pool & $\begin{array}{l}\text { A verification of the model which } \\
\text { relates converter output to emitter } \\
\text { distortion. Use PD-6 from the } \\
\text { Thermionic Technology Program. } \\
\text { (Ref. 3-2) }\end{array}$ \\
\hline$P C-3$ & $\begin{array}{l}\text { High } \\
\text { Strength } \\
\text { Emitter }\end{array}$ & $\mathrm{Nb}$ & Pool & $\begin{array}{l}\text { Establish data base on performance } \\
\text { with high strength emitter }\end{array}$ \\
\hline PC-1 & $\begin{array}{l}\text { Duplex W } \\
\text { (MOD) }\end{array}$ & $\mathrm{Nb}$ & Graphite & $\begin{array}{l}\text { UO }{ }_{2} \text { in contact with the emitter. } \\
\text { When compared to PC-1, differential } \\
\text { data on the } \mathrm{UO}_{2} \text { effect will be } \\
\text { available }\end{array}$ \\
\hline
\end{tabular}

TABLE 3-2

EX-REACTOR CYLINDRICAL CONVERTER TEST PROGRAM

Emitter Collector Reservolr Test $\begin{array}{lll}\text { Life } & \text { Rationale }\end{array}$

\begin{tabular}{|c|c|c|c|c|c|}
\hline $\mathrm{CC}-1$ & Duplex W & $\mathrm{Nb}$ & Graphite & Yes & $\begin{array}{l}\text { Performance map with } \\
\text { reference electrodes a } \\
\text { reservoir. Iife test f } \\
\text { long term stability wit } \\
\text { graphite-Cs reservoir. }\end{array}$ \\
\hline $\begin{array}{l}C C-2 \\
(C D-1)\end{array}$ & Duplex W & $\begin{array}{c}\text { MoO/Nb } \\
\text { (Oxygenated) }\end{array}$ & Pool & Yes & $\begin{array}{l}\text { Long term stability of } \\
\text { oxygenated electrodes. } \\
\text { Use CD-1 from Thermion } \\
\text { Technology Program. (Re }\end{array}$ \\
\hline $\mathrm{CC}-3$ & $\begin{array}{l}\text { High } \\
\text { strength } \\
\text { emitter }\end{array}$ & $\mathrm{Nb}$ & Pool & No & $\begin{array}{l}\text { Performance maps for a } \\
\text { high strength emitter }\end{array}$ \\
\hline
\end{tabular}




\subsection{CYLINDRICAL CONVERTER CC-1}

\subsubsection{CC-1 Design and Fabrication}

Fabrication of CC-1 was completed at Thermo Electron Corporation in September, 1987. The test configuration for the converter is shown in Fig. 3-1. The converter contains dual cesium reservoirs: a liquid pool reservoir and a pyrolytic graphite integral reservoir. A mechanical valve is located in a series flow arrangement with the liquid pool reservoir to allow the pool reservoir to be valved off when converter operation is desired with the integral reservoir alone.

The pyrolytic graphite is HOPG-ZYG manufactured by Union Carbide. The HOPG-ZYG material is $99.999 \%$ pure, has a density of $2.26 \mathrm{~g} / \mathrm{mc}^{3}$ (zero porosity), and loads cesium by intercalation. The graphite was used in the configuration supplied by the manufacturer, a rectangular solid $12 \mathrm{~mm} 12 \mathrm{~mm} x$ $2 \mathrm{~mm}$. A tantalum foll was loosely wrapped around the graphite to prevent direct contact between the graphite and the niobium reservoir housing.

\subsubsection{Operational Checks}

CC-I was set up in the test stand for operational checks prior to delivery to Rasor Associates for detailed performance testing. The initial checks were run with the mechanical valve open (liquid pool cesium reservoir operation). Abnormal converter operation was observed from the start. Current voltage (I-V) curves obtained under dynamic sweep conditions were very flat. Current output in the positive power quadrant was very low and the slope of the I-V curves was shallow.

A cold spot somewhere in the overall converter tubulation was initially suspected as the cause of the abnormal operation. A cold region would reduce the effective cesium pressure in the converter to a value associated with the cold spot temperature rather than the measured temperature of the pool reservolr. Additional auxillary heaters and thermocouples were installed in the test configuration to explore the possibility of cold spots, but none were found. 
Figure 3-1

8803-20

\section{CC-1 TEST CONFIGURATION}

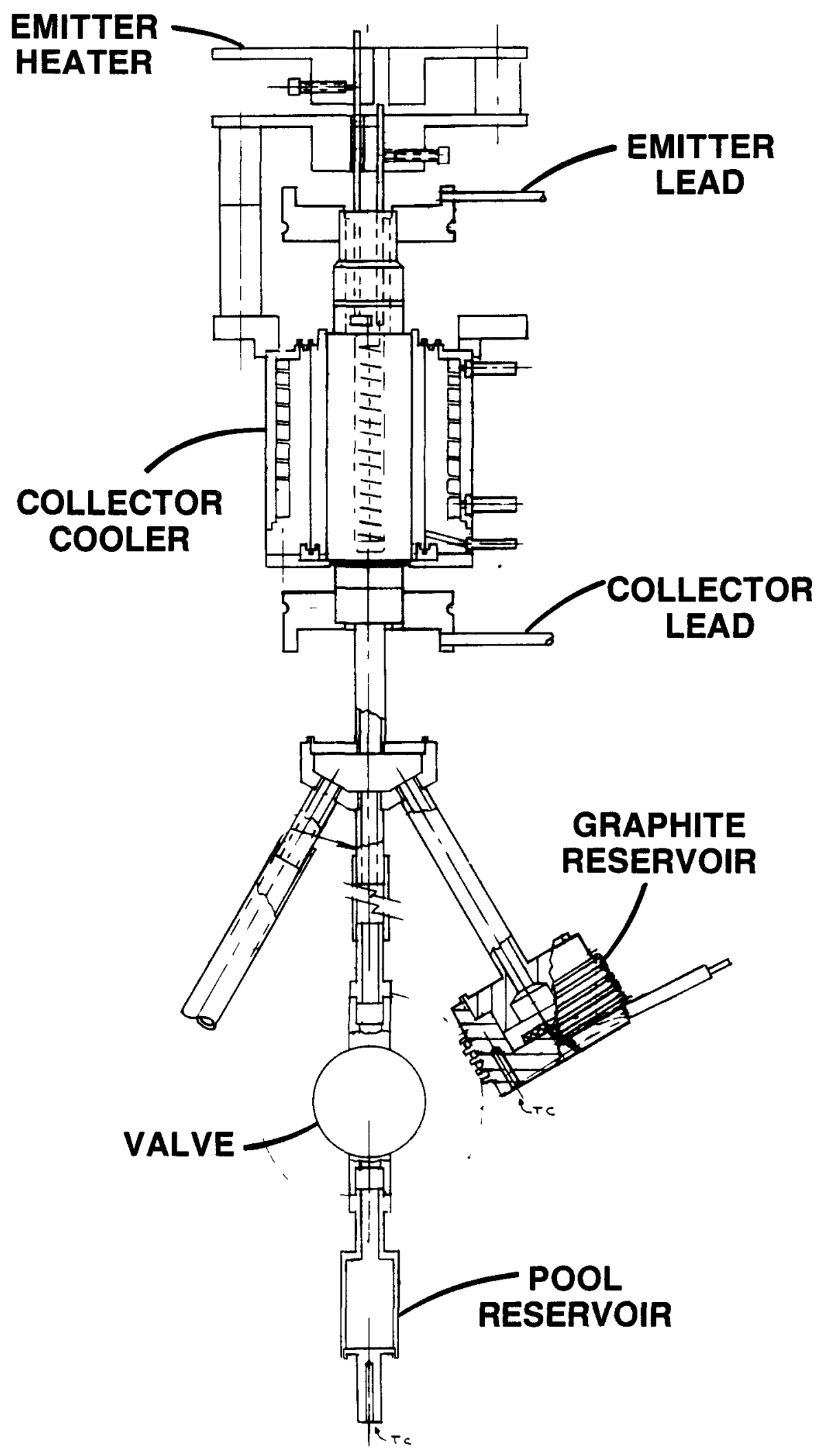


The observed abnormal performance could also be caused by the emitter surface exhibiting a low bare work function. To explore this possibility, a series of saturated current measurements were made over a wide range of emitter and cesium reservoir temperatures. The emitter was operated for extended periods at temperatures up to $1930 \mathrm{~K}$. Analysis of the saturated current measurements and correlation of the results on a Rasor/Warner plot (Fig. 3-2) revealed that the bare work function of the emitter was in the range of 4.8 to 4.9 volts, representative of CVD duplex tungsten emitters and indicative of normal operation. Additional I-V curves were taken at this time to check converter operation under typical power conditions: the abnormal performance had disappeared.

Converter operation was checked for two days and remained stable. The test vacuum system was opened to air and the converter rerun to check for a possible envelope leak. The I-V curves remained normal. After a weekend shutdown, additional saturated current measurements were made as a final check on the converter operation. These data, however, indicated that a change in emitter bare work function had occurred. A rerun of the power $I-V$ curves also showed abnormal performance. Converter operation had cycled from the original abnormal performance, through a period of normal performance, and back to abnormal performance. A high temperature soak of the emitter at $1930 \mathrm{~K}$ for eight days did not cause any further change in operation. Saturated current measurements during this period indicated a stable emitter work function of 4.1 volts and the presence of a contaminant on the emitter surface.

\subsubsection{Disassembly and Diagnostics}

CC-1 was disassembled to allow Inspection of the interior surfaces. The converter was first separated from the reservoirs. The sealed reservoir subassembly was sent to Rasor Associates for analysis of possible contaminants contained within the unit. The converter was leak checked and found to be leak tight. The seal skirt was cut and the emitter withdrawn from the collector. The emitter surface was shiny with small crystalline deposits. The collector surface was dull with black powdery deposits. 
Energy Dispersive spectroscopy

and all deposits were identified as niobium metal.

A cylindrical bare work function test assembly was fabricated to further investigate the emitter surface. The design of the assembly is shown in Fig. 3-3. The test assembly operates in a vac-ion pumped vacuum system at pressures of approximately $2 \times 10^{-8}$ torr. The emitter was first installed in the work function test assembly with the emitter surface in the same condition as disassembled from the converter. Measurements of the as-disassembled bare work function indicated a value of 4.5 volts. A change had occurred in the emitter surface upon disassembly ( 4.1 to 4.5 volts) but still the surface was significantly different then the expected 4.8 to 4.9 volts of a CVD duplex tungsten emitter.

Approximately, .002 inch of surface material was removed from the emitter, the surface electropolished, and the work function remeasured to determine if the contaminant (niobium metal) could be effectively removed. The resurfaced emitter bare work function was measured as a stable 4.9 volts, indicating that the contaminated layer has been removed. The emitter will be used in the rebuilding of CC-1 (CC-1X).

The collector trilayer was cut into small sections for analysis using Electron Spectroscopy for Chemical Analysis (ESCA). The ESCA results showed the presence on the collector surface of niobium, tungsten, carbon, oxygen, and nitrogen. Approximately $40 \%$ of the carbon was in the form of carbide.

The EDS and ESCA analysis results suggest the presence of a hydrocarbon gas such as methane $\left(\mathrm{CH}_{4}\right)$ in the converter interelectrode gap (possibly during outgassing and/or the initial periods of operation). The source of the hydrocarbon could be the pyrolytic graphite. A hydrocarbon gas in the interelectron gap would disassociate on contacting the hot emitter, releasing carbon (plus some refractory metal carbides) and hydrogen. The hydrogen could result in a cyclic process transferring niobium (niobium hydride) from the collector to the emitter. 


\section{EMITTER WORK FUNCTION TEST ASSEMBLY}

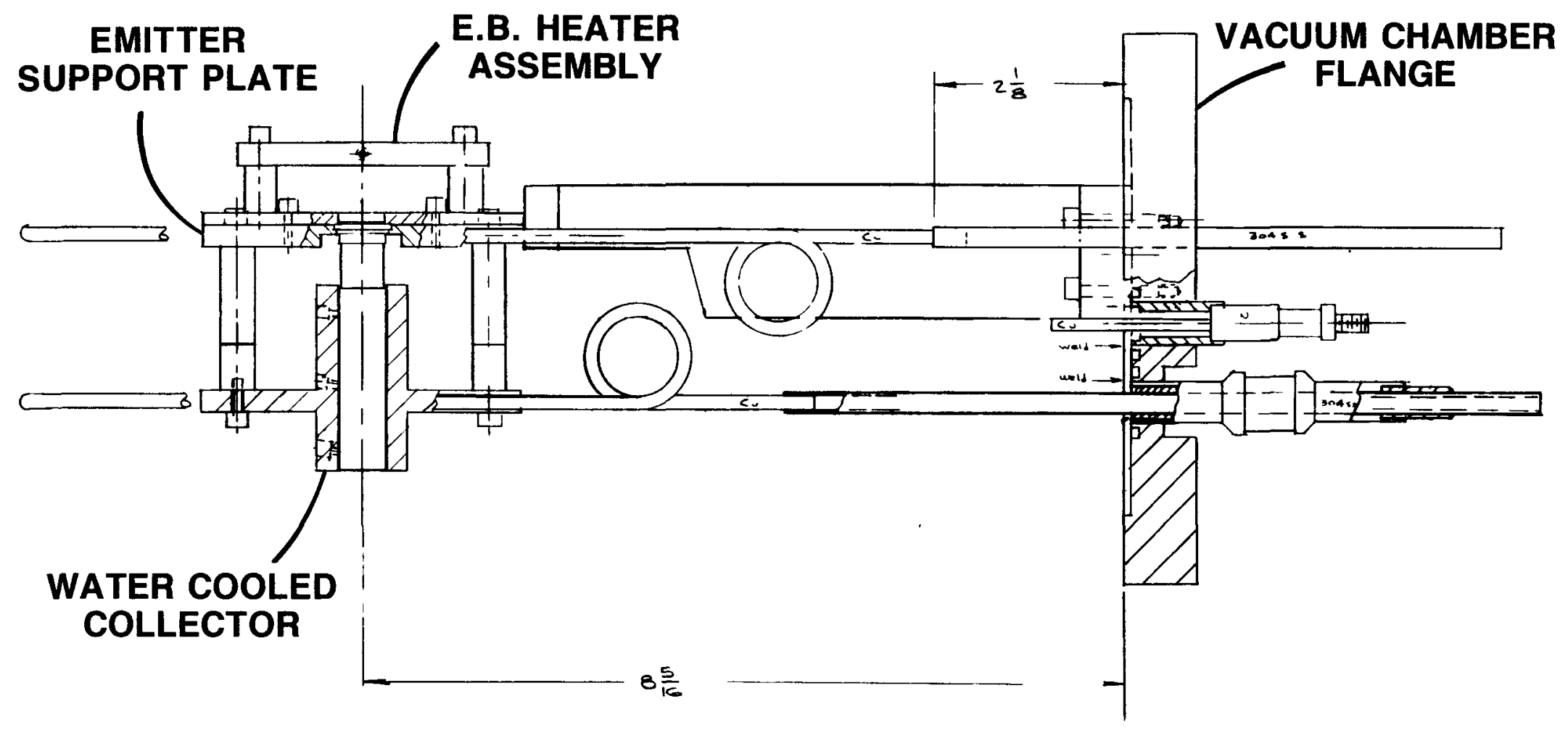




\subsubsection{Cesium Reservoir Analysis}

The ceslum manifold was placed in an Argon box and the secondary reservoir opened at the weld (see Fig. 3-4). The liquid cesium was transferred into a glass vial, while a pumping nipple was welded in to be connected to the residual gas analysis setup.

In addition to a hydrocarbon, another contaminant which could explain the transport of $\mathrm{Nb}$ is $\mathrm{Cl}_{2}$. In particular $\mathrm{Nb} \mathrm{C1}$, which melts at $205^{\circ} \mathrm{C}$, could have condensed with the cesium. Samples of the cesium collected as explained above were sent to an outside lab for analysis. X-ray fluorescence used to detect metal impurities showed no $\mathrm{Nb}$ peak with an upper limit on the concentration of $25 \mathrm{ppm}$. A search for the presence of C1 by wet chemistry proved equally unsuccessful.

Figure 3-5 shows a schematic of the experimenal setup used to analyze the gases evolving from the graphite reservolr while heated. The quadrupole mass spectrometer (QMS) is continuously pumped by a turbomolecular pump. The gases released from the graphite reservoir can be analyzed directly, or, if the overpressure is too high, safely sampled through the bypass leak valve. The pumping line inside the belljar was outgassed at $300^{\circ} \mathrm{C}$, and the outside line briefly outgassed at $100^{\circ} \mathrm{C}$.

The procedure initially adopted to study the gases evolved from the graphite and its container was to raise the container temperature in steps and to briefly open its lsolation valve while recording the mass spectrum. At $700 \mathrm{~K}$ substantial increases were observed at $1\left(\mathrm{H}_{2}\right), 14-15-16\left(\mathrm{Ch}_{4}\right.$ most likely), and in the 26-29 mass range. Much smaller peaks were observed at 36 and 38, hinting at the presence of $\mathrm{HC} 12$. No peaks were observed for $F$, $\mathrm{Cl}$ or $\mathrm{Cl}_{2}$ however, and a scan up to AMU 320 did not reveal any high mass component which could have been responsible for the $\mathrm{Nb}$ transport to the CC-1 emitter, e.g. Nb chlorides. Raising the graphite reservoir temperature up to $1300 \mathrm{~K}$ did not show the gases previously evolved at $700 \mathrm{~K}$.

The procedure was then modified to allow accumulation of the gases in the graphite reservoir over a long period of time so as to make the 


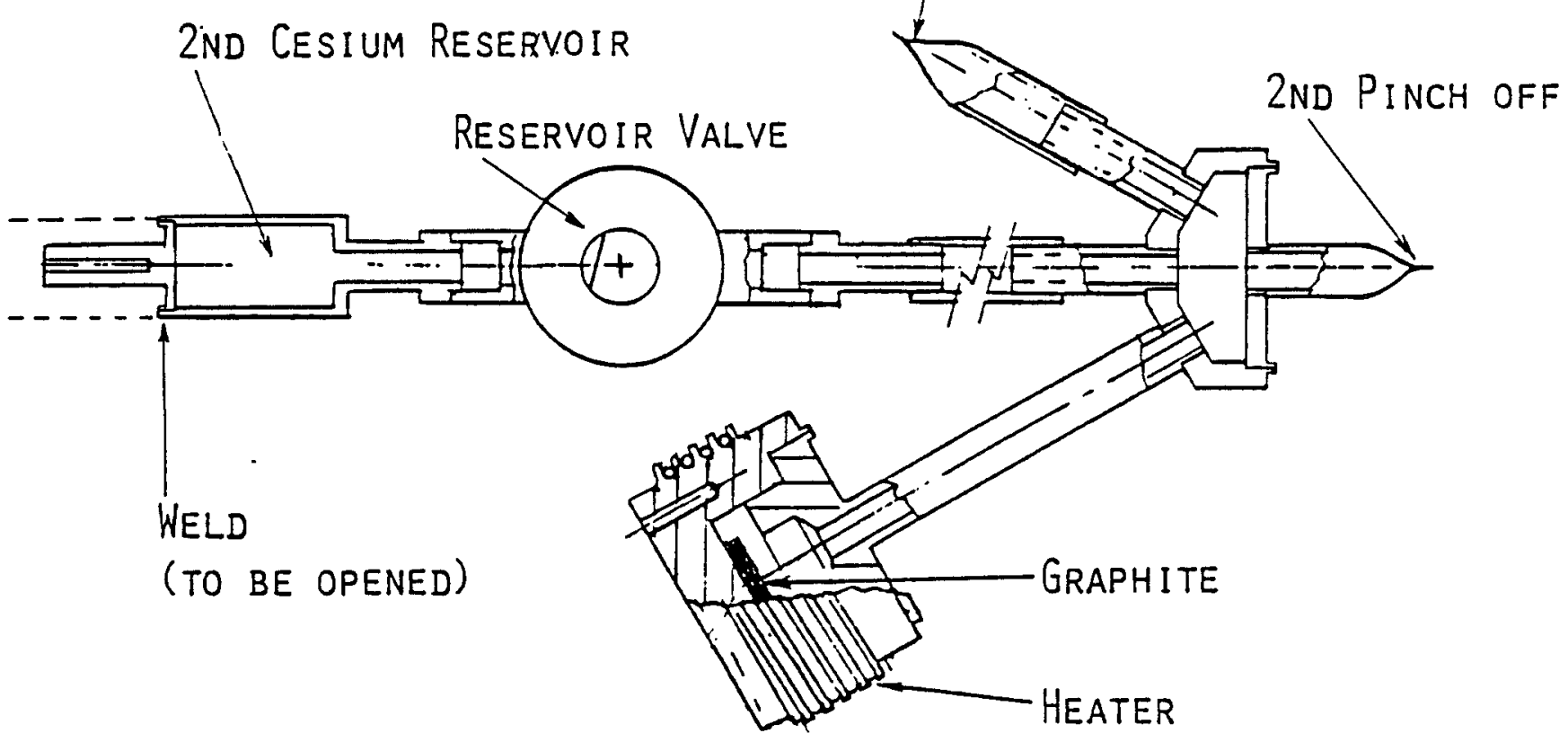

Figure 3-4 - CC-1 Reservoir Tabulation

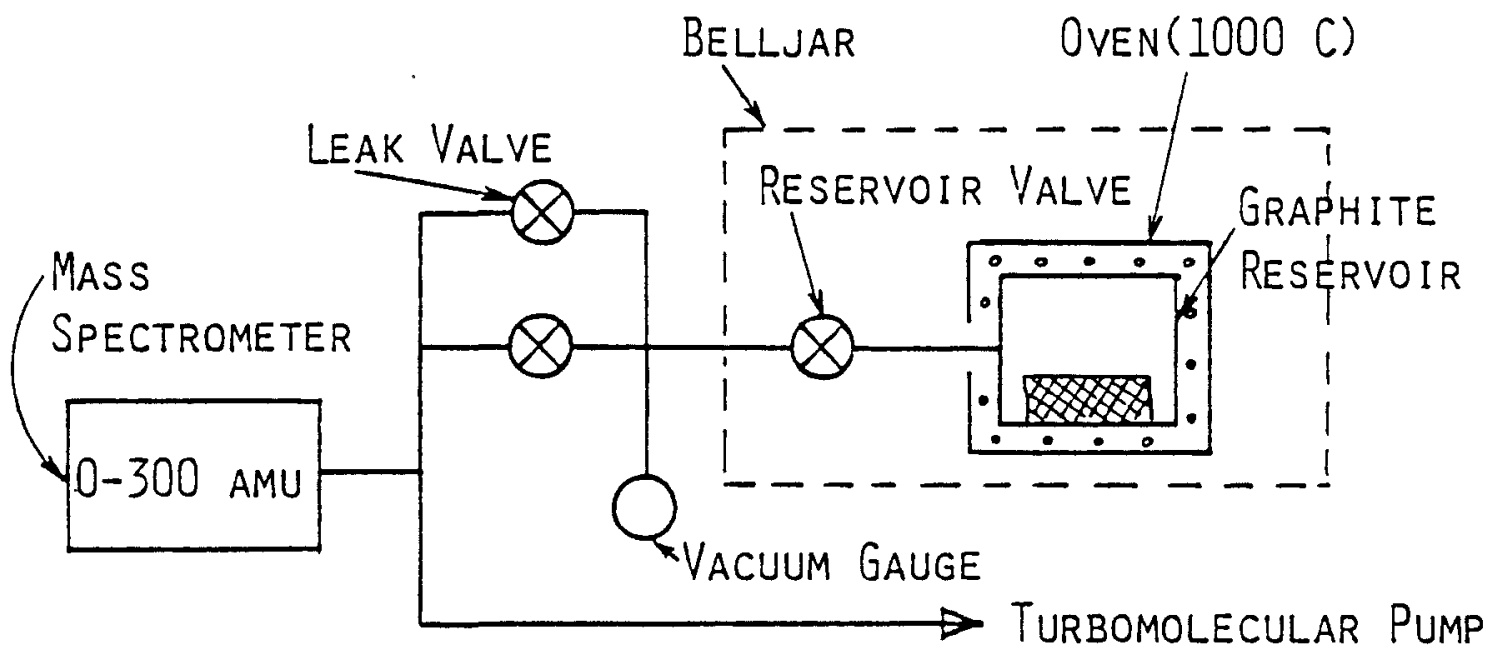

Figure 3-5 - Schematic of experimental setup for graphite reservoir evolved gas analysis 
detection more sensitive. A comparison of spectra obtained from the background (after a cooldown of the pumping line) and at the opening of the reservoir valve after holding the reservoir at $900^{\circ} \mathrm{K}$ for 16 hours is shown in Fig. 3-6. Very large increases were observed in the 14-16, 25-29, 38-45, 50-59 AMU ranges, tentatively associated with various aliphatic hydrocarbons. A large peak at 66 may not indicate a release of $\mathrm{Cs}$, as it appears likely that, the pumping line being at room temperature, any Cs vapor would have condensed before reaching the QMS.

Figure 3-7 shows a mass spectrum obtained after accumulating gases in the graphite reservoir for 4 hours at $1220^{\circ} \mathrm{K}$. Most noticeable, the peaks at 66 and 73 previously observed at $900^{\circ} \mathrm{K}$ were absent. Figure 3-7 also illustrates a problem commonly encountered in ordinary QMS: the detection sensitivity at high AMUs drops off considerably, mostly due to the exponential decrease in heavy ion transmission.

In summary, the mass spectroscopy of the gases evolved from the graphite reservoir support the following conclusions:

1) Halogens do not appear to be the cause of the $\mathrm{Nb}$ transport.

2) Hydrocarbons could be the cause.

Small amounts of heavy $\mathrm{Nb}$ compounds may have escaped detection due to the loss of sensitivity at high masses.

\subsubsection{Tantalum Fol1 Wrapped Around the Graphite Block}

Upon opening the graphite container in an Argon box, a white ring-like deposit was observed on the top $\mathrm{Ta}$ foil which was loosely wrapped around the graphite to prevent direct contact between niobium and graphite. The ring diameter appeared similar to the inside diameter of the $\mathrm{Nb}$ tube leading to the manifold (see Fig. 3-4). Strangely, a ring of similar dimensions was observed on the inside of the clrcular foil, i.e., facing the graphite (Fig. 3-8).

Figure 3-9 shows a scanning electron microscope (SEM) picture of a 

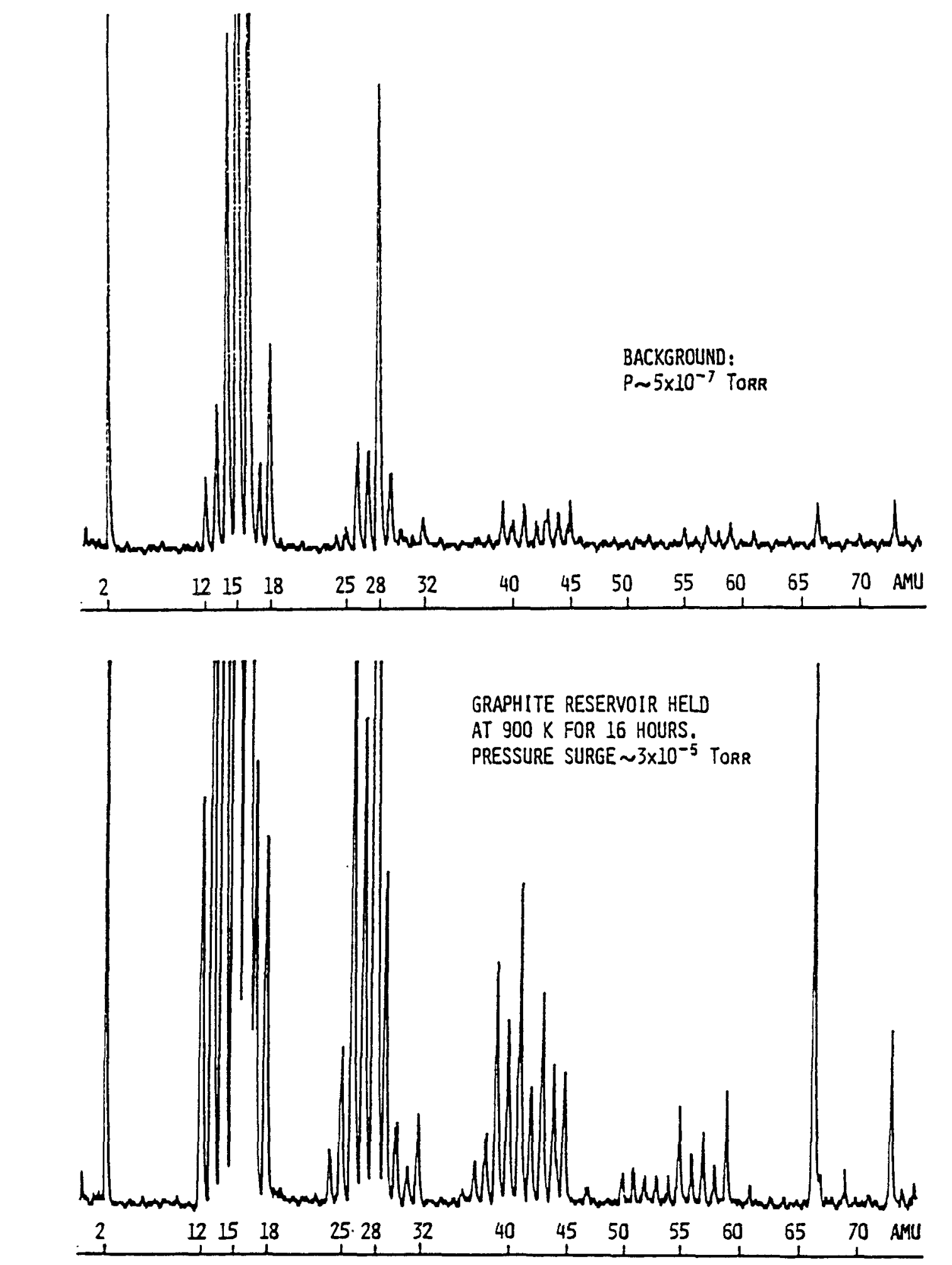

Figure 3-6 - Graphite reservoir evolved gas spectrum after 16 hours at $900 \mathrm{~K}$ 


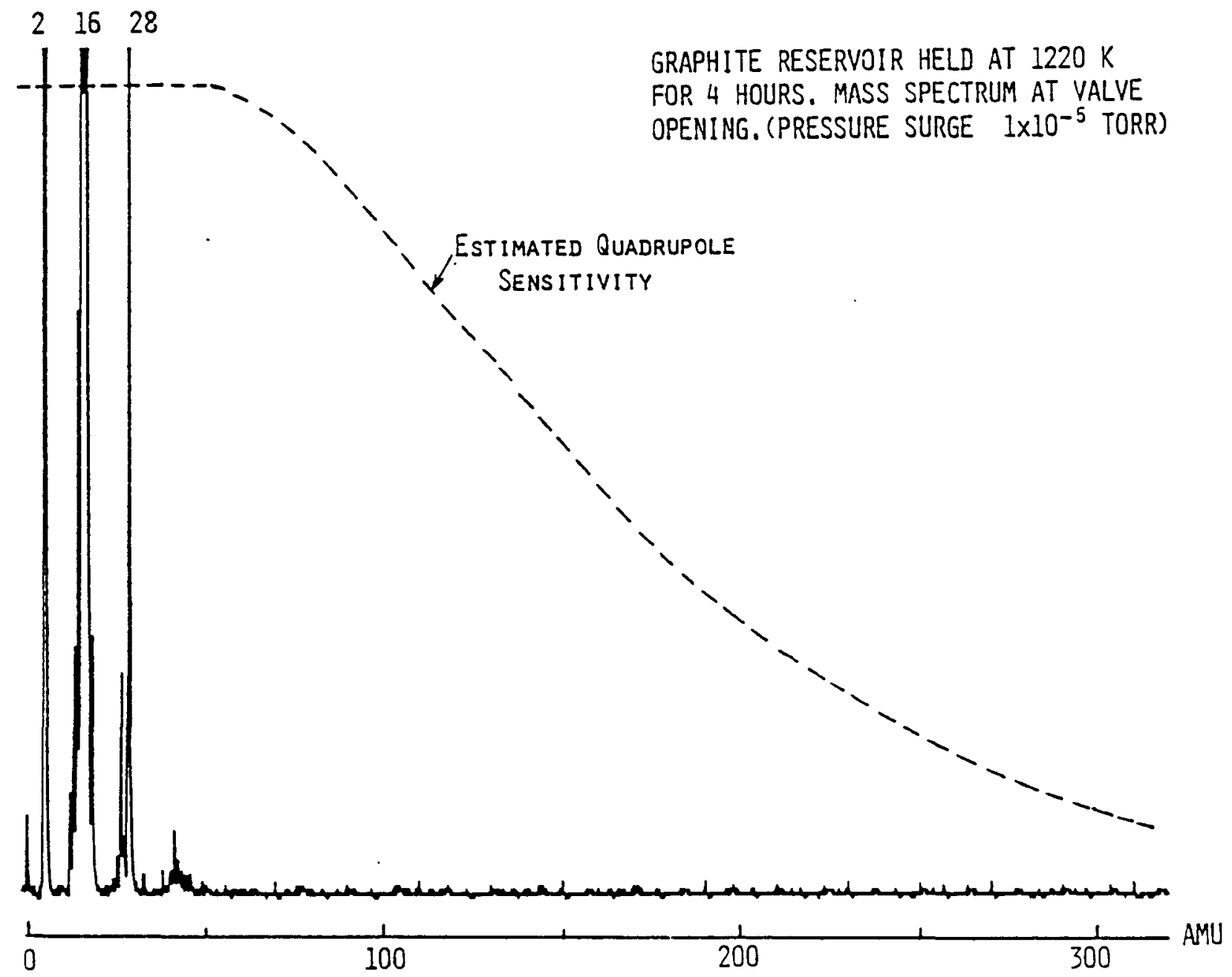

Figure 3-7 - Graphite reservoir evolved gas spectrum after 4 hours at $1220 \mathrm{~K}$ 

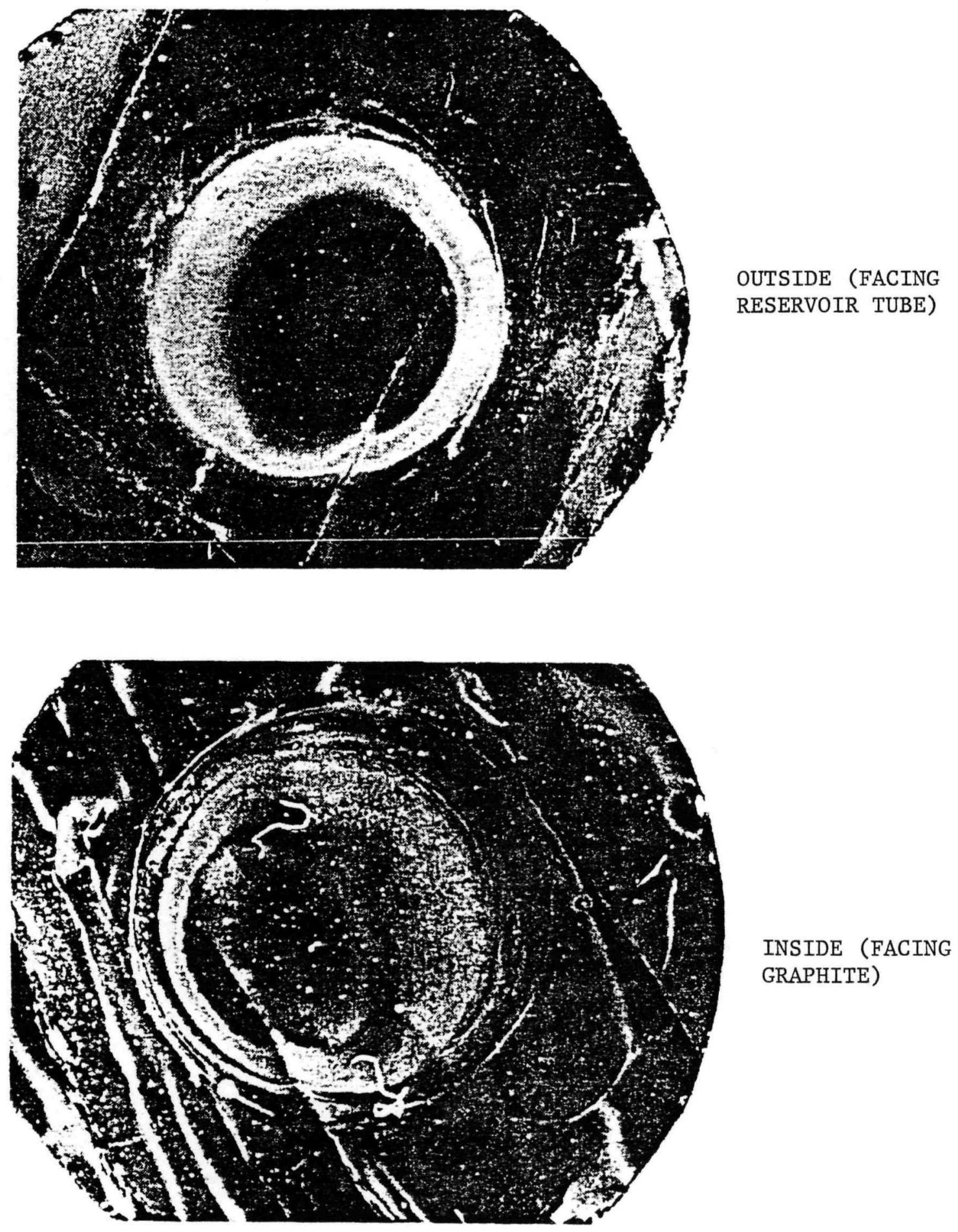

Figure 3-8 - Photo of ring deposit on Ta foil wrapped around the graphite block 


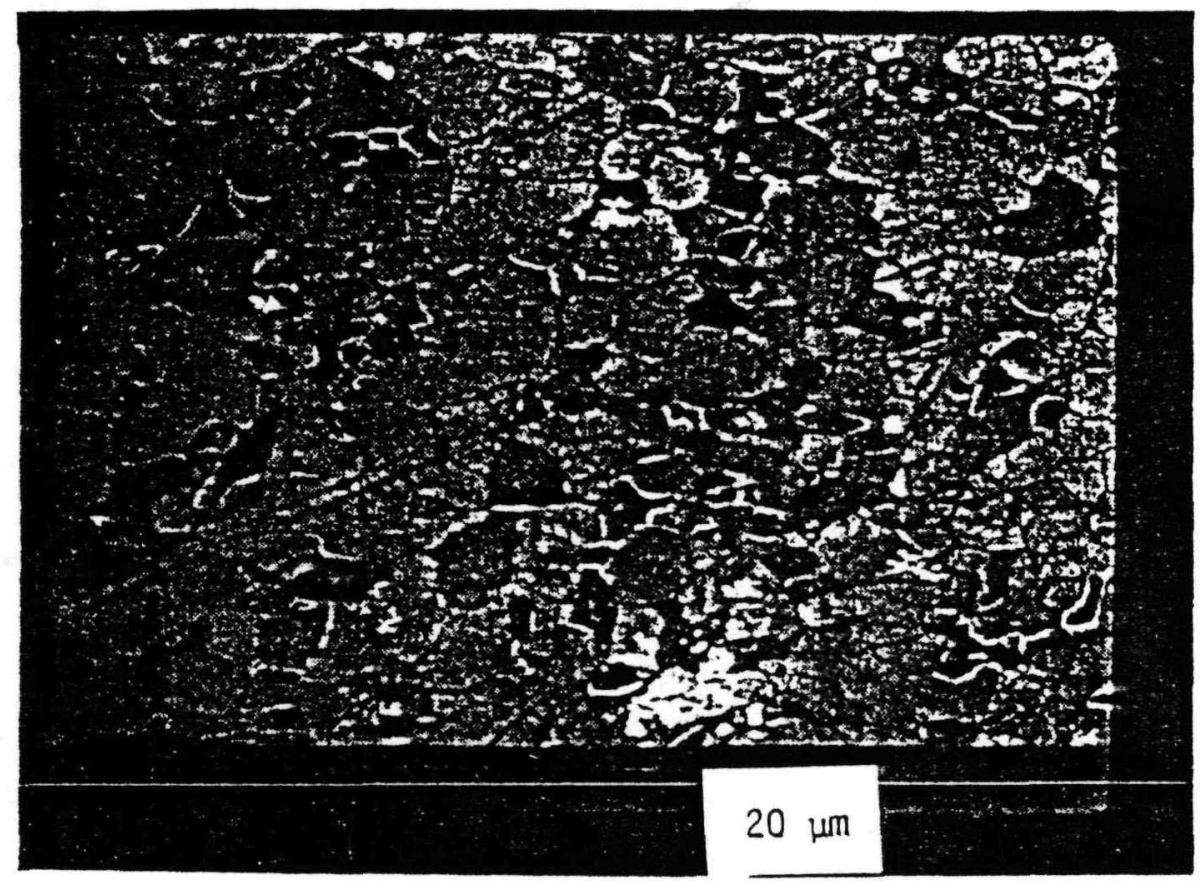

SEM

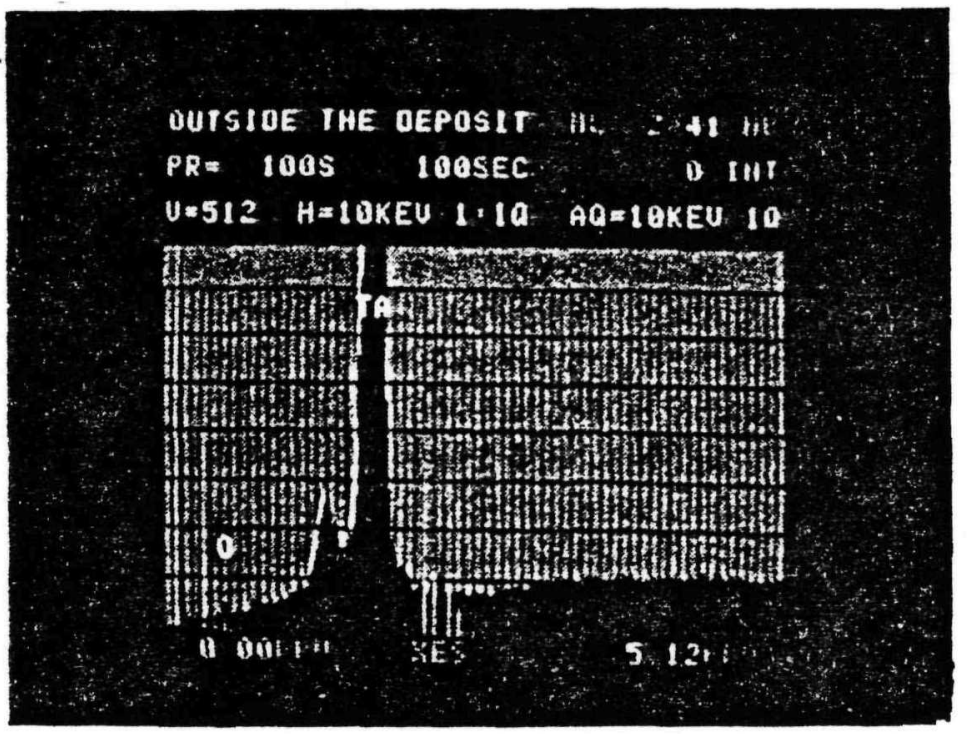

EDX: Ta ONLY

Figure 3-9 - SEM and EDX pictures obtained outside the ring deposit 
typical spot outside the ring and the corresponding energy-dispersive $x-r a y$ analysis (EDX): both are consistent with polycrystalline Ta (EDX samples about $2 \mu \mathrm{m}$ deep). Figure 3-10, which shows the SEM and EDX pictures obtained in the ring deposit, reveals a rough surface containing $\mathrm{Ta}, \mathrm{Cs}, \mathrm{Nb}$ and 0 . This seems to imply that a $\mathrm{Cs}-\mathrm{O}-\mathrm{Nb}$ compound was evaporating from the inside wall of the small $\mathrm{Nb}$ tube. Even more puzzling is the fact that the ring on the inside shows the same qualitative composition as if the deposit had penetrated the Ta foil itself.

\subsection{CC-1X DESIGN AND FABRICATION}

The CC-1 converter will be rebullt using POCO CZR-2 graphite as the integral reservoir material. This graphite is a high purity porous material which loads cesium by sorption rather than by intercalation. After bulk degassing, the graphite will be installed in a detached reservoir separated from the converter. The reservoir configuration is shown in Fig. 3-11. The assembly includes a cesium st111 arrangement which allows continuous vacuum pumping while cesium is loaded into the graphite. A mass spectrometer will be connected to the pumping line to analyze the gas species released during outgassing and during ceslum loading. After completion of cesium loading, the detached reservoir will be pinched off.

The loaded detached reservoir is connected to the converter as shown in Fig. 3-12. The configuration allows the converter to be outgassed, pinched off, and a bare emitter work function measurement to be made before the graphite reservoir connection is opened. After the reservoir connection is opened, the converter will be tested in the integral cesium reservoir mode of operation and the performance compared with operation using a liquid pool reservoir.

\subsection{H1 STARTUP AND CONVERTER DIAGNOSTIC}

\subsubsection{Project Goal}

The goal of this task is to develop a startup protocol and emitter temperature diagnostics for the TFE-1H1 incore test. Because the emitter 


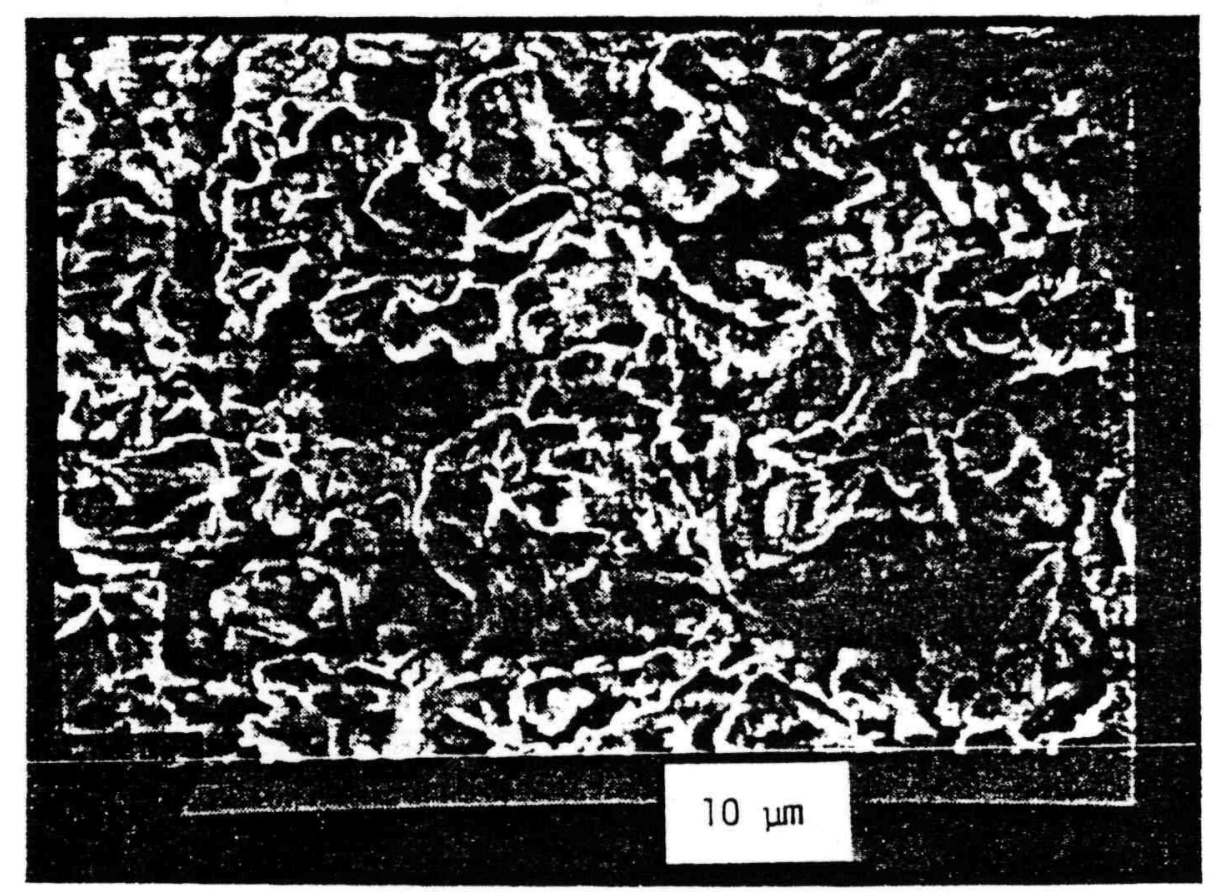

SEM

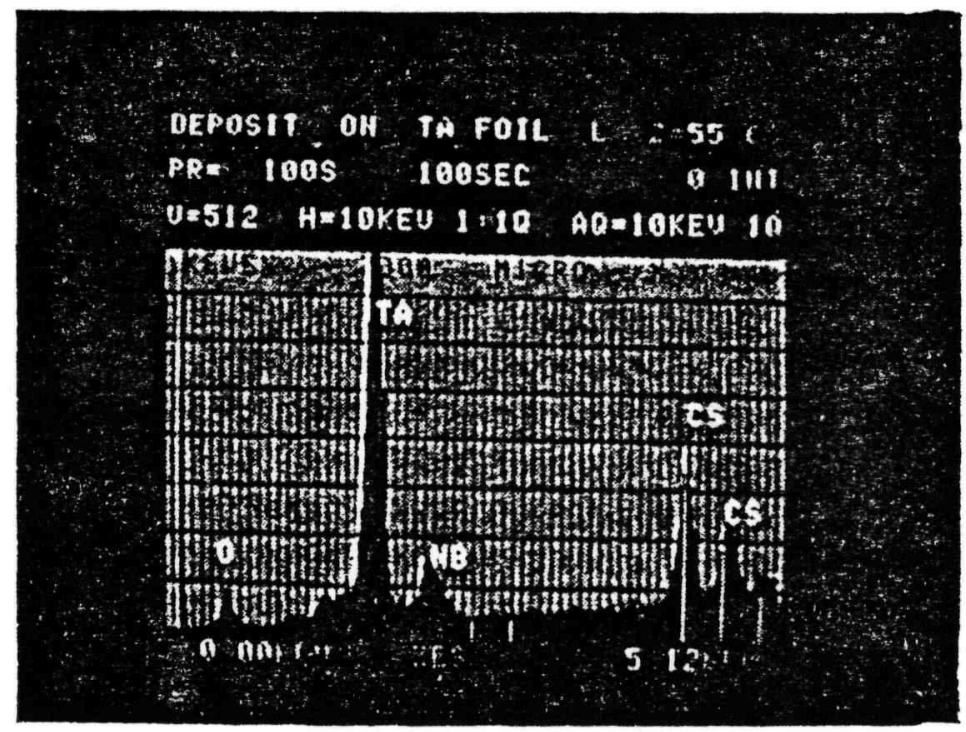

EDX: Ta

$\mathrm{Nb}, \mathrm{O}, \mathrm{Cs}$

Figure 3-10 - SEM and EDX pictures obtained inside the ring deposit 


\section{GRAPHITE RESERVOIR OUTGASSING AND CESIUM LOADING ASSEMBLY}

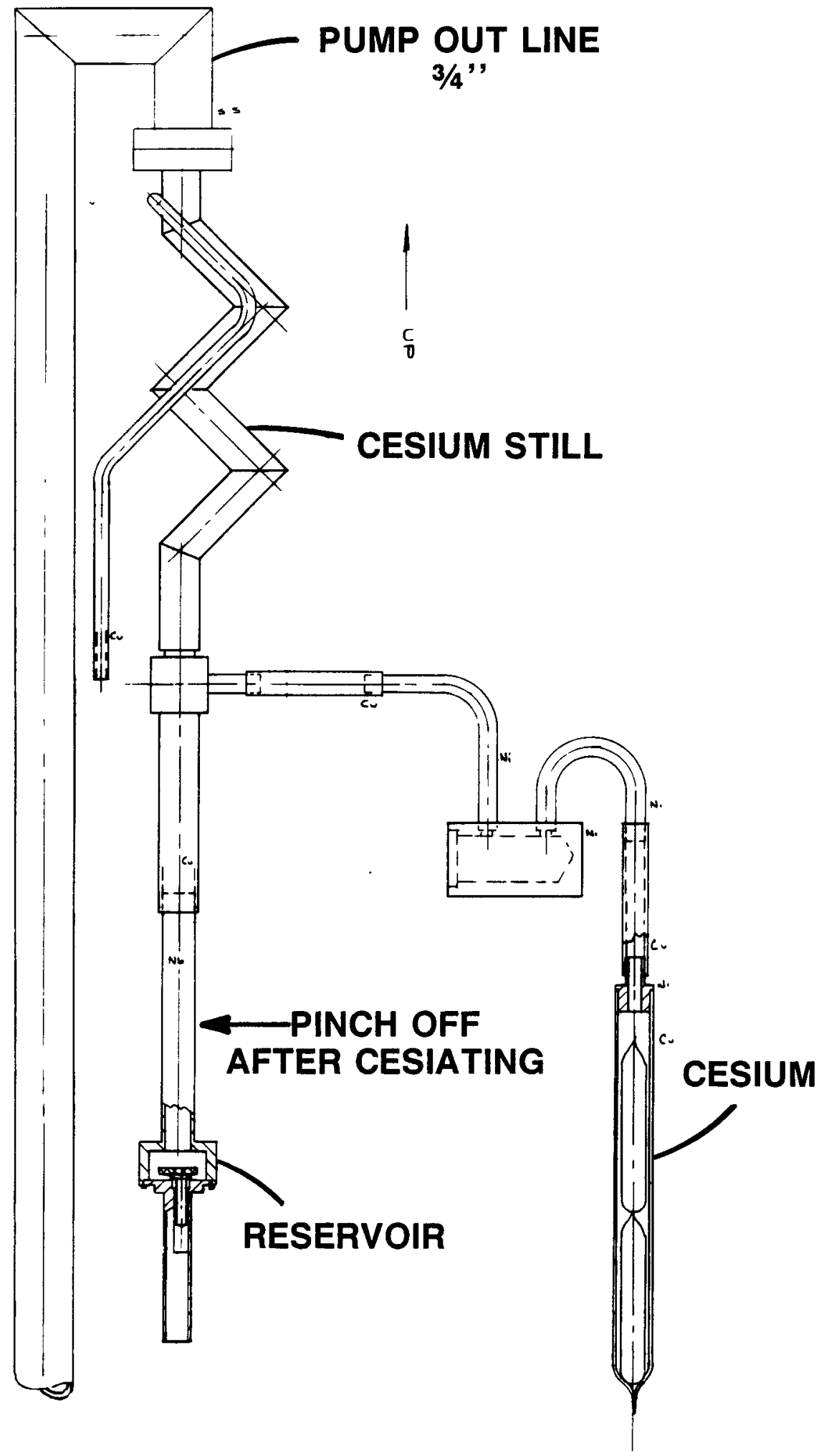




\section{CC-1X TEST CONFIGURATION}

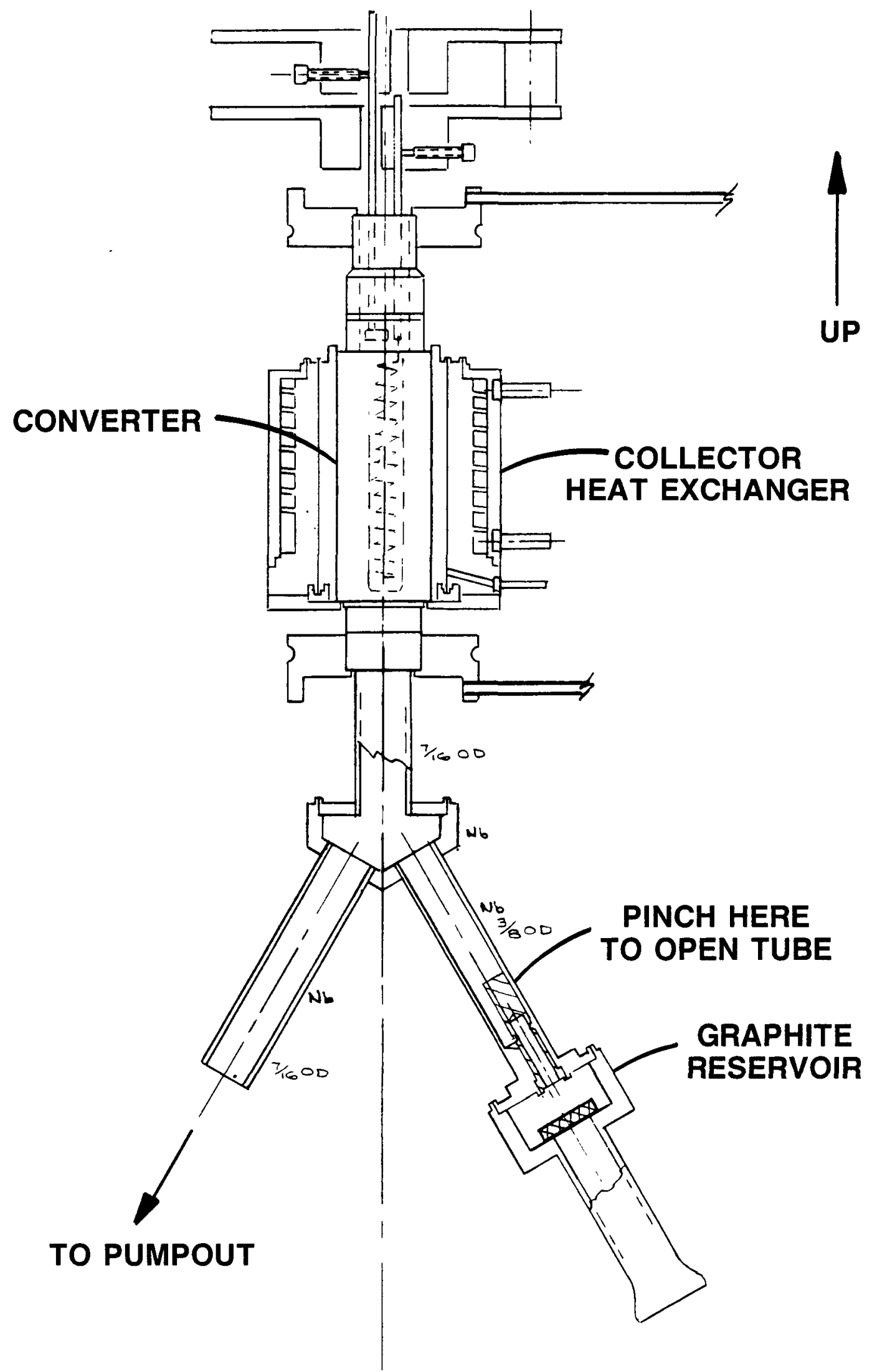


is of prototypic thickness in 1H1, a fully instrumented out-of-core test of an exact duplicate is impossible. Furthermore, the electron bombardment heating used in out-of-core tests is expected to give somewhat different axial temperature profiles than nuclear heating does. As a result, the task seeks to develop computational techniques which can take into account the effects of axial temperature distributions and ohmic effects, and produce accurate estimates of emitter temperature.

\subsubsection{Status of Diagnostics and Computer Models}

A computer model which calculates the effects of axial temperature profiles and ohmic losses has been described in the last semiannual report, Ref. 3-1. This program was made operational during this reporting period. Both unignited and ignited mode I-V curves have been produced using a sample emitter temperature distribution calculated by GA. The speed of program execution has been greatly increased by careful optimization. However, it is still slow enough that it may be impractical to generate computer I-V curves during startup. Data will be generated beforehand for use during startup. In addition, results from this cylindrical model show that the faster planar models may be accurate in determining the average emitter tmeperature.

The cylindrical converter model was used to compare I-V curves calculated with an emitter temperature profile with curves calculated using the average temperature of that profile. For all the cases studied, both in the ignited and unignited modes, there were only small differences between the cases with a profile and those with an average temperature. This indicates that the emitter temperature diagnostics are only indicators of the average temperature. Therefore, planar converter models and data can be used to give a fairly accurate temperature determination. Conversely, these diagnostics cannot give information on the profile if that should be desirable. The effect of temperature profile shape is indicated for the ignited mode in Fig. 3-13 and for the unignited mode in Fig. 3-14. Also, the effect of electrode resistance on the ignited mode $I-V$ curve is shown in Fig. 3-13. 


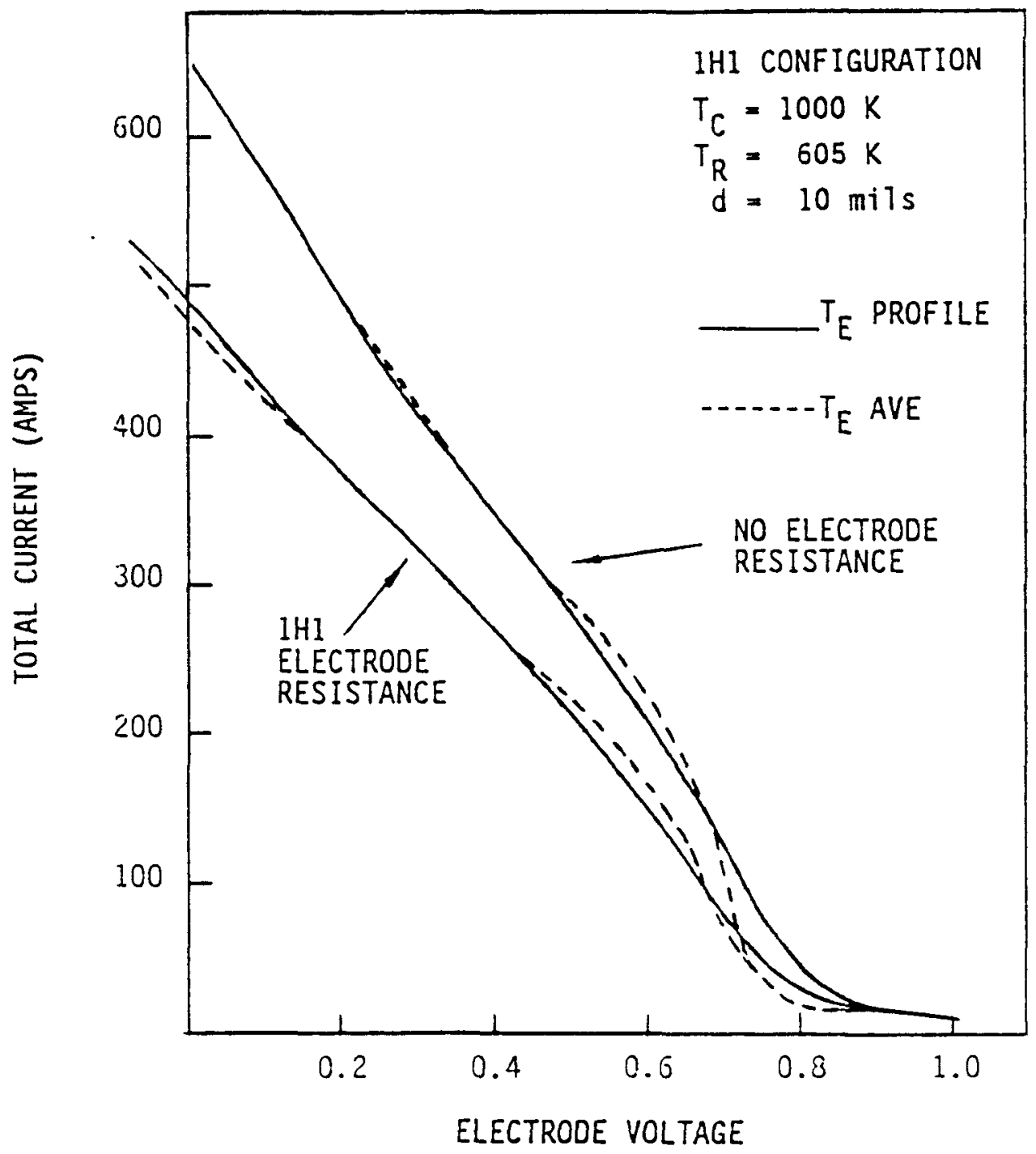

Figure 3-13 - Effect of temperature profile and electrode resistance on ignited model $I-V$ curves 


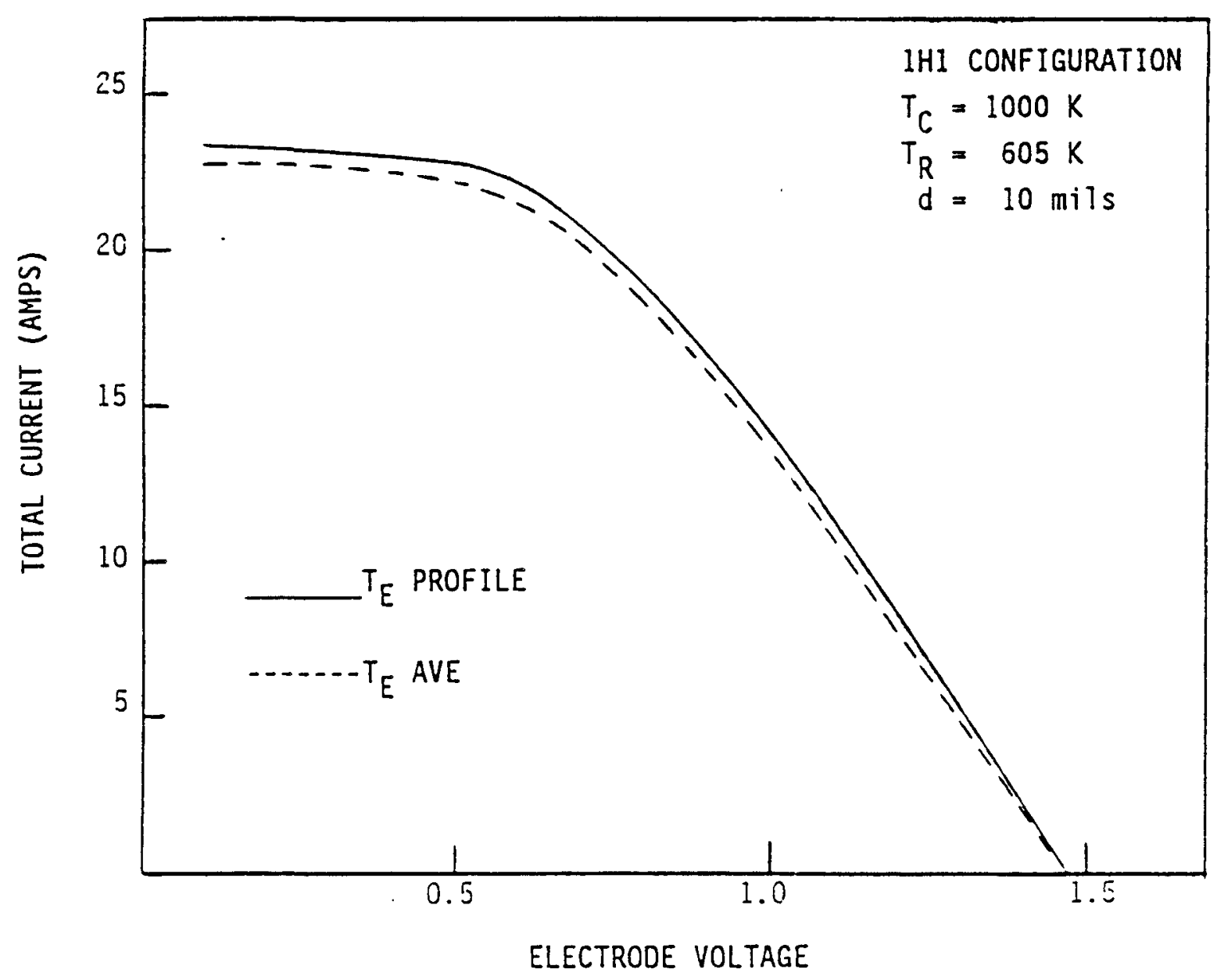

Figure 3-14 - Effect of temperature profile on unignited model $I-V$ curves 
Data from planar converter PD-6 (Ref. 3-2) was used to calibrate and verify the planar unignited mode model. After calibration, this model gave excellent agreement with data. Dependence of saturation current on emitter temperature, on cesium pressure, and general I-V curve shape were tested. The only feature which the model was unable to reproduce was the very slight slope in the saturation region. Comparison of computer I-V curves with measured curves from $1 \mathrm{H} 1$ should give a good temperature indication, as this diagnostic method is free of error due to lead resistance, collector work function effects, or error in reading the collector temperature.

The planar ignited mode model was also calibrated using PD- 6 data. Relationships for finding the collector and emitter work functions were derived from work function measurements on PD-6. With only minor modifications the model gives good agreement with data for the shift in voltage due to changing cesium pressure, collector temperature, and emitter temperature. The shape of the I-V characteristic in the region of the "knee" and in the saturation region is quite good. The computer curves have a slightly smaller slope in the obstructed region, however, as indicated in Fig. 3-15. The earlier survey of ignited mode models in Task 3 found that this was true of all of the models tested. Loss of energy by photons steepens the curves at low current. However, real I-V curves exhibit steepness which depends on the ratio of current to saturation current, so that curves with high saturation current are much steeper than could be accounted for by photon loss. One mechanism which could account for this is the trapping of positive ions in the double-valued sheath (the "virtual cathode") which forms at the emitter. For the purposes of temperature diagnostics, the ignited mode model can be used to match the knee region of experimental curves. In addition, experimental data form planar converters could be used to form the basis of an obstructed-mode voltage correlation. As this method is sensitive to the collector work function and the collector temperature it should be used in conjunction with the "ignition current" diagnostic.

An essential tool for a converter startup is a correlation of average emitter temperature as a function of input heat, with current as a 


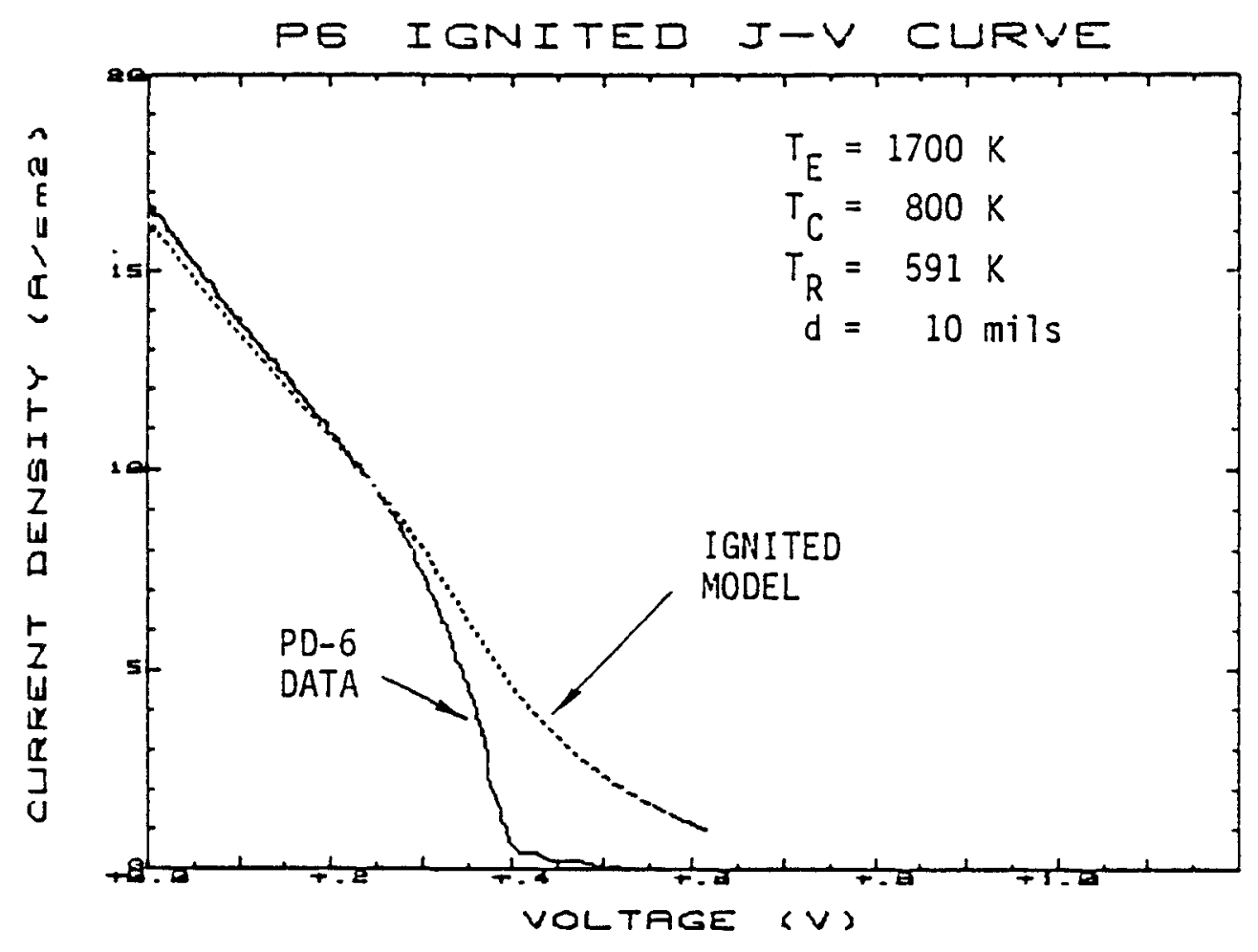

Figure 3-15 - Comparison of ignited planar model with data 
parameter. This requires a thermal model of the converter. For 1H1, it is important to be able to calculate end losses and emitter lead conduction. Space Power, Inc., has developed an ANSYS finite element description of the $1 \mathrm{H} 1$ converter. It is planned to use this existing model along with tabulated values of electron cooling, as calculated by our ignited mode model.

\subsubsection{Remaining Work}

A simple routine will be developed for taking into account the resistive drops in the emitter lead, the dummy cell, and other connections between the voltage probes and the electrodes. At this point a set of unignited and ignited mode $I-V$ curves will be produced for use as emitter temperature diagnostics during startup. The ANSYS model will be used to create the temperature vs. power charts which will guide the converter current increase during startup. Fast versions of the planar converter models will be made avallable which can supplement the precalculated I-V curves.

\section{References}

3-1 TFE Verification Program Semiannual Report for the Period Ending September 30, 1987, GA-A19115.

3-2 Thermionic Technology Program, FY-86 Final Technical Report, Velma P. Cone and John B. Dunlay, Thermo Electron Corporation, December, 1987. 


\section{INSULATOR SEAL TASK}

\subsection{OBJECTIVE}

The overall objective of the insulator seal task is to develop and validate the performance of an insulator seal for use in the thermionic fuel element. In particular, the objectives are:

1. Produce designs for the insulator seal.

2. Develop required designs aend fabrication processes for the insulator seal. Document the process specifications.

3. Fabricate insulator seals for in-reactor and ex-reactor testing.

4. Verify the performance characteristics and lifetimes associated with insulator seals by means of in-reactor and ex-reactor testing and modeling. Perform post-irradiation examination of the seal specimens and use the test results to improve the seal design.

5. Develop an analytical model of the performance and lifetime of the insulator seal and validate that model with test data.

\subsection{TASK DESCRIPTION}

The insulator seal task consists of five subtasks:

1. Seal Design. Seal designs consistent with the TFE requirements are to be developed. These designs include the taper seal, the standard and stress-relieved butt seal and trilayer seal.

2. Fabrication Development. Select appropriate insulator materials. Develop appropriate bonding techniques for each insulator material selected. Fabricate sufficient insulator seal specimens to support the in-reactor and ex-reactor test effort. Prepare and issue process specifications. 
3. Ex-Reactor Testing. Perform ex-reactor tests to evaluate the effects of thermal cycling, chemical compatibility and material interdiffusion on insulator seal performance and lifetime.

4. In-Reactor Testing. Perform in-reactor tests and the related post-irradiation examinations to determine seal mechanical stability, electrical resistance and hermeticity after exposure to fast neutron fluences on the order of $4 \times 10^{22} \mathrm{n} / \mathrm{cm}^{2}$ at temperatures of 1100 to $1200 \mathrm{~K}$.

5. Modeling. Develop and validate analytical models to predict seal lifetime and performance.

\subsection{RESULTS-TO-DATE}

The projected performance for the three insulator materials being developed is shown below.

\begin{tabular}{lcccc} 
Material & $\begin{array}{c}\text { Fast } \\
\text { Neutron } \\
\text { Stability }\end{array}$ & $\begin{array}{c}\text { Thermal } \\
\text { Properties }\end{array}$ & $\begin{array}{c}\text { Electrical } \\
\text { Properties }\end{array}$ & Fabricability \\
\hline $\mathrm{Y}_{2} \mathrm{O}_{3}$ & Good & Good & Adequate & Good \\
$\mathrm{YAG}$ & Excellent & Good & Excellent & More difficult \\
$\mathrm{Al}_{2} \mathrm{O}_{3}$ & Marginal & Good & Excellent & Good \\
\hline
\end{tabular}

YAG is clearly the first choice, however it has proved difficult to fabricate good test specimens. Work is continuing.

$\mathrm{Y}_{2} \mathrm{O}_{3}$ also appears good and, when fabricability is taken into account, it is the top priority material.

$\mathrm{Al}_{2} \mathrm{O}_{3}$ has marginal stability to high fast neutron exposure, although data being obtained are favorable. 
The status of ongoing and planned tests for insulator seals is given in Table 4-1. The UCA-1 irradiation test has been completed and a postirradiation examination of the seal test specimens is ongoing. The UCA-2 irradiation test is underway.

\subsubsection{Fabrication Development}

Development of metallizing and brazing single crystal YAG to $\mathrm{Nb}$ is continuing. Metallizing YAG disks with tungsten-2\%-Y $\mathrm{O}_{3}$ and firing at either $1800^{\circ} \mathrm{C}$ or $1850^{\circ} \mathrm{C}$ produced highly adherent coatings. Single crystal YAG rings were successfully metallized at $1800^{\circ} \mathrm{C}$ with $\mathrm{W}-2 \% \mathrm{Y}_{2} \mathrm{O}_{3}$, seal coated using CVD $\mathrm{W}$, and then brazed to $\mathrm{Nb}$ skirts using a $\mathrm{V}-\mathrm{Nb}$ alloy. Some difficulty was observed in brazing the skirts to the ceramic. Three out of seven seals brazed at $\sim 1800^{\circ} \mathrm{C}$ were found to contain areas of separation between skirt and ceramic. It appears that the braze temperature was higher than desired which could result in erosion of the metallized layer on the ceramic. A leakage path betwen the ceramic and metal skirt would then develop.

Six additional YAG seals are being fabricated using a reduced braze temperature. It has been determined that a braze temperature as low as $1830^{\circ} \mathrm{C}$ provides an acceptable braze joint.

\subsubsection{In-Reactor Testing}

Three types of insulator seals were fabricated and tested in UCA-1:

\begin{tabular}{lll} 
Material & \multicolumn{1}{c}{ Configuration } & $\begin{array}{c}\text { Number of Samples } \\
\text { and Designation }\end{array}$ \\
\hline $\mathrm{Al}_{2} \mathrm{O}_{3}$ & Single crystal taper (or Litton) & $3: \mathrm{L}-1, \mathrm{~L}-2, \mathrm{~L}-3$ \\
$\mathrm{Al}_{2} \mathrm{O}_{3}$ & Single crystal butt & $3: \mathrm{B}-1, \mathrm{~B}-2, \mathrm{~B}-4$ \\
$\mathrm{Y}_{2} \mathrm{O}_{3}$ & Graded trilayer & $3: \mathrm{T}-1, \mathrm{~T}-2, \mathrm{~T}-3$
\end{tabular}


TABLE $\quad 4-1$

INSULATOR SEAL - TECHNOLOGY STATUS

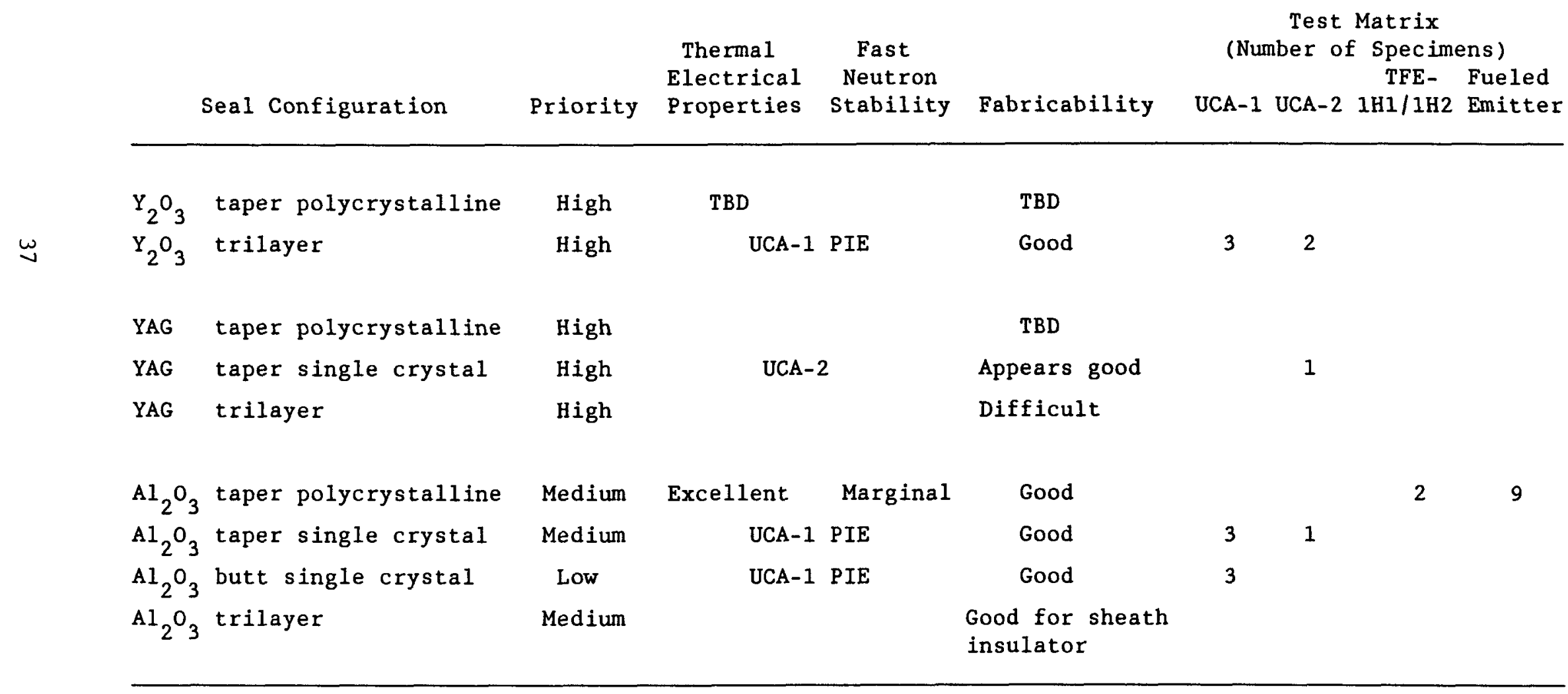


The initial results of the PIE of the single crystal taper (or Litton) seals were excellent:

\begin{tabular}{lccc} 
Sample & $\begin{array}{c}\text { Irradiation } \\
\text { Temperature (K) }\end{array}$ & $\begin{array}{c}\text { Fast Neutron } \\
\text { F1 } \\
11^{2} \text { Ince }_{\text {nvt }}\end{array}$ & Condition of Ceramic \\
\hline L-1 & 1100 & 3.9 & No cracks \\
L-2 & 1100 & 3.1 & No cracks \\
L-3 & 1100 & 7.2 & No cracks \\
\hline
\end{tabular}

If additional PIE results are favorable, this seal could become the reference design.

Pre- and post-irradiation pictures of sample L-3 are shown on Figs. 4-1 and 4-2, respectively. Also shown on Fig. 4-1 are design details of the sea1.

The infial results of the PIE of the single crystal butt seals showed some cracking:

\begin{tabular}{lccl}
$\begin{array}{c}\text { Sample } \\
\text { Number }\end{array}$ & $\begin{array}{c}\text { Irradiation } \\
\text { Temperature (K) }\end{array}$ & $\begin{array}{c}\text { Fast Neutron } \\
\text { Flyence } \\
10^{22^{n v t}}\end{array}$ & Condition of Ceramic \\
\hline B-1 & 1100 & 3.0 & Two cracks \\
B-2 & 1100 & 4.0 & Five cracks \\
B-4 & 1100 & 7.1 & Cracked \\
\hline
\end{tabular}

The cracks observed in $B-1$ and $B-2$ were parallel to the axis of the sample and may not have completely penetrated the ceramic. Other cracks may be found later. No further development of the butt seal is planned.

Pre- and post-irradiation pictures of sample $B-4$ are shown on Figs. 4-3 and 4-4, respectively. Also shown on Fig. 4-3 are design details of the seal. 
Figure 4-1

\section{UCA-1 POSTIRRADIATION EXAMINATIONS LITTON TAPERED SEAL $/ \mathrm{Al}_{2} \mathrm{O}_{3}$}

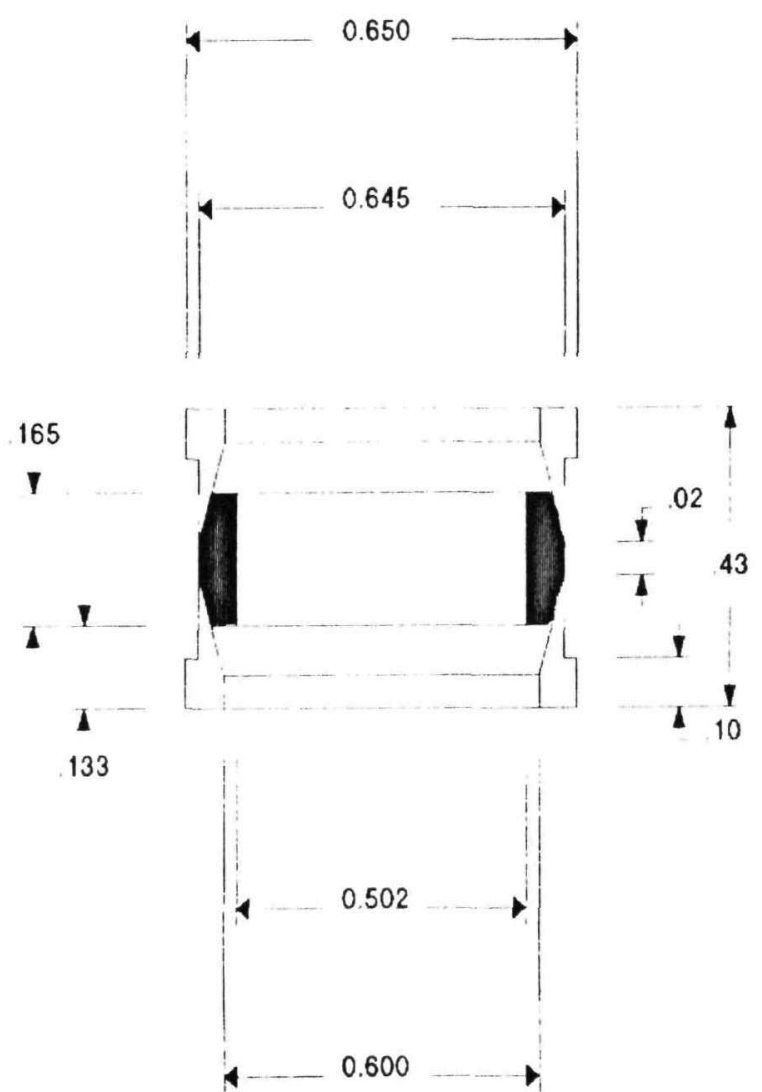

DESIGN

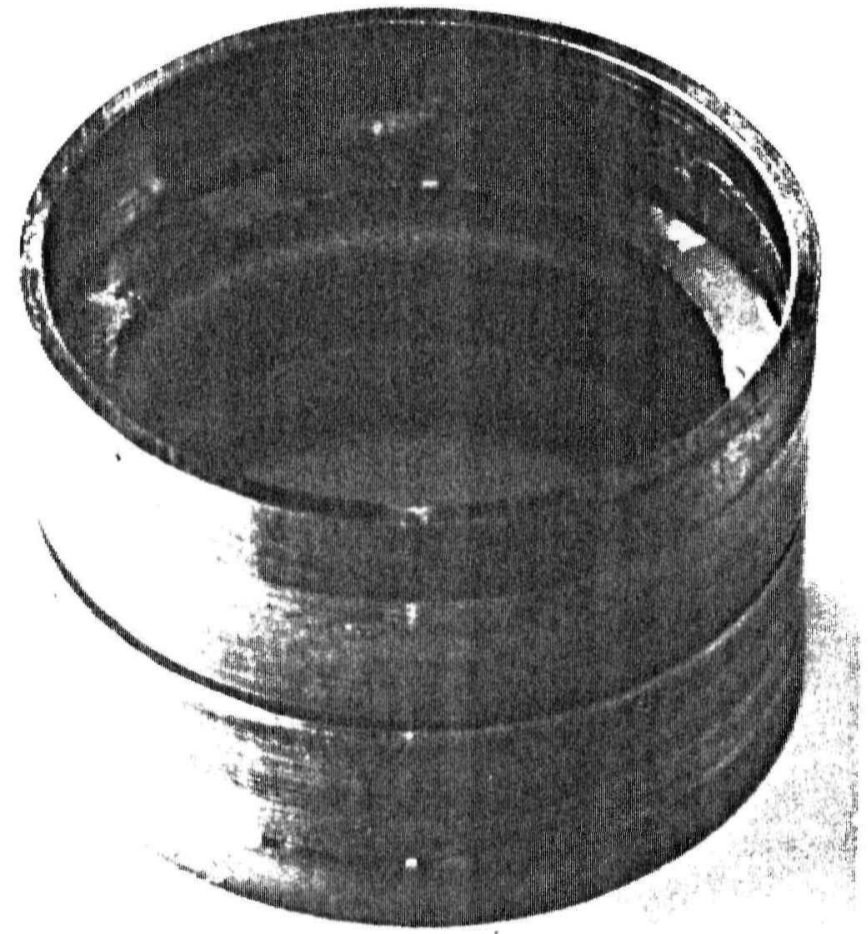

PRE-IRRADIATION 


\section{THERMIONIC FUEL ELEMENT \\ INSULATOR SEAL PERFORMANCE}

LITTON TAPERED SEAL

INSULATOR

SINGLE CRYSTAL ALUMINA

OPERATING CONDITIONS

TEMPERATURE

PROTOTYPIC (1100K)

FAST NEUTRON FLUENCE

3 TIMES AVERAGE FOR

A 7 YEAR $2 M W \Theta$ CORE

$\left(7 \times 10^{22} \mathrm{n} / \mathrm{cm}^{2}\right)$

VISUAL EXAMINATIONS

NO CRACKS DETECTED

IN CERAMIC

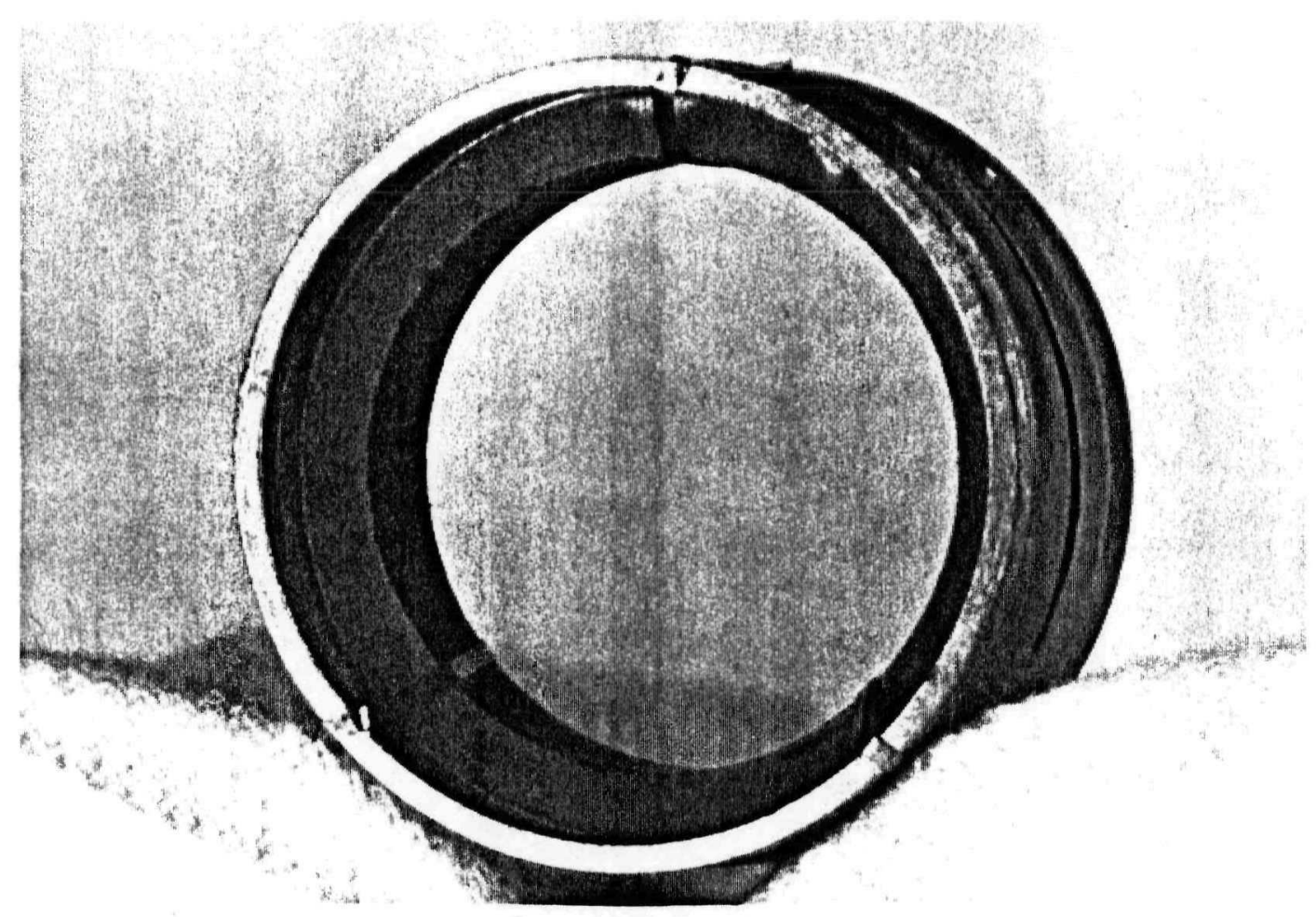

POST-IRRADIATION 


\section{UCA-1 POSTIRRADIATION EXAMINATIONS} GAS PRESSURE BONDED INSULATOR SEAL

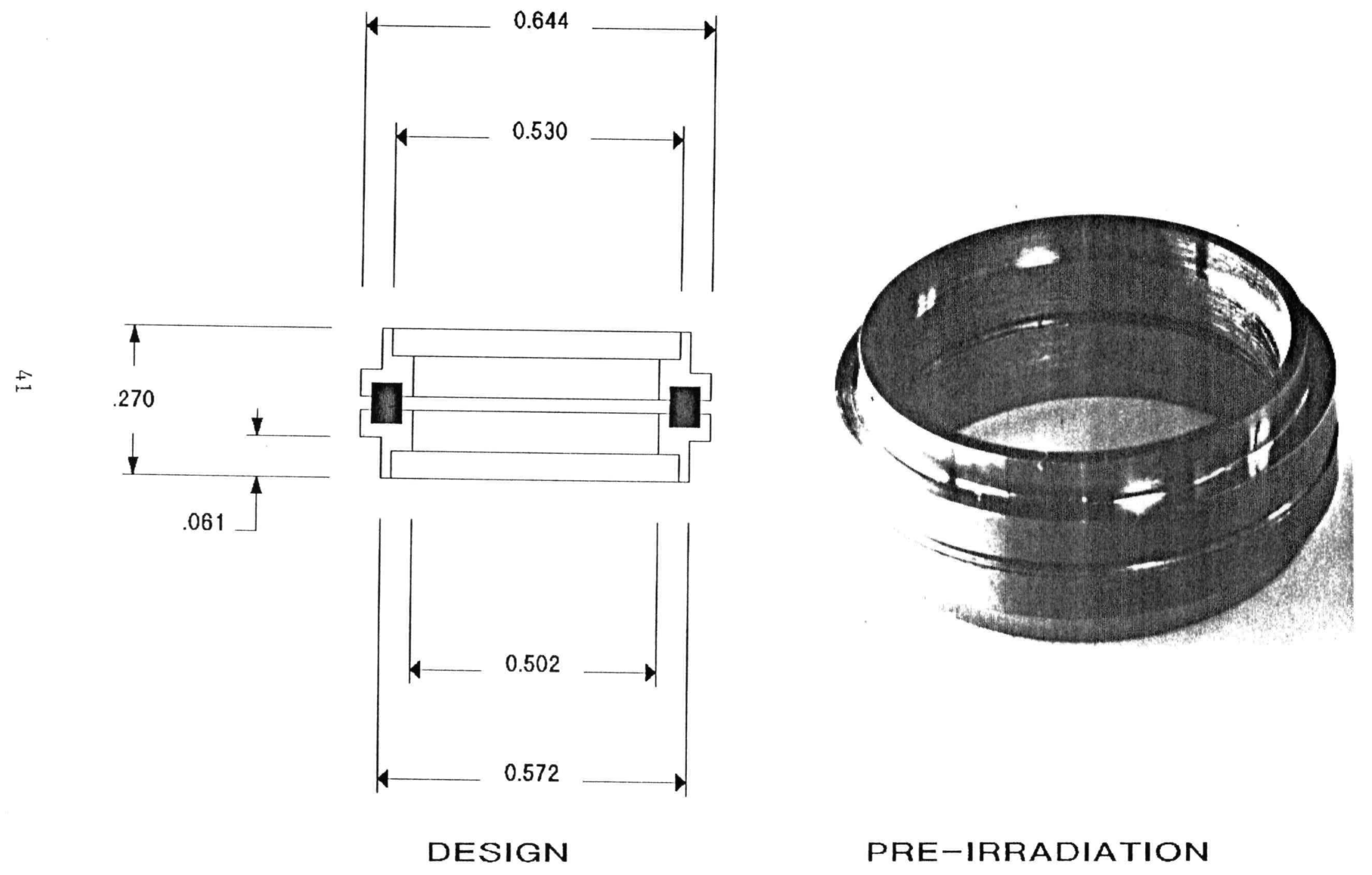


Figure 4-4

THERMIONIC FUEL ELEMENT INSULATOR SEAL PERFORMANCE

GAS PRESSURE BONDED SEAL

INSULATOR

SINGLE CRYSTAL ALUMINA

OPERATING CONDITIONS

TEMPERATURE

PROTOTYPIC (110OK)

FAST NEUTRON FLUENCE

3 TIMES AVERAGE FOR

A 7 YEAR $2 M W E$ CORE

$\left(7 \times 10^{22} \mathrm{n} / \mathrm{cm}^{2}\right)$

VISUAL EXAMINATIONS

NO CRACKING DETECTED

IN CERAMIC

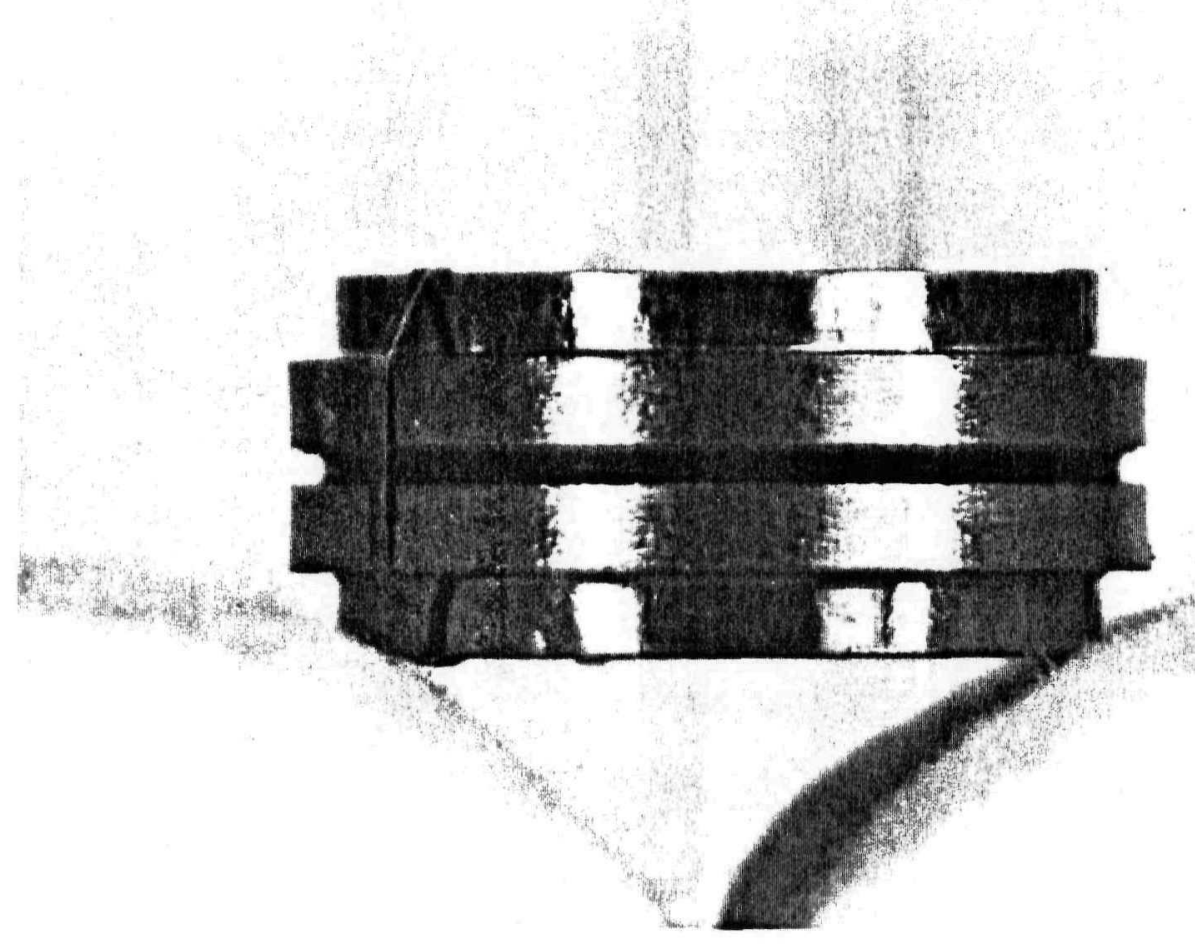

POST-IRRADIATION 
The initial results of the PIE of the yttria trilayer seals showed some cracking:

\begin{tabular}{lccl}
$\begin{array}{l}\text { Sample } \\
\text { Number }\end{array}$ & $\begin{array}{c}\text { Irradiation } \\
\text { Temperature (K) }\end{array}$ & $\begin{array}{c}\text { Fast Neutron } \\
\text { Fluence } 10^{25} \text { nvt }\end{array}$ & Condition of Ceramic \\
\hline & & 3.9 & Circumferential cracks \\
T-1 & 1100 & 3.0 & Hairline cracks \\
T-3 & 1100 & 7.2 & Circumferential cracks
\end{tabular}

Pre- and post-irradiation pictures of sample T-3 are shown on Figs. 4-5 and 4-6, the former also showing the seal design.

The data from UCA-1 show, so far, that:

1) $\mathrm{Al}_{2} \mathrm{O}_{3}$ single crystal taper seals performed better than expected.

2) $\mathrm{Al}_{2} \mathrm{O}_{3}$ single crystal butt seals showed many cracks.

3) $\mathrm{Y}_{2} \mathrm{O}_{3}$ trilayers showed some cracking, the severity of which remains to be determined.

The test matrix for UCA-2 is shown below:

$$
\begin{array}{ll}
\mathrm{Y}_{2} \mathrm{O}_{3} \text { trilayers } & -2 \text { specimens } \\
\mathrm{YAG} \text { taper single crystal } & -1 \text { specimen } \\
\mathrm{Al}_{2} \mathrm{O}_{3} \text { taper single crystal }-1 \text { specimen. }
\end{array}
$$

The emphasis is on $\mathrm{Y}_{2} \mathrm{O}_{3}$ for reasons noted earlier.

In addition to the seal specimens in UCA-2, there are several sheath insulator specimens whose performance will be equally applicable to seals:

$$
\begin{aligned}
& \mathrm{Y}_{2} \mathrm{O}_{3} \text { trilayers }-2 \text { specimens } \\
& \mathrm{YAG} \text { trilayers }-2 \text { specimens } \\
& \mathrm{Al}_{2} \mathrm{O}_{3} \text { trilayers }-2 \text { specimens. }
\end{aligned}
$$

While the sheath insulator design is obviously different than the seal design, the trilayer technology is identical for the two insulators. 
Figure 4-5

\section{UCA-1 POSTIRRADIATION EXAMINATIONS} YTTRIA TRI-LAYER SEAL

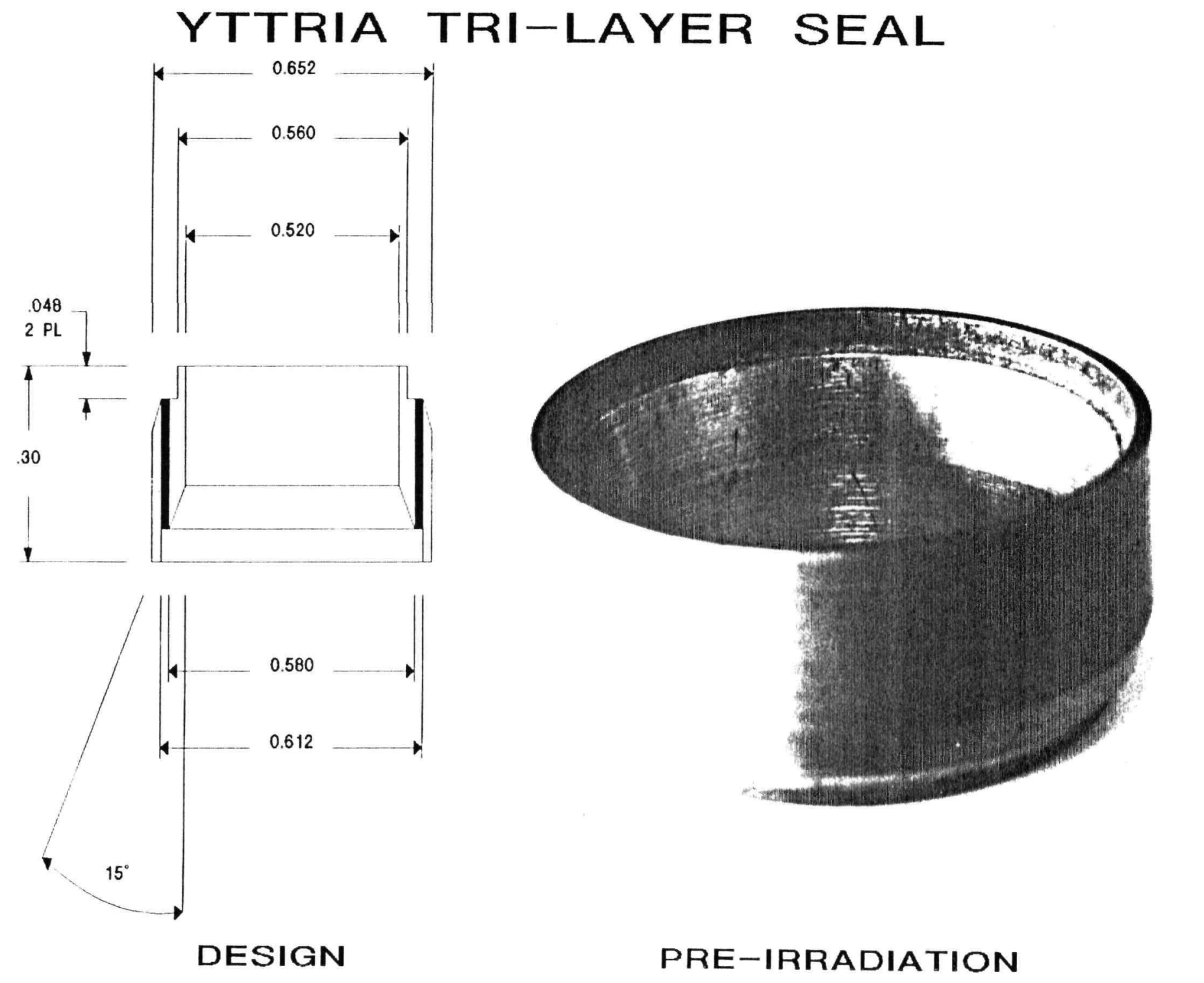




\section{THERMIONIC FUEL ELEMENT INSULATOR SEAL PERFORMANCE}

TRI-LAYER SEAL

INSULATOR

YTTRIA

OPERATING CONDITIONS

TEMPERATURE

PROTOTYPIC (1100K)

FAST NEUTRON FLUENCE

3 TIMES AVERAGE FOR

A 7 YEAR $2 \mathrm{MWO}$ CORE

$\left(7 \times 10^{22} \mathrm{n} / \mathrm{cm}^{2}\right)$

VISUAL EXAMINATIONS

CIRCUMFERENTIAL CRACK AT CERAMIC-METAL

INTERFACE

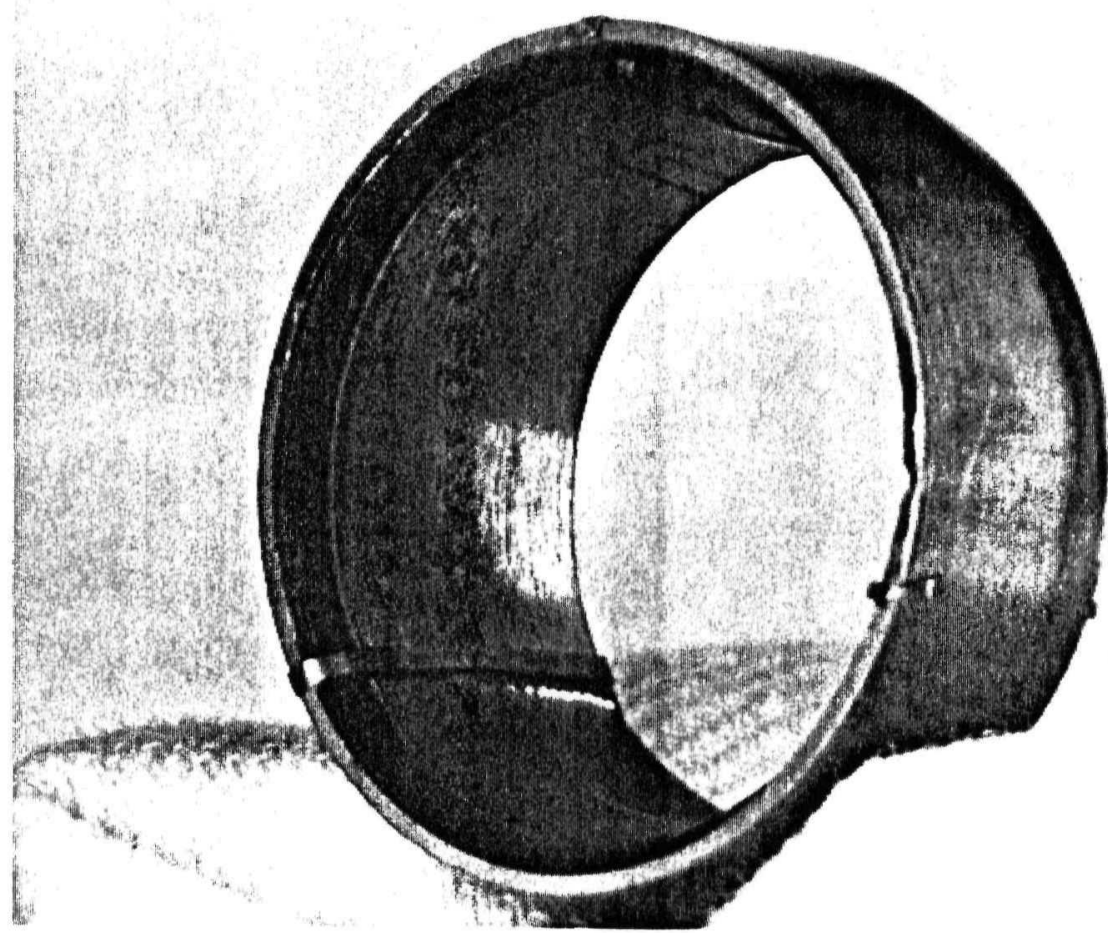

POST-IRRADIATION 


\section{SHEATH INSULATOR TASK}

\subsection{OBJECTIVE AND TECHNICAL APPROACH}

The function of the metal-ceramic sheath insulator is to electrically isolate the collector of each converter in a TFE from the outer sheath tube which is in contact with the reactor liquid metal coolant. The sheath insulator must also provide the thermal conductance between the collector and sheath tube. Requirements for sheath insulators are summarized in Table 5-1.

TABLE $\quad 5-1$

SHEATH INSULATOR REQUIREMENTS

\begin{tabular}{|c|c|}
\hline $\begin{array}{c}\text { Temperature, } \mathrm{K} \\
\text { Nominal } \\
\text { Maximum }\end{array}$ & $\begin{array}{l}1070 \\
1150\end{array}$ \\
\hline $\begin{array}{l}\text { Potential, +/-V DC } \\
\text { Average } \\
\text { Maximum }\end{array}$ & $\begin{array}{r}7.5 \\
15.0\end{array}$ \\
\hline $\begin{array}{l}\text { Neutron Fluence, } \mathrm{n} / \mathrm{cm}^{2} \mathrm{E}>.1 \mathrm{Mev} \\
\text { Average } \\
\text { Peak }\end{array}$ & $\begin{array}{l}2.7 \times 10^{22} \\
3.5 \times 10^{22}\end{array}$ \\
\hline Lifetime, years & 7 \\
\hline
\end{tabular}

The primary technical concerns are the unbonding of the sheath insulator structure due to fast neutron induced damage, and electrolysis which could lead to low electrical resistance, breakdown or poor bonding. The objective of the sheath insulator task is to resolve these concerns and to develop and validate the performance of a sheath insulator for use in a prototypic TFE.

The strategy to develop a sheath insulator (SI) to meet the above requirements is based on carrying several sheath insulator design options, determining their fabricability, performing ex-reactor and in-reactor testing to evaluate the designs, and finally to make decisions based on the test results. 
This strategy is shown in Tables 5-2 and 5-3 where the leading sheath insulator configurations are evaluated with respect to fabrication, electrical and thermal performance radiation resistance. Also indicated on the tables are the various configurations that are being evaluated.

\subsection{SHEATH INSULATOR FABRICATION DEVELOPMENT}

Two manufacturing processes and three insulator materials are currently being evaluated. The manufacturing processes are the graded trilayer and the cermet trilayer. The materials of choice are alumina $\left(\mathrm{Al}_{2} \mathrm{O}_{3}\right)$, yttria $\left(\mathrm{Y}_{2} \mathrm{O}_{3}\right)$, and $\mathrm{YAG}\left(\mathrm{Y}_{3} \mathrm{Al}_{5} \mathrm{O}_{12}\right)$. The development will include fabricating samples for both ex-reactor and in-reactor testing and for the $\mathrm{H}$ series TFEs.

\subsubsection{Cermet Sheath Insulator Fabrication}

The cermet sheath insulator development effort includes fabricating and electrically testing high purity yttria trilayers, fabricating crack-free YAG trilayers, and testing the compatibility of cesium with promising materials under study in the Thermionic Technology Program (Ref. 2). Tests are also planned to measure the mechanical properties (hardness, strength, and toughness) of cermets to compare the use of spherical versus irregular shaped niobium powders.

Yttria Trilayers. Measurements of the electrical characteristics of yttria trilayers have shown resistivity values ranging from $10^{10} \mathrm{ohm}-\mathrm{cm}$ at $1100 \mathrm{~K}$ to unstable conditions characterized by rapid degradation and electrical shorting. The high resistivity measurements were obtained with an applied voltage of 20 volts over an eight week test period. Resistivity values in the order of $10^{10} \mathrm{ohm}-\mathrm{cm}$ are comparable to those obtained for alumina and indicate that electrolysis should not limit the use of yttria for sheath insulators.

The poor performance of many of the yttria cermet sheath insulators was traced to carbon impurities present in the purchased ceramic powders. The carbon was usually present as small particles or inclusions in 
Design HIP Ceramic Initial Properties Process Additive End Grading Cycle Purity Density Cracks Elec

Plasma Sprayed - Hot Isostatically Processed (Graded Design)

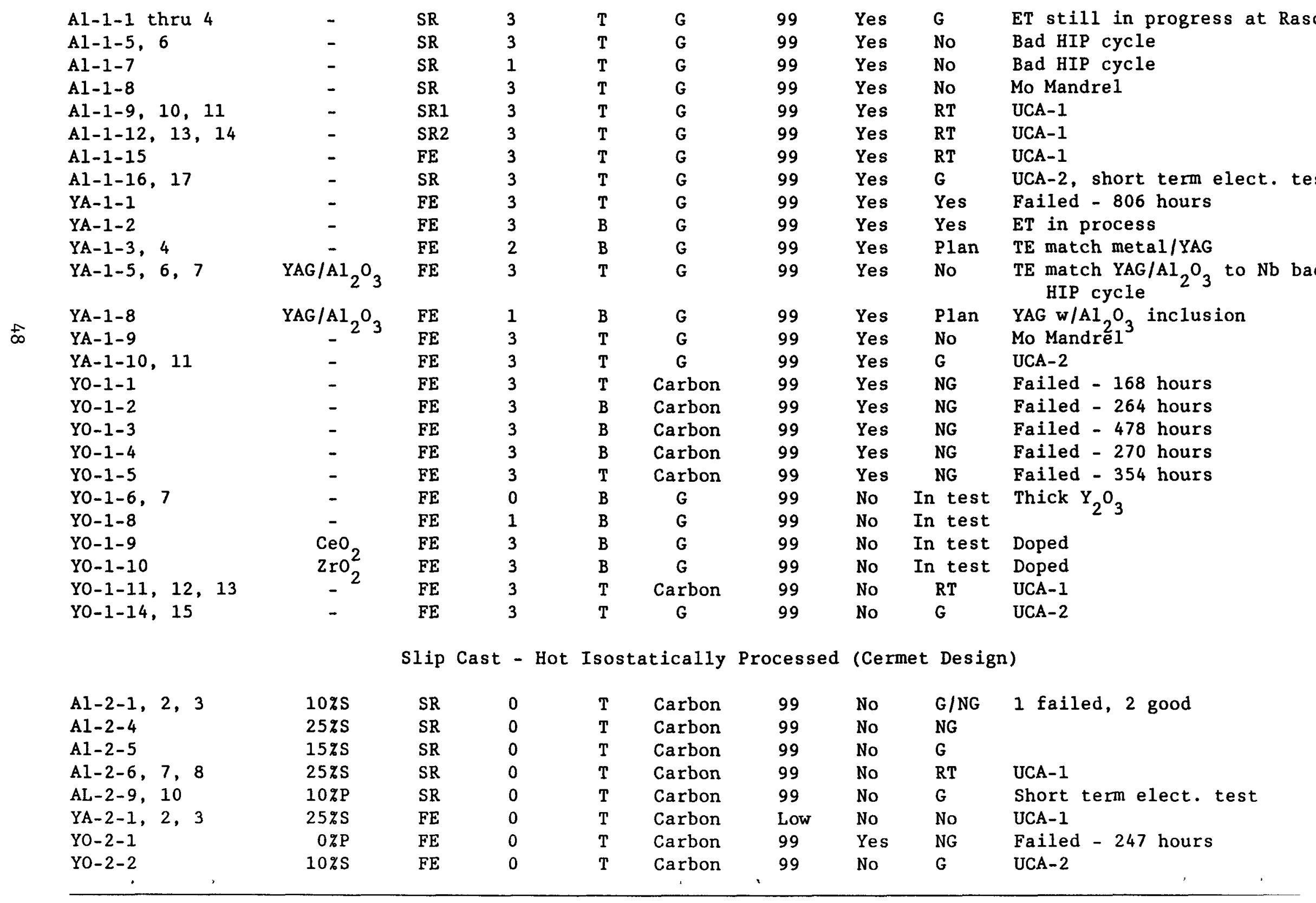


TABLE 5-3

SHEATH INSULATOR TESTING

Process Additive End Grading Ex-Reactor Tests Fluence Electrical Thermal Cracks

PLASMA SPRAYED - HOT ISOSTATICALLY PROCESSED

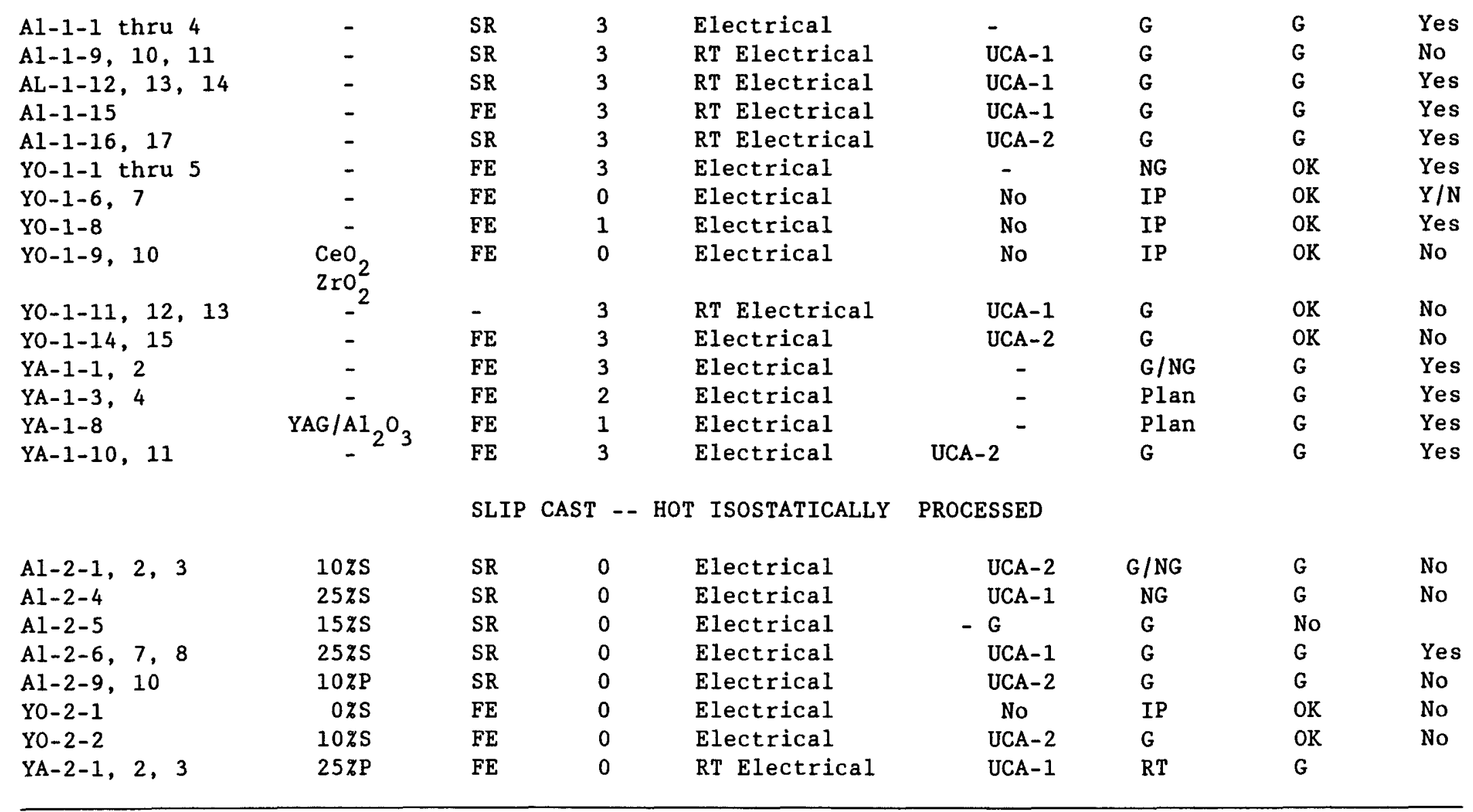

Al = Alumina

$\mathrm{FE}=\mathrm{Flat}$ Ends
$Y O=$ Yttria
$\mathrm{S}=$ Spheres
$Y A=Y A G$

$P=$ Powder
$\mathrm{SR}=$ Stress Relieved Ends

IP $=$ In Process 
agglomerates of yttria. The materials were purchased from several different sources as typically 99.99 percent pure yttrium oxide. Certificates of analysis supplied by the vendors, however, do not indicate that the listed purity levels are on a metals basis only. One expensive grade of material that is advertised as 99.999 percent pure actually contains as much as $1800 \mathrm{ppm}$ of carbon. A list of the yttria vendors and the carbon content present in the starting powders is given in Table 5-4.

TABLE $5-4$

CARBON CONTENT OF PURCHASED YTTRIA POWDERS

\begin{tabular}{|c|c|c|c|}
\hline Vendor & $\begin{array}{c}\text { Metals Basis } \\
\text { Purity } \\
(\%)\end{array}$ & $\begin{array}{l}\text { Heat } \\
\text { Treatment } \\
\text { (Air) }\end{array}$ & $\begin{array}{l}\text { Carbon } \\
\text { Content } \\
\text { (ppm) }\end{array}$ \\
\hline Aesar & $\begin{array}{l}99.99 \\
99.999\end{array}$ & $\begin{array}{l}\text { None } \\
\text { None }\end{array}$ & $\begin{array}{l}>1500 \\
>1500\end{array}$ \\
\hline Atomergic & 99.99 & None & High \\
\hline Hermann Stark & 99.99 & None & $\mathrm{High}$ \\
\hline Moly Corporation & 99.99 & $\begin{array}{l}\text { None } \\
4 \text { hours } 1100 \mathrm{C} \\
4 \text { hours } 1200 \mathrm{C} \\
4 \text { hours } 1300 \mathrm{C}\end{array}$ & $\begin{array}{r}1560 \\
275 \\
190 \\
220\end{array}$ \\
\hline Rhone-Poulanc & 99.99 & None & $>1500$ \\
\hline
\end{tabular}

During high temperature fabrication, and under applied voltages during subsequent electrical tests, the carbon particles react with yttria. The reaction zone around each particle enlarges with time and eventually can extend across the total thickness of the ceramic. Fabricating high resistivity yttria trilayers depends on using carbon-free yttria powder.

A special lot of materials has been ordered from Aesar Corporation which should contain less than $50 \mathrm{ppm}$ carbon and less than $100 \mathrm{ppm}$ of other metallic impurities. Until this powder arrives, the most reliable source of yttria is Moly Corporation. Firing this powder in air at 1500-1700 K removes all but $200 \mathrm{ppm}$ carbon and does not cause any signficant sintering. 
Cylinders of this yttria have been cold pressed, sintered in an air furnace and machined. These cylinders will be encapsulated with niobium and pressure bonded to form zero metal content trilayers. The yttria layer formed in this matter is transparent and the existence of carbon particles can be determined visually. If the yttria is carbon-free, the resistivity of the trilayers will be measured as a function of temperature.

\section{YAG Trilayers. Dense, crack-free YAG trilayers have yet to be} fabricated. One reason is the difference in thermal expansion between niobium and YAG. This difference in thermal expansion is most pronounced at temperatures above $1300 \mathrm{C}$. In addition, there is some evidence of a chemical reaction between niobium and YAG at temperatures above $1500 \mathrm{C}$ which could weaken the ceramic. Since the suspected chemical reactions and the mismatch in thermal expansion are accentuated at high temperature, the key to forming a flawless YAG trilayer may be first making a dense, high purity YAG cylinder and then bonding niobium to this cylinder at relatively low temperature and pressure. Cylinders have been made using YAG formed by reacting purified yttria with alumina. The microstructure of these ceramics was not completely uniform, probably due to variations in the density of the green ceramic before firing. It is important that the ceramics be strong, unfform and of high density because further sintering will not occur during low temperature pressure bonding.

Dense YAG cylinders cannot be made unless the powders are thoroughly mixed and uniformly packed before firing. Large voids or variations in the density of the unfired ceramic will cause porosity and irregular grain size. Powder processing techniques like filter pressing and slip casting, that were developed for making cermets, are being modified to make tubes of YAG powder with the unfform microstructure required to sinter to high density without the aid of high pressure. A variation of the filter pressing technique employs a porous metal cylinder which is mounted on a hollow pipe. A rubber sleeve is placed over the assembly and a slurry of powder is poured inside and sealed with a rubber stopper. The water is driven out of the slurry through the porous metal by a hydrostatic press. Dense and unfform ceramic tubes are formed around the central rod. Unfortunately, most of these tubes have cracked as they are taken off the 
filter. Smaller particle size filters and ceramic filters will be tried as a means of eliminating these cracks.

The availability of high purity YAG powder is also a problem. Transtek Corporation has agreed to make sinterable YAG powder of acceptable purity. About 20 pounds of this material was ordered and delivery is expected by April.

Cesium Compatibility. Sheath insulators can come in contact with and should be compatible with fission product cesium. Two promising sheath insulator materials from the Thermionic Technology Program (Ref. 2) (aluminum oxynitride and boron nitride) are being soak tested to evaluate chemical compatibility with cesium vapor. Separate capsules containing cylindrical trilayer samples of niobium with aluminum oxynitride, and samples of niobium with boron nitride were fabricated and placed on test. The test samples are operating at a temperature of $1250 \mathrm{~K}$ under a cesium vapor pressure of 10 torr. The tests will continue for a total perfod of 500 hours.

Mechanical Properties (Ref. 3). A series of tests are planned to investigate the hardness $(H)$, strength () , and toughness $\left(\mathrm{K}_{1 c}\right)$ of $\mathrm{Al}_{2} \mathrm{O}_{3}$ and $\mathrm{Y}_{2} \mathrm{O}_{3}$ cermets containing niobium metal over a range of 0 to 30 volume percent. Test specimens will be fabricated with niobium in the form of metal spheres and in the form of irregular powder to allow the mechanical properties of these two types of cermets to be direclty compared. The zero metal content tests will provide experimental data for comparison with published data. Tests will also be made on YAG ceramic specimens to provide comparative mechanical property data.

The test specimens will be small disks, 0.5 inch diameter by .040 inch thick. The disks will be strength tested in a ball on the ring biaxial test fixture shown in Fig. 5-1. The test specimen is supported by 10 stainless steel balls (1/8" diameter) placed in a circular groove .412 inch in diameter. The loading ball is a $1 / 4$ inch diameter stainless steel ball mounted in the end of the loading rod of an Instron Universal testing machine. The maximum stress occurs at the center of the tensile surface of 


\section{BIAXIAL STRENGTH TEST FIXTURE SCHEMATIC}
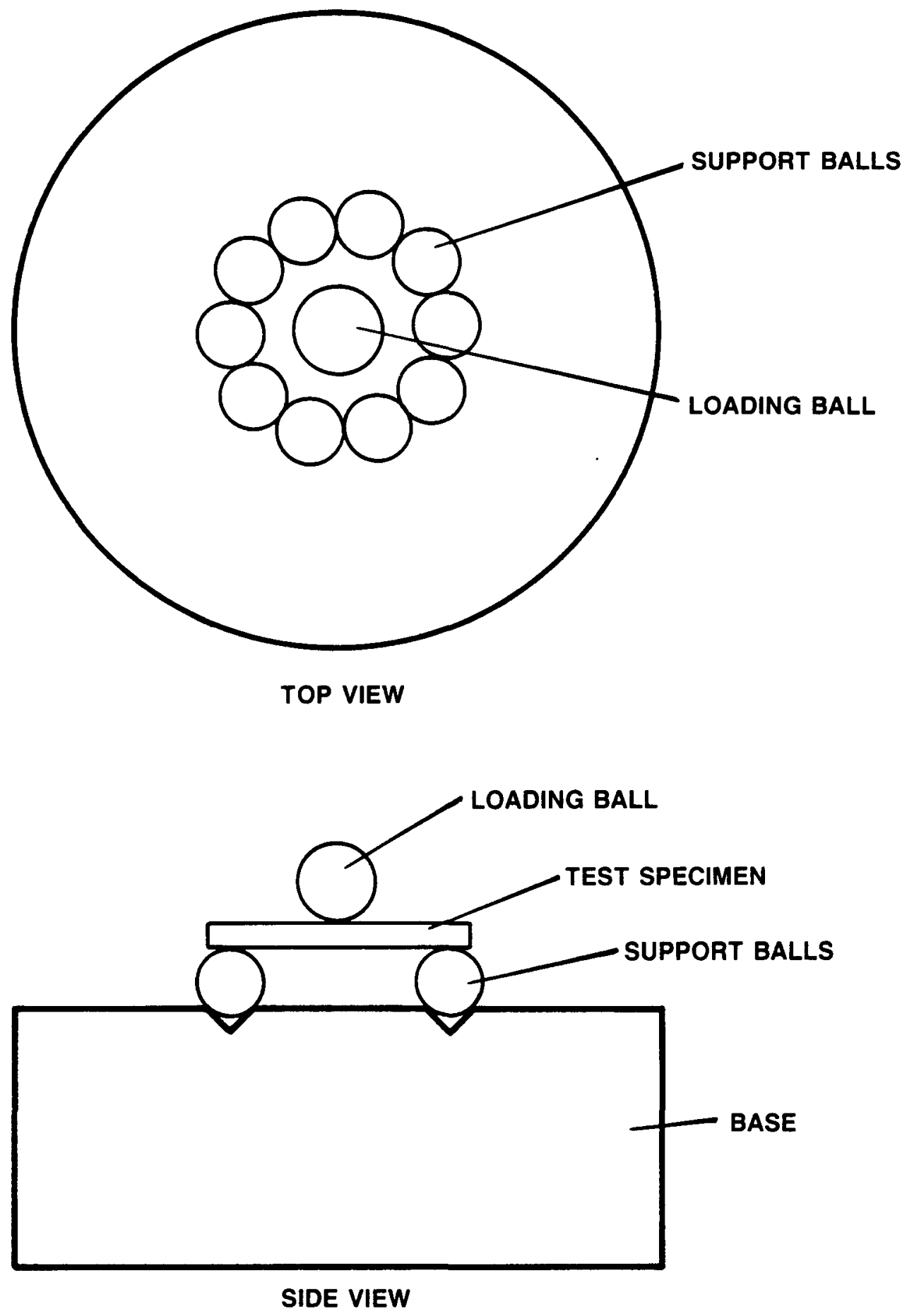
the specimen and is given by the equation (Ref. 4):

$$
\sigma=\left[\frac{3 F(1+\nu)}{4 \pi t^{2}} 1+2 \ln (a / b)+\frac{1-\nu}{1+\nu}\left(1-b^{2} / 2 a^{2}\right) a^{2} / x^{2}\right]
$$

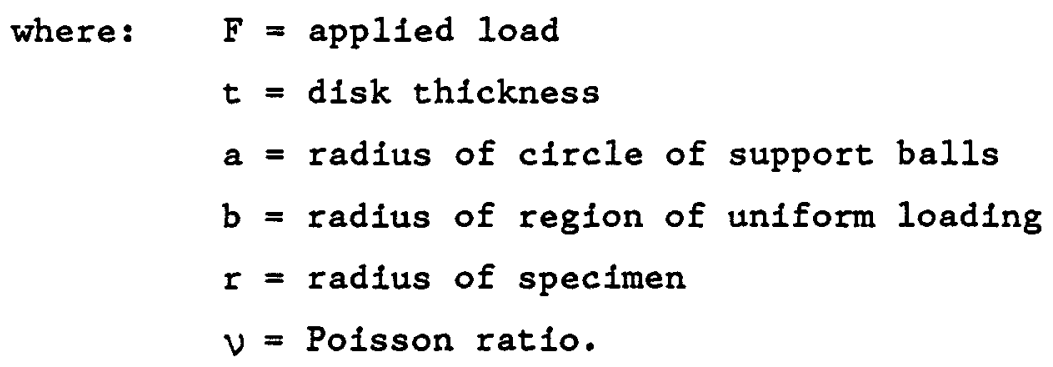

The fractured specimens will be hardness tested using a Tukon microhardness tester with a Vicker's indenter. Hardness is calculated from the dimensions of the indent in the specimen from the following equation:

$$
H=\frac{2 P \sin (\theta / 2)}{d^{2}}
$$

where: $P=$ indenter load

$\theta=$ angle between opposite faces of indenter

$d=$ length of the indent diagonal.

Above a threshold load, a Vicker's indent will produce a well defined pyramid shaped indent with radial cracks radiating from each of the four corners of the indent. The plain strain fracture toughness $\left(K_{1 c}\right)$ can be calculated from the dimensions of the radial cracks using the method of Anstis, et al. (Ref. 5):

$$
\mathrm{K}_{1 \mathrm{c}}=0.16(\mathrm{E} / \mathrm{H})^{1 / 2} \mathrm{P} / \mathrm{C}_{\mathrm{o}}^{3 / 2}
$$

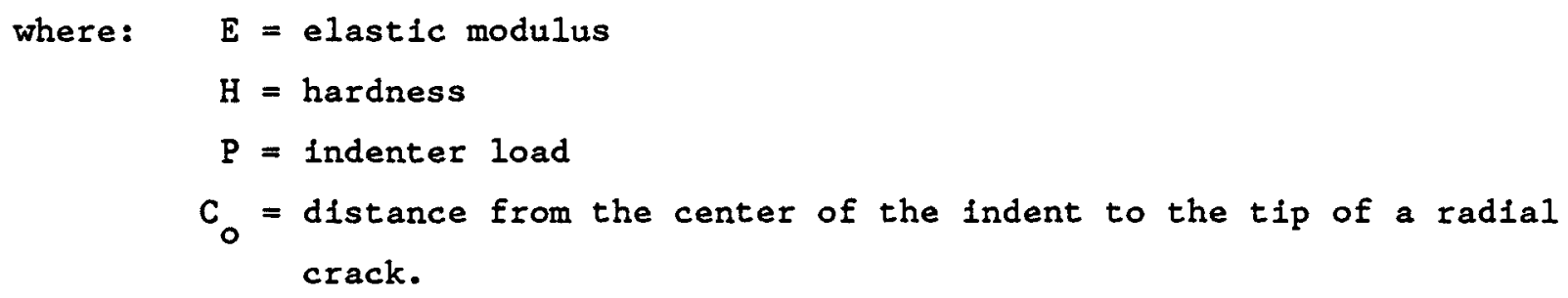
crack. 
Typical published values of mechanical properties for ceramics with zero metal content are listed in Table 5-5.

TABLE 5-5

CERAMIC MECHANICAL PROPERTIES (REF. 6)

\begin{tabular}{|c|c|c|c|}
\hline & $\mathrm{Al}_{2} \mathrm{O}_{3}$ & YAG & $\mathrm{Y}_{2} \mathrm{O}_{3}$ \\
\hline Strength (MPa) & 280 & 443 & - \\
\hline Hardness (GPa) & 20 & 18 & 6 \\
\hline Toughness $\left(\mathrm{MPa} \mathrm{m} \mathrm{m}^{1 / 2}\right)$ & 4 & 1.7 & - \\
\hline Elastic Modulus (GPa) & 400 & 290 & 177 \\
\hline
\end{tabular}

\subsubsection{Plasma Sprayed Sheath Insulator Fabrication}

Several gas pressure bonding (GPB) runs were done at TECO and at Battelle-Columbus to study cracking as a function of process variables. Nine 3-inch long mandrels were plasma sprayed with $\mathrm{YAG}, \mathrm{Al}_{2} \mathrm{O}_{3}$ or $\mathrm{YAG}-\mathrm{Al}_{2} \mathrm{O}_{3}$ mixtures, as shown in Table 5-6. The purpose of each particular mandrel is also listed in the table, but in general the goal was to examine the effect of thermal expansion matched metals to YAG, thermal expansion matched niobium to YAG-AI ${ }_{2} \mathrm{O}_{3}$, a crack-stopping layer of pure niobium, different $\mathrm{AI}_{2} \mathrm{O}_{3}$ source materials, and molybdenum mandrels where the ceramic should be put into compression. The nine mandrels underwent GPB at TECO. However, due to furnace difficulties during the bonding cycle, all six $\mathrm{Nb}$ mandrel assemblies were subjected to a nonstandard pressure/temperature protocol. Metallographic examination of these samples after bonding indicated that all were severely cracked, as anticlpated.

The three Mo mandrel samples were subjected to a successful standard pressure/temperature bonding cycle. However, preliminary metallographic examination of these samples indicated that all were cracked, indicating that the Mo mandrel did not sufficlently reduce the stresses which lead to cracking of the ceramic. 
TABLE 5-6

SHEATH INSULATOR FABRICATION DEVELOPMENT MATRIX

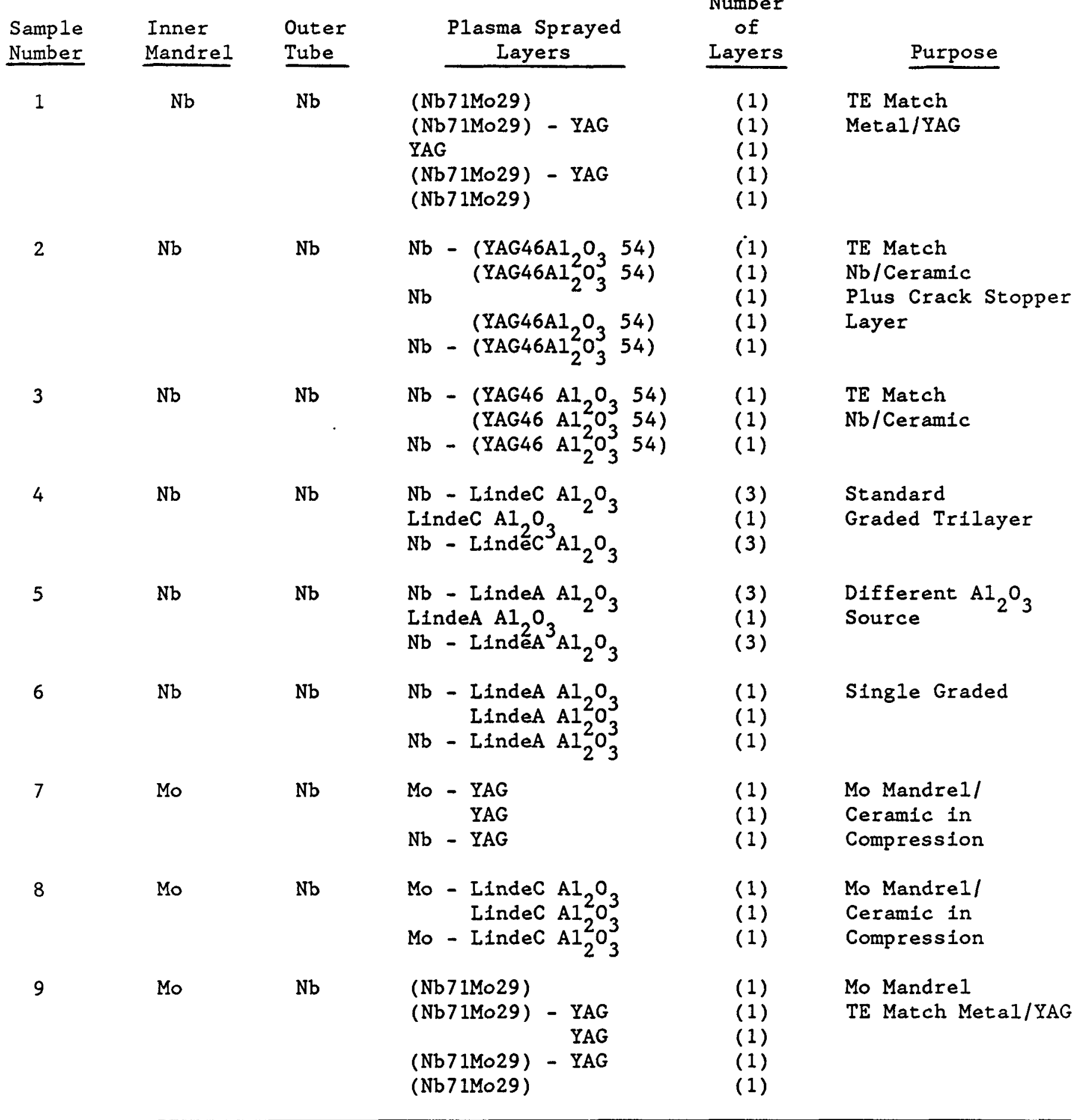


A second fabrication development matrix was fabricated to study ways of reducing cracking during GPB. The matrix along with the specific purpose for each of the manufactured mandrels is shown in Table 5-7. All $\mathrm{Y}_{2} \mathrm{O}_{3}$ and $\mathrm{YAG}$ powders were prefired at $850-950^{\circ} \mathrm{C}$ in air to reduce the carbon contamination present in the as-received powders. The Linde $\mathrm{C}_{2} 1_{2} \mathrm{O}_{3}$ powders had a very low carbon contamination level of $<50 \mathrm{ppm}$. After firing, the Johnson-Matthey (JM) $\mathrm{Y}_{2} \mathrm{O}_{3}$, Molycorp $\mathrm{Y}_{2} \mathrm{O}_{3}$ and UMC YAG powder, both the JM $\mathrm{Y}_{2} \mathrm{O}_{3}$ and UMC YAG powder would not flow properly in the plasma spray system. Therefore on1y Molycorp $\mathrm{Y}_{2} \mathrm{O}_{3}$ was used as the source of $\mathrm{Y}_{2} \mathrm{O}_{3}$. The mandrels were gas pressure bonded at Battelle using pressure and temperature cycles which had previously given crack free insulators. Subsequent metallographic examination indicated a marked improvement in the conditions of the ceramic material from previous fabrication runs. Table 5-8 summarizes the results: in general, the samples showed many fewer and finer cracks than previously obtained. Test specimens were fabricated from five of these mandrels and shipped to Rasor Associates for ex-reactor electrical testing.

Further fabrication development in the areas of matching the coefficlent of thermal expansion between the metal and ceramic or increasing the number of graded layers could lead to an acceptable sheath insulator. A test specimen matrix based on these results is being developed.

\subsection{EX-REACTOR TESTING PROGRAM}

\subsubsection{Introduction}

The ex-reactor testing program has the dual purpose of providing data to aid in the selection of specimens for the in-reactor tests and to assist in understanding degradation mechanism. The tests are divided into screening and life tests. The life tests include long term tests at nominal operating conditions and short term accelerated tests at higher temperature. These latter will allow a better understanding of the dominant degradation mechanisms. 
PLASMA SPRAYED SHEATH INSULATOR FABRICATION DEVELOPMENT MATRIX

\begin{tabular}{|c|c|c|c|}
\hline Sample No. & Plasma Sprayed Layers & No. of Layers & Purpose \\
\hline 1 & $\begin{array}{l}\text { (Nb } 71 \% \text { Mo } 29 \%) \\
(\mathrm{Nb} 71 \% \text { Mo } 29 \%) \text {-YAG } \\
\text { YAG } \\
\text { (Nb 71\% } \\
\text { Mo } 29 \%) \text {-YAG } \\
(\mathrm{Nb} 71 \% \text { Mo } 29 \%)\end{array}$ & $\begin{array}{l}1 \\
1 \\
1 \\
1\end{array}$ & $\begin{array}{l}\text { Thermal expansion } \\
\text { match of metal to } \\
\text { YAG }\end{array}$ \\
\hline 2 & $\mathrm{Y}_{2} \mathrm{O}_{3}$ & 1 & $\begin{array}{l}\text { Thick } \mathrm{Y}_{2} \mathrm{O}_{3} \\
\text { Molycorp } \mathrm{Y}_{2} \mathrm{O}_{3}\end{array}$ \\
\hline 3 & $\mathrm{Y}_{2} \mathrm{O}_{3}$ & 1 & $\begin{array}{l}\text { Thick } \mathrm{Y}_{2} \mathrm{O}_{3} \\
\text { Johnson Matthey } \mathrm{Y}_{2} \mathrm{O}_{3}\end{array}$ \\
\hline 4 & $\begin{array}{c}\mathrm{Nb}-\mathrm{Y}_{2} \mathrm{O}_{3} \\
\mathrm{Y}_{2} \mathrm{O}_{3} \\
\mathrm{Nb}-\mathrm{Y}_{2} \mathrm{O}_{3}\end{array}$ & $\begin{array}{l}1 \\
1\end{array}$ & $\mathrm{Y}_{2} \mathrm{O}_{3}$ with 1 graded \\
\hline 5 & 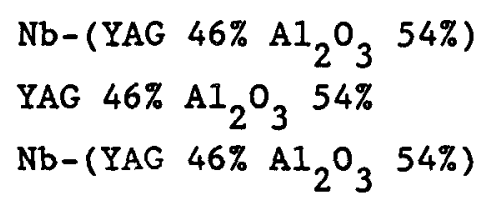 & $\begin{array}{l}1 \\
1 \\
1\end{array}$ & $\begin{array}{l}\text { Thermal expansion } \\
\text { match of ceramic to } \\
\mathrm{Nb}\end{array}$ \\
\hline 6 & $\begin{array}{c}\mathrm{Nb}-\mathrm{Al}_{2} \mathrm{O}_{3} \\
\mathrm{Al}_{2} \mathrm{O}_{3} \\
\mathrm{Nb}-\mathrm{Al}_{2} \mathrm{O}_{3}\end{array}$ & $\begin{array}{l}4 \\
1 \\
4\end{array}$ & $\begin{array}{c}\mathrm{Al}_{2} \mathrm{O}_{3} \text { with multiple } \\
\text { graded layers }\end{array}$ \\
\hline 7 & 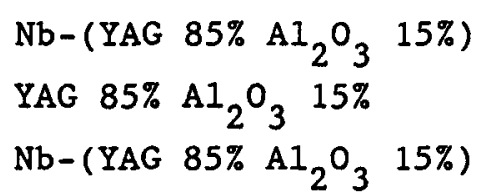 & $\begin{array}{l}1 \\
1 \\
1\end{array}$ & $\begin{array}{l}\text { YAG toughened by } \\
\mathrm{Al}_{2} \mathrm{O}_{3} \text { inclusions }\end{array}$ \\
\hline 8 & $\mathrm{Y}_{2} \mathrm{O}_{3} 98 \% \mathrm{CeO}_{2} 2 \%$ & 1 & $\begin{array}{l}\text { Thick } \mathrm{Y}_{2} \mathrm{O}_{3} \text {-donor } \\
\text { doped to reduce } \\
\text { ionic conductivity }\end{array}$ \\
\hline 9 & $\mathrm{Y}_{2} \mathrm{O}_{3} 99 \% \mathrm{ZrO}_{2}$ & 1 & $\begin{array}{l}\text { Thick } \mathrm{Y}_{2} \mathrm{O}_{3} \text {-donor } \\
\text { doped to reduce } \\
\text { ionic conductivity }\end{array}$ \\
\hline
\end{tabular}


TABLE 5-8

METALLOGRAPHIC EXAMINATION OF SHEATH INSULATORS

\begin{tabular}{|c|c|c|c|c|c|}
\hline $\begin{array}{l}\text { Sample } \\
\text { Number }\end{array}$ & $\begin{array}{l}\text { Insulator } \\
\text { Material }\end{array}$ & $\begin{array}{c}\text { Graded Layer } \\
\text { Material }\end{array}$ & $\begin{array}{c}\text { \% Relative } \\
\text { Porosity }\end{array}$ & $\begin{array}{l}\text { Number } \\
\text { Phases }\end{array}$ & $\begin{array}{l}\text { Number } \\
\text { Cracks }\end{array}$ \\
\hline 371 & Molycorp $\mathrm{Y}_{2} \mathrm{O}_{3}$ & None & $>10$ & 1 & None \\
\hline 373 & YAG-46\% & $\begin{array}{l}\mathrm{Nb}-\mathrm{YAG}-\mathrm{A} 1_{2} \mathrm{O}_{3} \\
\mathrm{Al}_{2} \mathrm{O}_{3}-54 \%^{2}\end{array}$ & $<5$ & 2 & 16 \\
\hline 374 & Molycorp YAG & $\mathrm{Nb}-\mathrm{Mo}-\mathrm{YAG}$ & $<5$ & 4 & 15 \\
\hline 375 & Linde $\mathrm{C} \mathrm{Al}_{2} \mathrm{O}_{3}$ & $\mathrm{Nb}-\mathrm{Al}_{2} \mathrm{O}_{3}$ & $<5$ & 1 & 29 \\
\hline 376 & Molycorp $\mathrm{Y}_{2} \mathrm{O}_{3}$ & None & $>10$ & 1 & 26 \\
\hline 401 & $\begin{array}{l}\mathrm{Y}_{2} \mathrm{O}_{3}-55.4 \% \\
\mathrm{AL}_{2} \mathrm{O}^{-44.6 \%}\end{array}$ & $\mathrm{Nb}-\mathrm{Y}_{2} \mathrm{O}_{3}-\mathrm{Al}_{2} \mathrm{O}_{3}$ & $<5$ & 4 & 18 \\
\hline 402 & $\begin{array}{l}\mathrm{Y}_{2} \mathrm{O}_{3}-99 \% \\
\mathrm{ZrO}_{2}-1 \%\end{array}$ & None & 5 & 1 & None \\
\hline 403 & $\begin{array}{l}\mathrm{Y}_{2} \mathrm{O}_{3}-98 \% \\
\mathrm{CeO}_{2}^{2-2 \%}\end{array}$ & None & 5 & 1 & None \\
\hline
\end{tabular}


The test specimens consist of a thin (approximately .015 in. thick) oxide insulator cylinder clad inside and out with niobium. The insulating layer may be a pure oxide, an oxide cermet or a graded oxide/metal. The configuration of the ex-reactor test specimens is shown in Fig. 5-2.

Test Description. The electrical resistance of the insulator samples is determined by applying a DC voltage across the inner and outer niobium sheaths. The resulting current is measured with an electrometer and the resistance calculated as the ratio of the voltage and current. The body and guard electrodes are held at the same potential, but the current through each is measured independently. The purpose of the guard ring is to eliminate possible effects of a high conductivity path along the surface of the sample. The utilization of guarded measurements is standard when examining highly resistive materials. A schematic diagram of the data acquisition system is shown in Fig. 5-3.

A number of specimens are tested within each oven by vertically stacking the samples along the axis of the molybdenum tube heating element. The samples are separated by niobium spacer rings which act as a common ground for the inner niobium sheaths but isolate the outer sheaths. Four thermocouples are attached to these spacer rings within each oven at various positions along the length of the heater to monitor the temperature profile. This configuration with the heater within the samples produces a thermal flux of several watts per square centimeter through the insulator trilayer at test temperatures. The thermal flux through a fueled emitter assembly will be considerably greater, but this internal heating scheme represents a first approximation to simulation. The oven and sample arrangements are 11lustrated in Fig. 5-4. Details of the spacer ring with dimensions is seen in Fig. 5-5.

While this type of heating does somewhat thermally simulate a fueled element, it does present problems as well. The temperature gradients observed along the length of the heaters have been quite large. The spread in measured temperatures among the four thermocouples in each oven is $100^{\circ}-170^{\circ} \mathrm{C}$ depending upon the specific heating element. The presence of these gradients requires that the temperature of each specimen be 


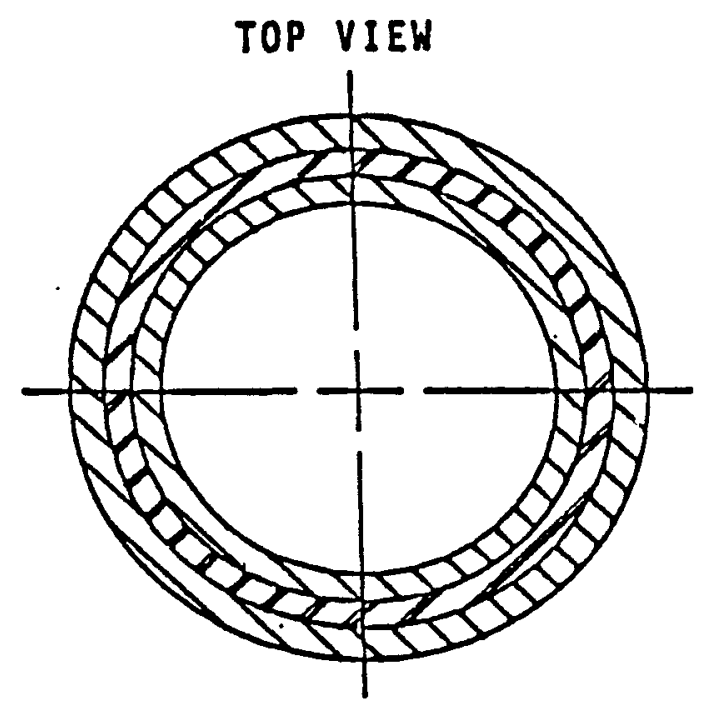

CROSS SECTIOH

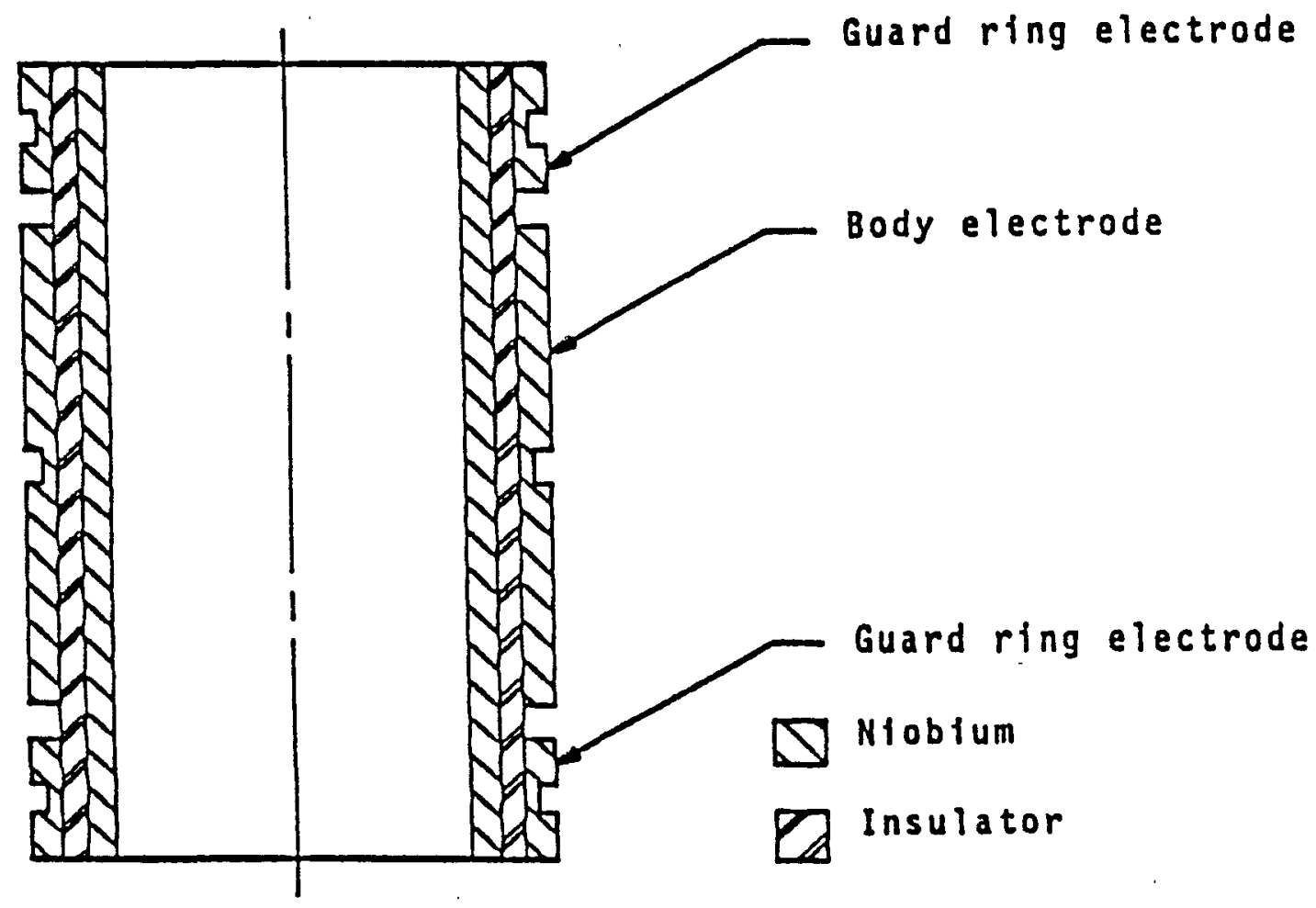

Figure 5-2 - Sheath insulator/electrode configuration. Length approximately $0.75^{\prime \prime}$. 


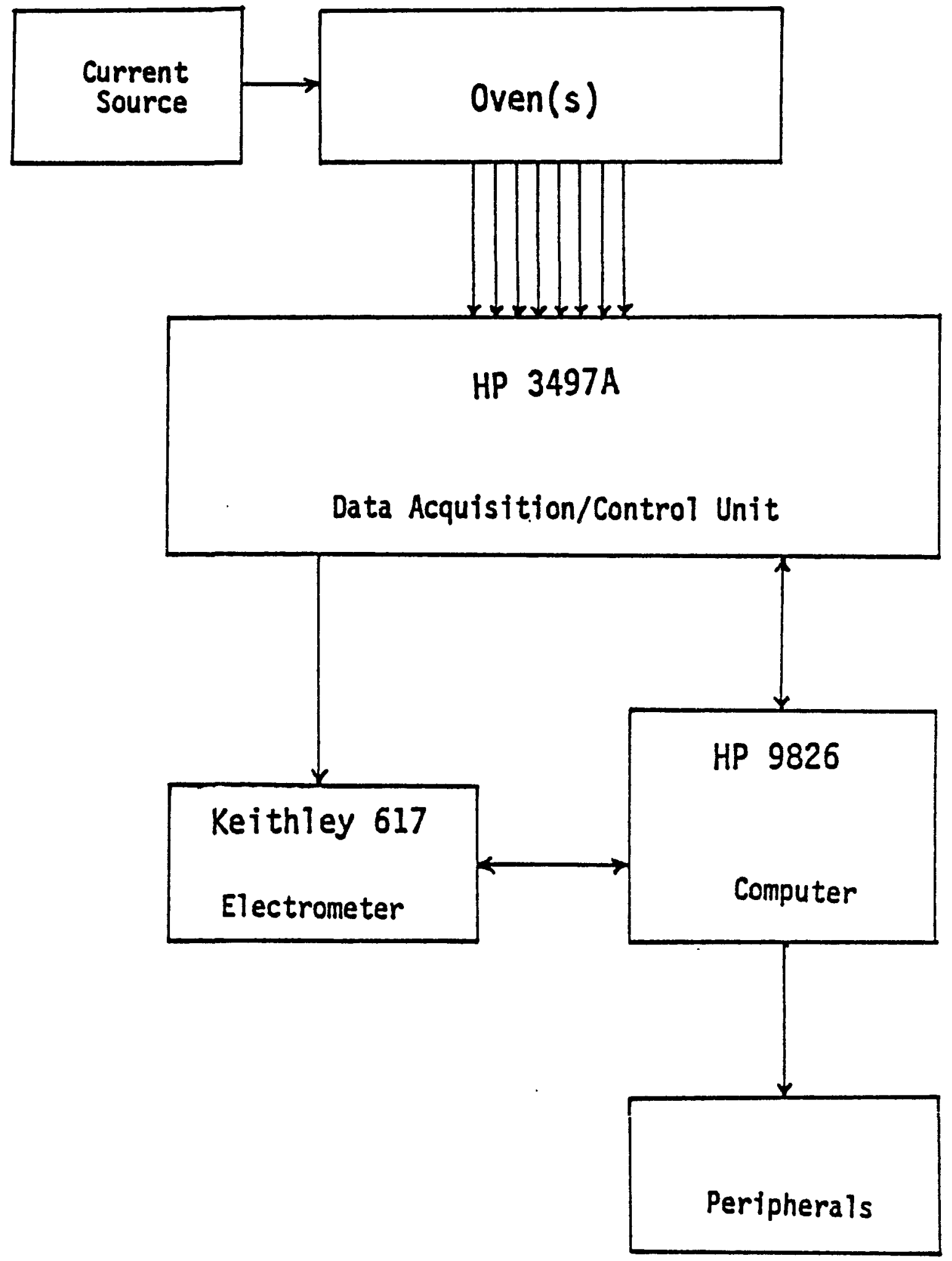

Figure 5-3 - TFE verification sheath insulator data acquisition system 


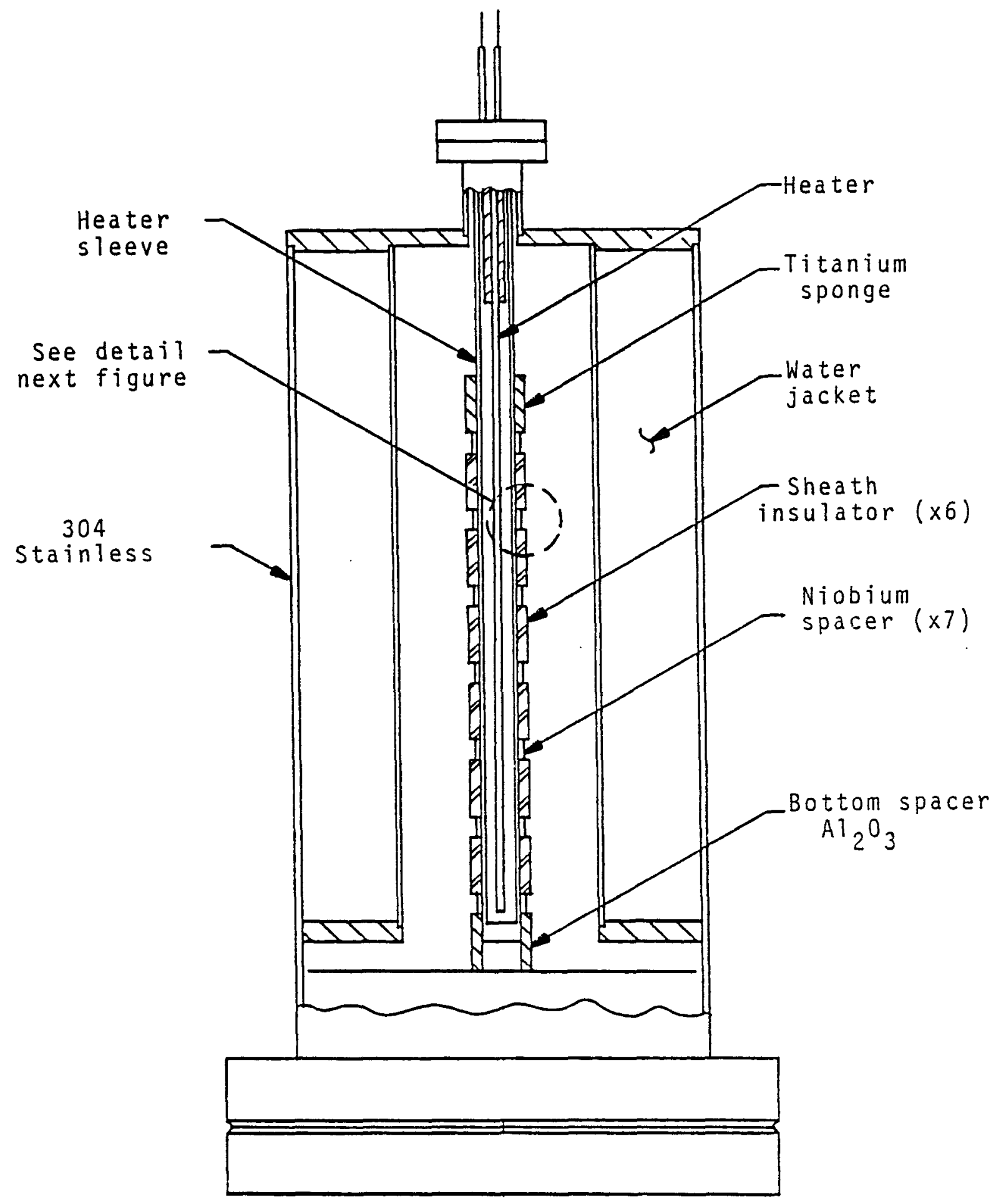

Figure 5-4 - Sheath insulator test oven showing samples in place 


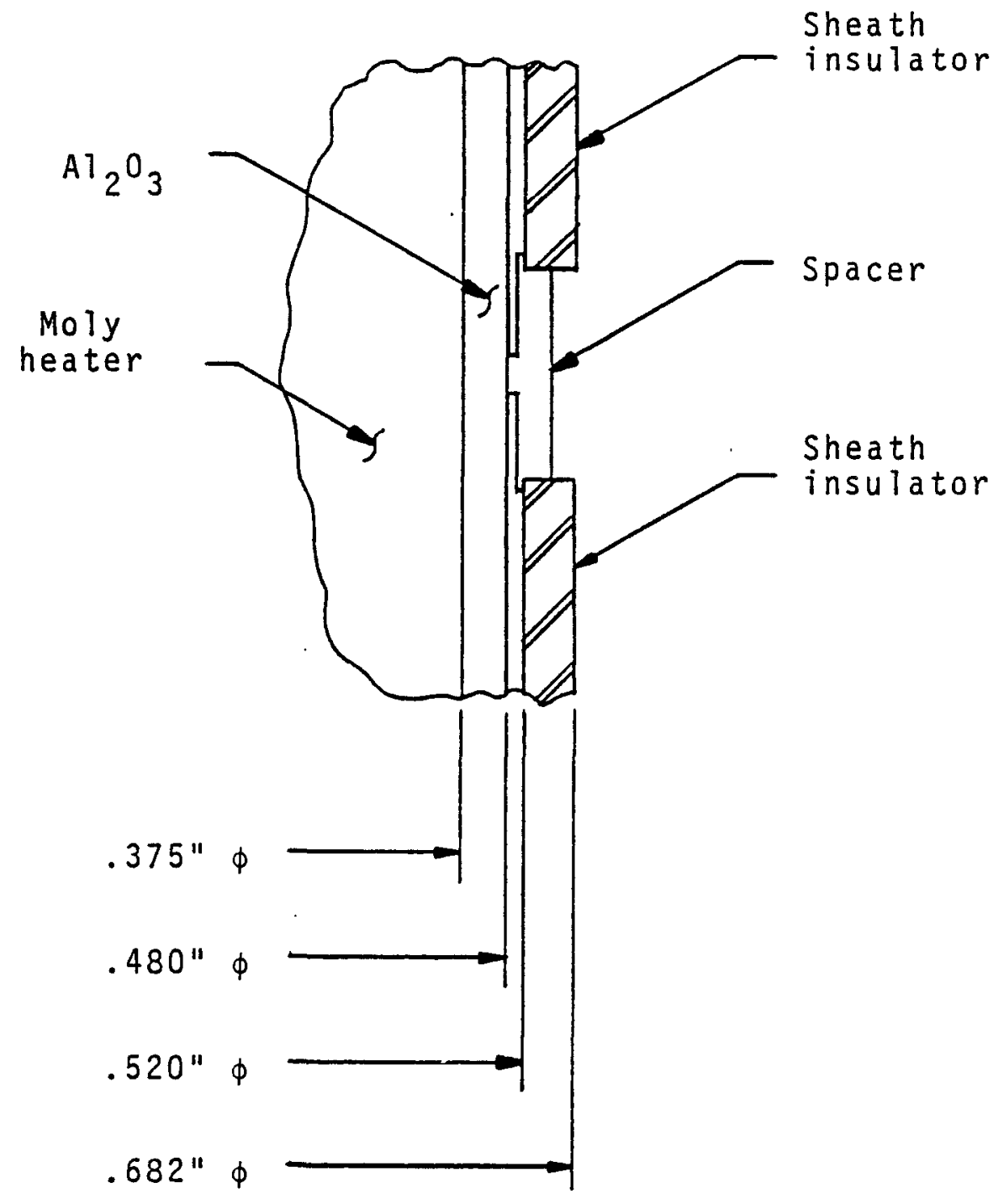

Figure 5-5 - Detail of sample/spacer configuration 
interpolated leading to some uncertainty. Uncertainties in temperature can be important when considering activated processes such as mass transport. The advantages of the thermal flux oven will be reevaluated and the use of isothermal ovens will be considered in order to obtain better temperature control.

Results-to-Date. The sheath insulator in the TFE assembly isolates the collector from the liquid metal coolant. If current can flow through this path, power will be lost. It has been estimated that an insulator of the dimensions of the test samples will provide adequate isolation if the resistance is greater than approximately $300 \mathrm{ohms}^{*}$ for at least seven years at an operating temperature of about $1070 \mathrm{~K}$. The specimens in these tests are considered to have failed when the resistance drops to a few hundred ohms or less.

A summary of the electrical resistance of the samples tested to-date is given in Tables 5-9 and 5-10. Table 5-9 shows the samples which have previously exhibited high temperature failure. The times given in Table 5-9 are the real times at the stated voltages and temperature. The temperatures were estimated by interpolating between the thermocouples within each oven. As can be seen, none of the samples survived more than 1000 hours before exhibiting large decreases in resistance.

From a practical point of view, the samples cannot be tested for their full seven year required lifetime. Therefore, accelerated tests are necessary to assess lifetime. Table 5-10 shows samples currently on-1ine in the test stand. The times listed for the samples are the estimated equivalent time at the nominal operating temperature of $1070 \mathrm{~K}$ with 10 volts applied. The actual degradation processes are not known, so it is assumed that the degradation is controlled by the same mechanism as the conduction. The equivalent time should therefore exhibit an Arrhenius behavior with an activation energy equal to that for the conduction process. An activation energy of $3.45 \mathrm{eV}$ (a nominal value for conduction

\footnotetext{
* The specific requirement is being reevaluated and it is estimated that a smaller value will be acceptable.
} 
TABLE 5-9

FINAL VALUES OF RESISTANCE FOR SAMPLES PREVIOUSLY TAKEN OFF-LINE

\begin{tabular}{|c|c|c|c|c|c|c|c|}
\hline \multirow{2}{*}{$\frac{\text { Sample \# }}{\mathrm{Y} 1}$} & \multirow{2}{*}{$\frac{\text { Materlal }}{\mathrm{Y}_{2} \mathrm{O}_{2}}$} & \multirow{2}{*}{$\frac{\text { Source }}{G A}$} & \multirow{2}{*}{$\begin{array}{c}\text { Approx. } \\
\text { Temp (K) } \\
1100\end{array}$} & \multicolumn{2}{|c|}{$\begin{array}{c}\text { Resistance } \\
\text { Body(ohm) Guard (ohm) }\end{array}$} & \multicolumn{2}{|c|}{$\begin{array}{l}\text { Time on Test } \\
\text { (Hours) (Volts) }\end{array}$} \\
\hline & & & & $<100$ & $<100$ & 354 & 15 \\
\hline 244 & $\mathrm{Y}_{2} \mathrm{O}_{3}$ & GA & 1060 & $<100$ & $<100$ & $\begin{array}{r}138 \\
16\end{array}$ & $\begin{array}{r}1 \\
10\end{array}$ \\
\hline 247 & YAG & $\mathrm{GA}$ & 1120 & $2.8 \times 10^{3}$ & $1.0 \times 10^{3}$ & $\begin{array}{l}138 \\
500 \\
168\end{array}$ & $\begin{array}{r}1 \\
10 \\
20\end{array}$ \\
\hline 253 & $\mathrm{Y}_{2} \mathrm{O}_{3}$ & $\mathrm{GA}$ & 1120 & $<100$ & $<100$ & $\begin{array}{r}138 \\
28\end{array}$ & $\begin{array}{r}1 \\
10\end{array}$ \\
\hline 254 & $\mathrm{Y}_{2} \mathrm{O}_{3}$ & $\mathrm{GA}$ & 1120 & $<100$ & $<100$ & $\begin{array}{r}138 \\
339 \\
1\end{array}$ & $\begin{array}{r}1 \\
1 \\
20\end{array}$ \\
\hline Y2 & $\mathrm{Y}_{2} \mathrm{O}_{3}$ & GA & 940 & $<100$ & $<100$ & $\begin{array}{r}838 \\
32\end{array}$ & $\begin{array}{l}10 \\
20\end{array}$ \\
\hline A11 & $\begin{array}{l}\mathrm{A}_{1}{ }^{\mathrm{O}}{ }^{2} \\
10 \% \mathrm{Nb}\end{array}$ & $\mathrm{TE}$ & 1130 & $<100$ & $<100$ & 97 & 10 \\
\hline
\end{tabular}


TABLE 5-10

RESISTANCE OF SAMPLES CURRENTLY IN PLACE IN TEST APPARATUS

\begin{tabular}{|c|c|c|c|c|c|c|}
\hline Sample \# & Material & Source & $\begin{array}{l}\text { Approx. } \\
\text { Temp (K) }\end{array}$ & $\begin{array}{l}\text { Resistanc } \\
\text { Body (ohm) }\end{array}$ & $\begin{array}{c}(3 / 1 / 88) \\
\text { Guard (ohm) }\end{array}$ & $t_{\text {eq }}$ (Days) \\
\hline YO & $\mathrm{Y}_{2} \mathrm{O}_{3}$ & $\mathrm{TE}$ & 1100 & Failed & $12 / 17 / 87$ & 247 \\
\hline $\mathrm{Al}_{2}$ & 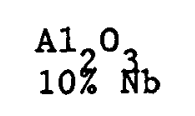 & $T E$ & 1210 & $3.3 \times 10^{7}$ & $3.4 \times 10^{7}$ & 1844 \\
\hline 255 & YAG & GA & 1200 & $6.4 \times 10^{3}$ & $1.4 \times 10^{4}$ & 1681 \\
\hline 245 & $\mathrm{~A}_{2} \mathrm{O}_{3}$ & GA & 1130 & $3.8 \times 10^{8}$ & $3.1 \times 10^{8}$ & 227 \\
\hline 250 & $\mathrm{Al}_{2} \mathrm{O}_{3}$ & GA & 1210 & $1.4 \times 10^{8}$ & $2.5 \times 10^{5}$ & 1053 \\
\hline 251 & $\mathrm{Al}_{2} \mathrm{O}_{3}$ & GA & 1220 & $3.1 \times 10^{8}$ & $2.8 \times 10^{5}$ & 1414 \\
\hline 252 & $\mathrm{Al}_{2} \mathrm{O}_{3}$ & GA & 1210 & $1.1 \times 10^{6}$ & 1200 & 1256 \\
\hline A14 & ${ }^{\mathrm{A} 1}{ }^{2} \mathrm{O}^{\mathrm{K}} \mathrm{\textrm {b }}$ & $\mathrm{TE}$ & 1150 & $4.7 \times 10^{6}$ & 470 & 419 \\
\hline
\end{tabular}


in $\mathrm{Al}_{2} \mathrm{O}_{3}$ ) has been assumed. The degradation process is also assumed to be linear with the applied voltage. The equivalent time is given by:

$$
t_{\text {eq }}=(V / 10) * \exp [(3.45 \mathrm{eV} / \mathrm{k})(1 / 1070-1 / \mathrm{T}) * \text { real time. }
$$

If a sample has been subjected to various temperatures and/or voltages, the equivalent times for each set of conditions are sumed to get the total times listed in Table 5-10. The temperatures listed are as of the date indicated and do not represent the temperatures for the entire duration of the tests. A number of samples have accumulated equivalent times of well over 1000 days while maintaining very high resistance across the body electrode.

When sample Y1 was removed from the test fixture, it was found to be a short circuit at room temperature. The region containing the defect was located by repeated sectioning and testing for continuity. The small piece containing the shorted region was polished and examined microscopically revealing a disruption of the graded layer. Volds through the entire thickness were observed, and particles of niobium were found scattered throughout the layer. This indicates that processing flaw(s) were responsible for the rapid failure.

The room temperature resistance was measured for all the other samples which had exhibited apparent high temperature fallure. With the exception of sample Y2, al1 samples have room temperature resistance of greater than $5 \times 10^{10}$ ohms. Sample $Y 1$ shows a body resistance of 32 megohms and a guard ring value of $25 \mathrm{kilohms.} \mathrm{Sample} \mathrm{Y} 1$ is the only sample which exhibits a short circuit at room temperature. All specimens have been retained for further electrical or microstructural evaluation.

At this point too few catastrophic fallures have occurred to draw specific conclusions, but a few generalizations may be drawn. All yttria samples tested to-date have shown apparent failure at high temperature. The longest lived of these is sample YO with an estimated equivalent time of 247 days which is only about one tenth of the required lifetime for a TFE sheath insulator. This may be due to the presence of carbon in the 
as-received powder. Later samples of yttria have been fabricated which have been fired to remove the carbon contamination. Testing of these samples will begin shortly. The two YAG samples show fairly low $\left(10^{3}\right.$ ohm range) resistance at high temperature but have not exhibited failure. YAG sample 255 has an estimated equivalent time on test of over 1600 days which is more than half the required lifetime.

With the exception of sample All, the alumina samples are behaving quite well with body resistances greater than $10^{6}$ ohms after equivalent times of 227 to 1844 days. The one apparent failure of an alumina sample (A11) occurred after only 4 days at 10 volts. If the body of this sample did Indeed fail, manufacturing defects would be the most likely cause considering the behavior of all other alumina specimens.

\subsection{IN-REACTOR TESTING PROGRAM}

The in-reactor testing program will determine the integrated performance of selected sheath insulator designs in two series of tests to be conducted in FFTF. The Uninstrumented Component Assembly (UCA) tests will be a series of three irradiations which will investigate the effect of time at temperature and fluence. The Instrumented Fast reactor Accelerated Component-Sheath Insulator (IFAC-SI) will investigate the additional effect of an applied voltage during the frradiation testing.

\subsubsection{UCA Irradiation Testing}

The UCA tests are a series of uninstrumented, accelerated irradiations to be conducted in the Material Open Test Assembly (MOTA) of FFTF. The objectives of these tests are to irradiate prototypic TFE components at typical operating temperatures to expected fluence levels and to evaluate performance and life limiting mechanisms. Evaluation will consist of nondestructive, preirradiation characterization of the specimens and a subsequent postirradiation examination.

UCA-1 Testing. UCA-1 is the first in this serles of in-reactor tests. The test matrix is shown in Table 5-11 and consists of various designs of 
TABLE 5-11

UCA-1 TEST MATRIX

Number of

Test Specimen Type

Materials

Samples

Seal insulator

$\mathrm{Y}_{2} \mathrm{O}_{3}$ trilayer

3

$\mathrm{AI}_{2} \mathrm{O}_{3}$ butt

3

$\mathrm{Al}_{2} \mathrm{O}_{3}$

Cesium reservoir

Cs loaded

Porous carbon

2

HOPG graphite

2

Unloaded

HOPG/POCO/porous graphite/graphite fibers

Sheath insulator

$\mathrm{Al}_{2} \mathrm{O}_{3}$ cermet

YAG cermet

$\mathrm{Y}_{2} \mathrm{O}_{3}$ trilayer (square end)

$\mathrm{Al}_{2} \mathrm{O}_{3}$ trilayer (stress relief 1 )

$\mathrm{Al}_{2} \mathrm{O}_{3}$ trilayer (stress relief 2)

3

$\mathrm{Al}_{2} \mathrm{O}_{3}$ trilayer (square end) 
sheath insulators, seal insulators, and cesium reservoirs. The design parameters for the sheath insulator specimens were as follows:

1) Flat and stress relieved end configuration, Fig. 5-6.

2) Alumina, Yttria, and YAG insulator materials.

3) Slip cast cermet and plasma sprayed graded configuration.

The seal insulators are discussed in Section 4 and the cesium reservoirs in Section 7.

The specimens were loaded into D9 stainless steel containers which were distributed into five MOTA canisters as shown in Fig. 5-7. Four of the canisters were located in MOTA level 5 and the other in MOTA level 4. Level 4 is closer to the FFTF core centerline so the specimens in this canister will have a higher end of test fluence. Irradiation was carried out in FFTF cycle 9. This cycle was originally scheduled to last 300 effective full power days (EFPD), however, due to increased efficiency in FFTF fuel ut1lization the cycle ran an extra 41.1 days. The UCA-1 specimens were therefore irradiated for 341.1 EFPDs and received the following fast neutron fluence:

$$
\begin{array}{ll}
\text { Leve1 } 4 & 6.5-7.2 \times 10^{22} \mathrm{n} / \mathrm{cm}^{2} \quad \mathrm{E}>.1 \mathrm{MeV} \\
\text { Level } 5 & 2.5-4.1 \times 10^{22} \mathrm{n} / \mathrm{cm}^{2} \quad \mathrm{E}>.1 \mathrm{MeV}
\end{array}
$$

The variations are due to the axial flux profile over the 5 inch length of the MOTA canisters. These values must be compared with expected TFE end of mission peak fluence of $3.1 \times 10^{22} \mathrm{n} / \mathrm{cm}^{2}$. Some of the UCA-1 specimens, therefore, recelved more than twice the expected peak values.

Following the end of cycle 9, post-irradiation examination according to a previously reviewed and approved schedule was inftiated, Fig. 5-8. The initial step was the recovery of the capsules from the MOTA assembly.

The canisters were cleaned to remove residual sodium. Reaction times in alcohol to react the residual sodium in canisters $5 \mathrm{a}$ and $5 \mathrm{~b}$ were 


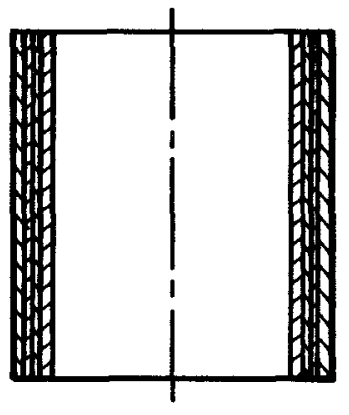

FLAT END CONFIGURATION

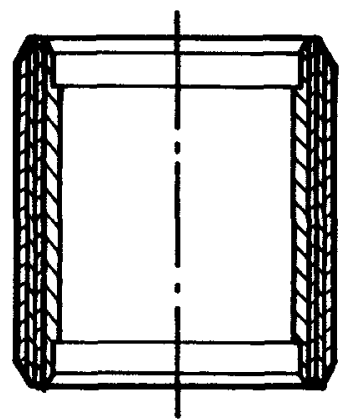

STRESS RELIEVED END CONFIGURATION DESIGN 2

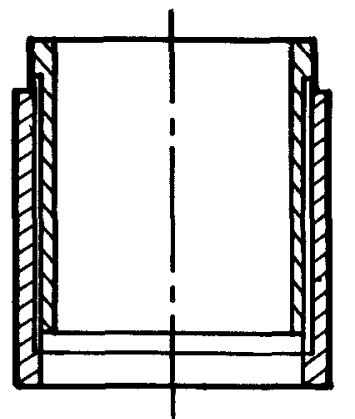

STRESS RELIEVED END CONFIGURATION DESIGN 3

Figure 5-6 - UCA-1 sheath insulator end configuration designs 


\section{UCA-1 TEST SPECIMEN LOCATION}

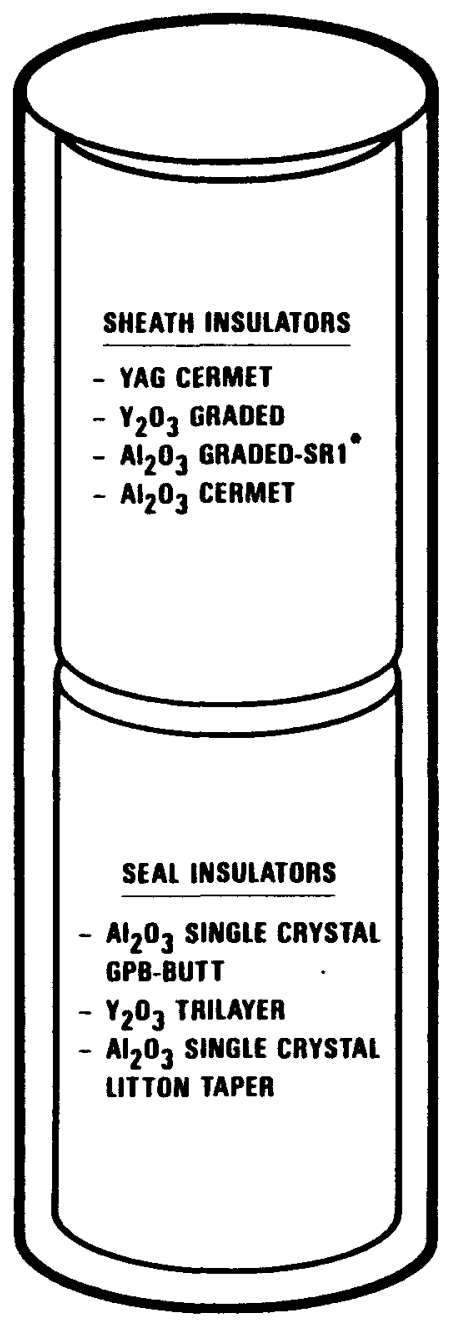

CANISTER 4B

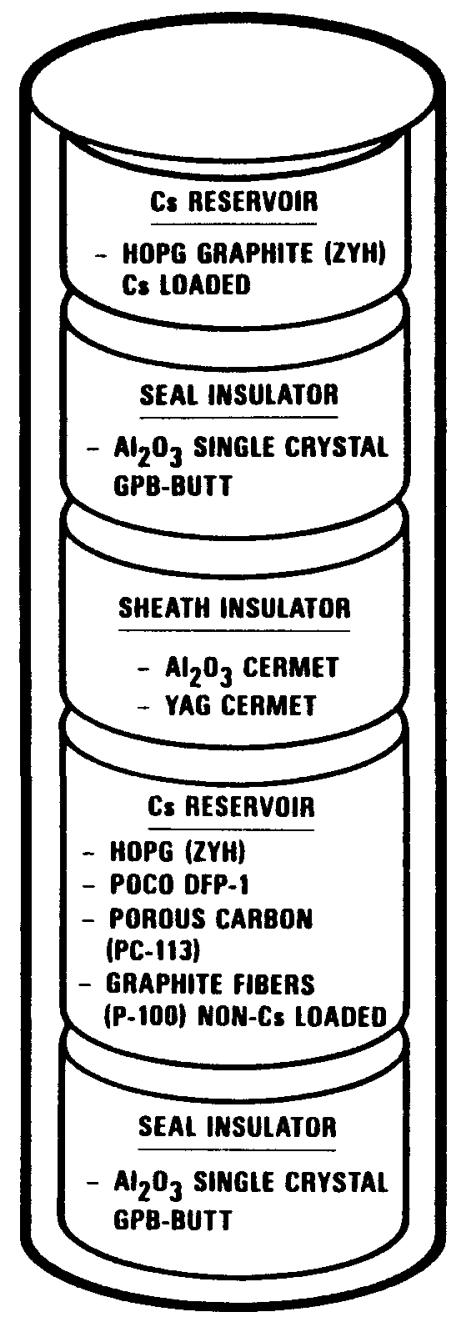

CANISTER 5A

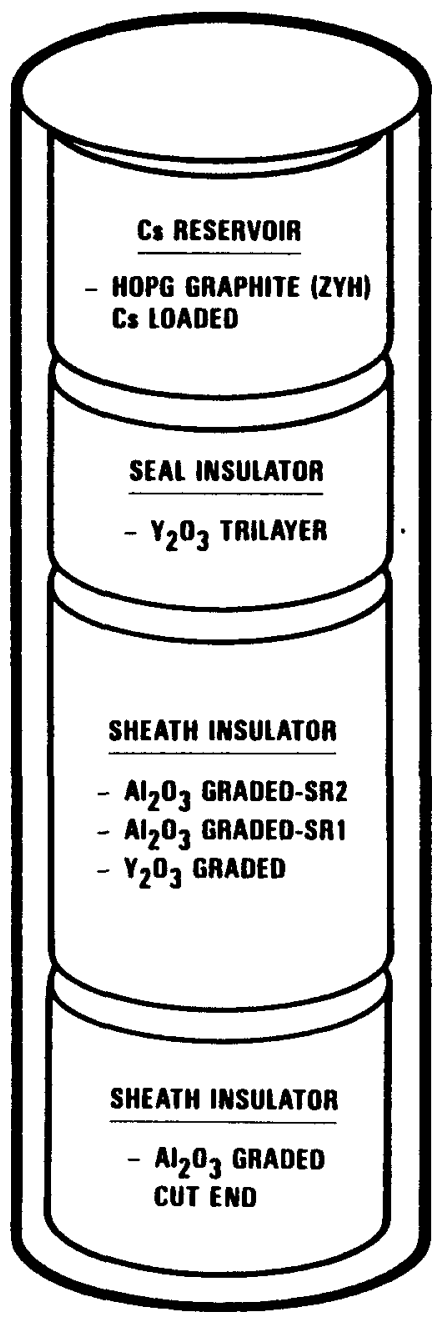

CANISTER 5B

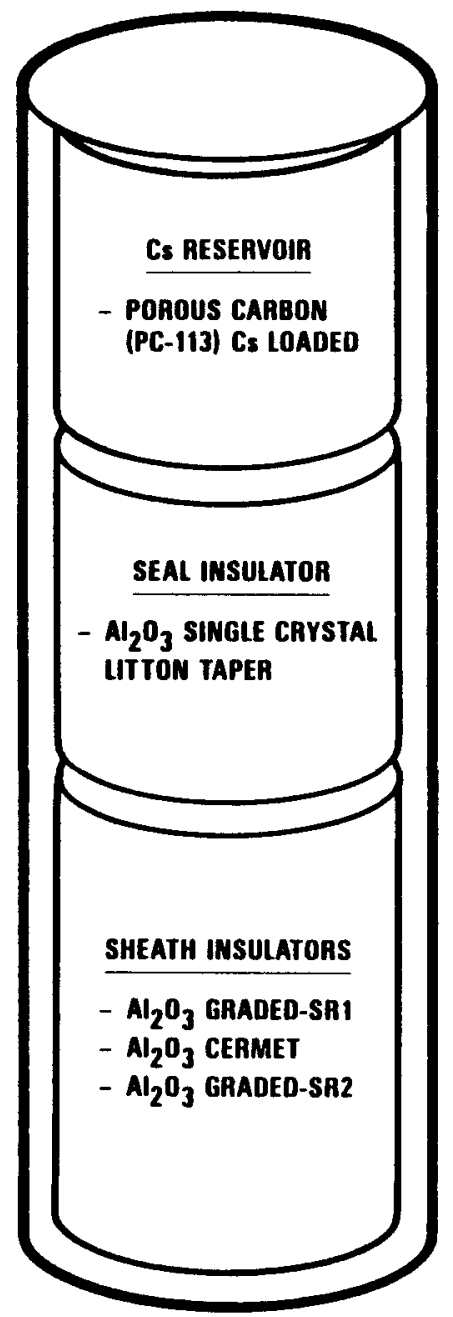

CANISTER 5C

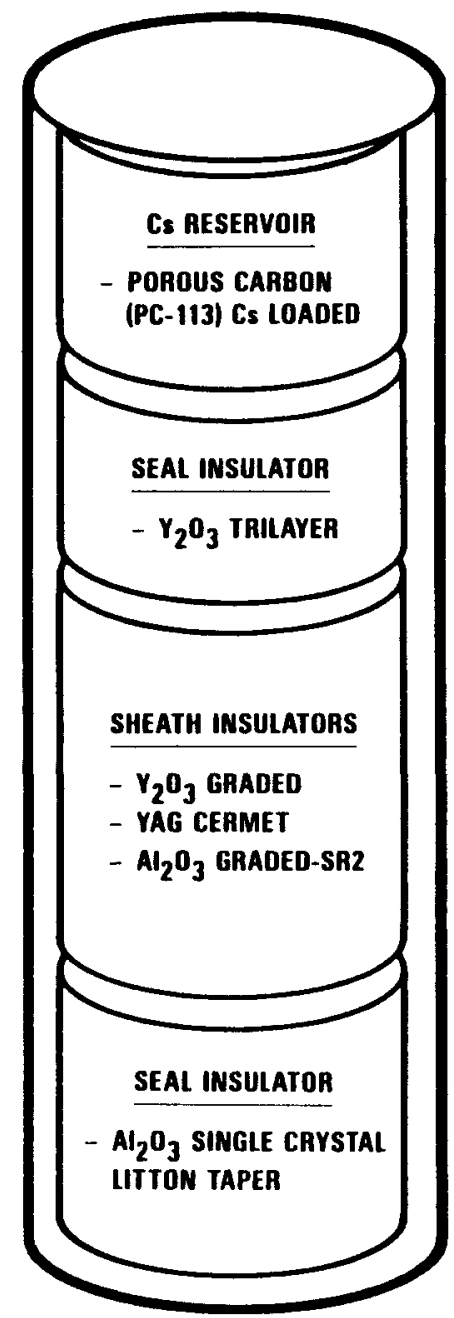

CANISTER 5D 
Figure 5-8

\section{FAST REACTOR IRRADIATION TESTING}

\section{UCA-1 PIE FLOW CHART}

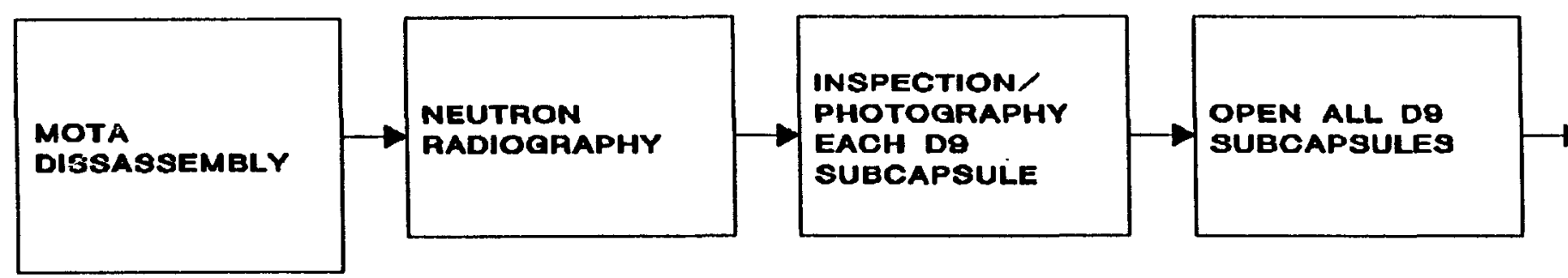

VISUALLY EXAMINEV

PHOTOGRAPH

ABNORMALITIES
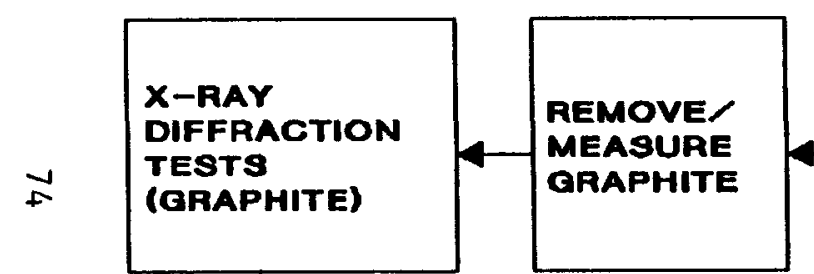

PRESSURE VS

TEMPERATURE

DIMENSIONAL

MEASUREMENTS

EXAMINE/

PHOTOGRAPH

Cs RESERVOIR

SPECIMENS
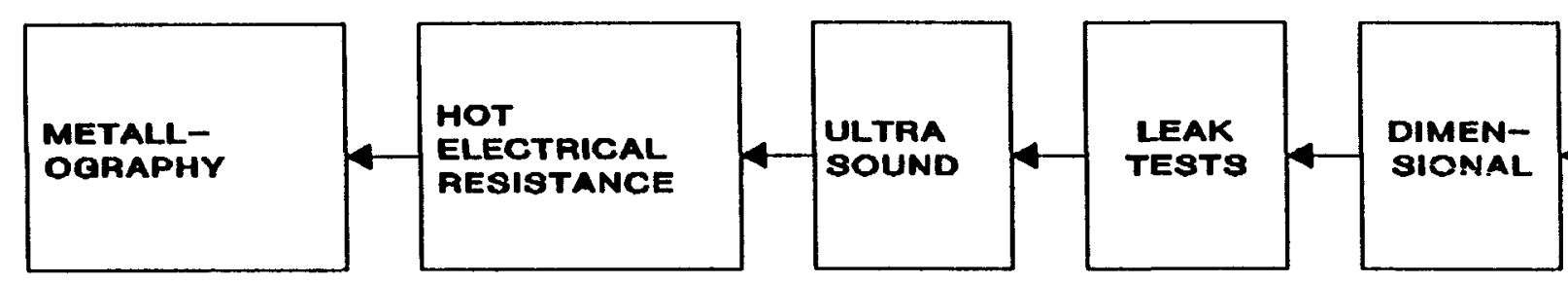

PHOTOGRAPH

SHEATH INS.

SPECIMENS
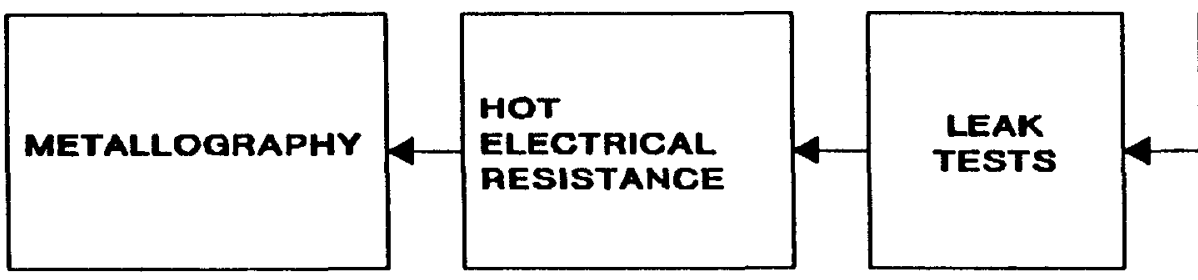

DIONSIONAL MEASUREMENTS

EXAMINE

PHOTOGRAPH

SEAL INS.

SPECIMENS 
unusually long. The cleaning of canisters $5 \mathrm{a}$ and $5 \mathrm{~b}$ was interrupted at the end of the normal shift, at which time $\mathrm{H}_{2}$ emissions indicated continued sodium reaction was occurring. Cleaning was restarted the next day, with a lack of $\mathrm{H}_{2}$ emissions indicating all available sodium was reacted. The sodium cleaning of the three other canisters was routine.

The baskets which hold the samples were removed from the canisters and the D9 capsules recovered. Visual examination of the capsules showed distortion of three Cs reservolr samples, C1, C4, and C5. Adjacent capsules also showed distortions, apparently as a result of the end expansion of the $C s$ reservoir capsules. Neutron radiographs of the capsules are shown in Figs. 5-9 and 5-10. The three Cs capsules which showed the distortion of the graphite all contained Highly oriented Pyrolytic Graphite (HOPG) and were loaded in canisters $5 \mathrm{a}$ and $5 \mathrm{~b}$.

The porous graphite samples, sheath insulators, and seal samples appear to be intact, with clear, distinct edges consistent with the fabrication of the different configurations. The neutron radiograph showed no evidence to suggest gross swelling or fracturing of the insulator material. The seals with single crystal $\mathrm{Al}_{2} \mathrm{O}_{3}$ showed very distinct edges and configurations very close to as-fabricated. Sheath insulator samples did not exhibit end distortion within the resolution of the radiographs, even in the samples without stress relief end designs. The radiograph suggests very minimal dimensional distortion in the sheath and seal samples as a result of the high temperature irradiation to fluence values two to three times the reference design. Capsules IS-3 adjacent to $\mathrm{C} 4, \mathrm{SH}-2$ and IS -4 adjacent to $\mathrm{C} 1$, and IS -5 adjacent to $\mathrm{C5}$ showed distortion consistent with interaction with the adjacent Cs reservoir.

The subcapsules were visually examined and photographed (Figs. 5-11 through 5-15). The types of samples, their identification numbers, and locations in each MOTA canister and subcapsule are also shown in the corresponding figures.

The insulator samples were recovered from the capsules, visually examined, and photographed. Visual examination at $10 \mathrm{X}$ magnification is 


\section{A}

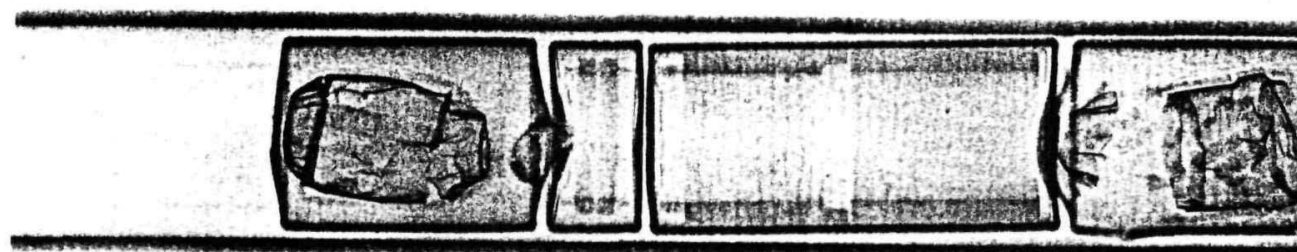

C4 IS-3 SH-2 $\quad$ C1 $\quad$ IS-4

5B

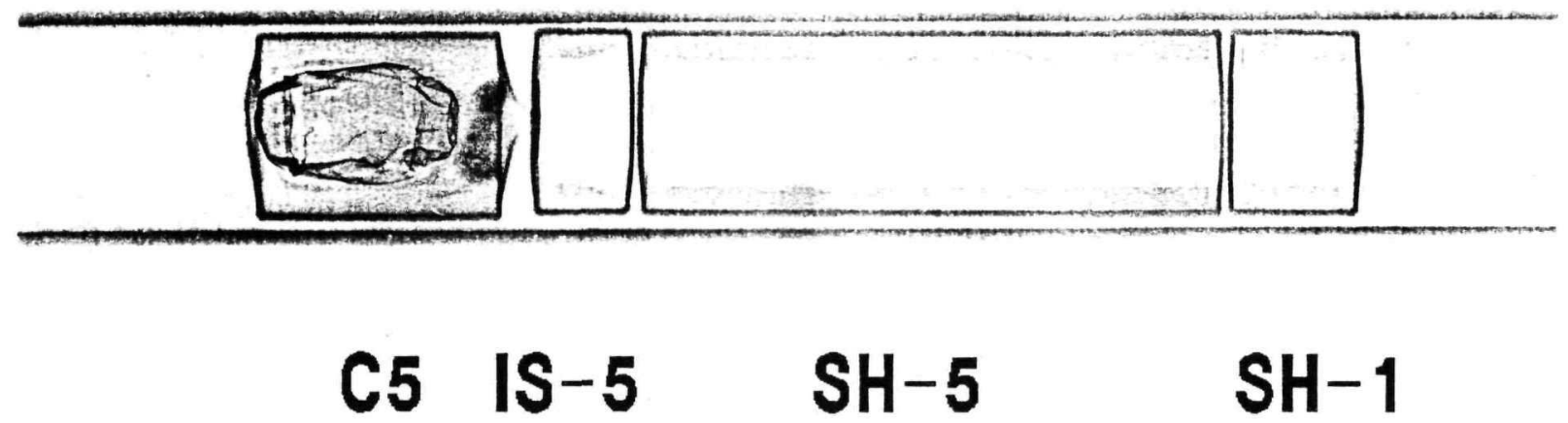

$\longleftarrow$ TOP DURING IRRADIATION

Figure 5-9 - Neutron radiographs of UCA-1 subcapsules from. MOTA canisters $5 \mathrm{a}$ and $5 \mathrm{~b}$ 


\section{$5 \mathrm{C}$}

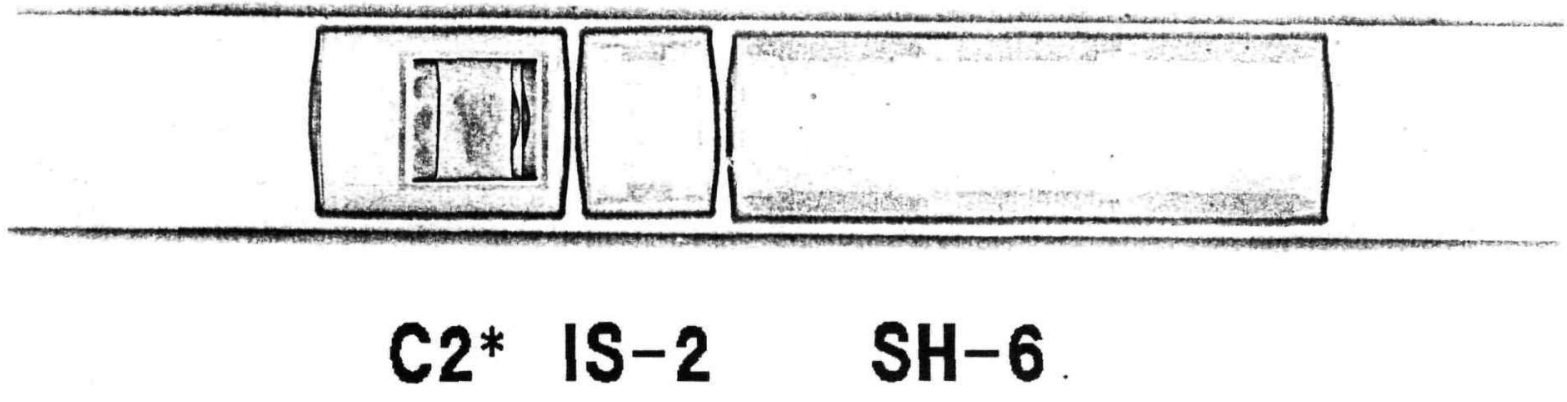

\section{D}

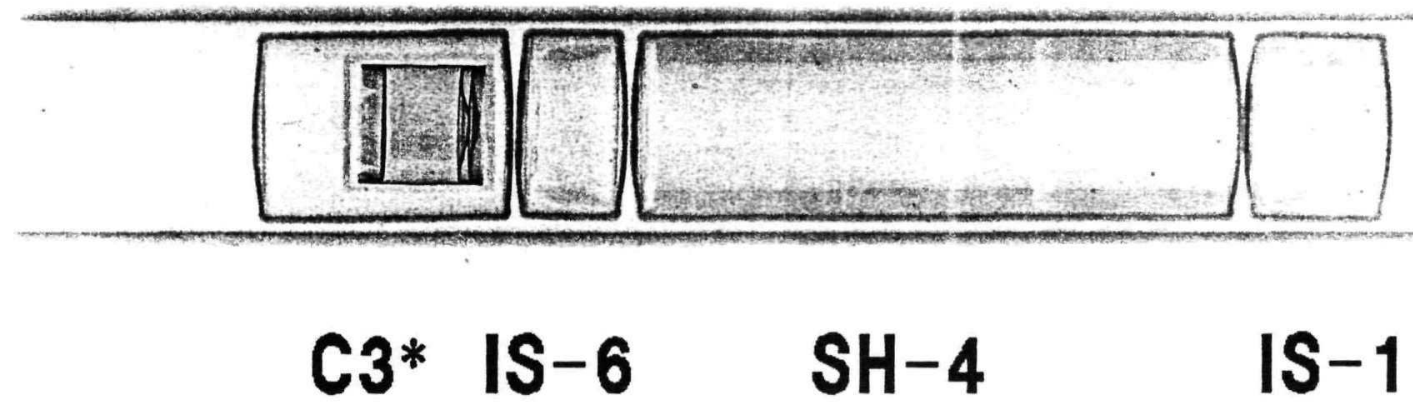

4B

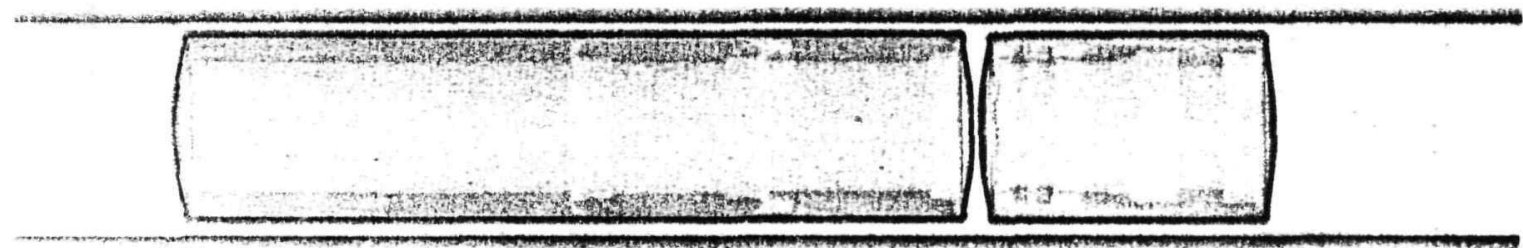

SH-3 IS-7

\section{$\longleftarrow$ TOP DURING IRRADIATION * POSITIONED INVERTED COMPARED TO IRRADIATION IN MOTA}

Figure 5-10 - Neutron radiographs of UCA-1 subcapsules from MOTA canisters $5 \mathrm{c}, 5 \mathrm{~d}$, and $4 \mathrm{~b}$ 


\title{
UCA-1 TEST CONTENT: CANISTER 4B
}

\author{
$\mathrm{SH}-3$ \\ IS -7
}

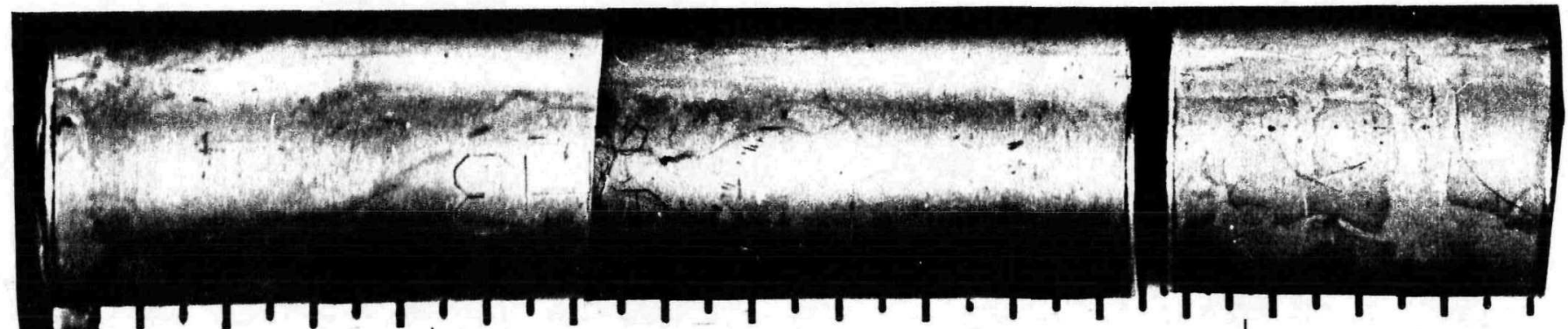

\section{SHEATH INSULATORS}

- TE-YAG-2 YAG CERMET

- $\mathrm{Y}-3$

- ALN-1

- TEA-2
GRADED YTTRIA

GRADED A1203 OPTIMUM STRESS RELIEVE Ni PLATING

Al203 CERMET

\section{SEALS}

- B-4 AI2O3 SINGLe CRYSTAL GAS PRESSURE BONDED

- T-3 YTTRIA TRI-LAYER

- $\mathbf{L}-3$ AI203 SINGLE CRYSTAL LITTON TAPERED 


\section{UCA-1 TEST CONTENT: CANISTER 5A}

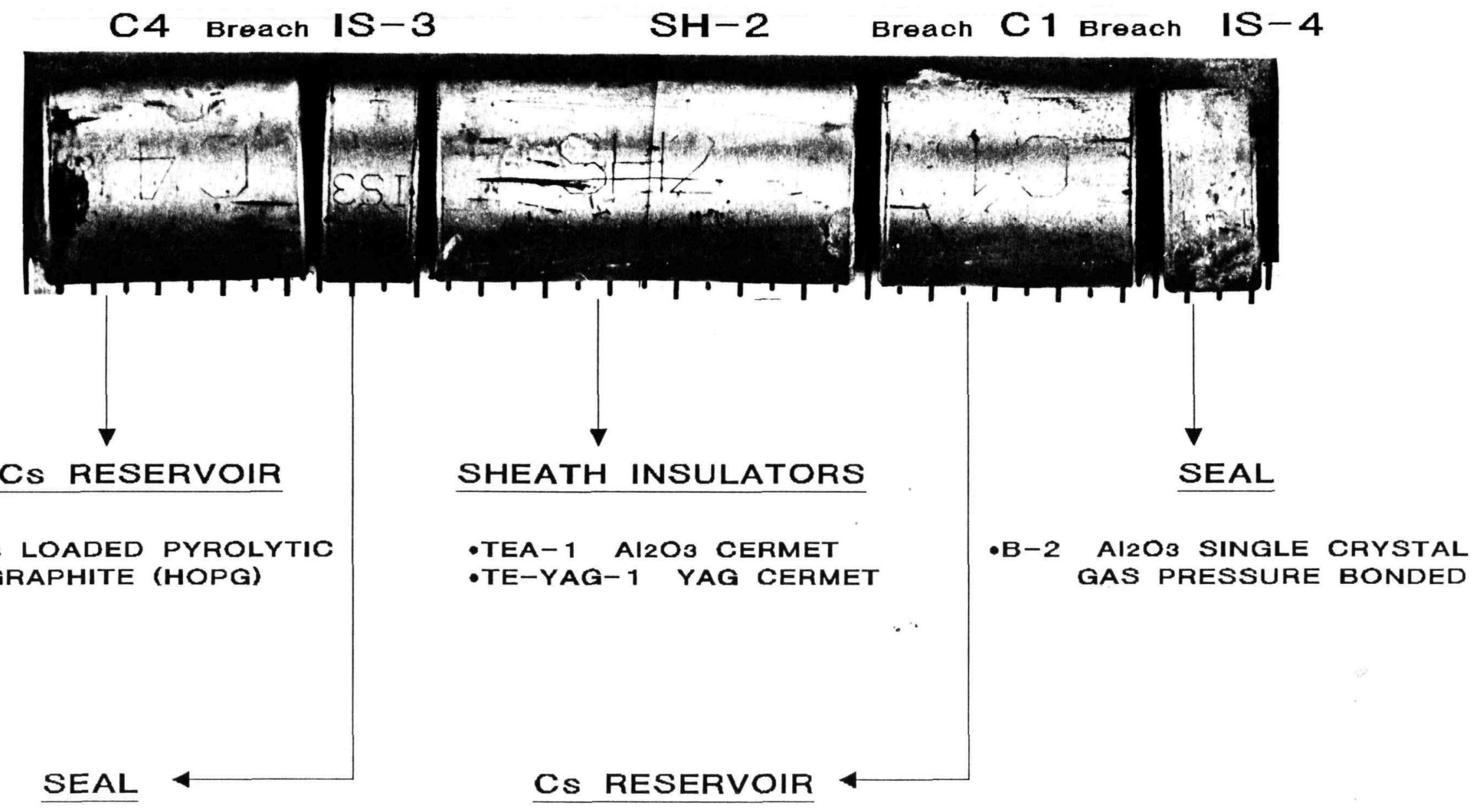

-B-1 Al2O3 SINGLE CRYSTAL GAS PRESSURE BONDED

-C PyROLytic GRAPHITE

POROUS GRAPHITE

POCO GRAPHITE

GRAPHITE FIBER 


\section{UCA- 1 TEST CONTENT: CANISTER $5 B$} Breach C5

$$
1 S-5
$$

SH-5

$\mathrm{SH}-1$
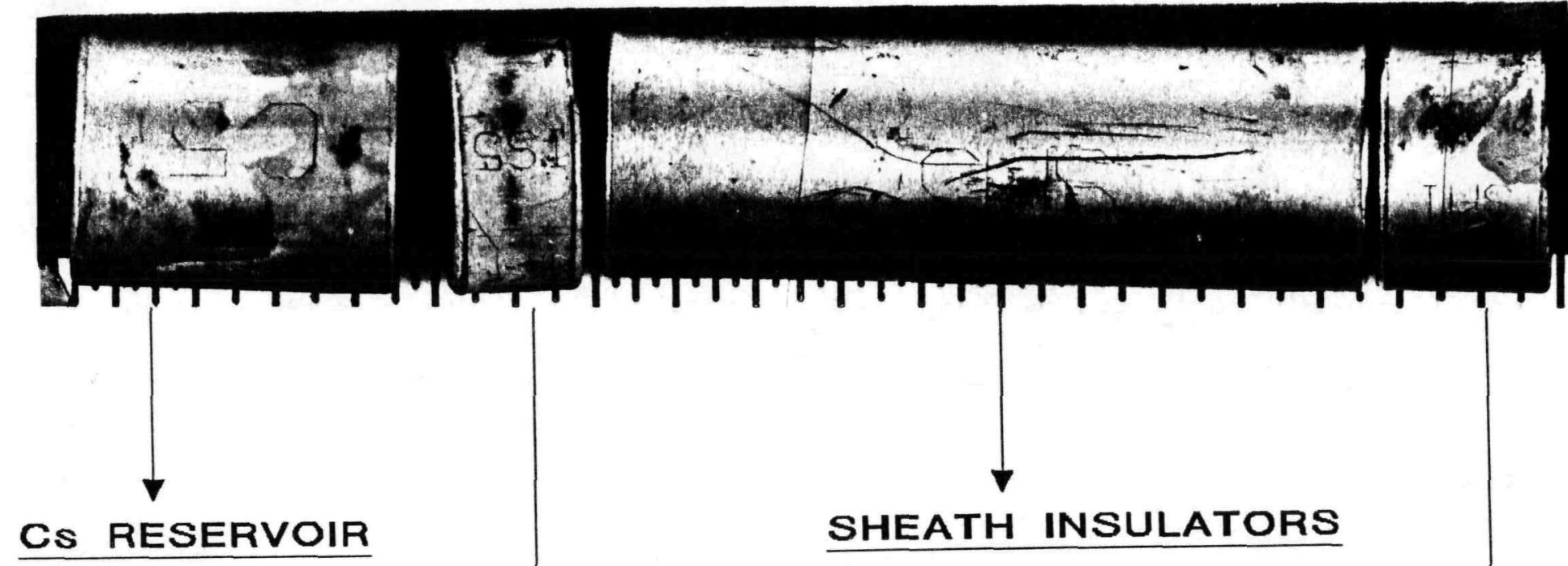

-D Cs LOADED PYROLYTIC GRAPHITE (HOPG)

SEAL

OPTIMUM STRESS RELIEF

-T-1 YTTRIA TRI-LAYER

-Y-2 GRADED YTTRIA

-ALH-1 GRADED AI2O3 CERMET HALF LENGTH 


\section{UCA-1 TEST CONTENT: CANISTER 5C}

C2

$1 S-2$

SH-6
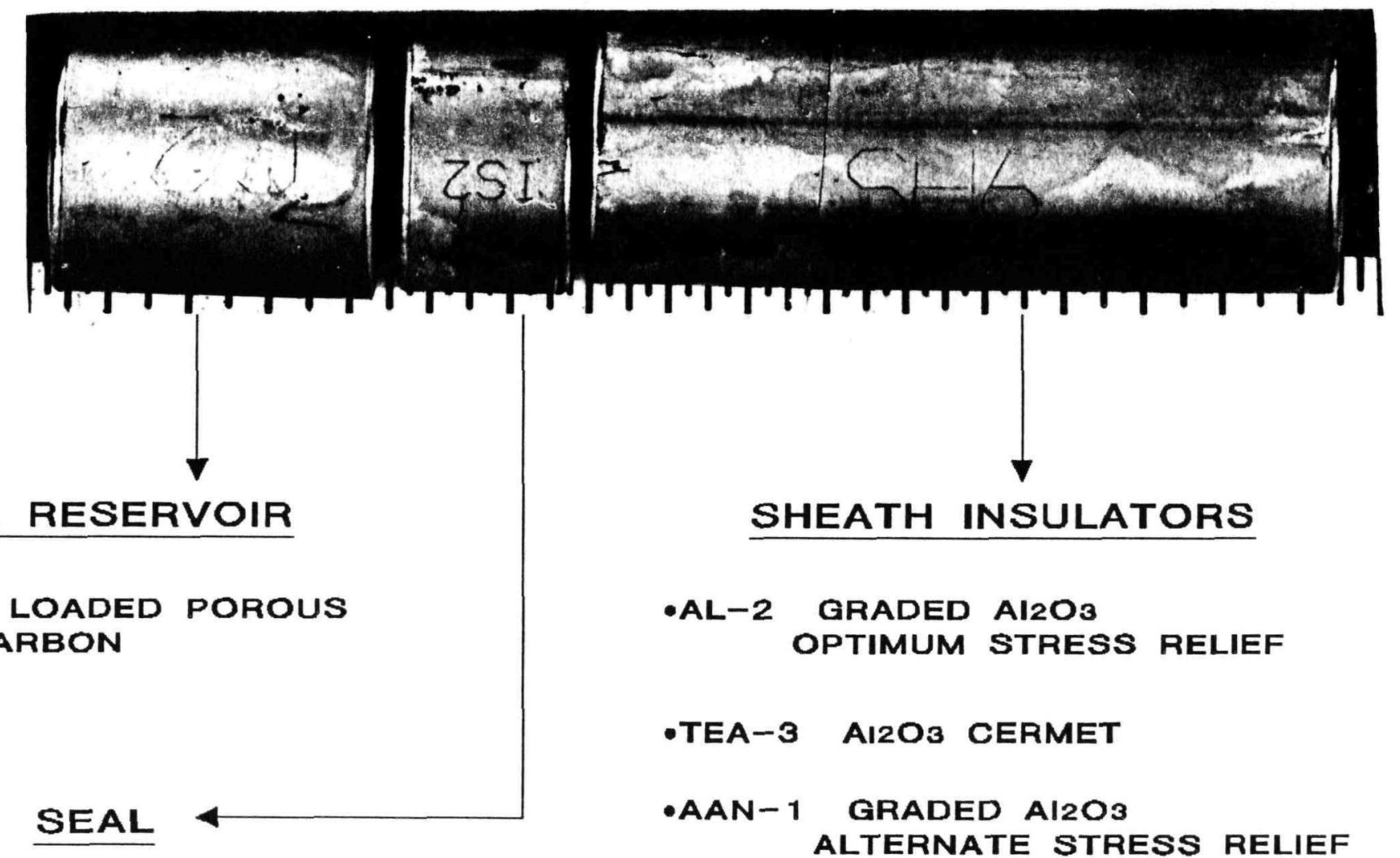

\section{CS RESERVOIR}

-B Cs loAdEd porous

-AL-2 GRADED Al2O3

SHEATH INSULATORS

-B CARBON OPTIMUM STRESS RELIEF

-TEA-3 A12O3 CERMET

-AAN-1 GRADED Al2O3

ALTERNATE STRESS RELIEF Ni-PLATING

-L-2 Al2O3 SINGLE CRYSTAL LITTON TAPERED

Figure 5-14 - UCA-1 test content in canister 5C and conditions following irradiation to fluences of $2.5 \times 10^{22} \mathrm{n} / \mathrm{cm}^{2}$ to $4.1 \times 10^{22} \mathrm{n} / \mathrm{cm}^{2}$ 


\section{UCA-1 TEST CONTENT: CANISTER 5D}
C3
IS -6
$\mathrm{SH}-4$
IS-1
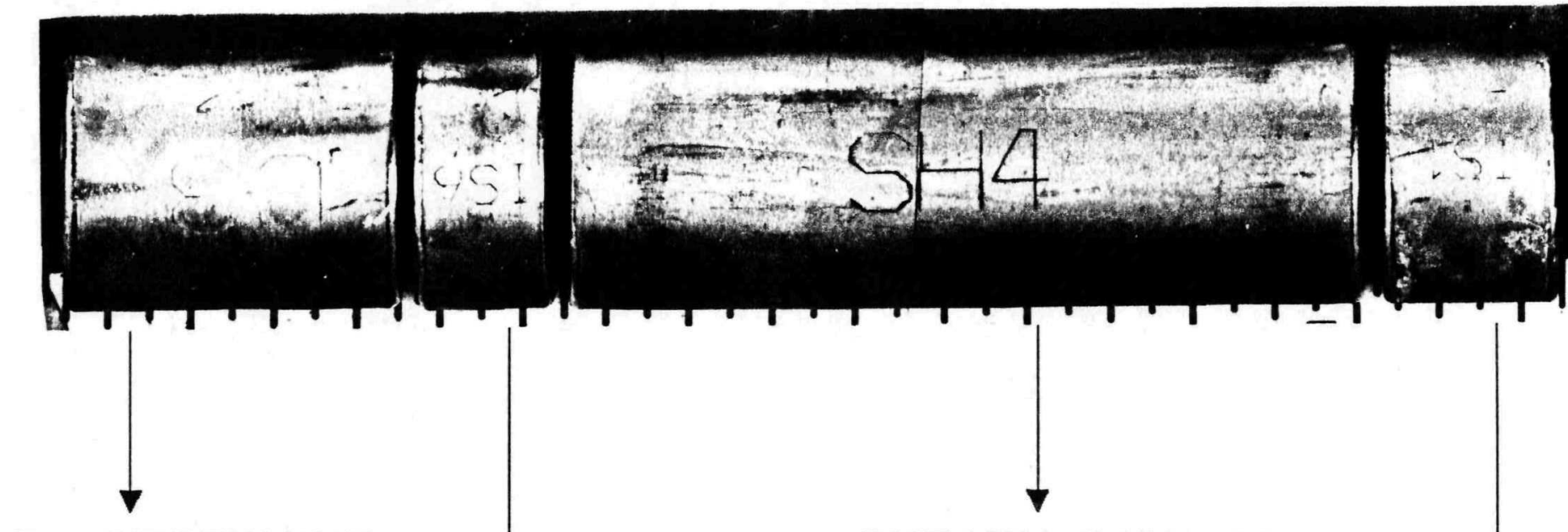

Cs RESERVOIR

SHEATH INSULATORS

- E Cs LOADED POROUS CARBON

SEAL

-T-2 YTTRIA TRI-LAYER
SEAL

-L-1 AI2O3 SINGLE CRYSTAL LITTON TAPERED 
summarized in Table 5-12 for the sheath insulators. Examples of the appearance of the YAG cermet and graded alumina sheath insulators are shown in Fig. 5-16. The YAG cermet is crack-free, whereas the graded alumina has a continuous circumferential crack. The crack pattern seen in this sample is similar to the circumferential cracks seen in the other sheath insulator samples with graded alumina.

UCA-2 Testing. UCA-2 is the second in this series of in-reactor component tests and the irradiation is underway. The test matrix is shown in Table 5-13 and consists of not only sheath insulators, seal insulators, and cesium reservoirs as in UCA-1 but also test specimens of the TFE end restraint and of the intercell insulation. The same insulator materials are under study in UCA-2 as in UCA-1. The insulator designs for stress relief at the end is shown on Fig. 5-17.

The intercell insulation specimen design is shown on Fig. 5-18.

The TFE end restraint specimen design is shown on Fig. 5-19.

The specimens were loaded into D9 stainless steel containers which were distributed into three MOTA canisters as shown in Fig. 5-20. Two of the canisters were located in MOTA level 1 and the other in MOTA level 4. The fast fluence at the end of the test is estimated to be $3.6 \times 10^{22} \mathrm{n} / \mathrm{cm}^{2}$ to $4.6 \times 10^{22} \mathrm{n} / \mathrm{cm}^{2}$ in Level 1 and $5.7 \times 10^{22} \mathrm{n} / \mathrm{cm}^{2}$ to $6.5 \times 10^{22} \mathrm{n} / \mathrm{cm}^{2}$ in Level 4. The preirradiation condition of the completed subcapsules is shown in Figs. 5-21, 5-22, and 5-23, along with the other explanatory data.

UCA-2 began Irradiation in FFTF in Cycle 10 on November 24, 1987, and the temperatures were increased in the three canisters to the operating temperatures of $800^{\circ} \mathrm{C}$. The He contents in the temperature controlling gas mixture are approximately $35 \%$ in the Level 1 canisters and $60 \%$ in the Level 4 canisters, which are close to target values and provide ample margin for control to maintain test temperatures at $800^{\circ} \mathrm{C} \pm 5^{\circ} \mathrm{C}$. The reactor is scheduled to complete Cycle 10 in January, 1989.

IFAC-SI. The objective of the IFAC-SI test is to establish the 
TABLE 5-12

SHEATH INSULATOR VISUAL INSPECTION

\begin{tabular}{|c|c|c|}
\hline Specimen ID & Ceramic Condition & Comments \\
\hline $\begin{array}{l}\text { TEA-1 } \\
\text { TEA-2 } \\
\text { TEA-3 }\end{array}$ & $\begin{array}{l}\text { No cracks } \\
\text { No cracks } \\
\text { No cracks }\end{array}$ & $\begin{array}{l}\text { Metal clean and bright } \\
\text { Clean, outer surface marred } \\
\text { Metal clean and bright }\end{array}$ \\
\hline $\begin{array}{l}\text { TE-YAG-1 } \\
\text { TE-YAG-2 } \\
\text { TE-YAG-4 }\end{array}$ & $\begin{array}{l}\text { No cracks } \\
\text { No cracks } \\
\text { No cracks }\end{array}$ & $\begin{array}{l}\text { Metal clean and bright } \\
\text { Metal clean and bright } \\
\text { Metal clean and bright }\end{array}$ \\
\hline $\begin{array}{l}Y-1 \\
Y-2 \\
Y-3\end{array}$ & $\begin{array}{l}\text { Circumferential cracks } \\
\text { Circumferential cracks } \\
\text { Circumferential cracks }\end{array}$ & $\begin{array}{l}\text { Metal clean, not bright } \\
\text { Metal clean and bright } \\
\text { Metal clean and bright }\end{array}$ \\
\hline $\begin{array}{l}\mathrm{AL}-1 \\
\mathrm{AL}-2\end{array}$ & $\begin{array}{l}\text { Circumferential cracks } \\
\text { Circumferential cracks }\end{array}$ & $\begin{array}{l}\text { Metal clean and bright } \\
\text { Metal clean and bright }\end{array}$ \\
\hline $\begin{array}{l}\mathrm{AA}-1 \\
\mathrm{AA}-2\end{array}$ & $\begin{array}{l}\text { Circumferential cracks } \\
\text { Circumferential cracks }\end{array}$ & $\begin{array}{l}\text { Metal clean and bright } \\
\text { Metal clean and bright, dark on one end }\end{array}$ \\
\hline $\begin{array}{l}\text { ALH }-1 \\
\text { ALN }-1\end{array}$ & $\begin{array}{l}\text { Circumferential cracks } \\
\text { Circumferential cracks }\end{array}$ & $\begin{array}{l}\text { Clean, removal damaged } \\
\text { Clean, outer surface marred }\end{array}$ \\
\hline AAN-1 & Circumferential cracks & Metal clean and bright \\
\hline
\end{tabular}




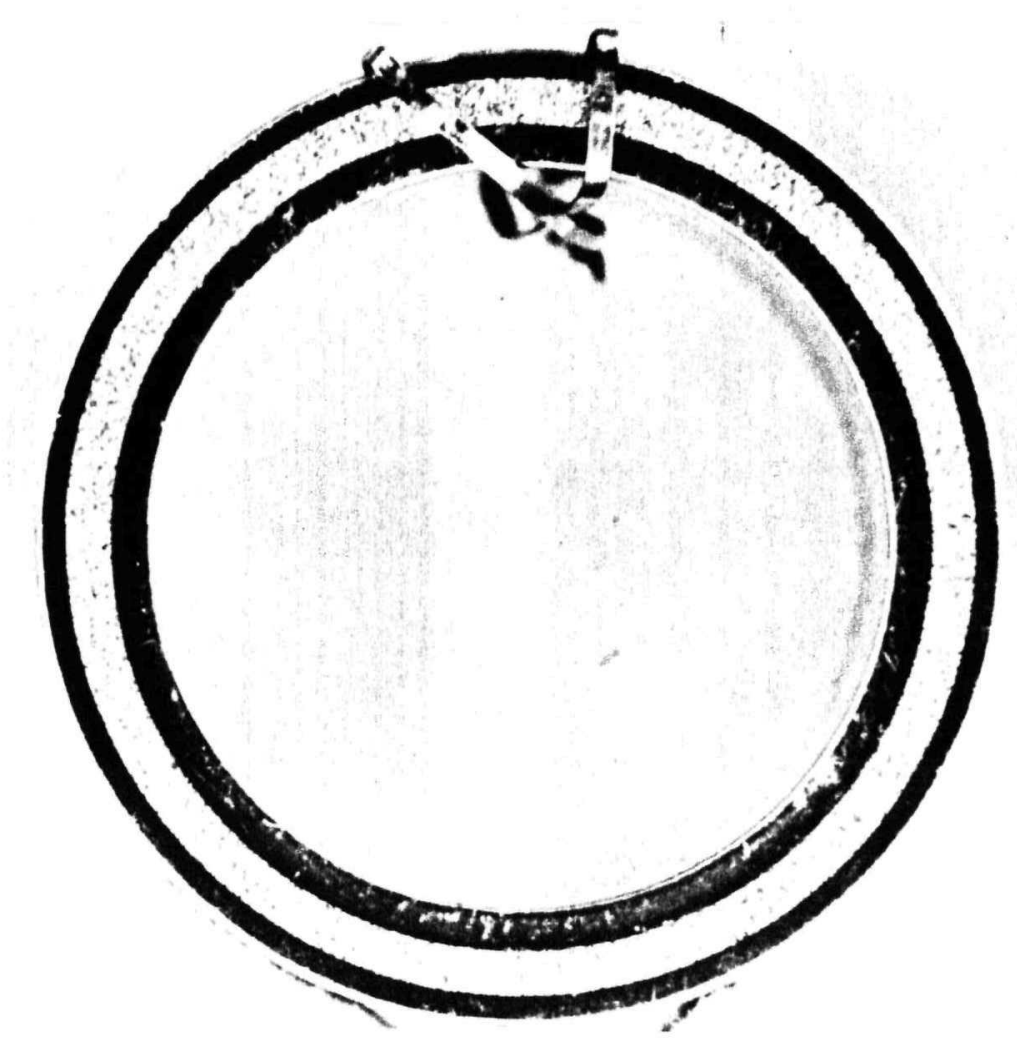

YAG CERMET SHEATH

INSULATOR (SAMPLE TE-YAG-4)

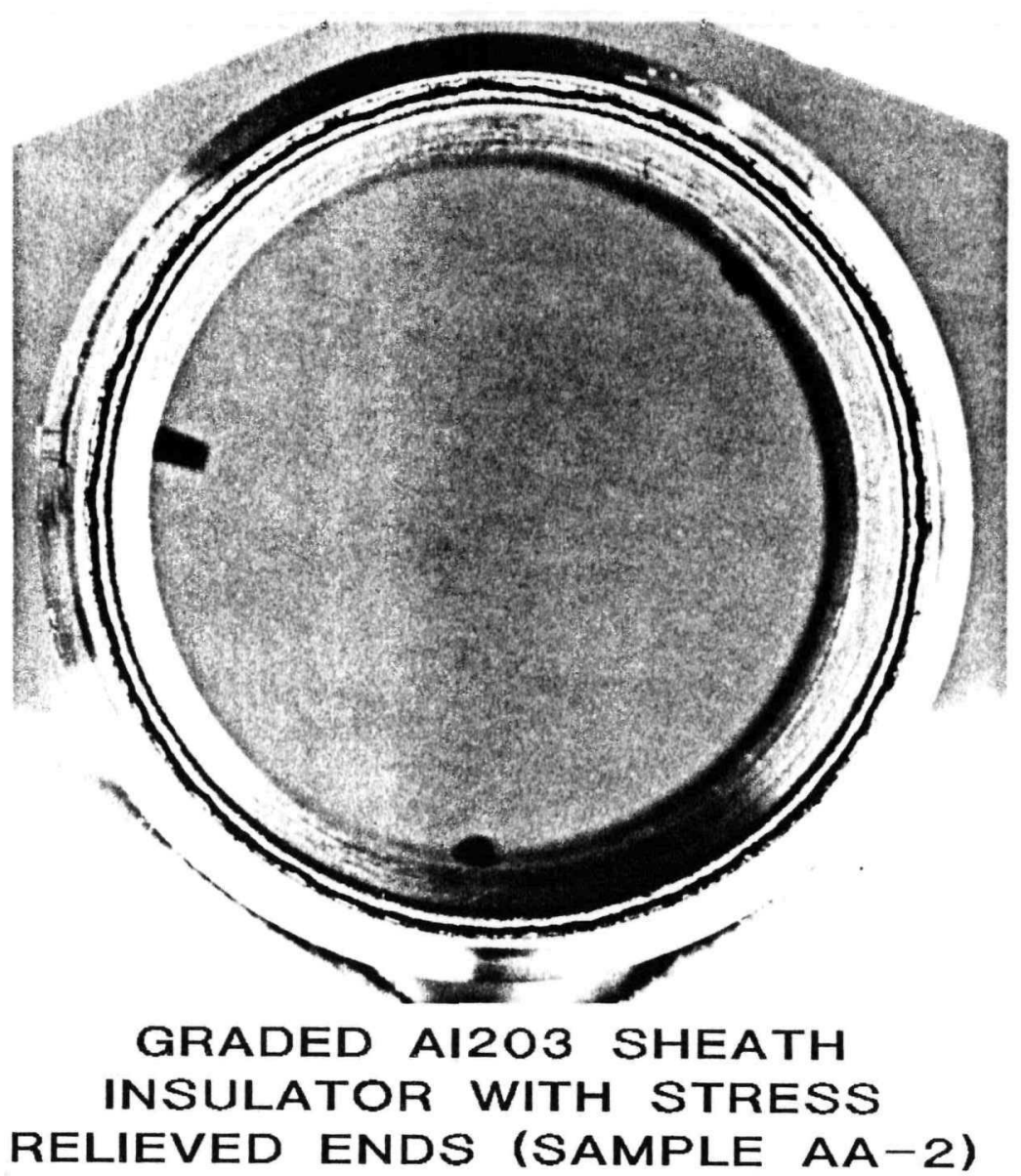

RELIEVED ENDS (SAMPLE AA-2)

FIGURE 2 YAG CERMET AND GRADED AI203 SHEATH INSULATORS IRRADIATED TO FLUENCES OF $3.4 \times 10^{22} \mathrm{n} / \mathrm{cm}^{2}$ AND $3.2 \times 10^{22} \mathrm{n} / \mathrm{cm}^{2}$, RESPECTIVELY.

Figure 5-16 - YAG cermet and graded $\mathrm{Al}_{2} \mathrm{O}_{3}$ sheath insulators irradiated to fluences of $3.4 \times 10^{22} \mathrm{n} / \mathrm{cm}^{2}$ and $3.2 \times 10^{22} \mathrm{n} / \mathrm{cm}^{2}$, respective1y 
TABLE $\quad 5-13$

UCA-2 TEST MATRIX

Test Specimen Type

Material

Number of Samples

Intercell insulation

$\mathrm{Y}_{2} \mathrm{O}_{3}$
$\mathrm{Al}_{2} \mathrm{O}_{3}$
$\mathrm{YAG}^{2}$

2

2

TFE end restraint

$\mathrm{Y}_{2} \mathrm{O}_{3}$

4

Seal insulator

$\mathrm{Y}_{2} \mathrm{O}_{3}$ trilayer

2

YAG taper

1

$\mathrm{Al}_{2} \mathrm{O}_{3}$ taper

1

Ceslum reservoir

$\begin{array}{ll}\text { HOPG } & 1 \\ \text { POCO graphite } & 1\end{array}$

Sheath insulator

$\begin{array}{ll}\mathrm{Al}_{2} \mathrm{O}_{3} \text { cermet } & 2 \\ \mathrm{Y}_{2} \mathrm{O}_{3} \text { cermet } & 2 \\ \mathrm{Y}_{2} \mathrm{O}_{3} \text { trilayer } & 2 \\ \mathrm{YAG} \text { trilayer } & 2 \\ \mathrm{Al}_{2} \mathrm{O}_{3} \text { trilayer } & 2\end{array}$



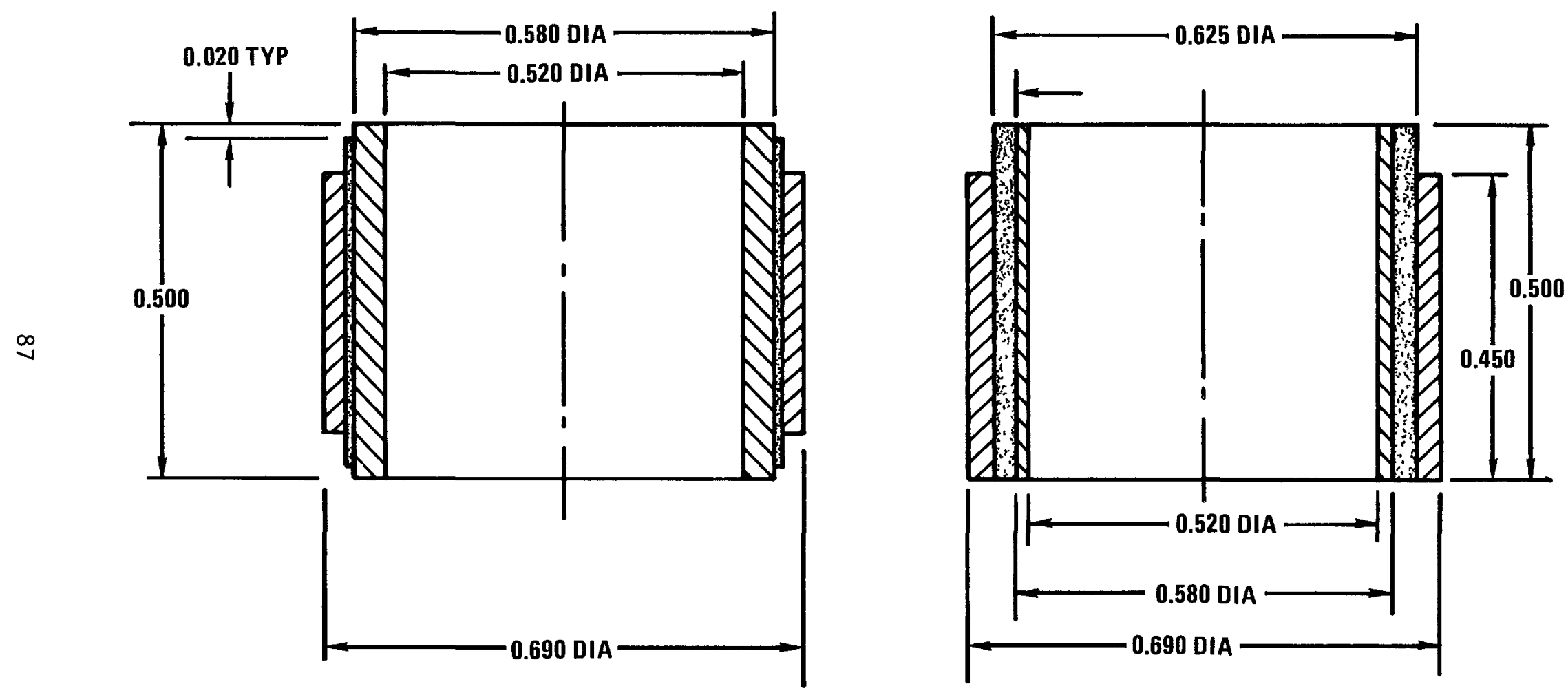

Figure 5-17 - UCA-2 sheath insulator end configurations 


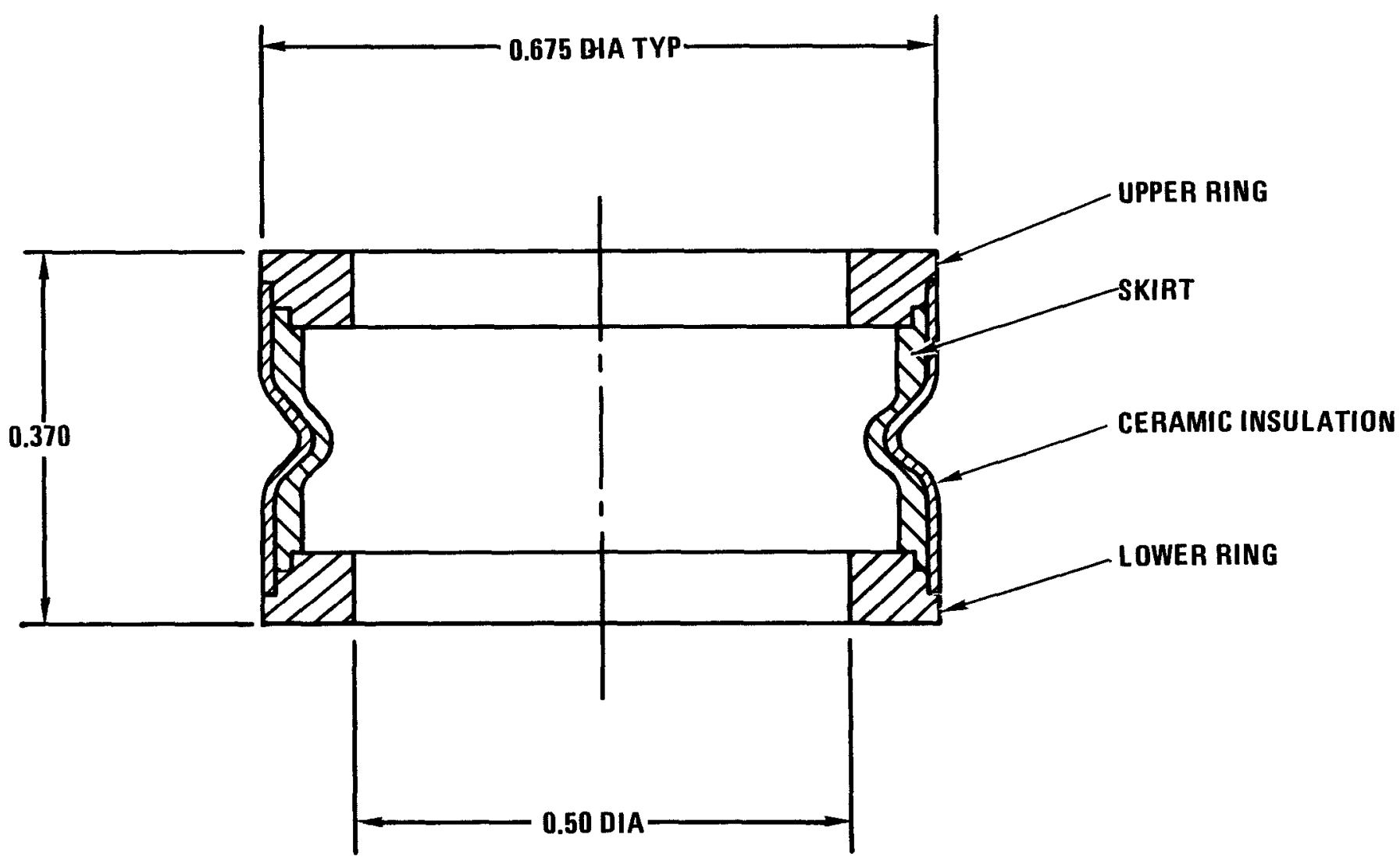

Figure 5-18 - UCA-2 intercell insulation test specimen 


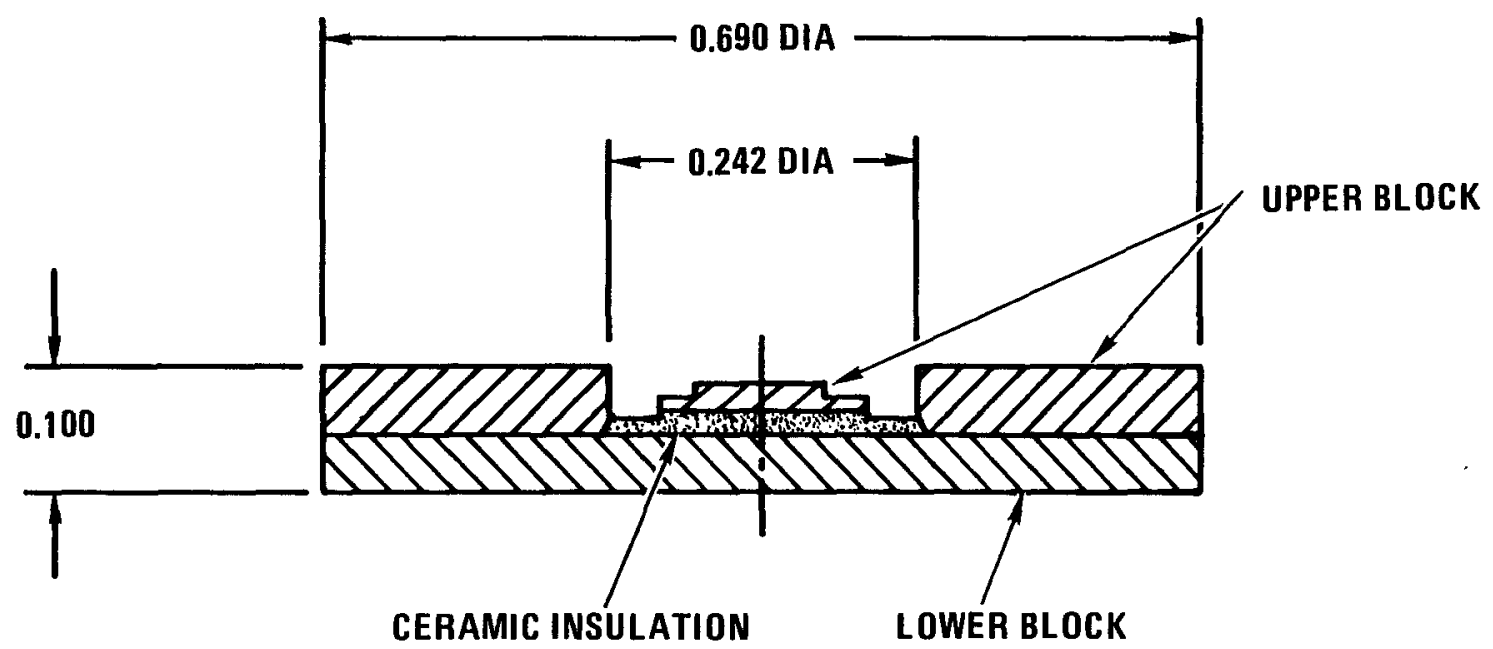

Figure 5-19 - UCA-2 TFE engineering restraint test specimen 


\section{UCA-2 TEST SPECIMEN LOCATION}
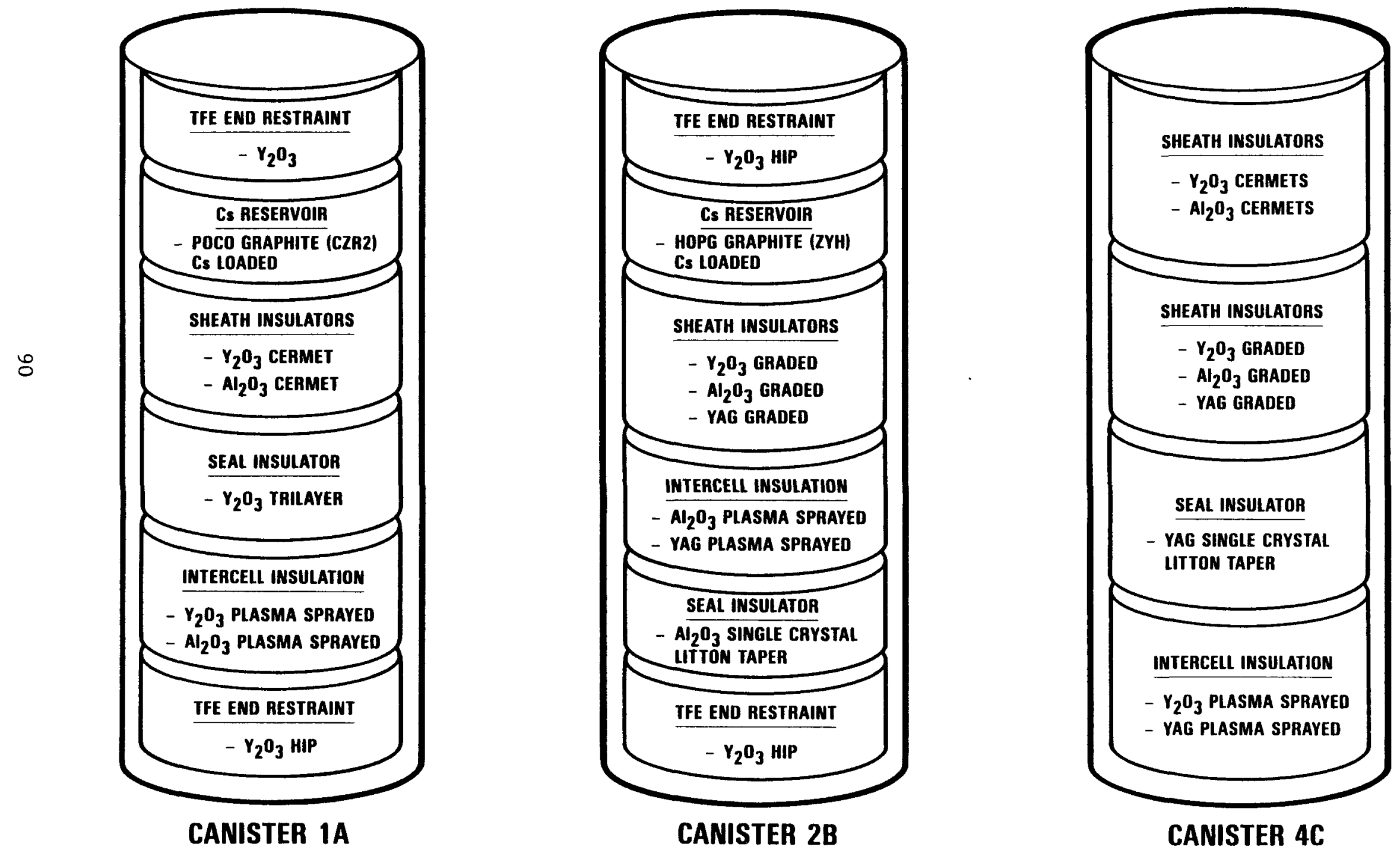


\section{UCA-2 TEST CONTENT: CANISTER 1A \\ $\begin{array}{llllll}1 A-1 & 1 A-2 & 1 A-3 & 1 A-4 & 1 A-5 & 1 A-6\end{array}$}

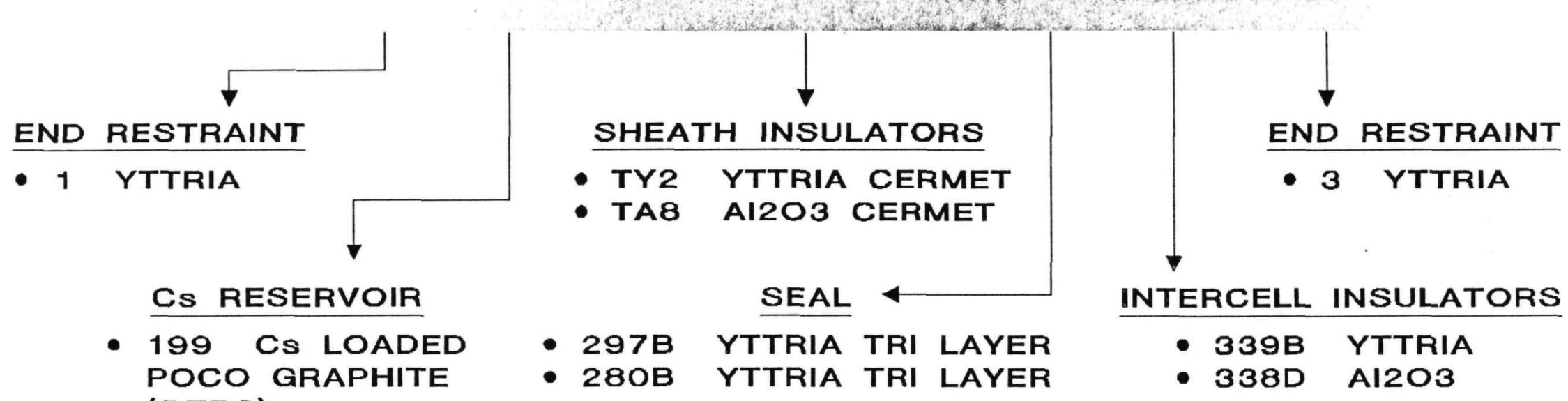

Figure 5-21 - Preirradiation condition and contents of the UCA-2 subcapsules in canister $1 \mathrm{~A}$ 


\section{UCA-2 TEST CONTENT: CANISTER $1 \mathrm{~B}$ $\begin{array}{llllll}1 \mathrm{~B}-1 & 1 \mathrm{~B}-2 & 1 \mathrm{~B}-3 & 1 \mathrm{~B}-4 & 1 \mathrm{~B}-5 & 1 \mathrm{~B}-6\end{array}$}

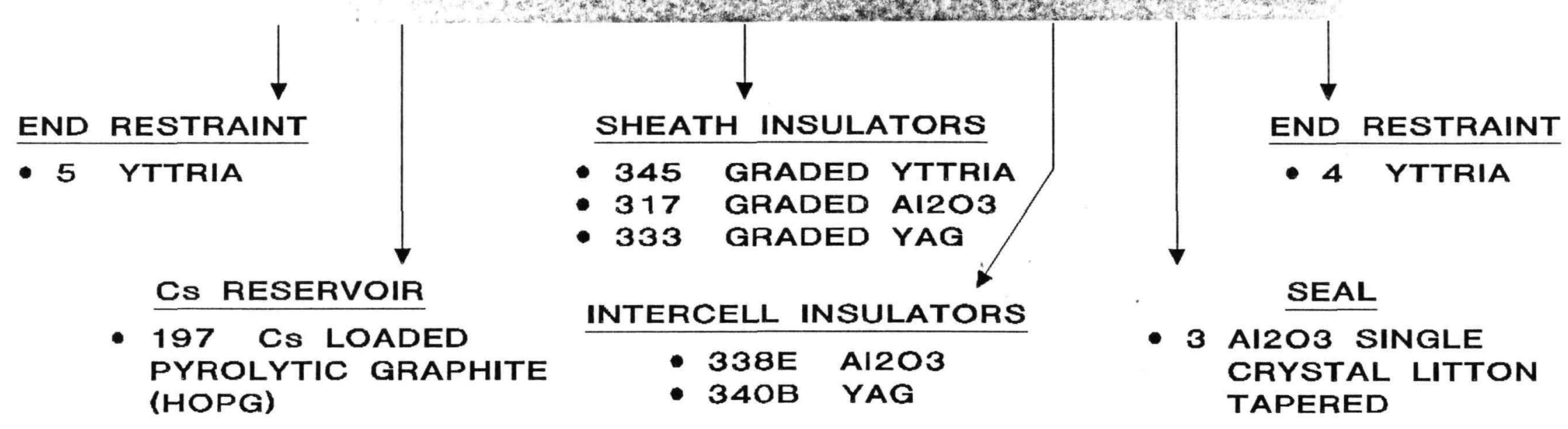




\section{UCA-2 TEST CONTENT: CANISTER 4C $\begin{array}{llll}4 \mathrm{C}-1 & 4 \mathrm{C}-2 & 4 \mathrm{C}-3 & 4 \mathrm{C}-4\end{array}$}

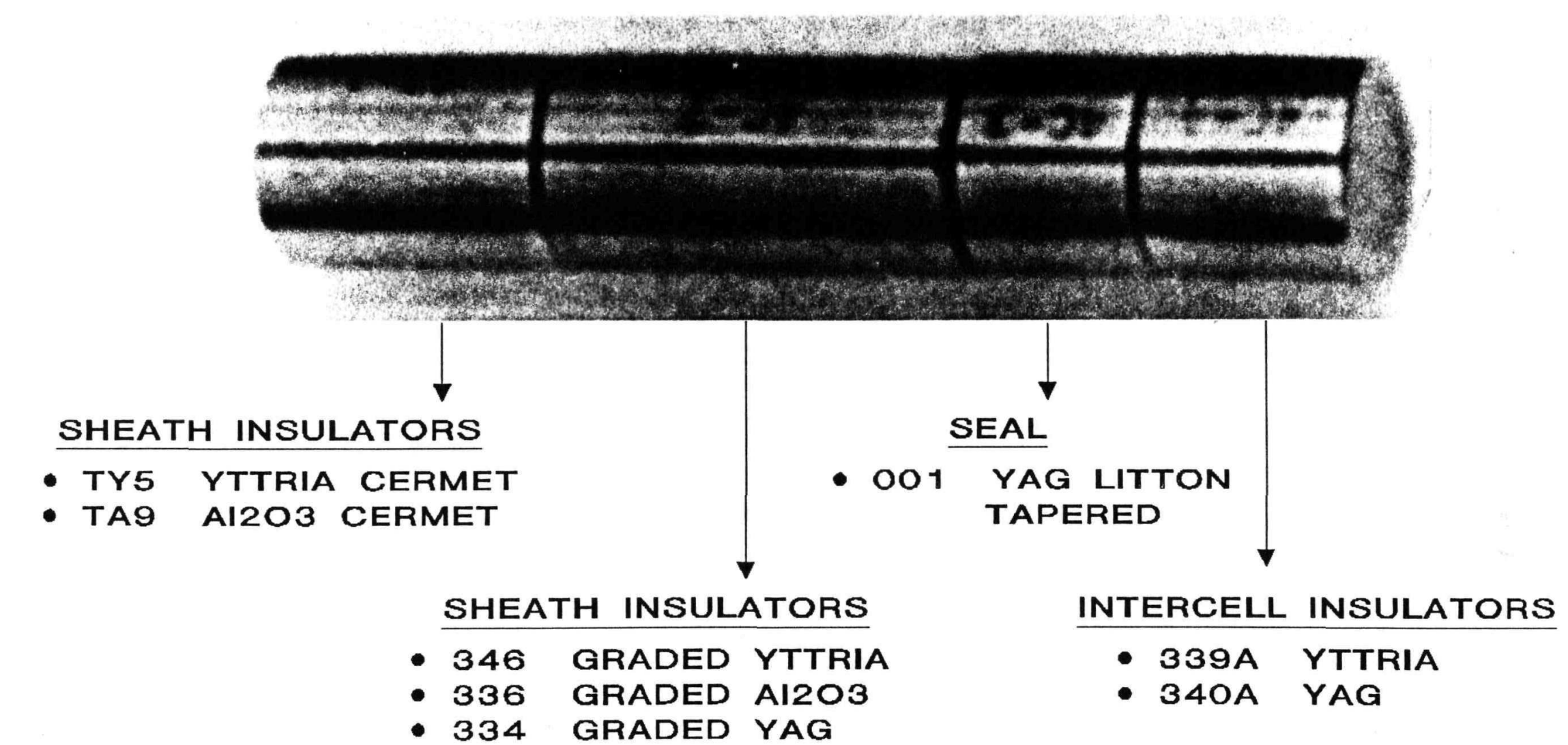

Figure 5-23 - Preirradiation condition and contents of the UCA-2 subcapsules in canister $4 \mathrm{C}$ 
performance of sheath insulators under prototypic conditfons of temperature, fluence, and voltage. The test will (tentatively) consist of four sheath insulator samples in a fully instrumented test train with a voltage applied across the insulator to simulate operation in a TFE. The test vehicle will include on-line temperature control using a gas insulating gap and He/Ar gas mixtures. The instrumented IFAC-SI test train will be inserted into an in-reactor thimble (IRT) being procured for the test.

Drawing revisions were completed for the procurement of a modified IRT. The corresponding fabrication spectfication was completed. The completed drawings and the fabrication specification were included in the purchase requisition for the modified IRT. Test specimen delivery is scheduled for delivery to WHC in July, 1989, with irradiation beginning in February, 1990.

\section{References}

1. GA-A19115, TFE Verification Program Semiannual Report for the Period Ending September 30, 1987, March, 1988.

2. TTP Program.

3. Dunlay, W. A., "Mechanical Properties of Laser Synthesized Reaction Bonded Silicon Nitride", M. S. Thesis, MIT, September, 1987.

4. Shetty, D. K., et al., "Blaxial Flexture Tests for Ceramics", Amer. Ceramics Society Bulletin, $\underline{59}$ (12) 1193-1197 (1980).

5. Austis, G. R., et al., "A Critical Evaluation of Indentation Techniques for Measuring Fracture Toughness", Journal American Ceramics Society, 64 (9) 533 (1981).

6. DeWith, G. and J. E. D. Parren, "Transluscent $\mathrm{Y}_{3} \mathrm{Al}_{5} \mathrm{O}_{12}$ Ceramics: Mechanical Properties", Phillips Research Laboratories, Solid State Ionics, 16 (1985) 87-94. 


\section{FUELED EMITTER TASK}

6.1 OBJECTIVE AND TECHNICAL APPROACH

The function of the fueled emitter is to generate the heat necessary to drive the thermionic conversion process with the geometry, power densities and temperatures required by the reference TFE design, using materials compatible with both the thermionic process and reactor requirements. Specific requirements for the emitter are given in Table 6-1.

TABLE 6-1

\section{FUELED EMITTER DESIGN REQUIREMENTS}

\section{Emitter}

Material

Outside diameter, $\mathrm{cm}$

Thickness, $\mathrm{cm}$

Emitter/collector gap, cm

Nominal temperature, $\mathrm{K}$

Nominal current Density, a/ $\mathrm{cm}^{2}$

Fuel

Outside diameter, $\mathrm{cm}$

Inside diameter, $\mathrm{cm}$

Enrichment, \% U-235

Fuel length, cm

Nominal fuel burnup, atom percent

Peak fuel burnup, atom percent

Nominal fast neutron fluence, $\mathrm{n} / \mathrm{cm}^{2}$ (E).1 Mev)

Peak fast neutron fluence, $\mathrm{n} / \mathrm{cm}^{2}$ (E).1 Mev)
Duplex Tungsten

1.27

0.10

0.025

1800

7

$$
\begin{gathered}
1.0 \\
\text { Variable } \\
93 \\
4.65 \\
4.1 \\
5.3 \\
2.7 \times 10^{22} \\
3.5 \times 10^{22}
\end{gathered}
$$

The key technical concern is the emitter distortion as a result of fuel swelling over the 7-year lifetime. It is the objective of the fueled 
emitter task to develop and demonstrate by appropriate ex-reactor testing, in-reacter testing and analytical verification a fueled emitter capable of meeting the above design requirements.

The strategy to demonstrate the performance and lifetime of the fueled emitter is based on extensive in-reactor testing. While duplex tungsten will be the focus of most of the testing, alternate materials, particularly the HfC strengthened materials, look very promising and will be considered. Additionally, alternate fuel forms (to $\mathrm{UO}_{2}$ pellets) will be evaluated which either weaken the fuel or change its swelling characteristics, thereby minimizing emitter distortion. These forms include insulated fuel, wafered fuel, and metal felt inclusion.

During the reporting period, the testing of UFAC Batch 1 emitters continued. The scope and objectives of the Instrumented Fast reactor Accelerated Component-Fueled Emitter test (IFAC-FE) were reviewed and a redirection of the program toward more extensive ex-reactor testing and passive instrumentation was adopted. Preliminary plans for Batch 2 were made.

The irradiation of fueled emitters in TRIGA continued; 24,000 hours of real time testing were obtained on some of the test specimens.

\subsection{EX-REACTOR TESTING}

The objectives of the ex-reactor testing are twofold. First, modeling studies will be performed early to determine if there is the possibility for thermal ratcheting and/or fission gas induced bladder deformation of the emitter. These studies have been completed, and these deformation mechanisms are not important to overall fuel emitter distortion. No further work is planned at this time.

Secondly, ex-reactor tests will be performed to investigate the creep strength characteristics of the duplex tungsten and other candidate emitter materials. This work remains to be done. 


\subsection{UFAC IN-REACTOR TESTING}

The UFAC testing will be performed in three separate batches consisting of about ten emitters each. Batch-1 is presently being irradiated in EBR-II. Figure 6-1 shows the current test schedule for the UFAC experiments. The first line of the schedule gives the EBR-II operating intervals (known as cycle numbers) and the duration of each operating period.

The basic UFAC design consists of individually encapsulated fueled emitter test specimens which are contained within the EBR-II irradiation assemblies. This was described in Ref. 2 .

A part of this design effort was an extensive ex-reactor test effort at Thermo Electron Corporation to assure that the desired emitter temperatures were obtained. The test setup used to obtain the results described in Ref. 2 is shown on Fig. 6-2. A tungsten emitter and niobium sleeve were fabricated similar to Batch 1 test specimens. The niobium sleeve had a calibration heater brazed to its outer surface, while an electron bombardment heater was placed within the emitter. The gas in the space between the emitter and collector was controllable. A heat transfer test was performed at temperatures of $1700^{\circ} \mathrm{K}, 1800^{\circ} \mathrm{K}$, and $1900^{\circ} \mathrm{K}$. Heat generation data appropriate to EBR-II was supplied by ANL-West. An effective emissivity was calculated between the emitter and collector surface for each operating temperature. In addition, tests were performed using the thermal conductivity cell to quantify the conductivity of various helium to argon gas mixtures. One and two dimensional analytical models were performed to support the test program. The results were favorable, as reported earlier. The uncertainity in the emitter temperature is in the range of $30^{\circ} \mathrm{K}$ to $40^{\circ} \mathrm{K}$.

\subsubsection{UFAC Batch 1 Status}

The ten UFAC Batch 1 specimen were Inserted in the EBR-II in May, 1987 at the start of cycle 144 (see Fig. 2-1). After irradiation for 95 days, 
Figure 6-1 - UFAC EBR-II testing schedule

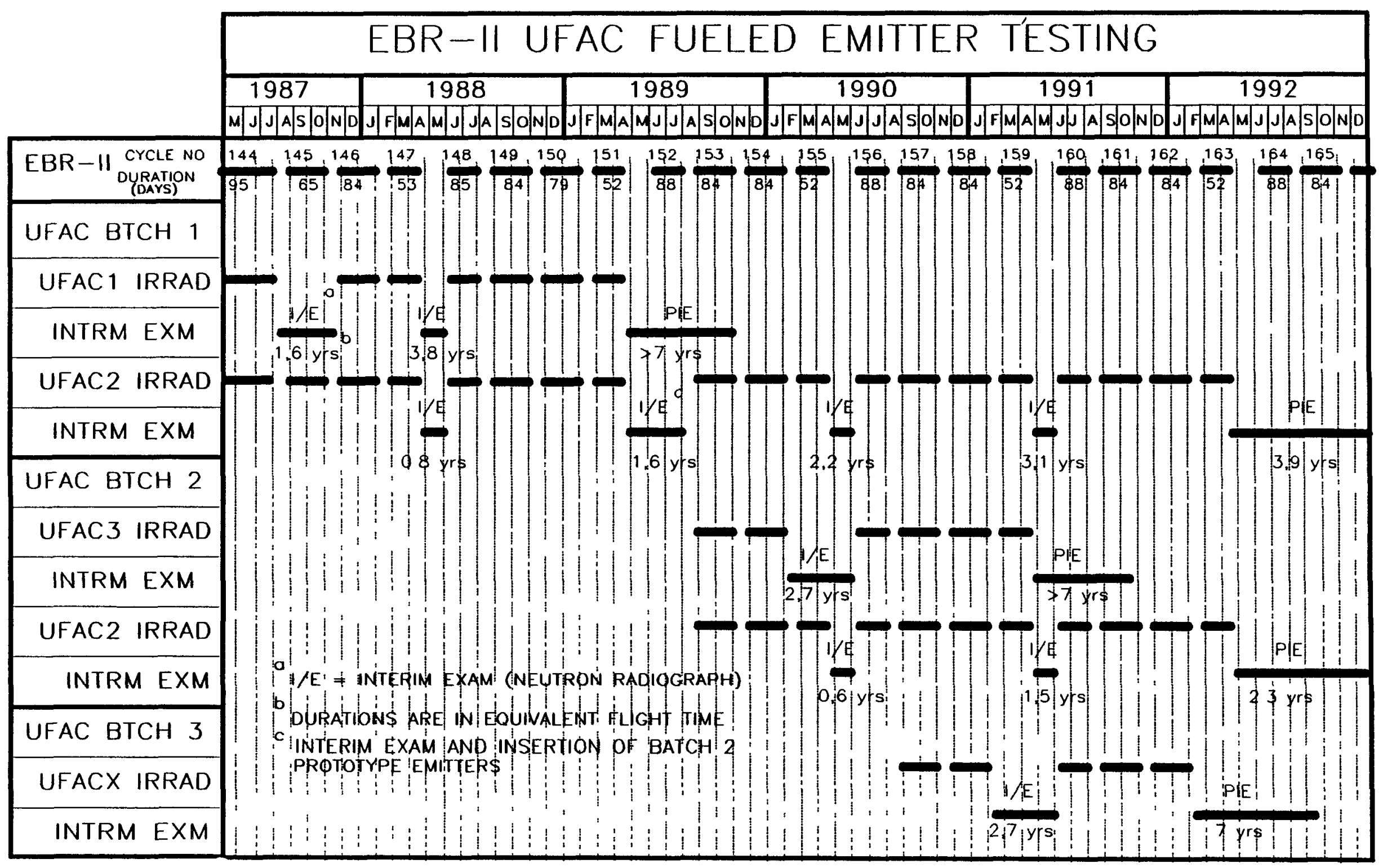




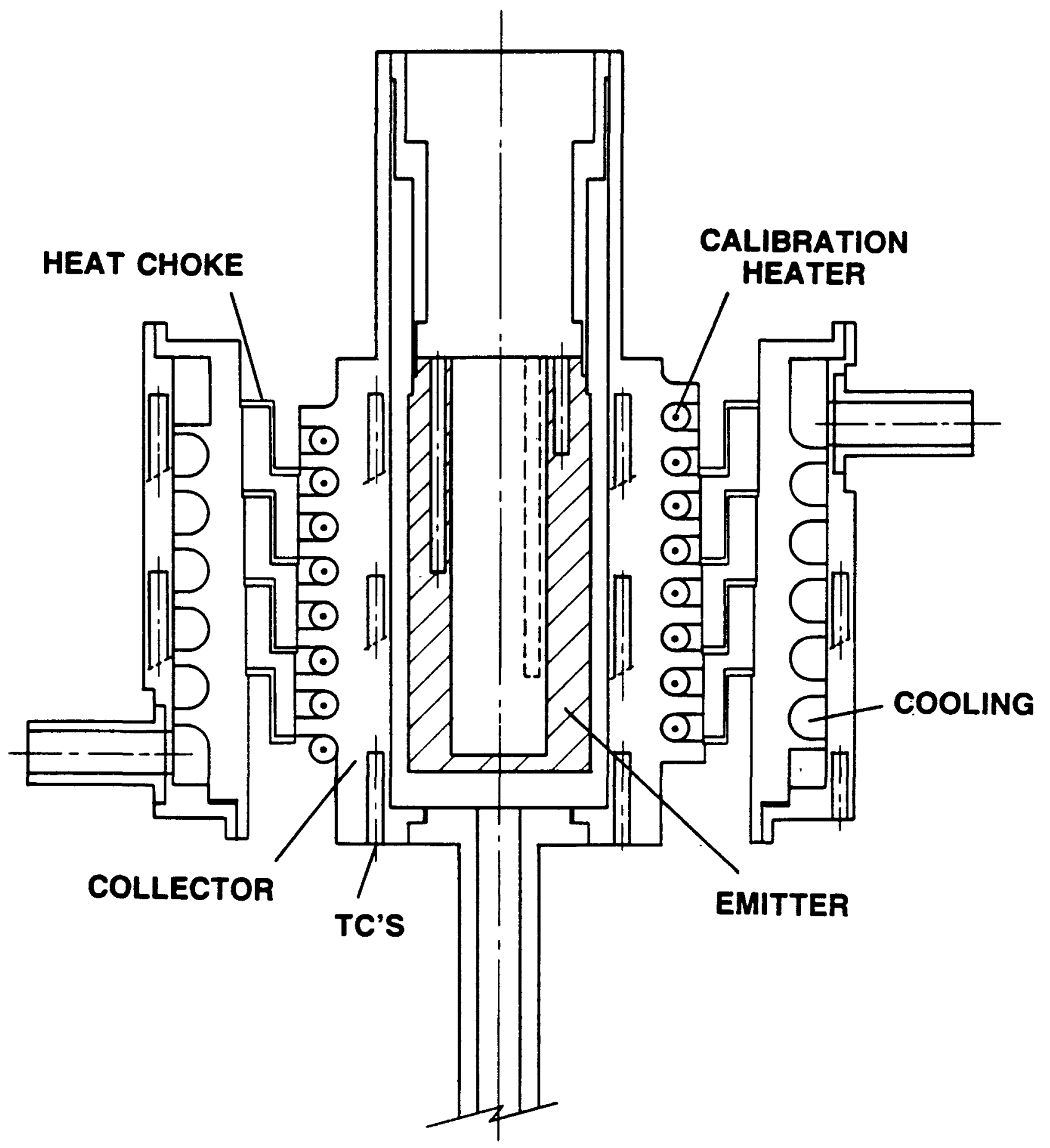

Figure 6-2 - TECO's UFAC Batch 1 heat transfer test setup 
equivalent to 1.6 years of flight time, the seven accelerated emitters, specimens 4 through 10 were removed. Neutron radiographs were taken of these specimens to enable interim measurement of changes in emitter diameter. These specimens were then reinserted in the EBR-II for cycle 146. The next scheduled removal for interim examination is in April, 1988, when the test time will be equivalent to 3.8 years flight time.

The three real-time or prototypic emitters, specimens 1, 2 and 3 , are scheduled for their first removal in April, 1988, after 297 days of irradiation. The accumulated burnup for the Batch 1 specimens at that time is summarized in Table 6-2.

TABLE 6-2

UFAC BATCH 1 IRRADIATION HISTORY ESTIMATED FOR APRIL 1, 1988

Assembly EFPD ${ }^{(a)} \quad$ Fluence $^{(b)}$ Burnup $^{(c)}$ Time, Years

$\begin{array}{lllll}\operatorname{UFAC}{ }_{1}{ }^{(d)} & 220.5 & 3.6 & 2.1 & 3.8 \\ \operatorname{UFAC~}_{2}{ }^{(e)} & 285.0 & 2.8 & 0.7 & 0.8\end{array}$
(a) EFPD - Effective Full Power Days
(b) Fast fluence $\times 10^{22}$ neutrons $/ \mathrm{cm}^{2}$
(c) U-235 atom \% burnup
(d) Accelerated emitters in EBR-II row 5
(e) Prototype emitters in EBR-II row 7

A comparison of the measured emitter distortion with analysis is shown on Figs. 6-3 through 6-9. Measured emitter distortions are much less than those predicted by the IIFE-4 code, and while the data are too few to permit a firm conclusion, it appears that LIFE-4 is a conservative tool for the design of thermionic space devices. More NR measured emitter distortions will be available in April, 1988. 
Figure 6-3

\section{EBR-II UFAC BATCH 1 FUELED EMITTER SU1-4}
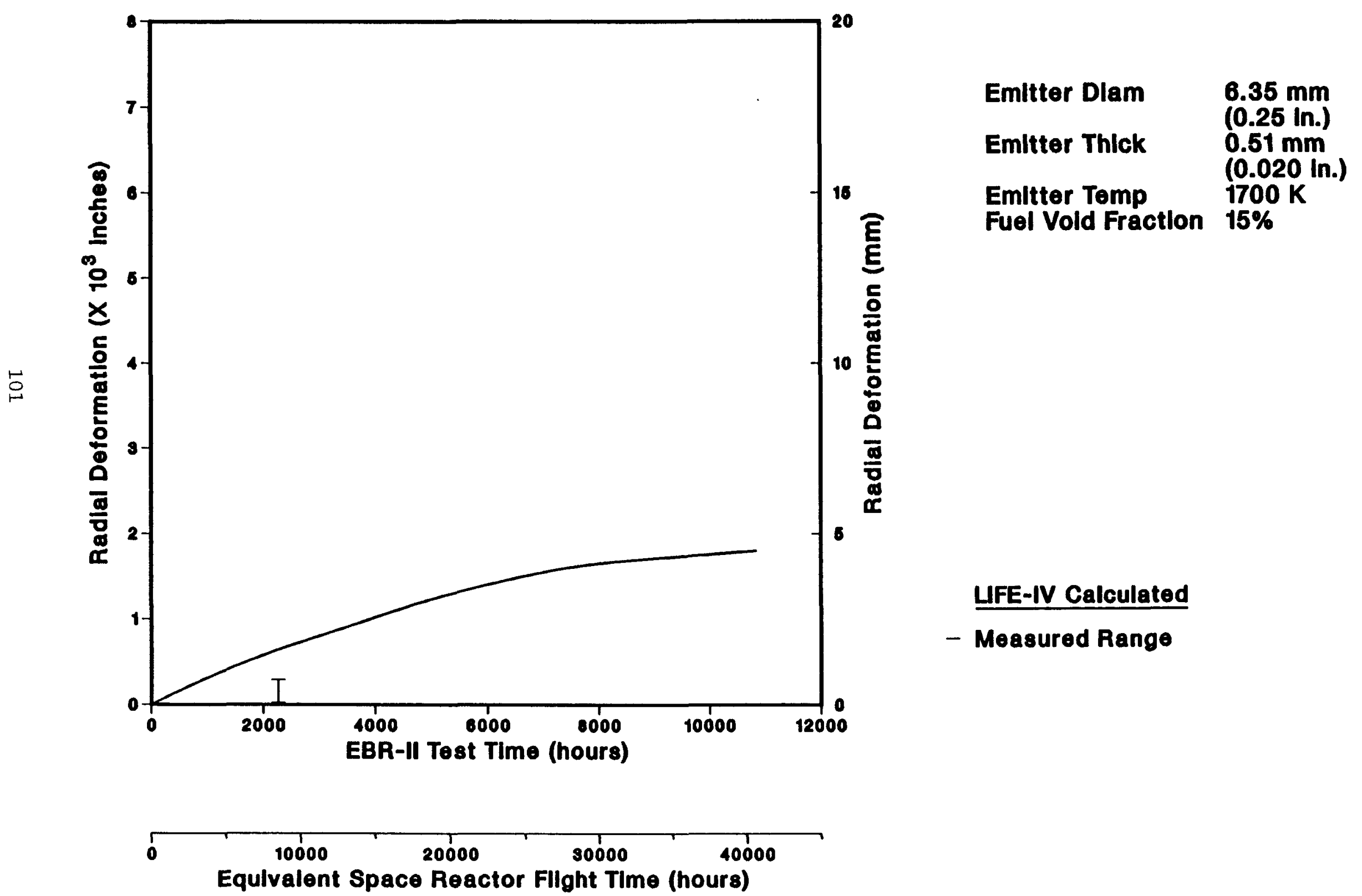


\section{EBR-II UFAC BATCH 1 FUELED EMITTER SU1-5}

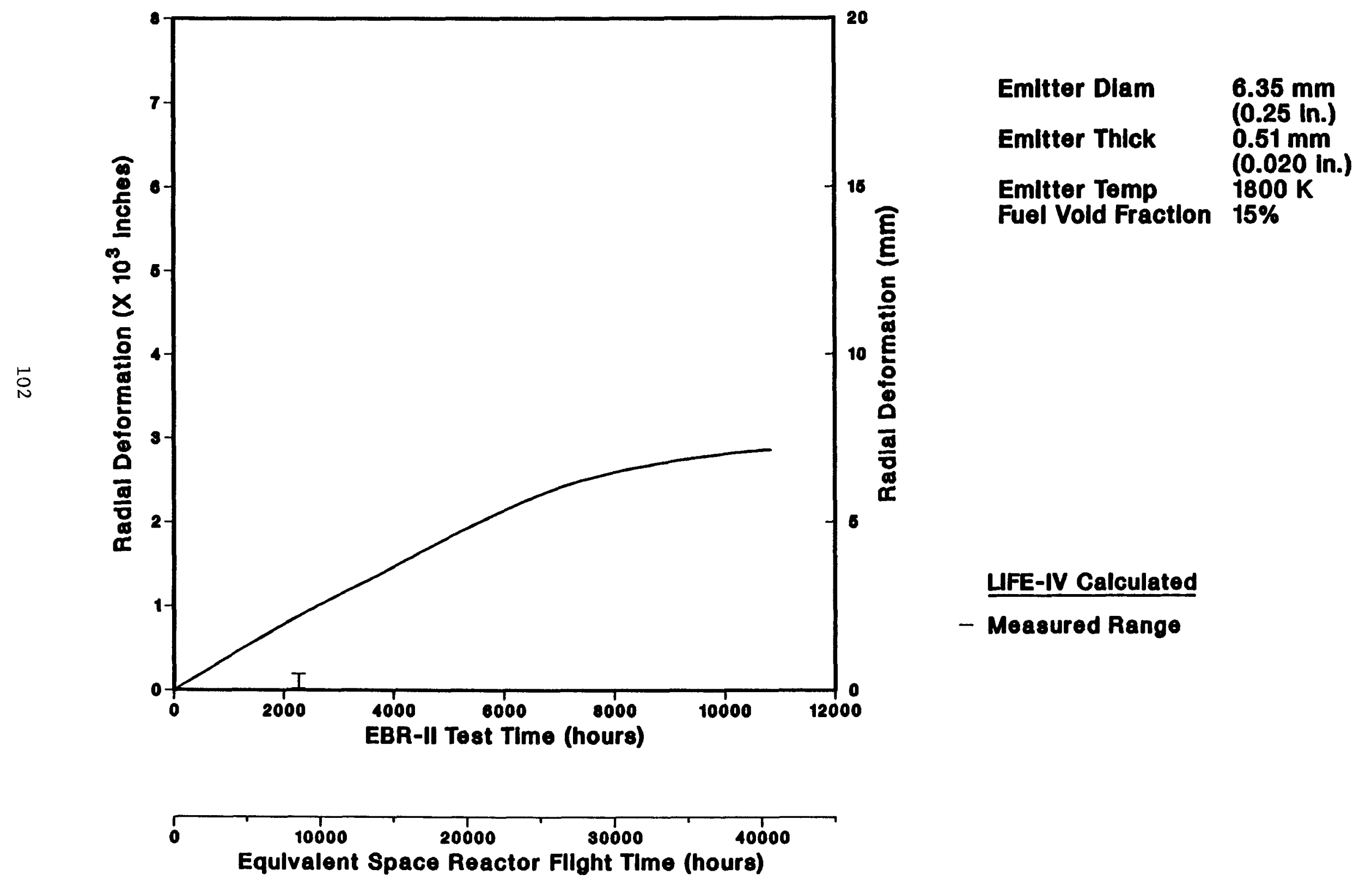


Figure 6-5

\section{EBR-II UFAC BATCH 1 FUELED EMITTER SU1-6}
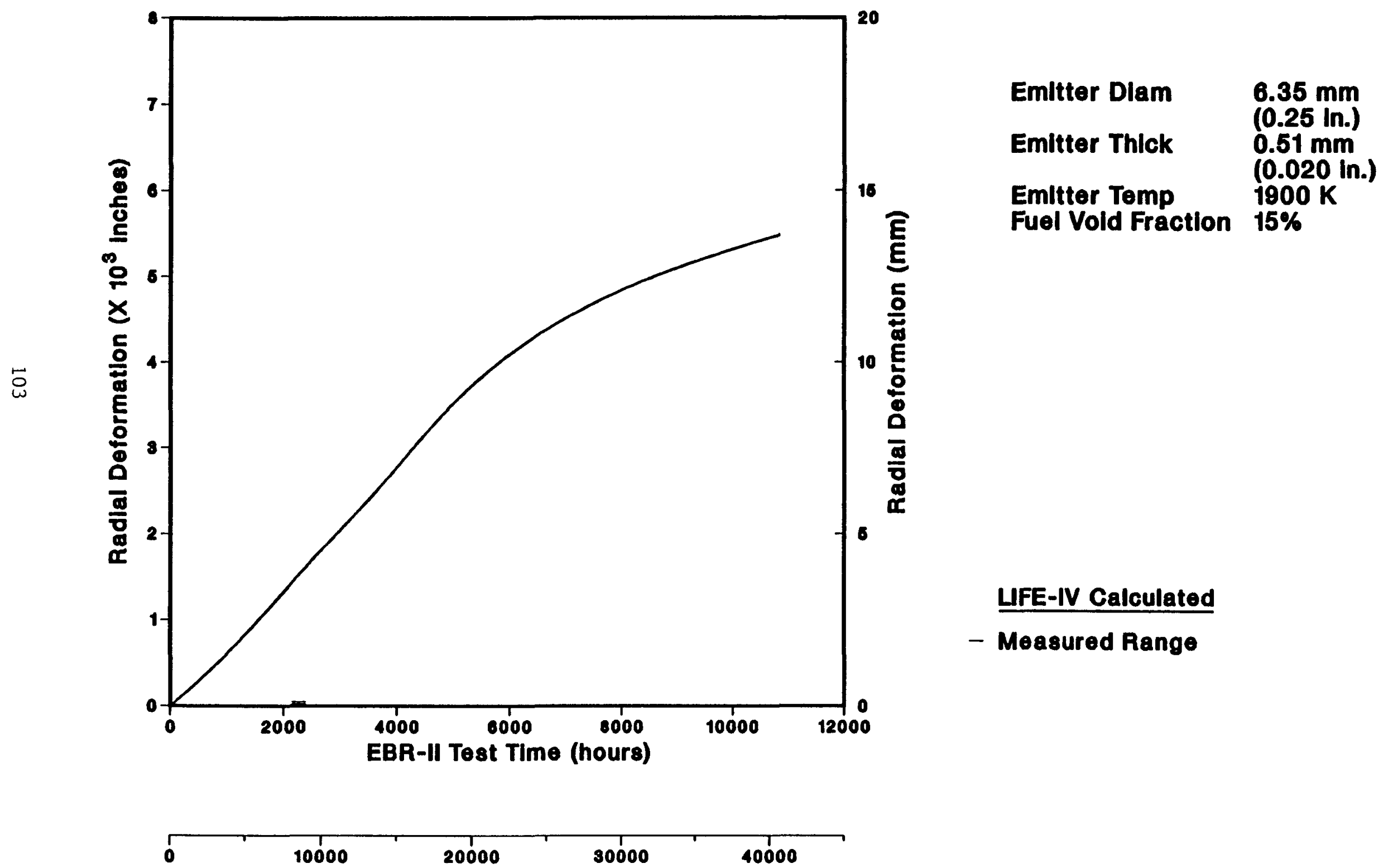

Equivalent Space Reactor Filght TIme (hours) 
Figure 6-6

\section{EBR-II UFAC BATCH 1 FUELLED EMITTER SU1-7}

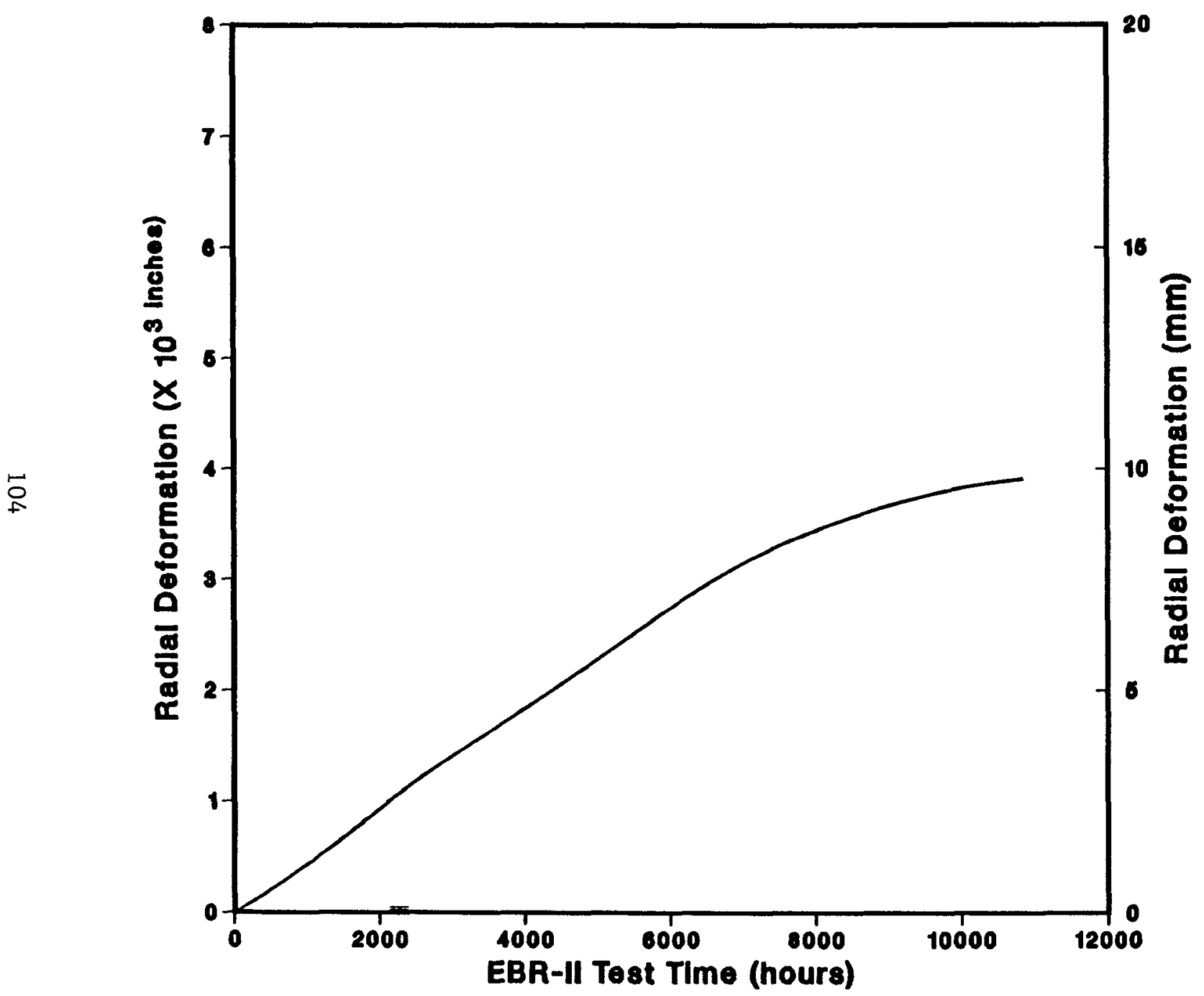

$$
\begin{array}{ll}
\text { Emitter Diam } & \begin{array}{l}
6.35 \mathrm{~mm} \\
(0.25 \mathrm{in} .)
\end{array} \\
\text { Emitter Thick } & 0.51 \mathrm{~mm} \\
& (0.020 \mathrm{ln} .) \\
& 1800 \mathrm{~K} \\
\text { Emitter Temp } & 0 \% \\
\text { Fuel Vold Fraction } & 0 \%
\end{array}
$$

LIFE-IV Calculated

- Measured Range

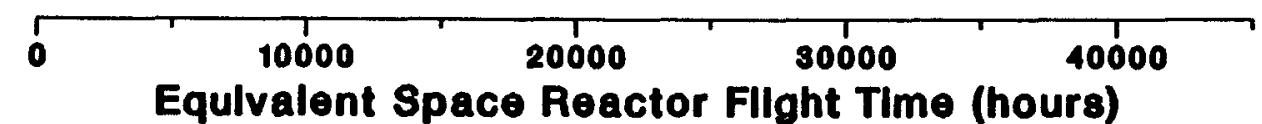


Figure 6-7

\section{EBR-II UFAC BATCH 1 FUELED EMITTER SU1-8}

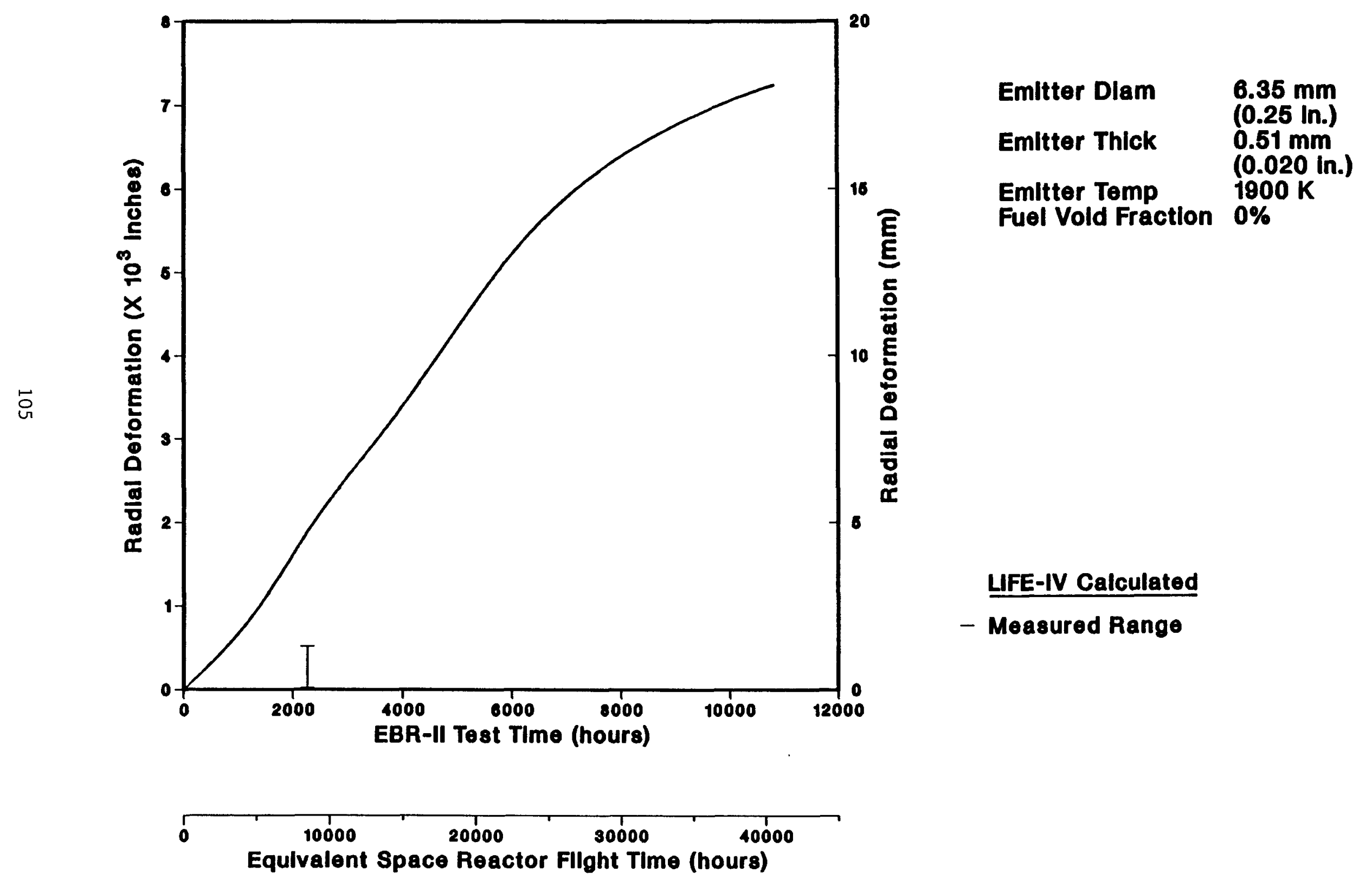


Figure 6-8

\section{EBR-II UFAC BATCH 1 FUELED EMITTER SU1-9}
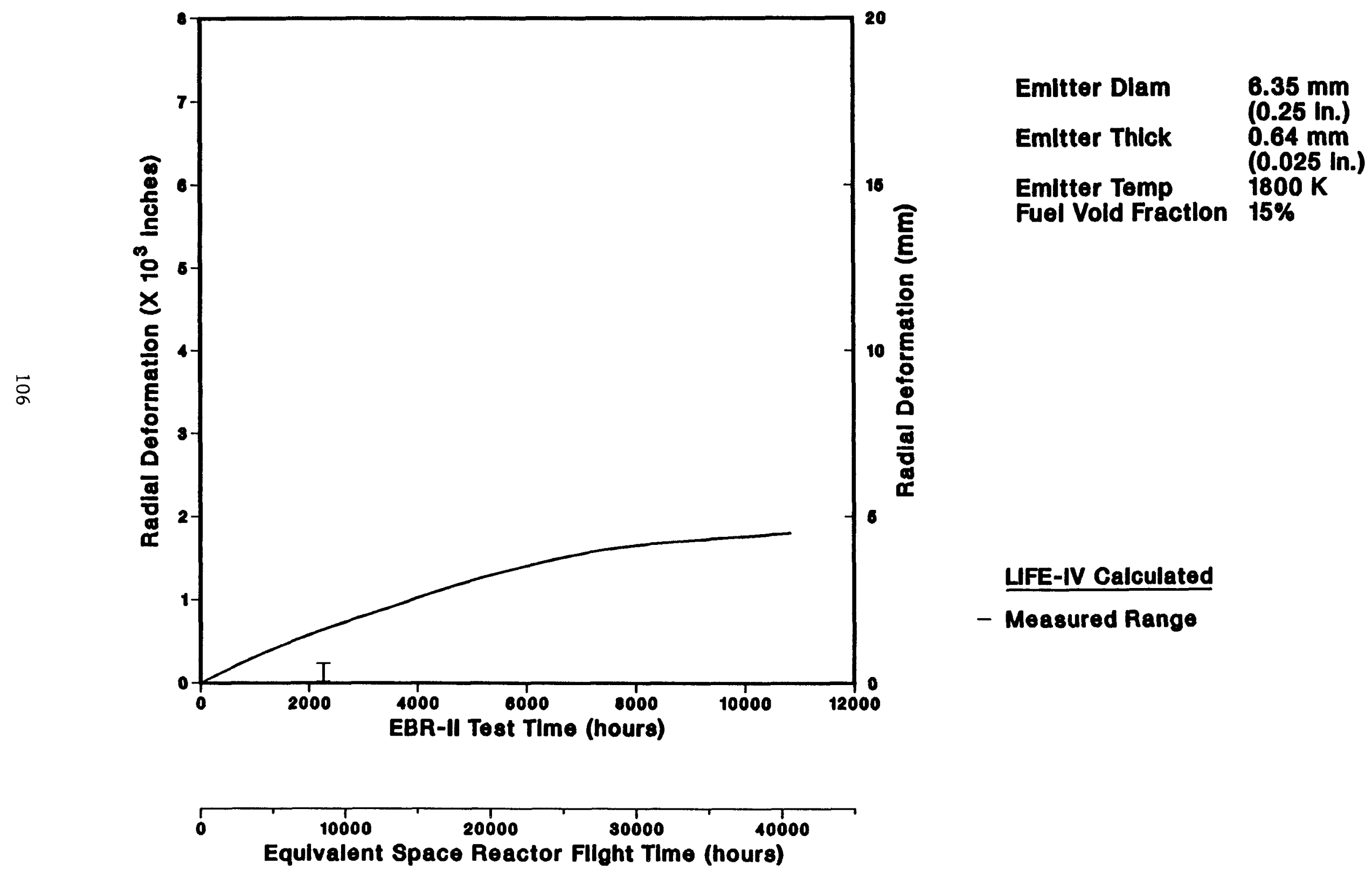


\section{EBR-II UFAC BATCH 1 FUELED EMITTER SU1-10}

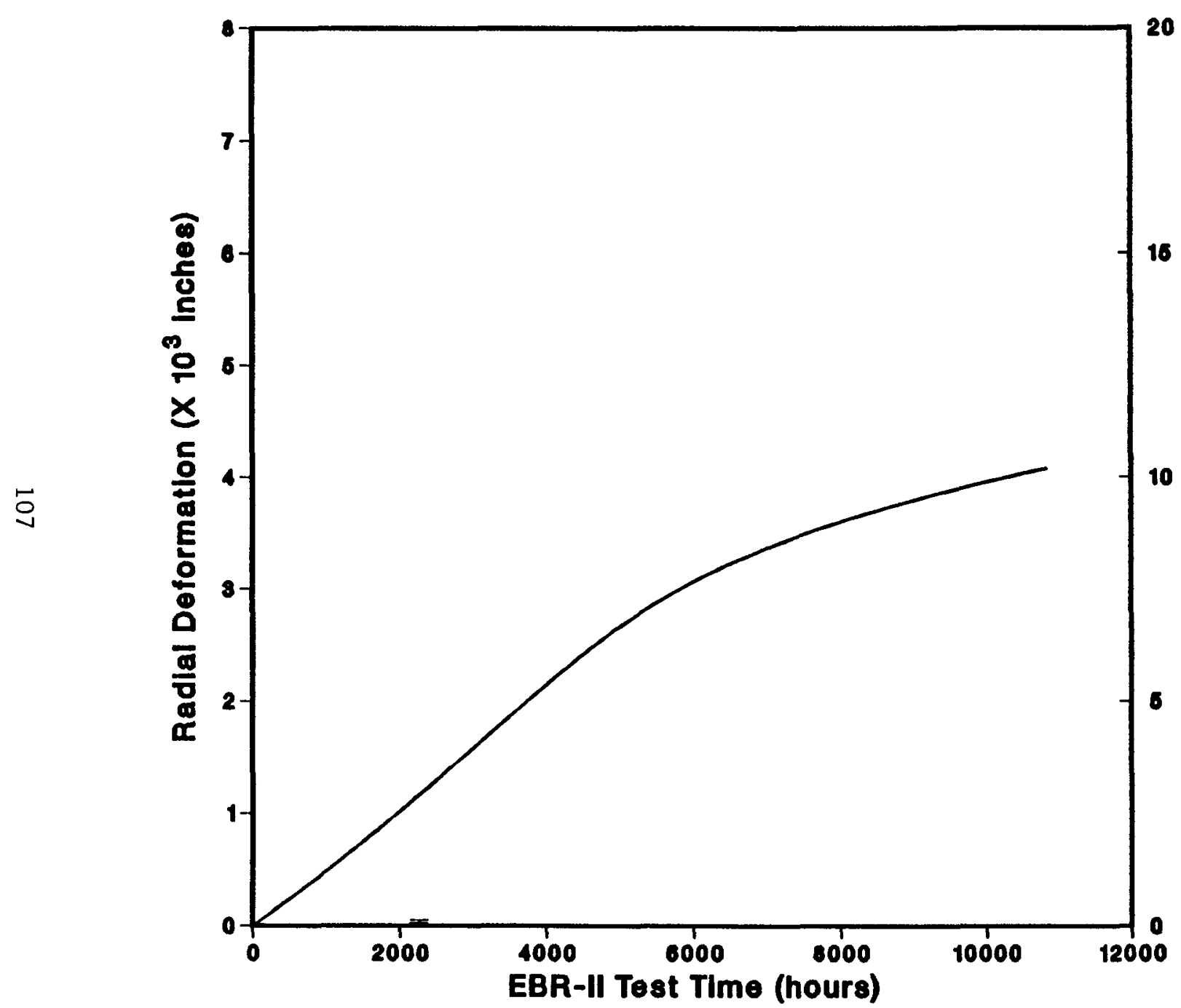

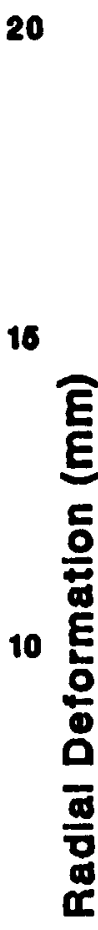

UFE-IV Calculated

- Measured Range

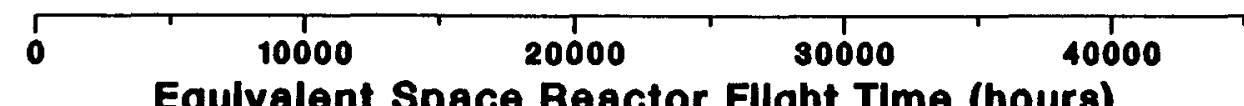

Equivalent Space Reactor Fllght TIme (hours) 
The acceleration factor for the accelerated test specimens is a factor of 4 to 5. The geometry of the accelerated emitters is half size to ensure that cell thermal gradients are prototypical and fuel burnup (atom \%) after 15,000 test hours will equal that of a real time emitter after 7 years. The LIFE-4 code was used to determine the deformation characteristics of the accelerated specimens and their equivalent real time emitters. Figures 6-10 through 6-16 present the results of these analyses. For each UFAC accelerated emitter, LIFE-4 predicted higher end-of-life deformations than for their equivalent real time counterparts. This is a favorable result from the standpoint of the significance of the experimental results.

LIFE-4 Code: The analytical tool being used to study emitter deformation is the LIFE-4 fuel element thermomechanical analysis code (Ref 3). The code is being verified for use in establishing the cell design and predicting performance and lifetime characteristics. Verification consists in modeling the test specimens and comparing the calculated emitter distortion with measured emitter measurements. Major input parameters include cell geometry, operating power, test speclmen geometries, central fuel void fractions, and design operating temperatures. The power level for each accelerated specimen is based on ANL-W calculations. Approximately a $10 \%$ decrease in power over the full life of the experiment (15,000 hours) due to U-235 burnup was assumed. Future LIFE-4 runs will incorporate experiment temperature decreases over time due to this power decrease and temperature increases due to reorificing of the EBR-II assemblies. Modifications were made to this code by Los Alamos National Laboratory (LANL) to more closely predict tungsten emitter deformation at the relatively high fuel temperature characteristics of thermionic space reactors (Ref. 4). Th1s is an ongoing effort.

\subsubsection{UFAC Batches 2 and 3}

As shown in Fig. 6-1, UFAC Batches 2 and 3 are scheduled for irradiation testing beginning mid-1989 and mid-1990 respectively. The presently proposed Batch 2 test matrix, Table 6-3, consists of additional Batch 1 type specimens with some samples extending the annular fuel design 
Figure 6-10

\section{EBR-II UFAC BATCH 1 FUELED EMITTER SU1-4}
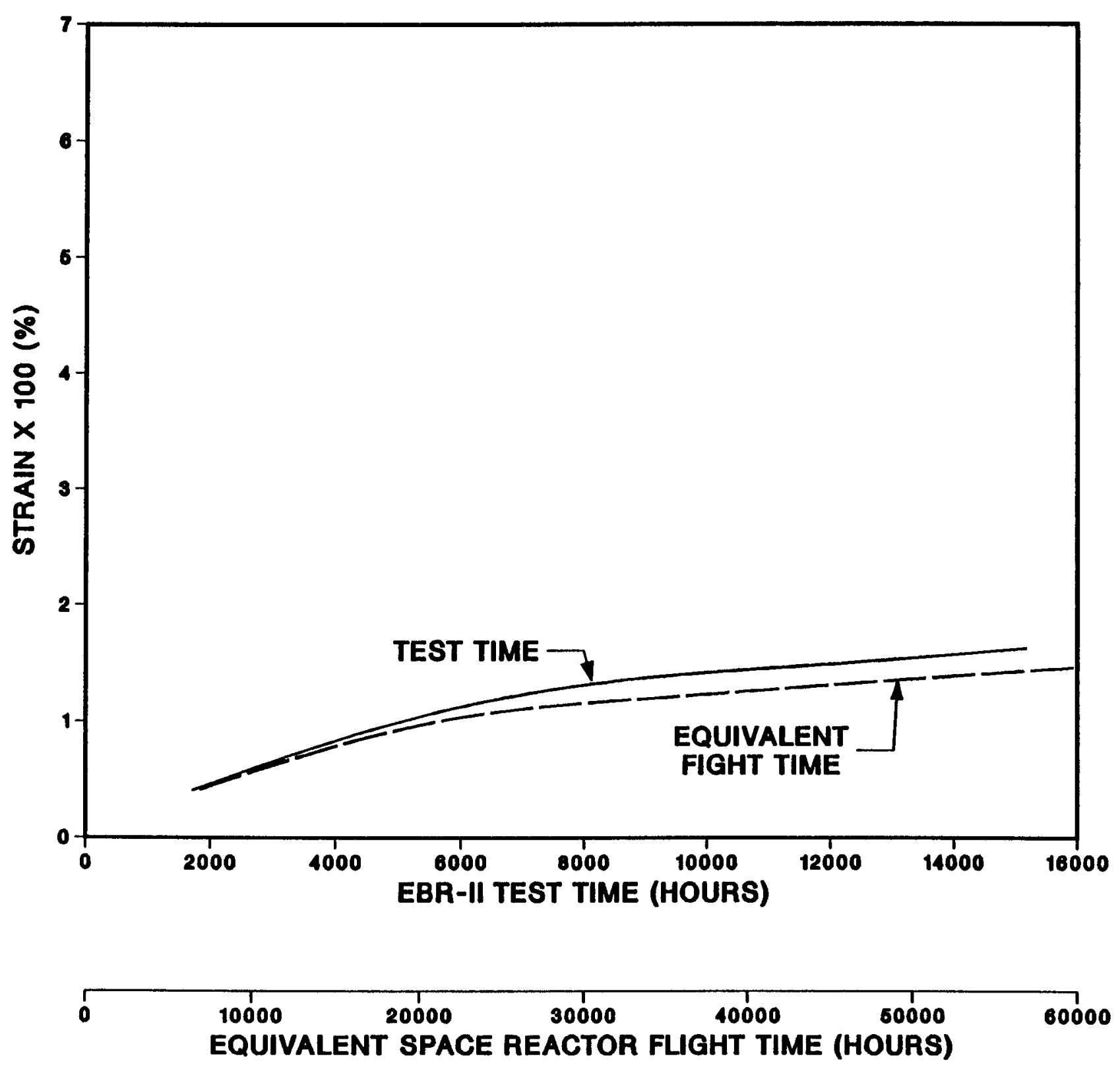


\section{EBR-II UFAC BATCH 1 FUELED EMITTER SU1-5}
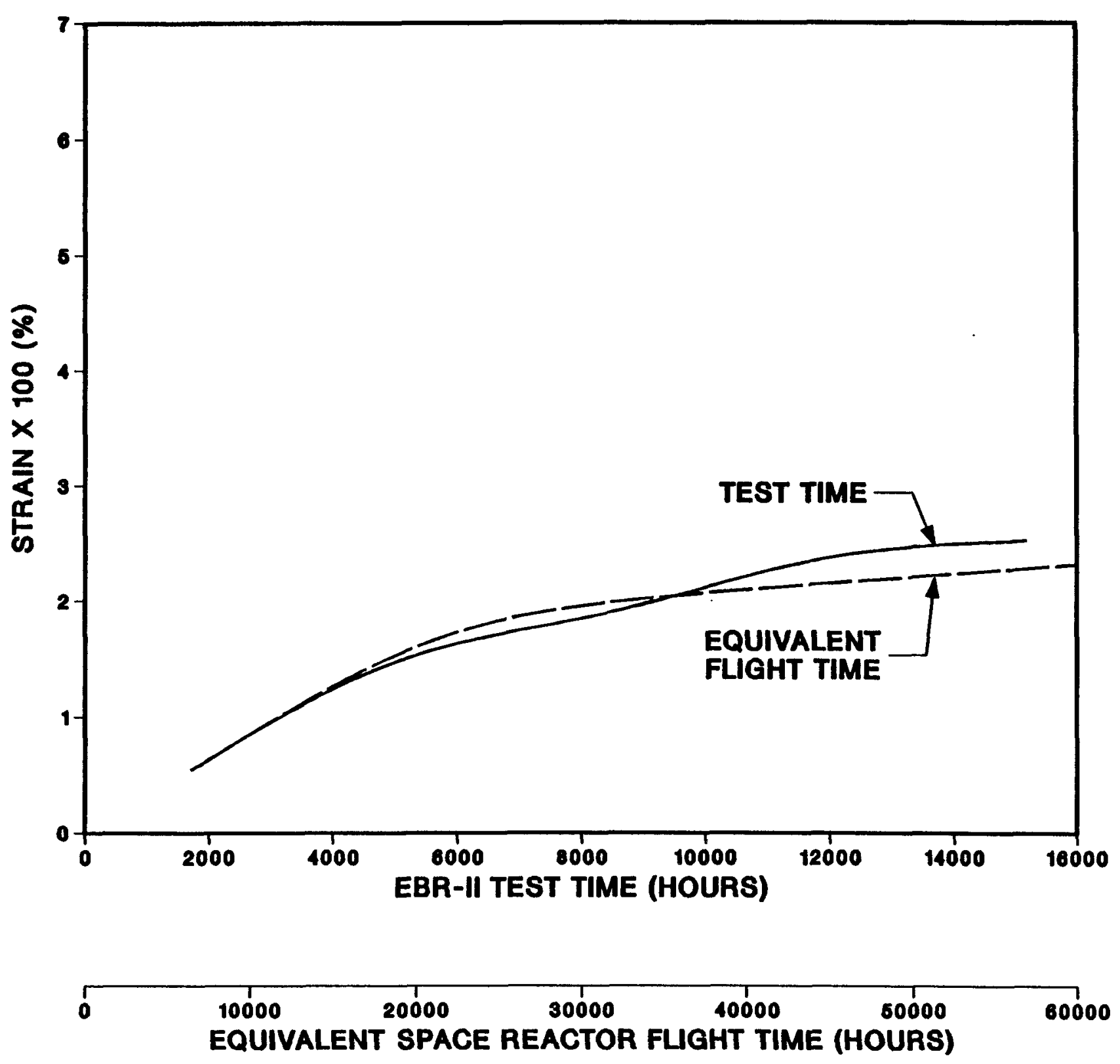
Figure 6-12

\section{EBR-II UFAC BATCH 1 FUELED EMITTER SUI-6}
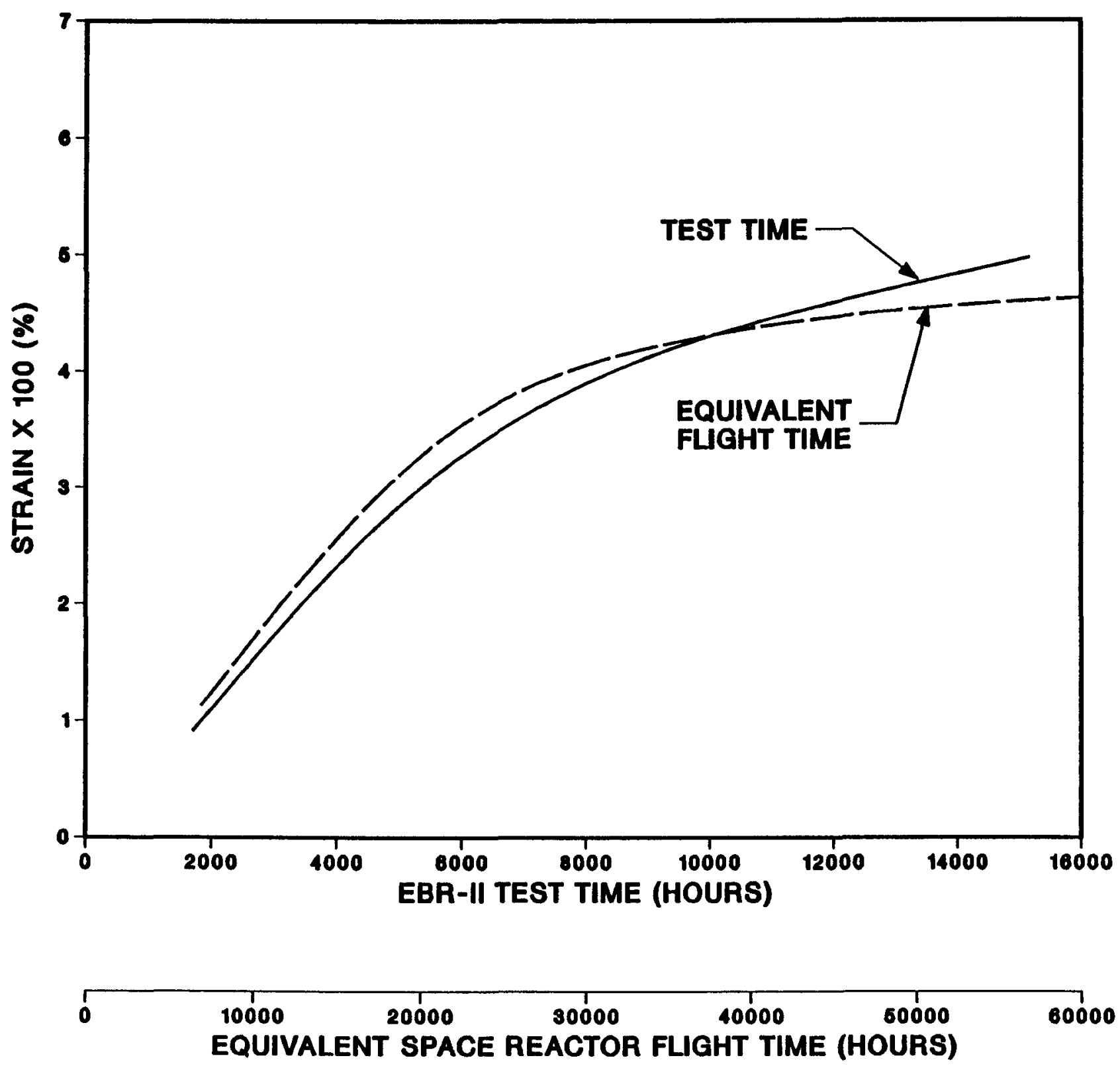


\section{EBR-II UFAC BATCH 1 FUELED EMITTER SUI-7}

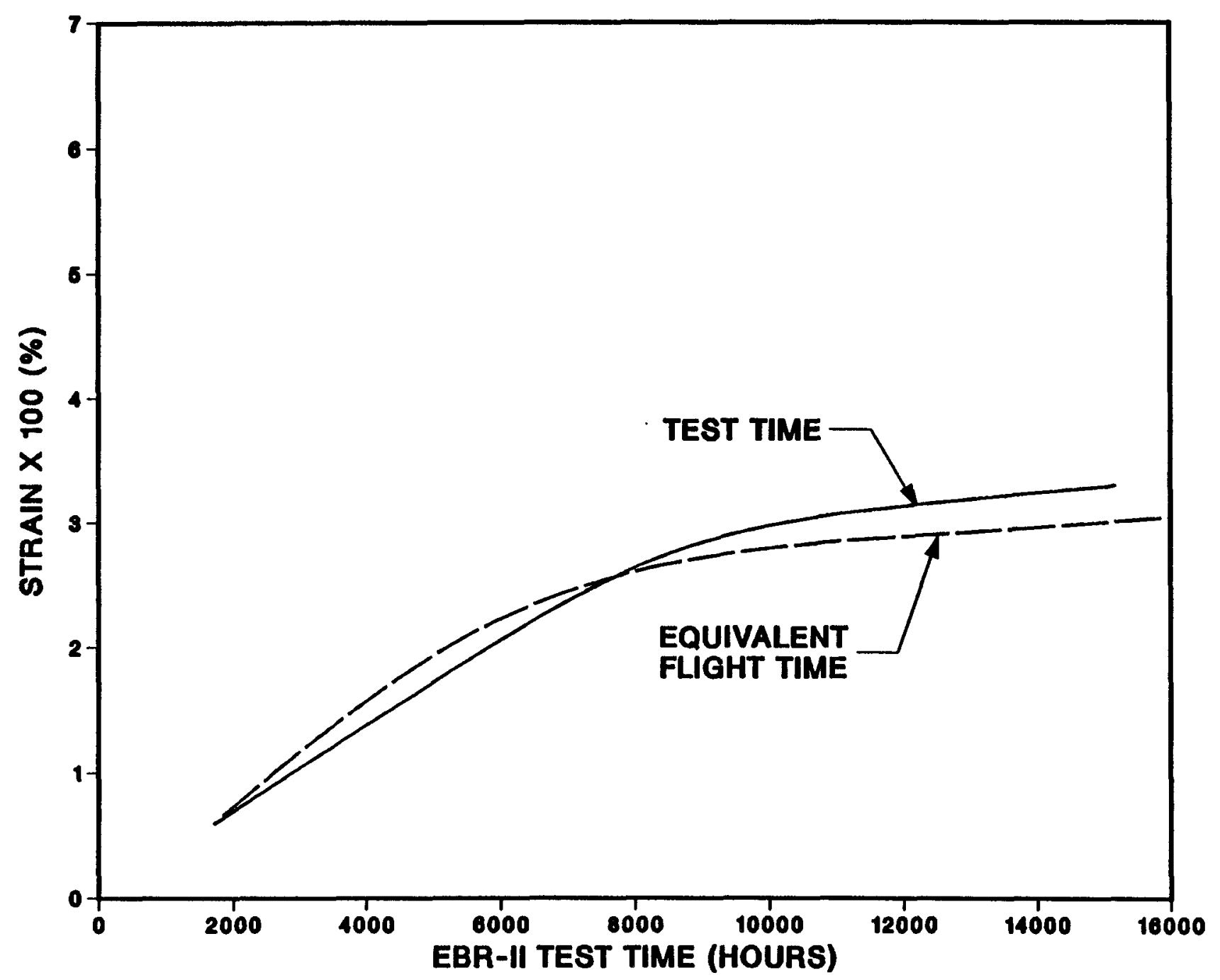

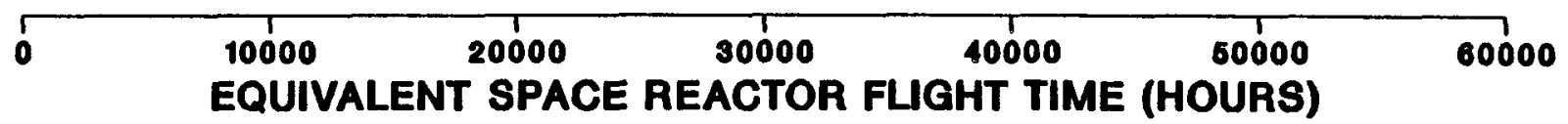


Figure 6-14

\section{EBR-II UFAC BATCH 1 FUELED EMITTER SUI-8}
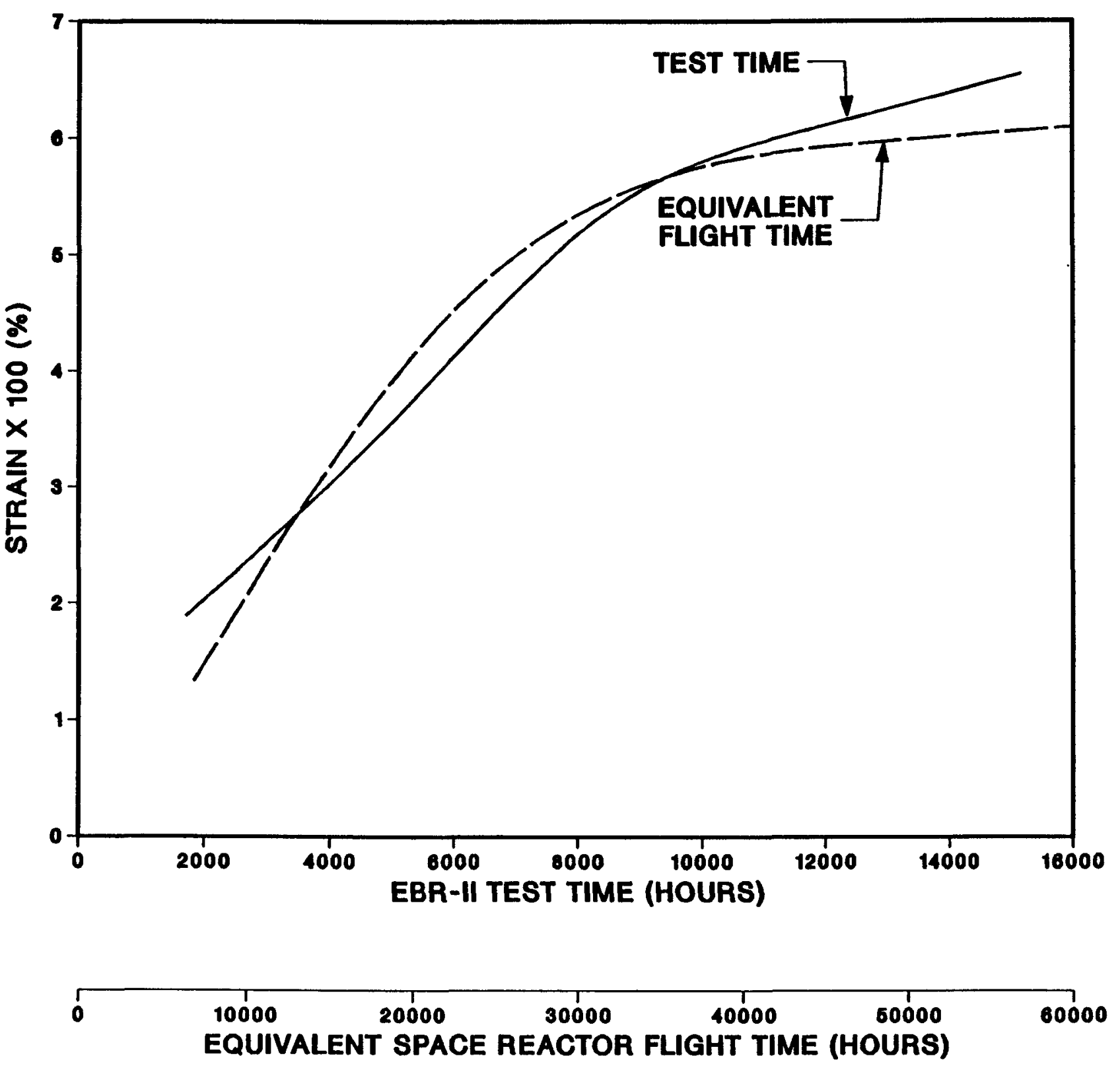


\section{EBR-II UFAC BATCH 1 FUELED EMITTER SU1-9}
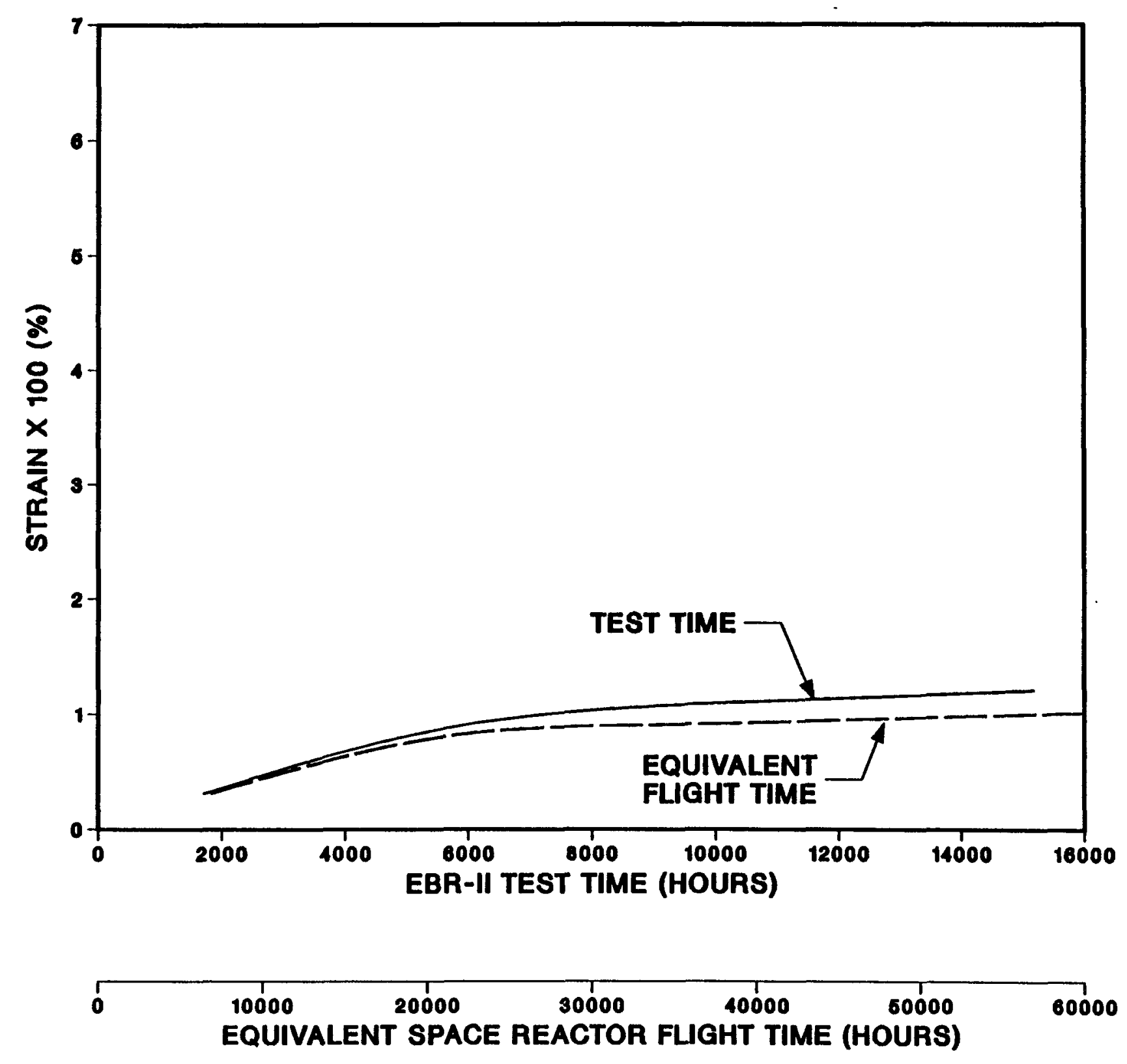
Figure 6-16

\section{EBR-II UFAC BATCH 1 FUELED EMITTER SUI-10}
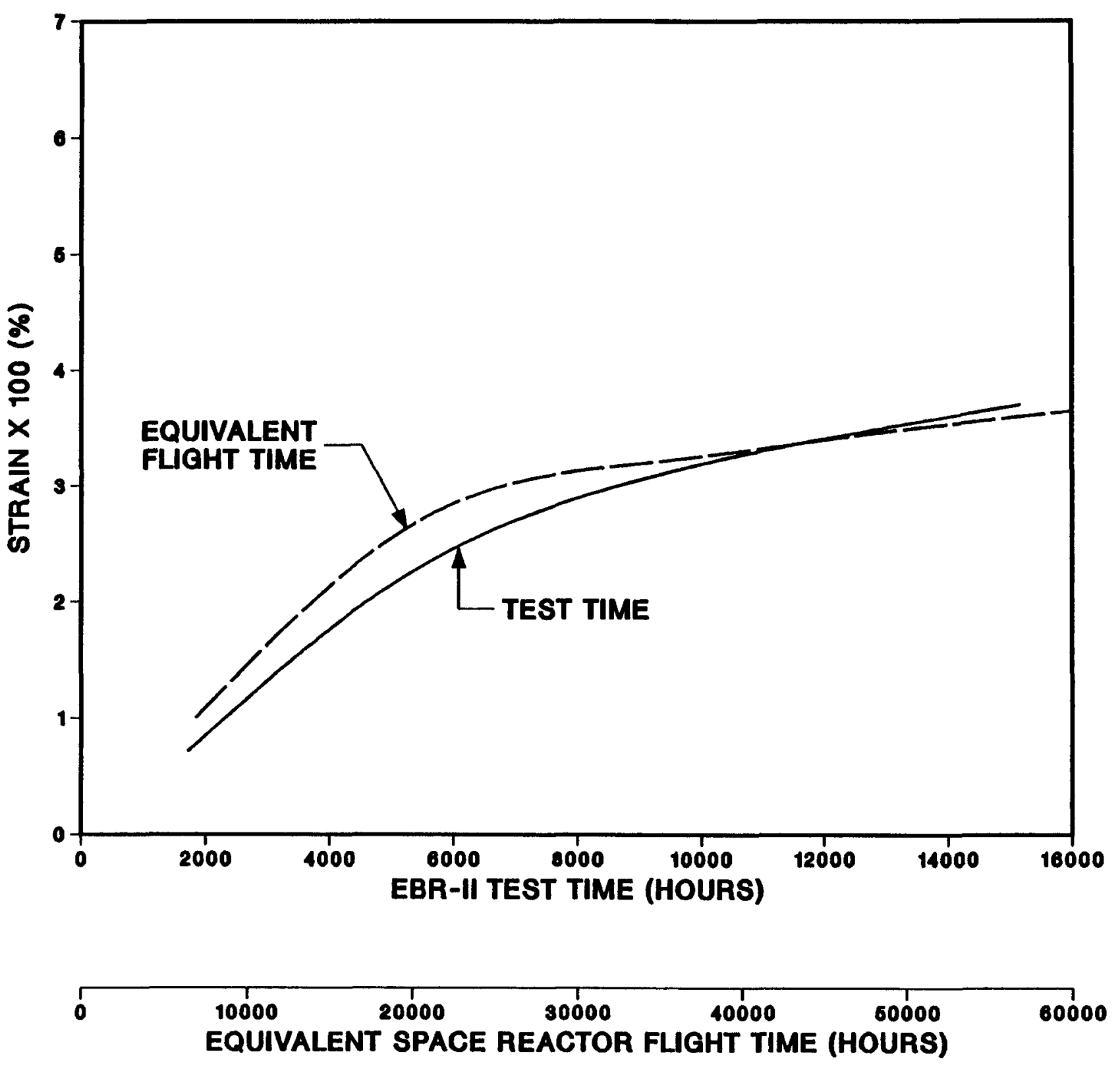
to a 25\% fuel void fraction. New concepts to be evaluated for testing include the use of advanced emitter materials, felt inserts, wafered fuel designs, insulated/weakened fuel, and doped/weaker fuel. These concepts were discussed in Ref. 2. The Batch 3 matrix will depend on results from prior batches.

TABLE 6-3

UFAC BATCH 2 PROPOSED TEST MATRIX

Test Number Emitter Materlal Fuel Remarks

Prototype Emitters

$\begin{array}{lcll}1 & \mathrm{CVD}-\mathrm{W} & \mathrm{UO}_{2}, \text { annular } & \text { Batch 1 replica } \\ 2 & \text { Advanced material } & \mathrm{UO}_{2}, \text { annular } & \text { Strong emitter } \\ 3 & \mathrm{CVD}-\mathrm{W} & \text { Felt insert, annular } \mathrm{UO}_{2} \text { Low Distortion } \\ 4 & \mathrm{CVD}-\mathrm{W} & \text { Wafered Fuel } & \text { Low Distortion }\end{array}$

\section{Accelerated Emitters}

$\begin{array}{rlll}5 & \text { CVD-W } & \mathrm{UO}_{2} \text {, annular } & \text { Batch } 1 \text { replica } \\ 6 & \text { CVD-W } & \mathrm{UO}_{2} \text {, annular } & 25 \% \text { fuel void } \\ 7 & \text { CVD-W } & \text { Insulated, annular } & \text { Weak fuel } \\ 8 & \text { Advanced Material } & \mathrm{UO}_{2} \text {, annular } & \text { Strong emitter } \\ 9 & \text { Advanced Material } & \mathrm{UO}_{2} \text {, annular } & \text { Alternate temp. } \\ 10 & \text { CVD-W } & \text { Wafered fuel } & \text { Low distortion }\end{array}$

\subsubsection{IFAC-FE}

A central issue to the UFAC series of tests is confirmation of the calculated operating temperatures of the experiment. The parametric UFAC tests are based on calculated emitter temperatures augmented by specially designed heat transfer tests. A set of Instrumented Fast Reactor Accelerated Component Fueled Emitters (IFAC-FEs) were originally planned to directly measure the emitter surface temperatures of specimens in EBR-II to 
verify the calculated emitter temperatures. Cost estimates and design concerns relating to the difficulties of high temperature measurements have resulted in a replacement of the IFAC-FE tests with other efforts to reduce uncertainties in emitter temperatures. Presently a program plan is being drafted for the replacement to the IFAC-FE tests. Major elements of this proposed plan include:

1) Detailed uncertainty calculations to supplement the work previously done.

2) Development of a passive temperature monitor for use in the UFAC tests.

3) Early Post Irradiation Examinations (PIEs) of selected UFAC Batch 1 specimens.

4) Additional in-reactor uninstrumented tests.

5) Additional ex-reactor laboratory tests to characterize heat transfer mechanisms of the UFAC specimen.

\subsubsection{Neutron Radiography}

Neutron radiography, NR, is the primary means for obtaining periodic emitter distortion data. It is nondestructive with an accuracy of \pm 0.001 inches.

The neutron radiographic process used at the Hot Fuel Examination Facility (HFEF) by ANL-W on the UFAC specimen is well established. The source of neutrons is a TRIGA reactor operating at $250 \mathrm{~kW}$ thermal power. A collimated beam of neutrons is ported radially from the TRIGA reactor core to intercept the specimen and radiographic foils. The thin metal radiographic foils are positioned behind the specimen when exposed. The metal foil is then placed against ordinary $X$-ray film and the beta particle emission of the foll image exposes the X-ray film. The X-ray film is then developed using standard wet chemical photographic techniques. Several 
controllable parameters in the process include (1) choice of foil material, (2) foil thickness, (3) neutron exposure time, and (4) beam aperture.

The dimension of interest on the NR is the outside diameter of the emitter cylinder. Two UFAC-like standards were fabricated to quantify the accuracy of the NR measurement techniques. A series of radiographic trials on these standards were conducted in which the controllable parameters were varied to determine their effect on the accuracy of the emitter diameter measurement. It was possible to determine a reference set of parameters to obtain the desired accuracy.

Several NR evaluation techniques have been investigated during UFAC Batch 1 testing. These are discussed below.

Omnicon-3500. The first NR taken of the UFAC test specimen during August of 1987 was evaluated with a Bosch and Lomb Omnicon-3500 quantitative metallography Image analysis system to measure the emitter outer diameter of the film image. A serles of radiographic trials were performed to optimize a film image for use with the Omnicon. Figure 6-17 shows a photograph of the NR film taken of a UFAC specimen during the first interim examination in August, 1987.

The Omnicon measured the emitter diameter of the image along many axial positions. Unfortunately, the Omnicon's analysis process was based on the absolute transmittance properties of the radiograph film image. When the measurement window was moved axially along the emitter image, small background film density changes would introduce errors in the reported data. The Omnicon yielded inaccurate measurements, and this method has been dropped from consideration.

Microdensitometry. A microdensitometer is also being used to evaluate the radiographic image. Transmission data are collected over a contiguous array of pixels and stored on computer tape. Several methods of interpreting this data have been investigated by ANL-W, the most promising method being to compute the even moments of the image, compare this to an ideal response for a known geometric system of concentric cylinders, and 


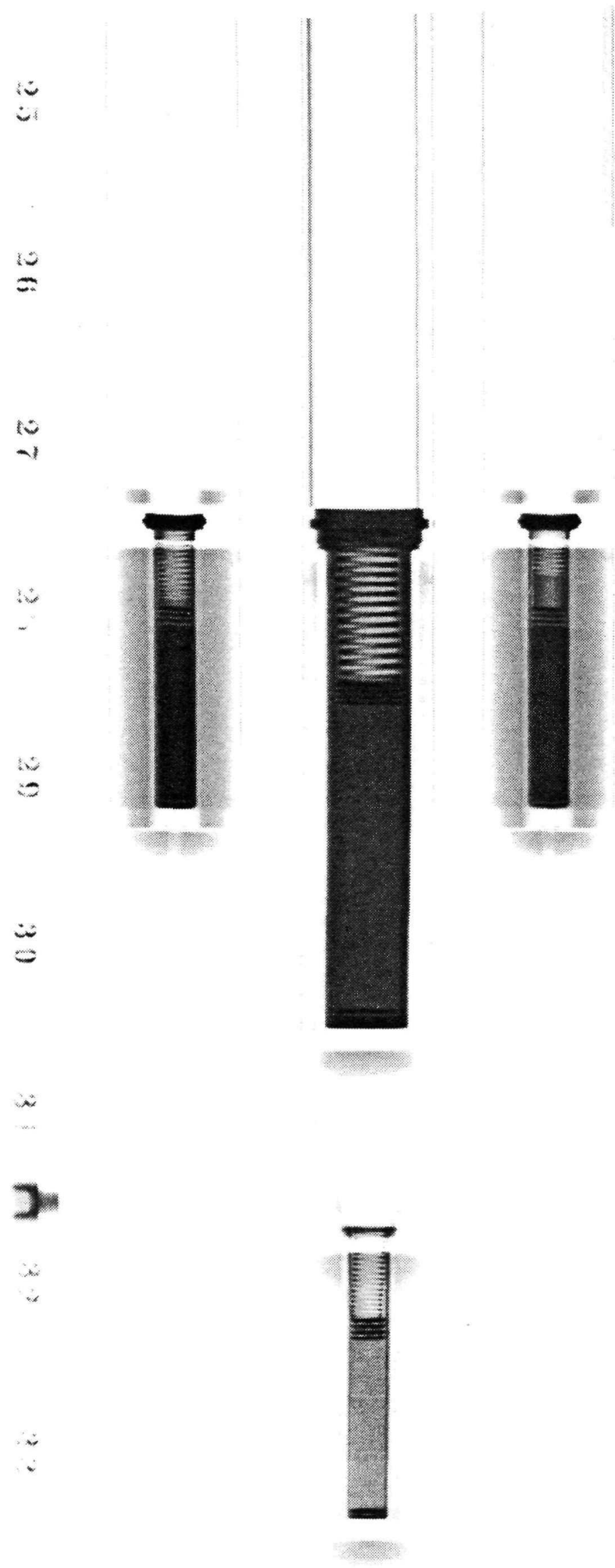

Figure 6-17 - Photograph of $60^{\circ}$ NR film taken August, 1987 by ANL-W. Specimen shown are UFAC Batch 1 specimen 10 (top left), UFAC Batch 1 prototype emitter standard (top center), UFAC Batch 1 specimen 6 (top right), and UFAC Batch 1 accelerated emitter standard (bottom center). 
solve for the image geometry. The calculated error associated with the preliminary results of this measurement technique suggest an accuracy $<.001$ inch. ANL-W is proceeding to perfect this even moments technique for NR image interpretation.

Optical Scope. A simple if tedious procedure for measuring emitter diameters from NR films has been developed at General Atomics. The NR reading is done manually using a light box behind the film image with a lox eyeplece on a traveling leadscrew. The leadscrew is attached to a digital linear transducer whose output is directed to a dedicated personal computer for data storage. Data are taken at several equally spaced elevations along the length of the emitter. Many improvements have been made during the course of the tests, including improved system setup, operation, Interpretation, and use of the same operator to operate the system and take the readings. General Atomics has been able to obtain readings from the NRs accurate to \pm 0.001 inches. This process has been used to determine diameter measurements for both the TRIGA irradiation tests and recently for the Batch 1 emftters.

\subsection{TRIGA IRRADIATION TESTING}

\subsubsection{Status}

Irradiation of fueled emitters in the TRIGA Mark F reactor is continuing. There were two scheduled shutdowns during the period: in September for neutron radiography and at the end of December during a company wide shutdown. The capsules were otherwise $100 \%$ on-line. As of April 15, the total irradiation time for capsule 1' was 19,425 hours, for capsule 2 was 24,582 hours, and for capsule 3 was 20,608 hours. A total of 193,845 hours of irradiation testing has been accumulated since the capsules were originally installed in the TRIGA in 1985. The accumulated fluence and burnup for the nine emitters is shown on Table 6-4.

Prior to the September shutdown all three emitters in capsule 1 had ceased functioning as thermionic emitters. A review of the neutron radiographs taken during the two previous outages showed that the seal 
TABLE $6-4$

TRIGA IRRADIATION TESTING

$$
\text { Fluence }{ }^{(a)} \quad \text { Burnup }{ }^{(b)}
$$

Capsule 1 (19,425 hours)

$\begin{array}{llll}\mathrm{Ce} 11 & 1 & 1.47 & 0.33 \\ \mathrm{Ce} 11 & 2 & 2.18 & 0.49 \\ \mathrm{Ce} 11 & 3 & 1.74 & 0.39\end{array}$

Capsule 2 (24,582 hours)

$\begin{array}{llll}\mathrm{Ce} 11 & 1 & 1.62 & 0.32 \\ \mathrm{Ce} 11 & 2 & 2.90 & 0.57 \\ \mathrm{Ce} 11 & 3 & 2.37 & 0.47\end{array}$

Capsule 3 (20,608 Hours)

$\begin{array}{llll}\mathrm{Ce} 11 & 1 & 2.41 & 0.42 \\ \mathrm{Cel1} & 2 & 2.60 & 0.51 \\ \mathrm{Cel1} & 3 & 2.26 & 0.45\end{array}$

(a) Fast fluence $\times 10^{21}$ neutrons $/ \mathrm{cm}^{2} \quad \mathrm{E}>0.1 \mathrm{MeV}$

(b) U-235 atom \% burnup.

TABLE 6-5

TRIGA IRRADIATION TESTING

Capsule/Diode Status

\begin{tabular}{cccc} 
Capsule & Cell & $\begin{array}{c}\text { Status as of } 4 / 15 / 88 \\
\text { Electrical }\end{array}$ & Temperature \\
\hline & & Removed from core \\
1 & 1 & Removed from core \\
1 & 2 & Removed from core \\
2 & 3 & Good & Norma1 \\
2 & 1 & Shorted & Normal \\
2 & 2 & Open & Cold \\
3 & 3 & Good & Normal \\
3 & 1 & Open & Cold \\
3 & 2 & Shorted & Cold \\
\hline
\end{tabular}


Insulators on two of the diodes had cracked and allowing helium from the primary containment to leak into the interelectrode space. The helium prevented the diodes from being ignited, and generally lowered the overall emitter temperature. The cause of the crack is due to a combination of factors: the heavy weight of the test specimen attached to the seal; the stresses caused by several reactor scrams over a period of 2 to 3 years; and a weakening of the $\mathrm{Al}_{2} \mathrm{O}_{3}$ material due to fast neutron exposure. During the outage the capsule was therefore permanently removed from the core and is currently being stored at poolside for postirradiation examination in FY-89. The status of the diodes in the other two capsules is shown in Table 6-5.

\subsubsection{TRIGA Data Reduction}

The data acquisition system for the TRIGA irradiation experiment consists of a Hewlett Packard 9000 serfes minicomputer which is capable of monitoring up to 100 variables. Although the system monitors the variables continuously they are recorded and stored on floppy discs once every hour. A total of 135 discs of stored data have been accumulated since the irradiation program began in 1985. Reduction of the data has been difficult because the HP format is not easily compatible with other large frame computer systems. A task was initiated which will convert the data from the HP floppies to the VAX system available at General Atomics for data reduction and analysis.

The data from all 135 floppies has been transferred to the VAX and has been incorporated into a spread sheet software package, RS1, for easy access and manipulation. As an example of the available data, Table 6-6 presents the RS1 spread sheet format for 10 hours worth of data taken in February, 1988. Column headings in this table represent each of the 108 on-line monitored variables. Note that at the time these data were obtained, capsule 1 had been removed from testing. Therefore, in the table the data for devices $1.1,1.2$, and 1.3 all read 0 . It can also be seen that the data acquisition system is configured to accept data for capsules $5.1,6.1$, etc. which correspond to TFE-1H1, TFE-1H2, etc. Data will appear in these columns when these TFEs are inserted in the core. Thus, columns of data for devices $5.1,6.1$, etc. all read 0 . 
TABLE 6-6

RS1 SPREAD SHEET - TRIGA DATA

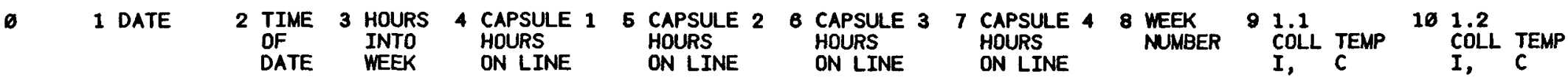

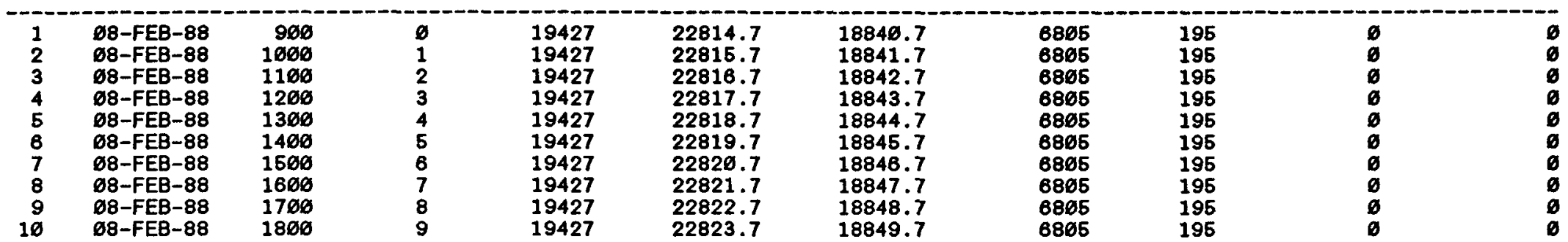

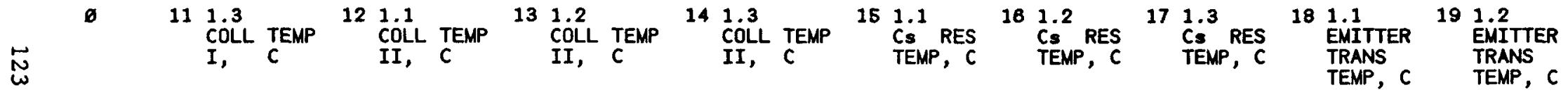

\begin{tabular}{|c|c|c|c|c|c|c|c|c|c|}
\hline $\begin{array}{r}1 \\
2 \\
3 \\
4 \\
5 \\
6 \\
7 \\
8 \\
9 \\
10\end{array}$ & $\begin{array}{l}\emptyset \\
\varnothing \\
\emptyset \\
\emptyset \\
\varnothing \\
\emptyset \\
\emptyset \\
\emptyset \\
\emptyset \\
\varnothing\end{array}$ & $\begin{array}{l}\emptyset \\
\emptyset \\
\emptyset \\
\emptyset \\
\emptyset \\
\emptyset \\
\varnothing \\
\varnothing \\
\varnothing \\
0\end{array}$ & $\begin{array}{l}\emptyset \\
\emptyset \\
\emptyset \\
\emptyset \\
\emptyset \\
\emptyset \\
\emptyset \\
\emptyset \\
\emptyset \\
\emptyset\end{array}$ & $\begin{array}{l}\emptyset \\
\emptyset \\
\emptyset \\
\emptyset \\
\emptyset \\
\emptyset \\
0 \\
\emptyset \\
\emptyset \\
0\end{array}$ & $\begin{array}{l}\emptyset \\
\emptyset \\
\emptyset \\
\emptyset \\
\emptyset \\
\emptyset \\
\emptyset \\
\emptyset \\
\emptyset \\
\emptyset\end{array}$ & $\begin{array}{l}0 \\
0 \\
0 \\
0 \\
0 \\
0 \\
0 \\
0 \\
0 \\
0\end{array}$ & $\begin{array}{l}\emptyset \\
\emptyset \\
\emptyset \\
\emptyset \\
\emptyset \\
\emptyset \\
\emptyset \\
\emptyset \\
\emptyset \\
\emptyset\end{array}$ & $\begin{array}{l}0 \\
0 \\
0 \\
0 \\
0 \\
0 \\
0 \\
0 \\
D \\
D\end{array}$ & $\begin{array}{l}0 \\
0 \\
0 \\
0 \\
0 \\
0 \\
0 \\
0 \\
0 \\
0\end{array}$ \\
\hline
\end{tabular}

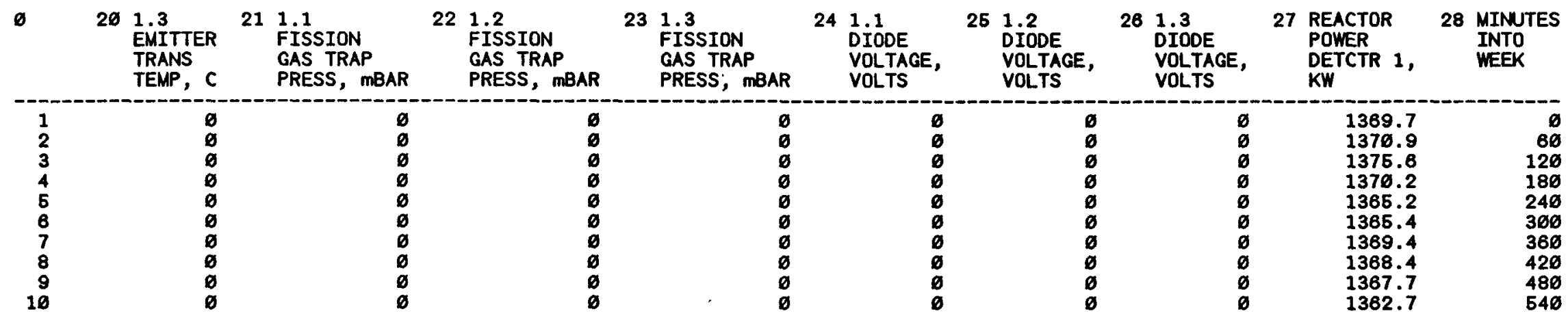


TABLE 6-6

RS 1 SPREAD SHEET - TRIGA DATA (CONT)

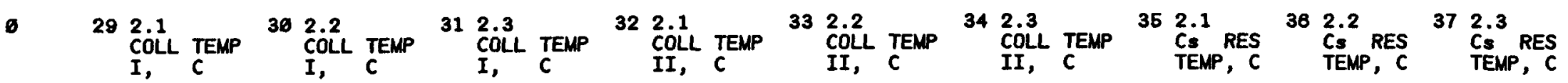

\begin{tabular}{|c|c|c|c|c|c|c|c|c|c|}
\hline $\begin{array}{r}1 \\
2 \\
3 \\
4 \\
5 \\
6 \\
7 \\
8 \\
9 \\
10\end{array}$ & $\begin{array}{l}457.4 \\
457.2 \\
457.0 \\
456.9 \\
456.8 \\
456.3 \\
467.3 \\
457.1 \\
458.5 \\
456.8\end{array}$ & $\begin{array}{l}586.2 \\
588.4 \\
686.5 \\
586.0 \\
587.9 \\
587.1 \\
587.4 \\
586.8 \\
587.6 \\
586.5\end{array}$ & $\begin{array}{l}689.8 \\
609.1 \\
509.3 \\
689.1 \\
688.8 \\
608.9 \\
509.3 \\
609.1 \\
609.2 \\
509.7\end{array}$ & $\begin{array}{l}456.4 \\
456.2 \\
456.0 \\
456.9 \\
455.9 \\
456.2 \\
456.3 \\
456.1 \\
456.5 \\
456.8\end{array}$ & $\begin{array}{l}575.7 \\
578.1 \\
576.6 \\
575.6 \\
577.6 \\
578.8 \\
577.6 \\
576.3 \\
576.6 \\
576.0\end{array}$ & $\begin{array}{l}509.7 \\
589.2 \\
509.4 \\
589.1 \\
508.8 \\
509.8 \\
569.3 \\
509.2 \\
569.2 \\
509.6\end{array}$ & $\begin{array}{l}334.7 \\
334.9 \\
334.8 \\
334.8 \\
334.1 \\
334.3 \\
334.3 \\
334.3 \\
334.5 \\
334.5\end{array}$ & $\begin{array}{l}336.1 \\
336.1 \\
336.1 \\
336.1 \\
336.1 \\
336.1 \\
336.1 \\
336.1 \\
336.2 \\
336.0\end{array}$ & $\begin{array}{l}336.9 \\
336.1 \\
336.1 \\
336.0 \\
336.9 \\
337.5 \\
337.5 \\
338.1 \\
338.0 \\
337.4\end{array}$ \\
\hline
\end{tabular}

\begin{tabular}{|c|c|c|c|c|c|c|c|c|c|c|c|c|c|c|c|c|c|c|}
\hline$\cdot 0$ & 38 & $\begin{array}{l}2.1 \\
\text { EMITTER } \\
\text { TRANS } \\
\text { TEMP, C }\end{array}$ & 39 & $\begin{array}{l}2.2 \\
\text { EMITTER } \\
\text { TRANS } \\
\text { TEMP, C }\end{array}$ & 40 & $\begin{array}{l}2.3 \\
\text { EMITTER } \\
\text { TRANS } \\
\text { TEMP, C }\end{array}$ & $\begin{array}{rl}41 & 2 \\
F \\
G \\
P\end{array}$ & $\begin{array}{l}2.1 \\
\text { FISSION } \\
\text { GAS TRAP } \\
\text { PRESS, mBA }\end{array}$ & 42 & $\begin{array}{l}2.2 \\
\text { FISSION } \\
\text { GAS TRAP } \\
\text { PRESS, mBAR }\end{array}$ & $\begin{array}{ll}43 & 2.3 \\
\text { FISSIO } \\
\text { GAS TR } \\
\text { PRESS, }\end{array}$ & $\begin{array}{l}\text { DN } \\
\text { RAP } \\
\text { mBAR }\end{array}$ & 44 & $\begin{array}{l}2.1 \\
\text { DIODE } \\
\text { VOLTAGE, } \\
\text { VOLTS }\end{array}$ & 45 & $\begin{array}{l}2.2 \\
\text { DIODE } \\
\text { VOLTAGE, } \\
\text { VOLTS }\end{array}$ & & $\begin{array}{l}2.3 \\
\text { DIODE } \\
\text { VOLTAGE, } \\
\text { VOLTS }\end{array}$ \\
\hline \multirow[t]{3}{*}{$\stackrel{N}{\sim}$} & & $\begin{array}{l}423.2 \\
422.4 \\
422.9 \\
421.3 \\
423.0 \\
420.6 \\
424.0 \\
421.8 \\
421.9 \\
421.9\end{array}$ & & $\begin{array}{l}525.0 \\
\mathbf{5 2 5 . 5} \\
\mathbf{5 2 5 . 1} \\
\mathbf{5 2 4 . 2} \\
526.1 \\
\mathbf{5 2 5 . 5} \\
\mathbf{5 2 5 . 8} \\
\mathbf{5 2 4 . 4} \\
\mathbf{5 2 5 . 1} \\
\mathbf{5 2 5 . 0}\end{array}$ & & $\begin{array}{l}562.8 \\
560.5 \\
561.5 \\
561.5 \\
560.8 \\
562.2 \\
560.9 \\
561.8 \\
561.1 \\
562.1\end{array}$ & & $\begin{array}{l}19.5 \\
19.5 \\
19.4 \\
19.5 \\
19.4 \\
19.5 \\
19.5 \\
19.4 \\
19.4 \\
19.4\end{array}$ & & $\begin{array}{l}61.08 \\
61.01 \\
61.86 \\
61.04 \\
61.86 \\
61.10 \\
61.84 \\
61.03 \\
6 \varnothing .93 \\
61.84\end{array}$ & & $\begin{array}{l}37.68 \\
37.68 \\
37.66 \\
37.09 \\
37.68 \\
37.10 \\
37.19 \\
37.03 \\
37.63 \\
37.63\end{array}$ & & $\begin{array}{l}-\emptyset .280 \\
-0.278 \\
-\varnothing .278 \\
-\varnothing .279 \\
-\varnothing .275 \\
-\varnothing .276 \\
-\varnothing .271 \\
-\varnothing .274 \\
-0.275 \\
-\varnothing .275\end{array}$ & & $\begin{array}{l}-0.361 \\
-0.367 \\
-0.368 \\
-0.363 \\
-\emptyset .369 \\
-0.370 \\
-0.364 \\
-0.365 \\
-0.362 \\
-0.362\end{array}$ & & $\begin{array}{l}\emptyset .849 \\
6.849 \\
\emptyset .847 \\
\varnothing .847 \\
\emptyset .846 \\
\emptyset .844 \\
\emptyset .847 \\
\emptyset .848 \\
\varnothing .848 \\
\varnothing .849\end{array}$ \\
\hline & 47 & $\begin{array}{l}\text { BUS BAR } \\
\text { WATER } \\
\text { PRESS, } \\
\text { psig }\end{array}$ & 48 & $\begin{array}{l}\text { CURRENT } \\
\text { JUNCTION } \\
\text { PROBE } \\
\text { VOLTAGE, }\end{array}$ & v & 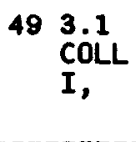 & TEMP & 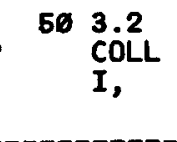 & $\begin{array}{l}\text { TEMP } \\
\text { C }\end{array}$ & $\begin{array}{l}513.3 \\
\text { COLL TEMP } \\
\text { I, C }\end{array}$ & 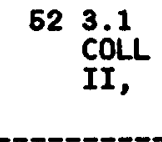 & $\underset{C}{\text { TEMP }}$ & 53 & $\begin{array}{l}3.2 \\
\text { COLL TEMP } \\
\text { II, } C\end{array}$ & 54 & $\begin{array}{l}3.3 \\
\text { COLL TEMP } \\
\text { II, C }\end{array}$ & 56 & $\begin{array}{l}3.1 \\
\text { Cs RES } \\
\text { TEMP, C }\end{array}$ \\
\hline & & $\begin{array}{l}7.719 \\
7.784 \\
7.659 \\
7.660 \\
7.698 \\
7.743 \\
7.778 \\
7.694 \\
7.731 \\
7.641\end{array}$ & & & $\begin{array}{l}0 \\
0 \\
0 \\
0 \\
0 \\
0 \\
0 \\
0 \\
0 \\
0\end{array}$ & & $\begin{array}{l}655.3 \\
555.3 \\
555.7 \\
554.7 \\
554.4 \\
564.1 \\
565.5 \\
564.1 \\
564.4 \\
564.6\end{array}$ & 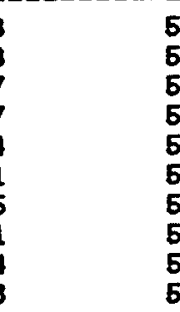 & $\begin{array}{l}553.4 \\
553.1 \\
563.3 \\
552.7 \\
562.1 \\
553.0 \\
552.9 \\
552.9 \\
552.7 \\
553.1\end{array}$ & $\begin{array}{l}529.0 \\
628.8 \\
529.1 \\
528.7 \\
528.0 \\
528.8 \\
529.7 \\
528.2 \\
528.3 \\
628.9\end{array}$ & & $\begin{array}{l}555.3 \\
556.3 \\
555.7 \\
654.8 \\
554.8 \\
554.1 \\
555.4 \\
554.1 \\
554.3 \\
564.7\end{array}$ & & $\begin{array}{l}547.5 \\
547.2 \\
547.5 \\
546.8 \\
546.3 \\
547.4 \\
547.1 \\
546.9 \\
546.8 \\
547.3\end{array}$ & & $\begin{array}{l}626.0 \\
525.7 \\
526.1 \\
525.9 \\
525.9 \\
525.9 \\
526.7 \\
525.3 \\
525.4 \\
526.1\end{array}$ & & $\begin{array}{l}334.6 \\
334.6 \\
334.6 \\
334.8 \\
334.5 \\
334.7 \\
334.7 \\
334.8 \\
334.5 \\
334.5\end{array}$ \\
\hline
\end{tabular}


TABLE 6-6

RSI SPREAD SHEET - TRIGA DATA (CONT)

\begin{tabular}{|c|c|c|c|c|c|c|c|c|c|}
\hline$\theta$ & $\begin{array}{l}66 \begin{array}{l}3.2 \\
C S\end{array} \text { RES } \\
\text { TEMP, C }\end{array}$ & $\begin{array}{l}67.3 \\
\text { CS RES } \\
\text { TEMP, C }\end{array}$ & $\begin{array}{l}58 \text { 3.1 } \\
\text { EMITTER } \\
\text { TRANS } \\
\text { TEMP, C }\end{array}$ & $\begin{array}{l}59 \text { 3.2 } \\
\text { EMITTER } \\
\text { TRANS } \\
\text { TEMP, C }\end{array}$ & $\begin{array}{l}30.3 \\
\text { EMITTER } \\
\text { TRANS } \\
\text { TEMP, C }\end{array}$ & $\begin{array}{l}31 \text { 3.1 } \\
\text { FISSION } \\
\text { GAS TRAP } \\
\text { PRESS, mBAR }\end{array}$ & $\begin{array}{l}62 \text { 3.2 } \\
\text { FISSION } \\
\text { GAS TRAP } \\
\text { PRESS, mBAR }\end{array}$ & $\begin{array}{ll}63 & 3.3 \\
\text { FISSION } \\
\text { GAS TRAP } \\
\text { PRESS, mBAR }\end{array}$ & $\begin{array}{l}34.1 \\
\text { DIODE } \\
\text { VOLTAGE, } \\
\text { VOLTS }\end{array}$ \\
\hline $\begin{array}{r}1 \\
2 \\
3 \\
4 \\
5 \\
6 \\
7 \\
8 \\
9 \\
10\end{array}$ & $\begin{array}{l}335.5 \\
335.1 \\
335.1 \\
335.0 \\
335.4 \\
334.9 \\
335.4 \\
335.6 \\
335.2 \\
335.7\end{array}$ & $\begin{array}{l}334.9 \\
335.1 \\
335.0 \\
335.2 \\
336.5 \\
335.6 \\
335.3 \\
335.2 \\
335.4 \\
335.3\end{array}$ & $\begin{array}{l}384.7 \\
384.8 \\
384.8 \\
384.3 \\
384.2 \\
384.1 \\
384.4 \\
383.8 \\
384.1 \\
383.9\end{array}$ & $\begin{array}{l}572.1 \\
571.7 \\
572.0 \\
571.4 \\
671.0 \\
571.6 \\
671.8 \\
571.1 \\
571.4 \\
671.7\end{array}$ & $\begin{array}{l}566.1 \\
565.2 \\
565.7 \\
565.1 \\
565.1 \\
565.8 \\
566.1 \\
564.6 \\
565.8 \\
565.5\end{array}$ & $\begin{array}{l}38.49 \\
38.48 \\
38.48 \\
38.52 \\
38.54 \\
38.54 \\
38.63 \\
38.49 \\
38.48 \\
38.49\end{array}$ & $\begin{array}{l}0.08 \\
0.07 \\
0.07 \\
0.08 \\
0.07 \\
0.06 \\
0.08 \\
0.07 \\
0.07 \\
0.06\end{array}$ & $\begin{array}{l}28.39 \\
28.39 \\
28.36 \\
28.36 \\
28.38 \\
28.36 \\
28.46 \\
28.28 \\
28.27 \\
28.29\end{array}$ & $\begin{array}{l}-\varnothing .294 \\
-\varnothing .291 \\
-\varnothing .292 \\
-\varnothing .294 \\
-\varnothing .160 \\
-\varnothing .222 \\
-\varnothing .214 \\
-\varnothing .210 \\
-\varnothing .205 \\
-\varnothing .196\end{array}$ \\
\hline
\end{tabular}

6653.2

DIODE VOLTAGE, VOLTS
663.3

DIODE

VOLTAGE, VOLTS
67 PWR SPLY $\quad 68 \quad 695.1$

COOLANT WTR psig

\begin{tabular}{|c|c|c|c|c|c|c|c|c|c|}
\hline $\begin{array}{r}1 \\
2 \\
3 \\
4 \\
5 \\
6 \\
7 \\
8 \\
9 \\
10\end{array}$ & $\begin{array}{l}\emptyset .308 \\
\emptyset .363 \\
\emptyset .308 \\
0.305 \\
0.302 \\
0.307 \\
0.308 \\
0.305 \\
0.305 \\
0.306\end{array}$ & $\begin{array}{l}-0.001 \\
-0.001 \\
-0.001 \\
-0.001 \\
-0.001 \\
-0.001 \\
0.000 \\
-\varnothing .001 \\
-\varnothing .001 \\
-\varnothing .001\end{array}$ & $\begin{array}{l}18.872 \\
18.868 \\
18.953 \\
18.948 \\
18.921 \\
18.845 \\
18.928 \\
18.969 \\
18.792 \\
18.908\end{array}$ & $\begin{array}{l}1133 \\
1142 \\
1145 \\
1155 \\
1172 \\
1191 \\
1268 \\
1218 \\
1227 \\
1234\end{array}$ & $\begin{array}{l}0 \\
0 \\
0 \\
0 \\
0 \\
0 \\
0 \\
0 \\
0 \\
0\end{array}$ & $\begin{array}{l}0 \\
0 \\
0 \\
0 \\
0 \\
0 \\
0 \\
0 \\
0 \\
0\end{array}$ & $\begin{array}{l}0 \\
0 \\
0 \\
0 \\
0 \\
0 \\
0 \\
0 \\
0 \\
0\end{array}$ & $\begin{array}{l}0 \\
0 \\
0 \\
0 \\
0 \\
0 \\
0 \\
0 \\
0 \\
0\end{array}$ & $\begin{array}{l}0 \\
0 \\
0 \\
0 \\
0 \\
0 \\
0 \\
0 \\
0 \\
0\end{array}$ \\
\hline
\end{tabular}

766.1

COLL
715.1

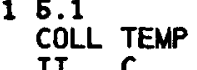

726.1 COLL TEMP II, C

(

$$
746.1
$$

765.1

$76{ }^{6.1}$ RES

$775.1 \quad 786.1$

$\begin{array}{ll}78 \text { 6.1 } & 79 \text { E.1 } \\ \text { EMITTER } & \text { DIODE }\end{array}$

806.1

DiODE
VOLAGE,
VOLTS

816.1

SHEATH

826.1 STEM TEMP, CS RES TEMP, C TRANS

1
2
3
4
5
6
7
8
9
10

$\begin{array}{ll}0 & 0 \\ 0 & 0 \\ 0 & 0 \\ 0 & 0 \\ 0 & 0 \\ 0 & 0 \\ 0 & 0 \\ 0 & 0 \\ 0 & 0 \\ 0 & 0\end{array}$

$\begin{array}{ll}0 & 0 \\ 0 & 0 \\ 0 & 0 \\ 0 & 0 \\ 0 & 0 \\ 0 & 0 \\ 0 & 0 \\ 0 & 0 \\ 0 & 0\end{array}$

$\begin{array}{lll}0 & 0 & 0 \\ 0 & 0 & 0 \\ 0 & 0 & 0 \\ 0 & 0 & 0 \\ 0 & 0 & 0 \\ 0 & 0 & 0 \\ 0 & 0 & 0 \\ 0 & 0 & 0 \\ 0 & 0 & 0 \\ 0 & 0 & 0\end{array}$

$\begin{array}{ll}0 & 0 \\ 0 & 0 \\ 0 & 0 \\ 0 & 0 \\ 0 & 0 \\ 0 & 0 \\ 0 & 0 \\ 0 & 0\end{array}$

$\begin{array}{ll}0 & 0 \\ 0 & 0 \\ 0 & 0 \\ 0 & 0 \\ 0 & 0 \\ 0 & 0 \\ 0 & 0 \\ 0 & 0 \\ 0 & 0\end{array}$

5.1 STEM TEMP, 
TABLE 6-6

RSI SPREAD SHEET - TRIGA DATA (CONT)

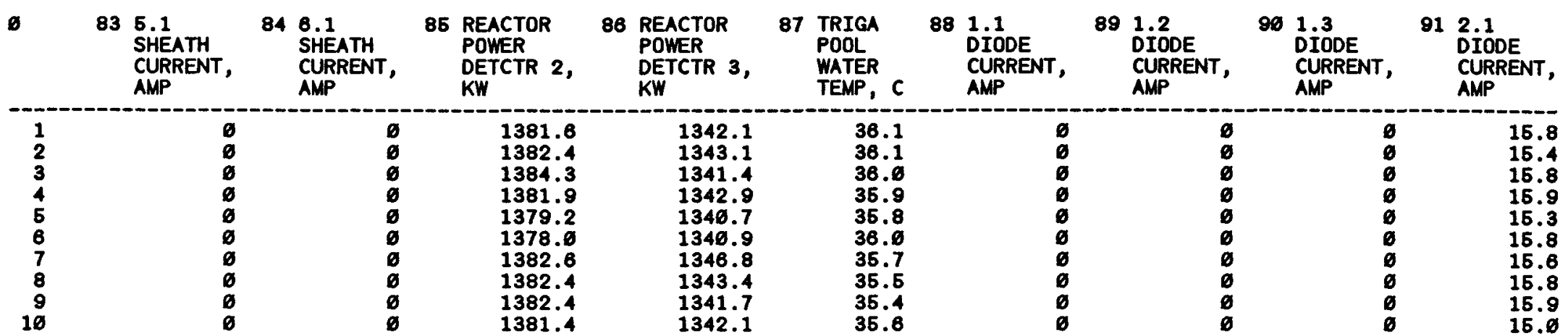

\begin{tabular}{|c|c|c|c|c|c|c|c|c|c|c|}
\hline 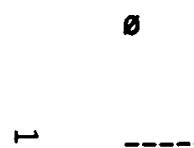 & $\begin{array}{ll}92 & 2.2 \\
\text { DIODE } & \\
\text { CURRENT, } & \\
\text { AMP } & \end{array}$ & 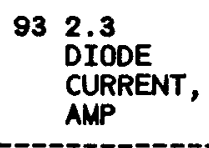 & 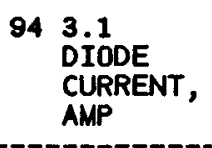 & 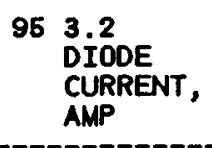 & $\begin{array}{ll}98 & 3.3 \\
& \text { DIODE } \\
& \text { CURRENT, } \\
& \text { AMP }\end{array}$ & $\begin{array}{l}97 \text { LOAD WATER } \\
\text { TEMP FLAG } \\
\sigma=0 . K . \\
1=\text { PROBLEM }\end{array}$ & $\begin{array}{l}98.1 \\
\text { DIODE } \\
\text { CURRENT, } \\
\text { AMP }\end{array}$ & $\begin{array}{l}99 \text {. } 1 \\
\text { DIODE } \\
\text { CURRENT, } \\
\text { AMP }\end{array}$ & 100 & $\begin{array}{l}\text { UPPER SEC. } \\
\text { CONT. PRESS } \\
\text { CAPSULE 1, } \\
\text { PSIO }\end{array}$ \\
\hline $\begin{array}{r}1 \\
2 \\
3 \\
4 \\
5 \\
6 \\
7 \\
8 \\
9 \\
10\end{array}$ & $\begin{array}{l}61.4 \\
61.3 \\
61.5 \\
61.6 \\
61.6 \\
61.7 \\
61.8 \\
61.6 \\
61.5 \\
62.8\end{array}$ & $\begin{array}{l}-0.1 \\
-0.1 \\
-0.2 \\
-0.1 \\
-0.1 \\
-0.1 \\
-0.1 \\
-0.2 \\
-0.1 \\
-0.1\end{array}$ & $\begin{array}{l}158.5 \\
157.6 \\
157.4 \\
167.5 \\
158.6 \\
167.9 \\
158.3 \\
158.7 \\
169.3 \\
159.8\end{array}$ & $\begin{array}{l}-0.1 \\
-0.1 \\
-0.2 \\
-0.1 \\
-0.2 \\
-0.2 \\
-0.1 \\
-0.2 \\
-0.1 \\
-0.1\end{array}$ & $\begin{array}{l}-0.1 \\
-\emptyset .1 \\
-0.2 \\
-0.1 \\
-\emptyset .1 \\
-\emptyset .2 \\
-\emptyset .1 \\
-\emptyset .1 \\
-\emptyset .2 \\
-\emptyset .1\end{array}$ & $\begin{array}{l}0 \\
0 \\
0 \\
0 \\
0 \\
0 \\
0 \\
0 \\
0 \\
0\end{array}$ & $\varnothing$ & $\begin{array}{l}0 \\
0 \\
0 \\
0 \\
0 \\
0 \\
0 \\
0 \\
0 \\
0\end{array}$ & & \\
\hline
\end{tabular}

\begin{tabular}{|c|c|c|c|c|c|c|c|c|c|c|c|c|c|c|c|}
\hline 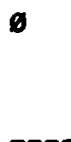 & 101 & $\begin{array}{l}\text { UPPER SEC. } \\
\text { CONT. PRESS } \\
\text { CAPSULE 2, } \\
\text { PSia }\end{array}$ & 102 & $\begin{array}{l}\text { UPPER SEC. } \\
\text { CONT. PRESS } \\
\text { CAPSULE } 3 \text {, } \\
\text { psia }\end{array}$ & 103 & $\begin{array}{l}\text { SEC CONT. } \\
\text { PRESS } \\
\text { CAPSULE } 5 \text {, } \\
\text { psia }\end{array}$ & 104 & $\begin{array}{l}\text { LOWER SEC. } \\
\text { CONT. PRESS } \\
\text { CAPSULE 1, } \\
\text { psia }\end{array}$ & 105 & $\begin{array}{l}\text { LOWER SEC. } \\
\text { CONT. PRESS } \\
\text { CAPSULE 2, } \\
\text { psia }\end{array}$ & 168 & $\begin{array}{l}\text { LOWER SEC. } \\
\text { CONT. PRESS } \\
\text { CAPSULE } 3 \text {, } \\
\text { psia }\end{array}$ & 107 & $\begin{array}{l}\text { SEC. CONT. } \\
\text { PRESS } \\
\text { CAPSULE 6, } \\
\text { psia }\end{array}$ & 168 \\
\hline $\begin{array}{r}1 \\
2 \\
3 \\
4 \\
5 \\
6 \\
7 \\
8 \\
9 \\
10\end{array}$ & & $\begin{array}{l}12.419 \\
12.436 \\
12.410 \\
12.412 \\
12.400 \\
12.426 \\
12.416 \\
12.399 \\
12.387 \\
12.401\end{array}$ & & $\begin{array}{l}13.036 \\
13.036 \\
13.043 \\
13.056 \\
13.070 \\
13.055 \\
13.075 \\
13.024 \\
13.023 \\
13.022\end{array}$ & & $\begin{array}{l}\emptyset \\
\emptyset \\
\emptyset \\
0 \\
0 \\
0 \\
\emptyset \\
\emptyset \\
\emptyset \\
\emptyset\end{array}$ & & $\begin{array}{l}\emptyset \\
\emptyset \\
\emptyset \\
\emptyset \\
\emptyset \\
0 \\
\emptyset \\
\emptyset \\
\emptyset \\
\emptyset\end{array}$ & & $\begin{array}{l}2.577 \\
2.684 \\
2.691 \\
2.613 \\
2.620 \\
2.612 \\
2.610 \\
2.618 \\
2.615 \\
2.609\end{array}$ & & $\begin{array}{l}1.471 \\
1.468 \\
1.468 \\
1.475 \\
1.468 \\
1.472 \\
1.467 \\
1.471 \\
1.468 \\
1.468\end{array}$ & & $\begin{array}{l}0 \\
0 \\
0 \\
0 \\
0 \\
0 \\
0 \\
0 \\
0\end{array}$ & $\begin{array}{r}19427.0 \\
22982.7 \\
19008.7 \\
6805 . \varnothing \\
0.0 \\
0.0 \\
0.0 \\
0.0\end{array}$ \\
\hline
\end{tabular}


Data analysis has been performed to insure that data files have been transferred and interpreted correctly from their original recorded format. Efforts are proceeding to compile all raw data parameters into graphical output for each test capsule and for the sheath insulators. This will facilitate visual interpretation of three years of data points. Data on reactor scrams, TRIGA core composition changes, control rod position, etc. will be added to the ordered data base. Estimates for emitter power and temperature will then be inferred and used in LIFE-4 analyses.

\subsubsection{LIFE-4 Analyses}

Emitter distortion has been estimated and compared with neutron radiography data. The latest graphs including data from the February and October, 1987 shutdowns are shown in Figs. 6-18 through 6-26. Only for diode 3.1, which is deforming in an "hourglass" shape, are the calculated distortions significantly less than measured.

\section{$\underline{\text { References }}$}

1. TFE Verification Program, Semiannual Report for the Period Ending March 31, 1987, GA-A18780, Apri1, 1987.

2. TFE Verification Program, Semiannual Report for the Period Ending September 30, 1987, GA-A19115, March, 1988.

3. IIFE-4.

4. IIFE-4 Modification. 
TRIGA Irradiation Testing

Capsule 1 Diode 1

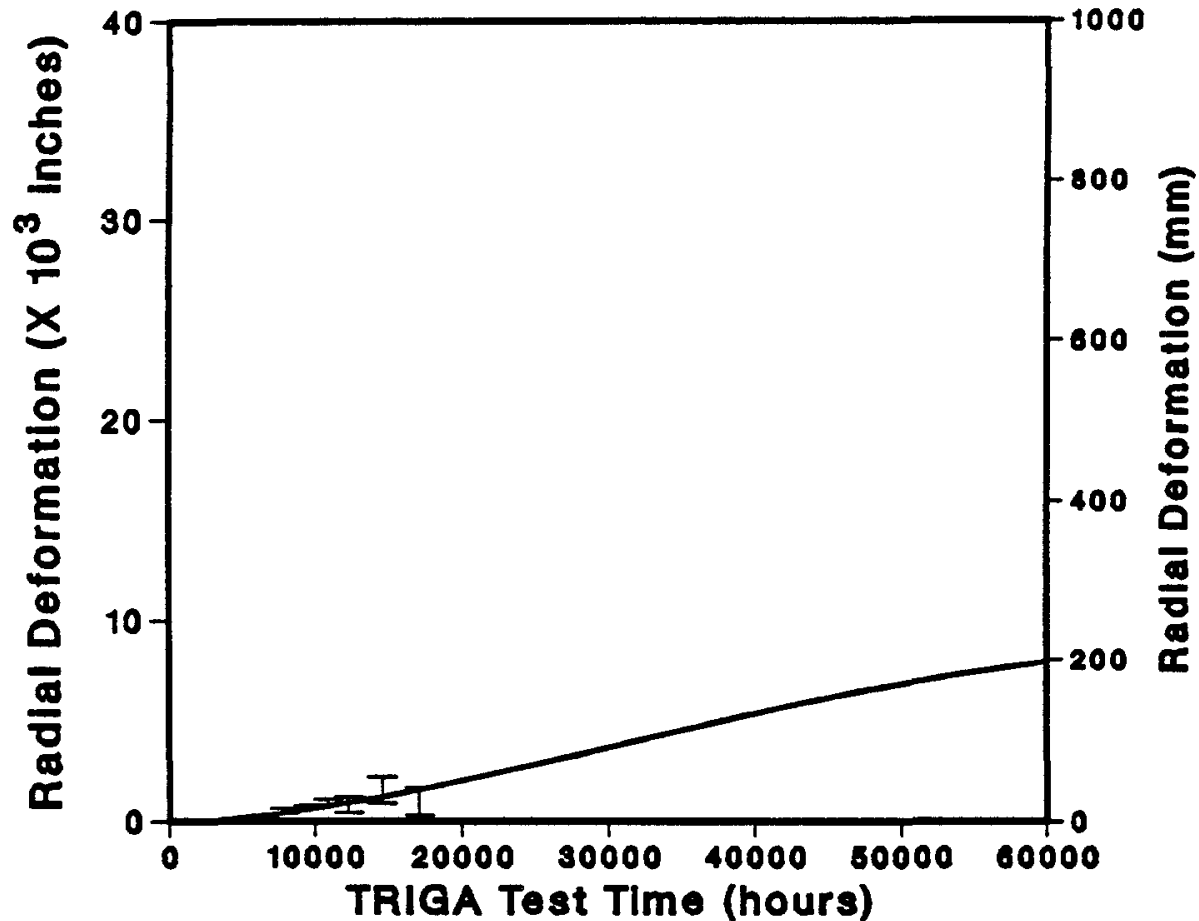

(Equivalent Space Reactor Filght Time (hours))
Emitter OD

Emitter Thickness

Irrad Time

Emitter Temp

LIFE-IV Calculated

- Measured Rango
1.100 in

0.100 in $17090 \mathrm{hr}$ $1750 \mathrm{~K}$

\section{Local Emitter Distortion}

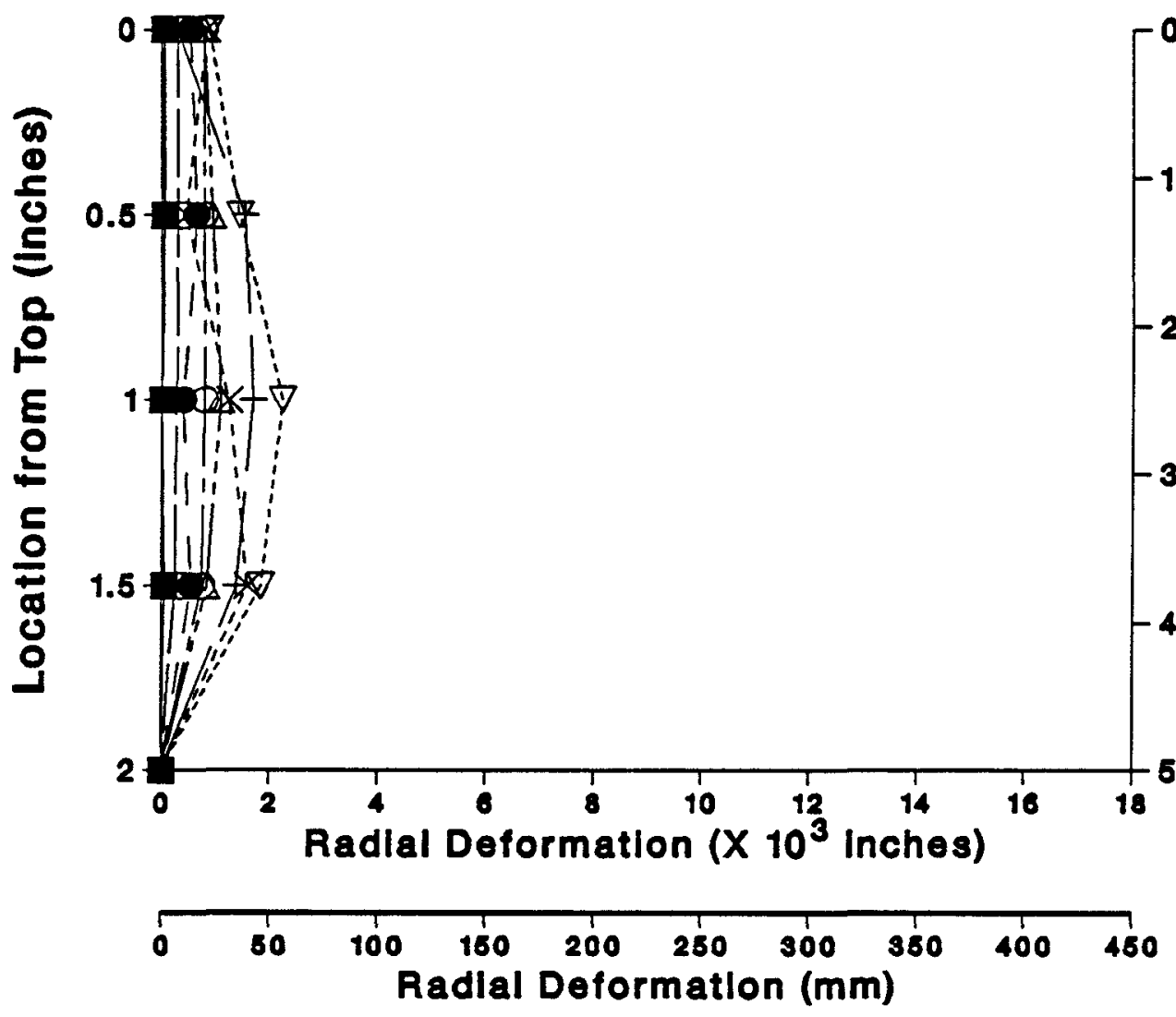




\section{TRIGA Irradiation Testing Capsule 1 Diode 2}

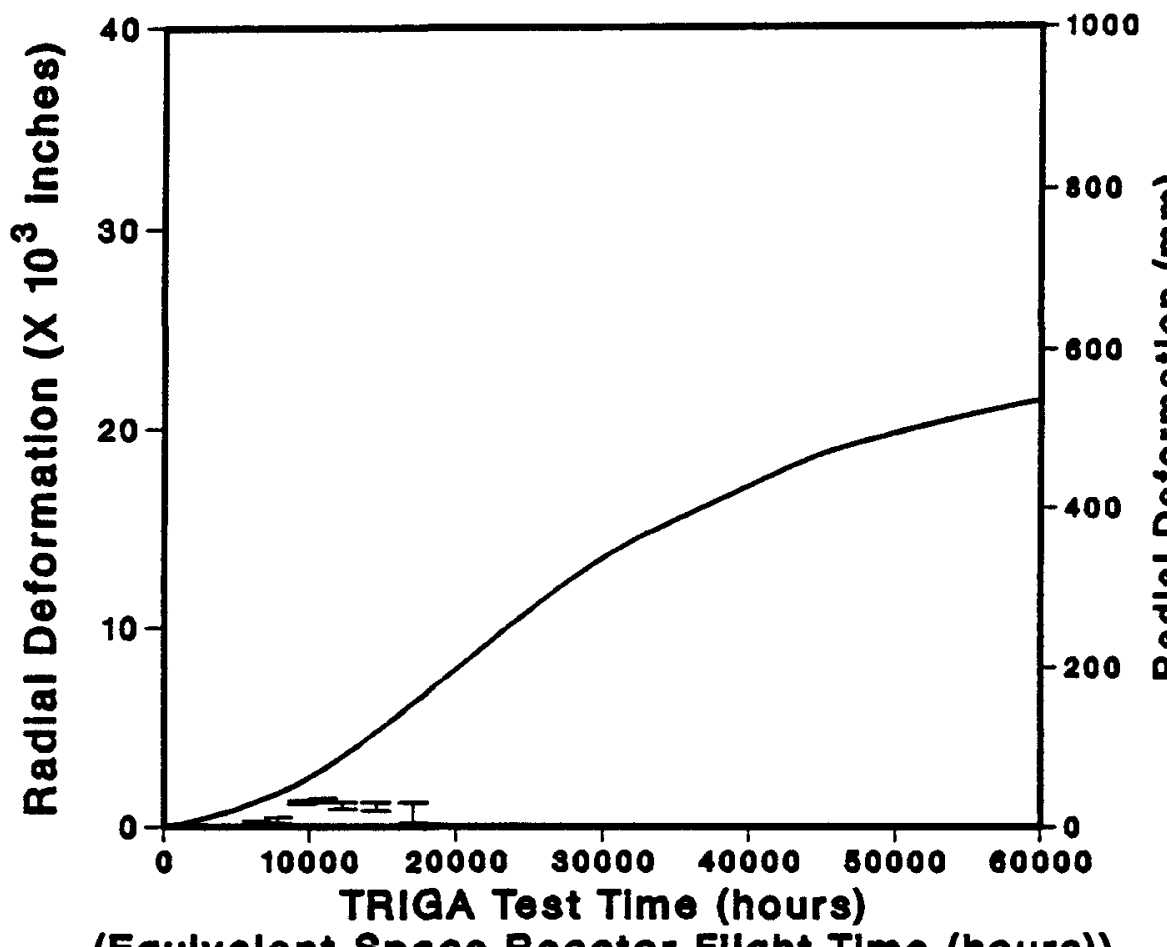

Emitter OD $\quad 1.100$ in Emitter Thickness 0.100 in Irrad Time $17090 \mathrm{hr}$ Emitter Temp $1850 \mathrm{~K}$

\section{UIFE-IV Calculated}

- Measured Range

(Equlvalent Space Reactor Filght Time (hours))

\section{Local Emitter Distortion}

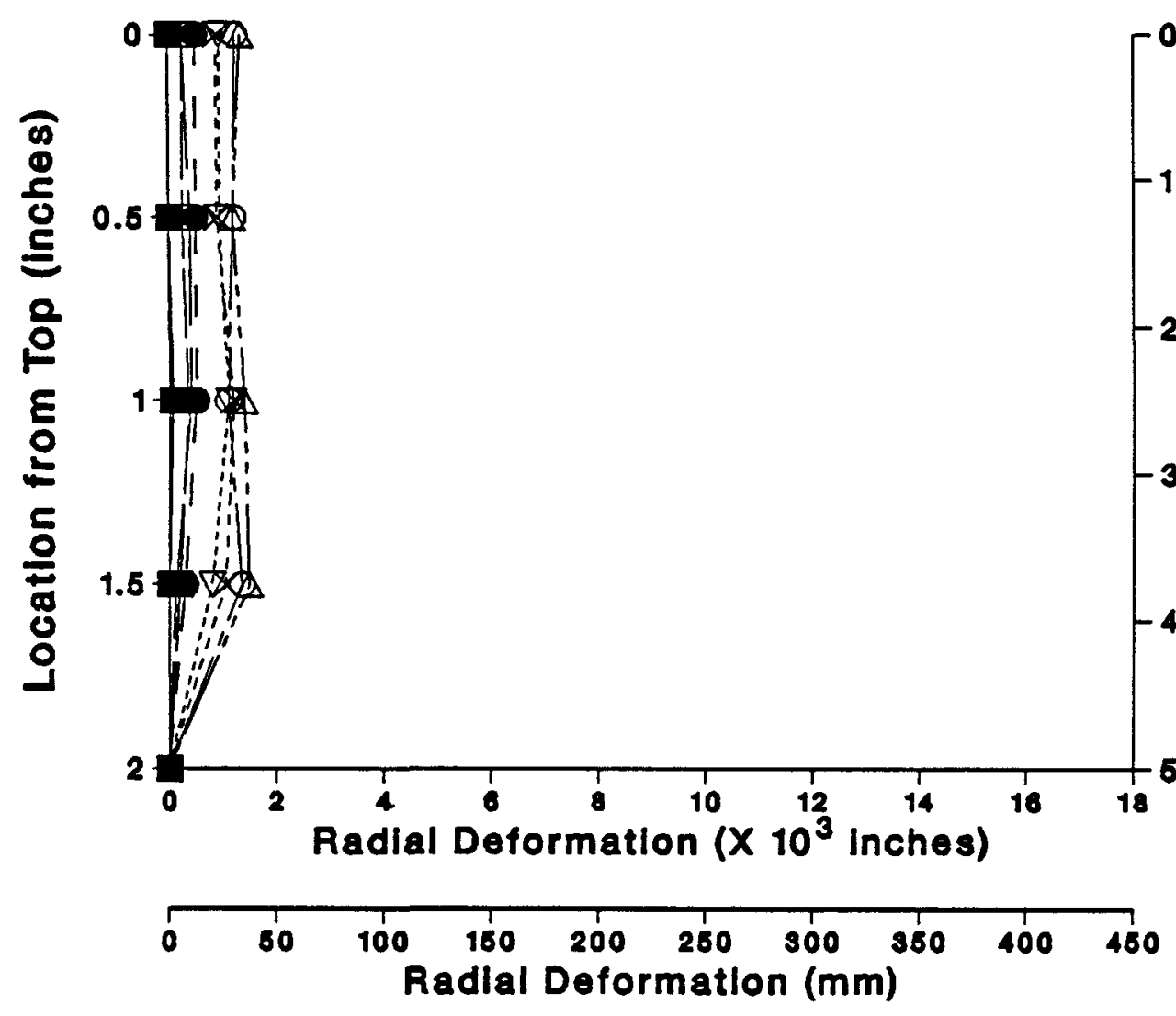


TRIGA Irradiation Testing

Capsule 1 Diode 3

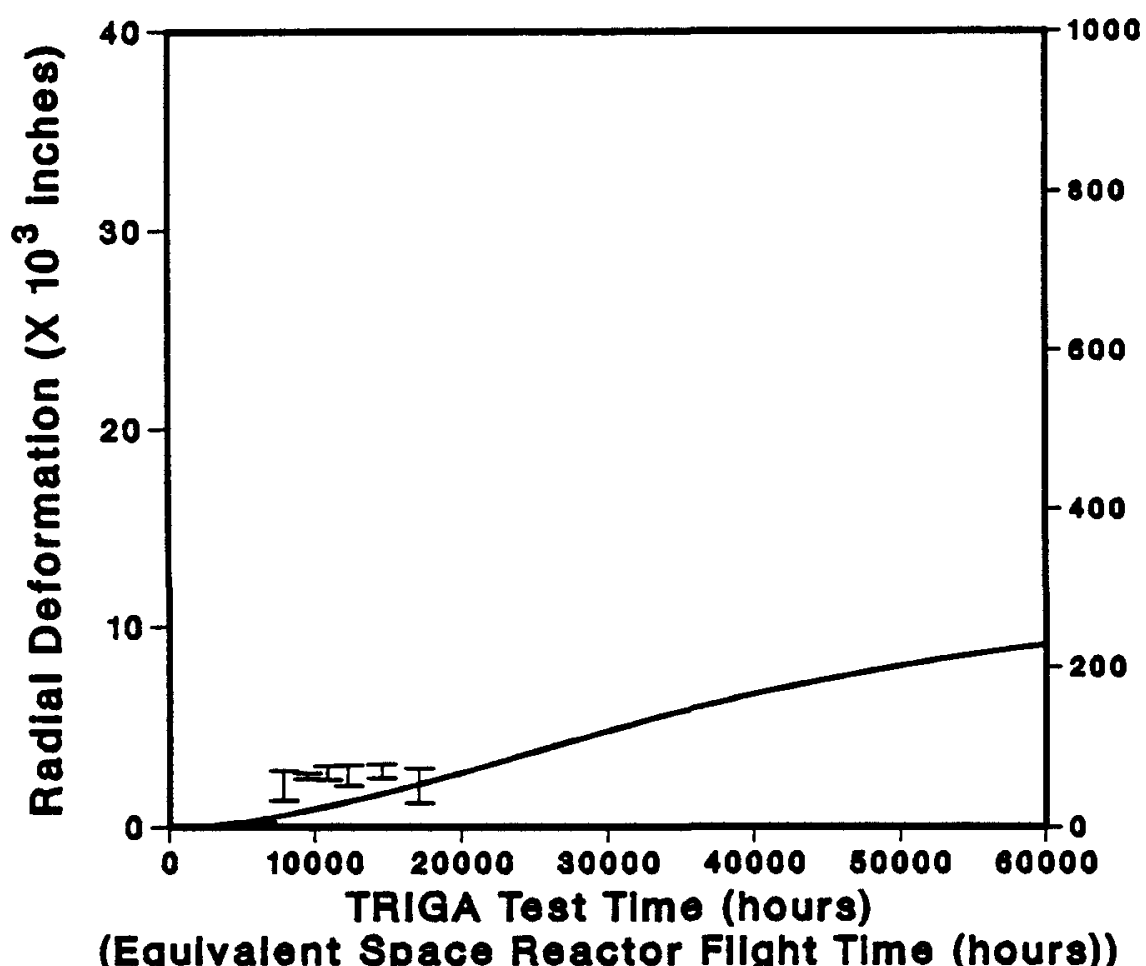

Emitter OD $\quad 1.100 \mathrm{in}$

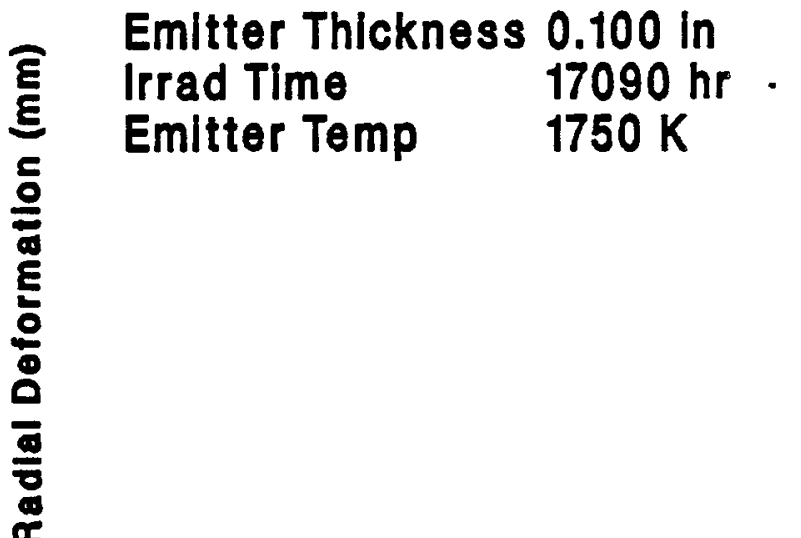

LIFE-IV Calculated

- Measured Range

(Equivalent Space Reactor Filght Time (hours))

\section{Local Emitter Distortion}

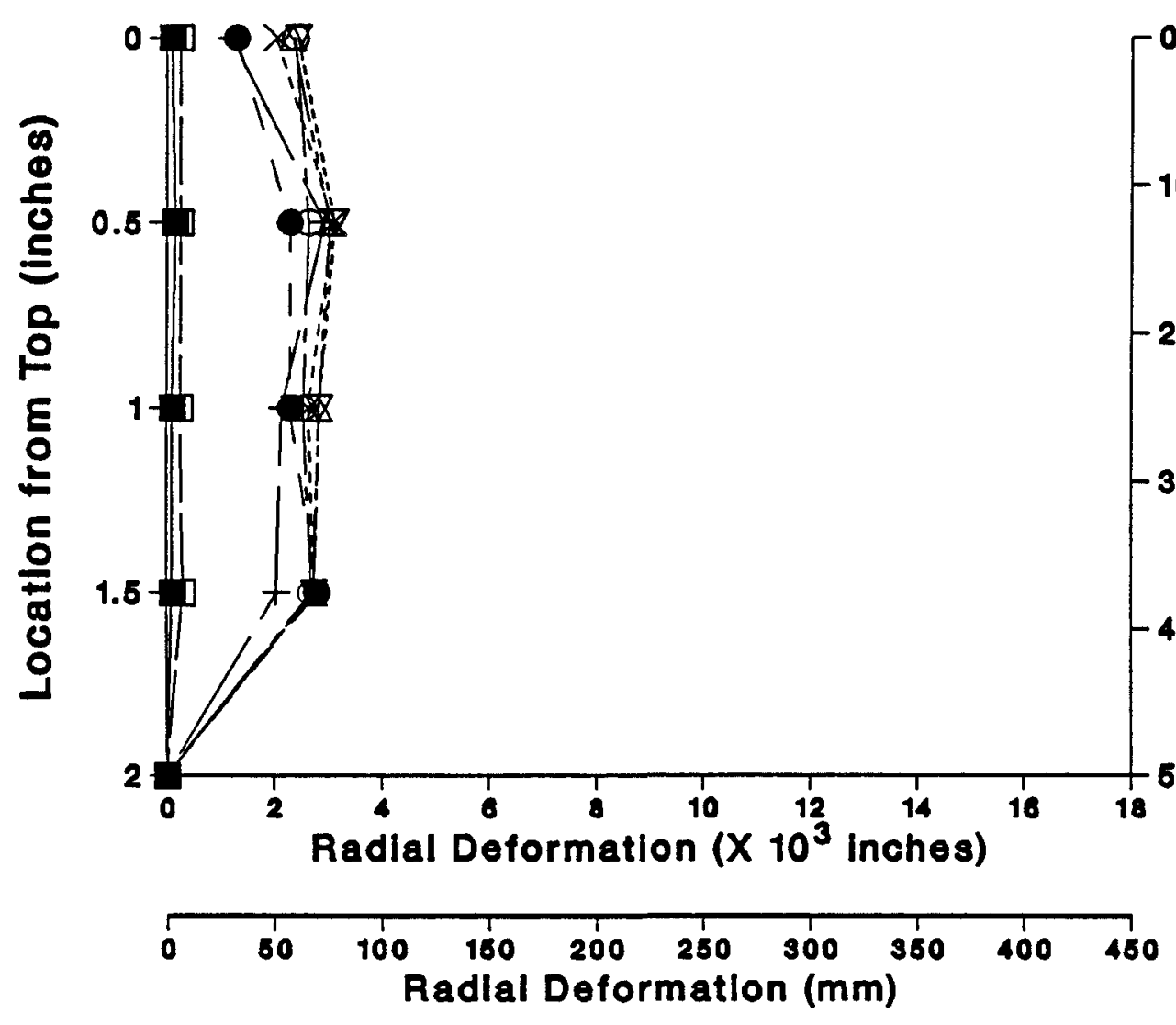


TRIGA Irradiation Testing

Capsule 2 Diode 1

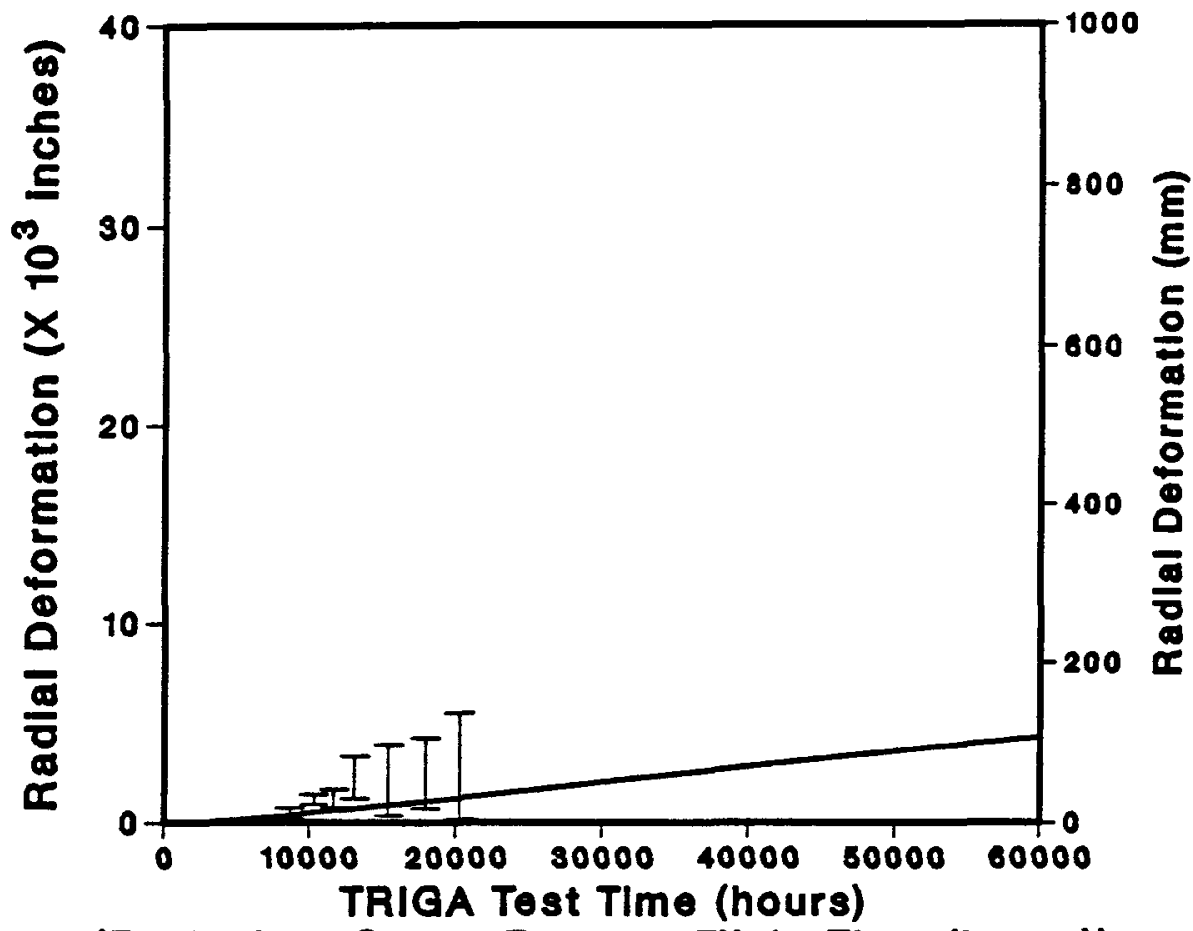

(Equivalent Space Reactor Flight Time (hours))
Emitter OD $\quad 1.100$ in Emitter Thlckness 0.070 in Irrad Time Emltter Temp $20255 \mathrm{hr}$ $1650 \mathrm{~K}$

\section{LLFE-IV Calculated \\ - Measured Range}

\section{Local Emitter Distortion}

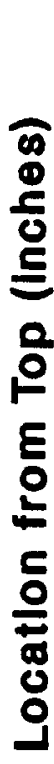

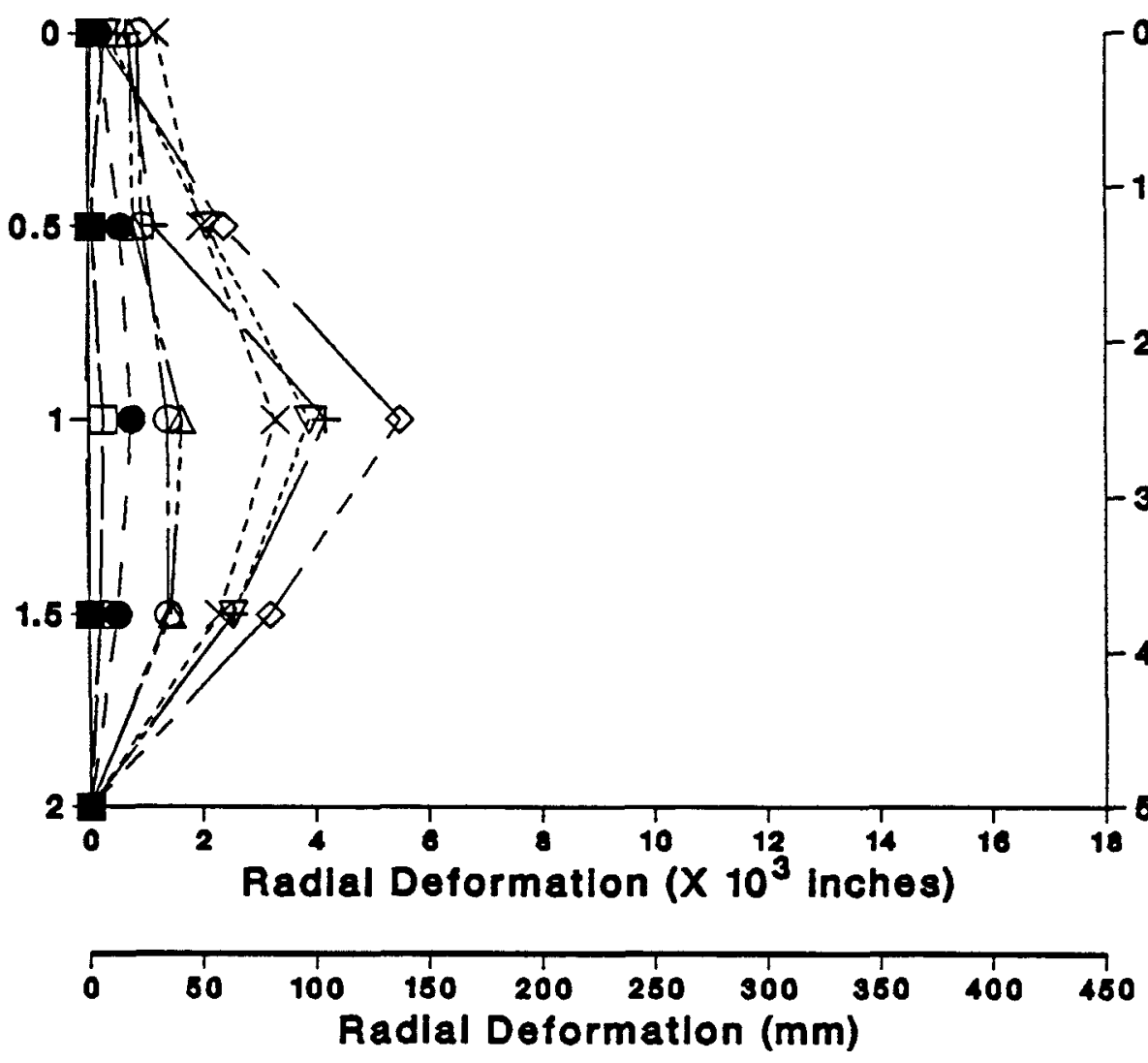

Legend

5388.2 Hours

7173.0 Hours -

- 8693.0 Hours

10318.9 Hours

$\triangle$ 11691.0 Hours

$\times$ 13080.0 Hours

$\nabla$ 15408.0 Hours

+17920.0 Hours

$\diamond 20255.0$ Hours

\section{Radlal Deformation (mm)}


TRIGA Irradiation Testing

Capsule 2 Diode 2

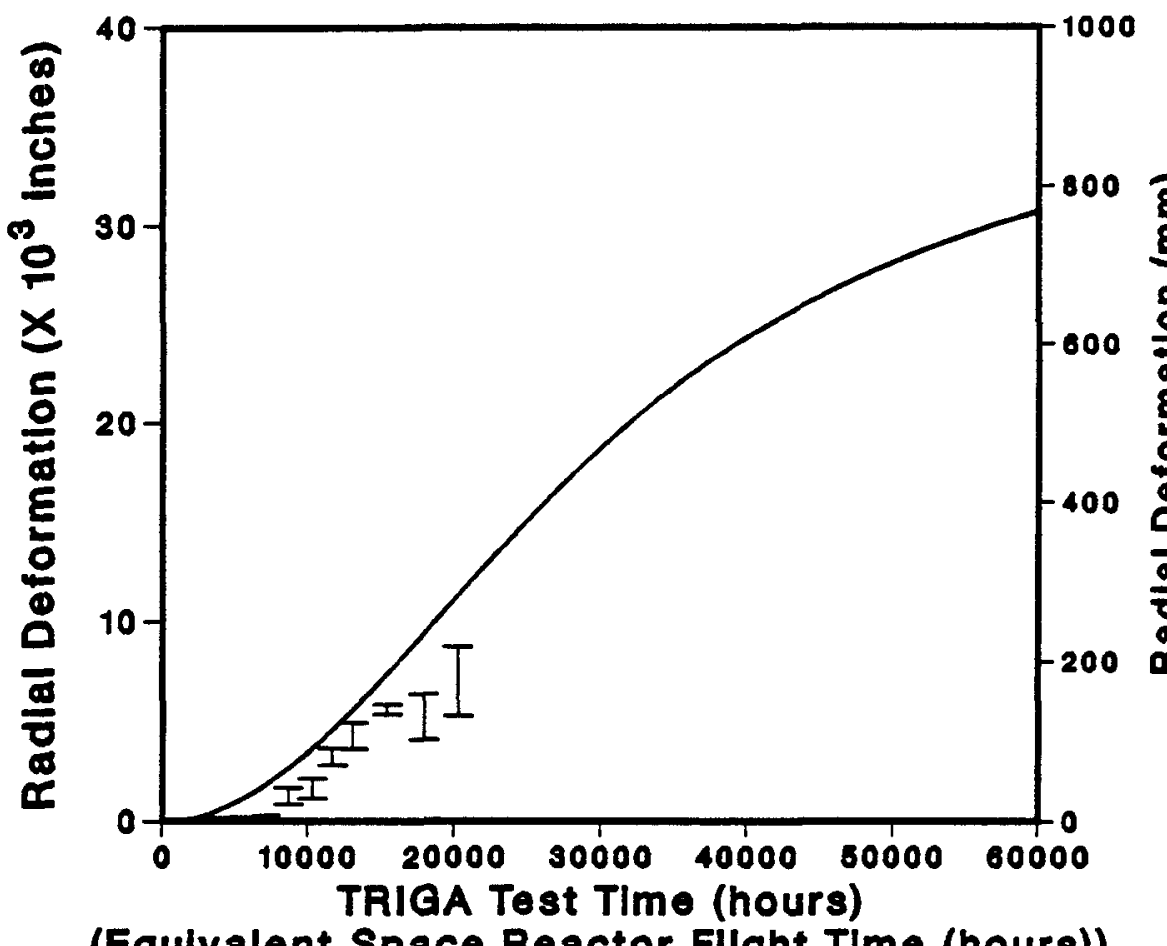

Emitter OD 1.100 in Emitter Thickness $0.070 \mathrm{ln}$ Irrad Time $20255 \mathrm{hr}$. Emitter Temp $1850 \mathrm{~K}$

\section{Legend}

\section{LIFE-IV Calculated}

- Measured Range

(Equivalent Space Reactor Filght Time (hours))

\section{Local Emitter Distortion}

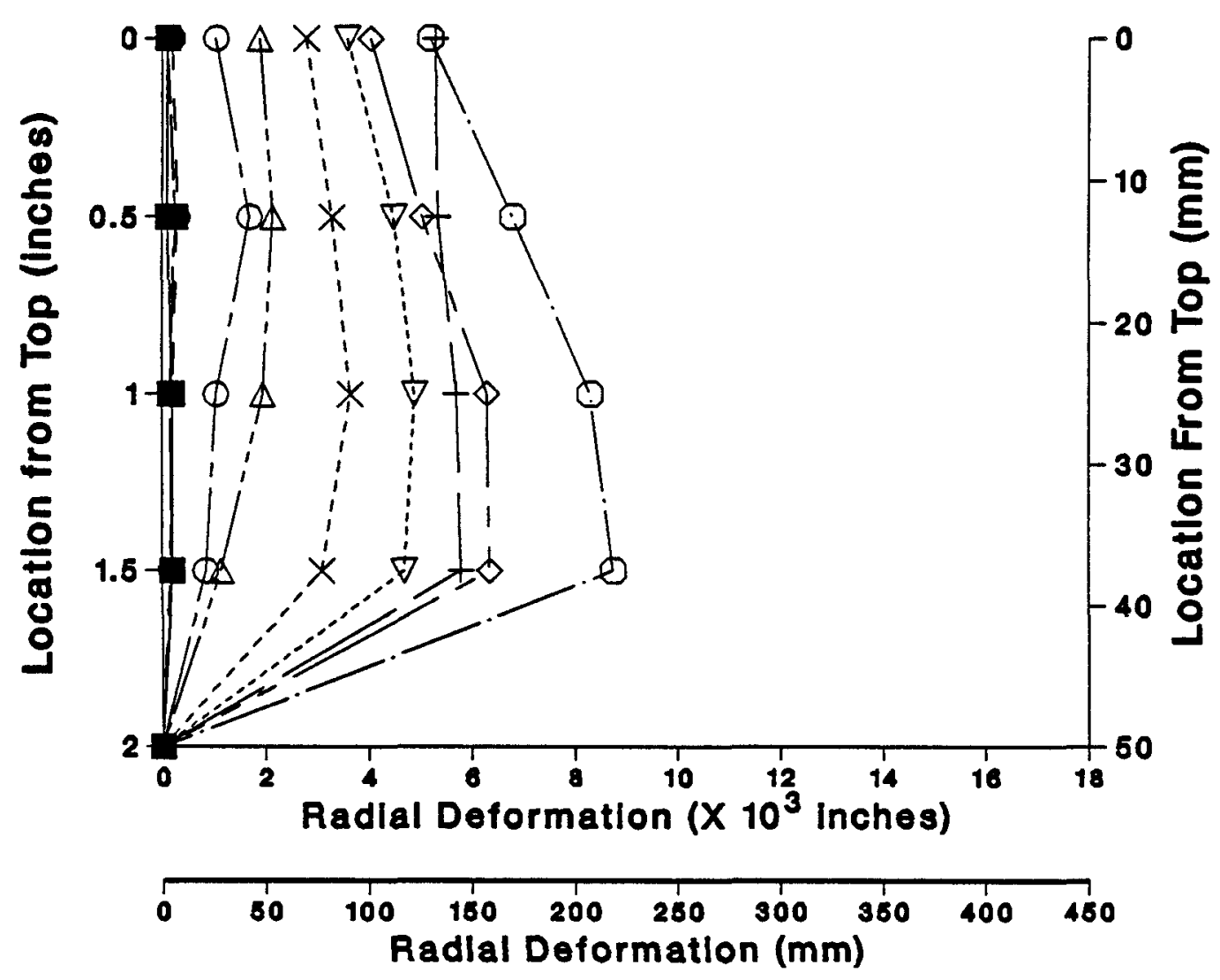

Legend

3971.5 Hours

5388.2 Hours.

- 7173.0 Hours

8 8683.0 Hours

$\triangle$ 10318.9 Hours

$\times$ 11691.0 Hours

$\nabla$ 13080.0 Hours

+15408 Hours

$\diamond 17920.0$ Hours

0 20255.0 Hours 
TRIGA Irradiation Testing

Capsule 2 Diode 3

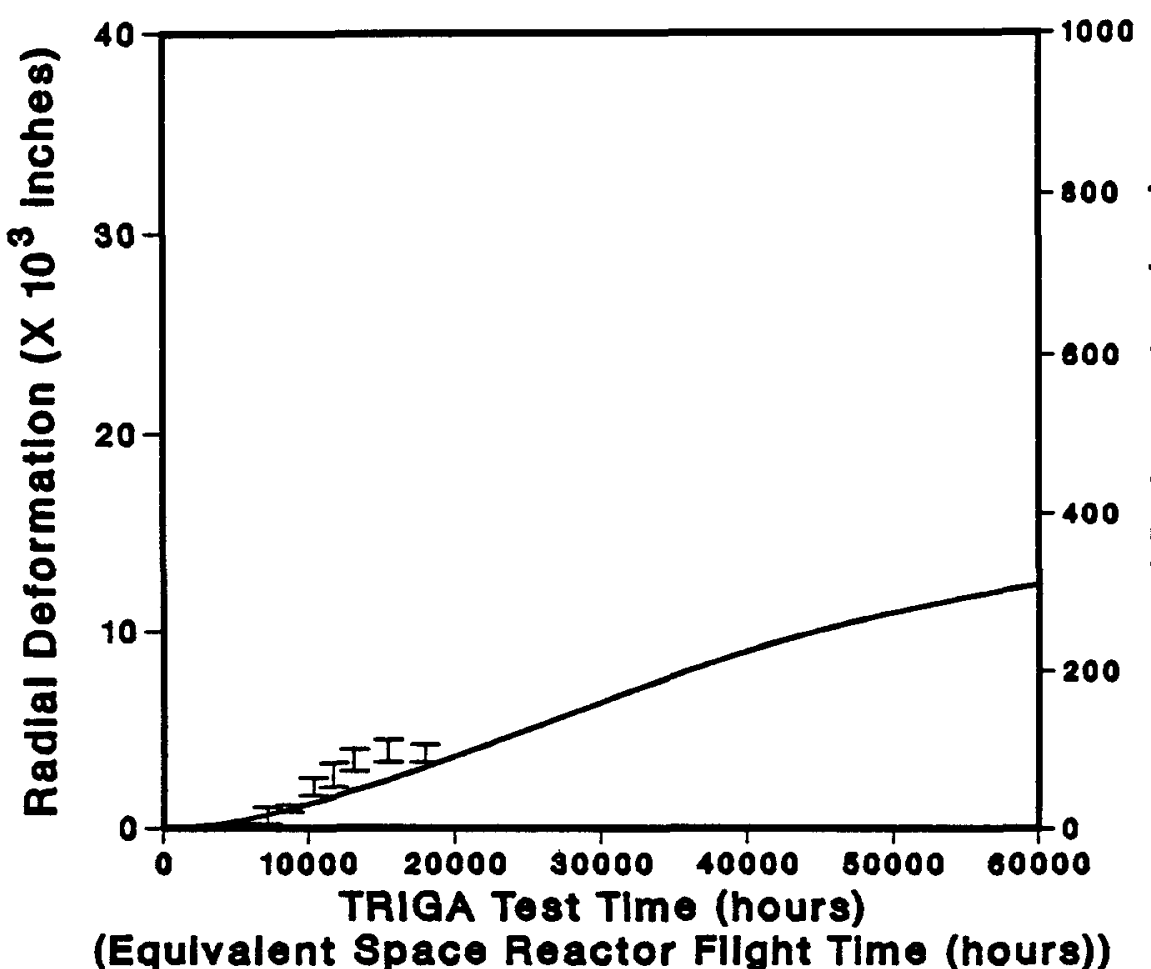

Emitter OD

1.100 in

Emitter Thickness $0.070 \mathrm{ln}$

Irrad Time $17920 \mathrm{hr}$

Emitter Temp $1750 \mathrm{~K}$

\section{LIFE-IV Calculated}

- Measured Range

(Equivalent Space Reactor Flight Time (hours))

\section{Local Emitter Distortion}

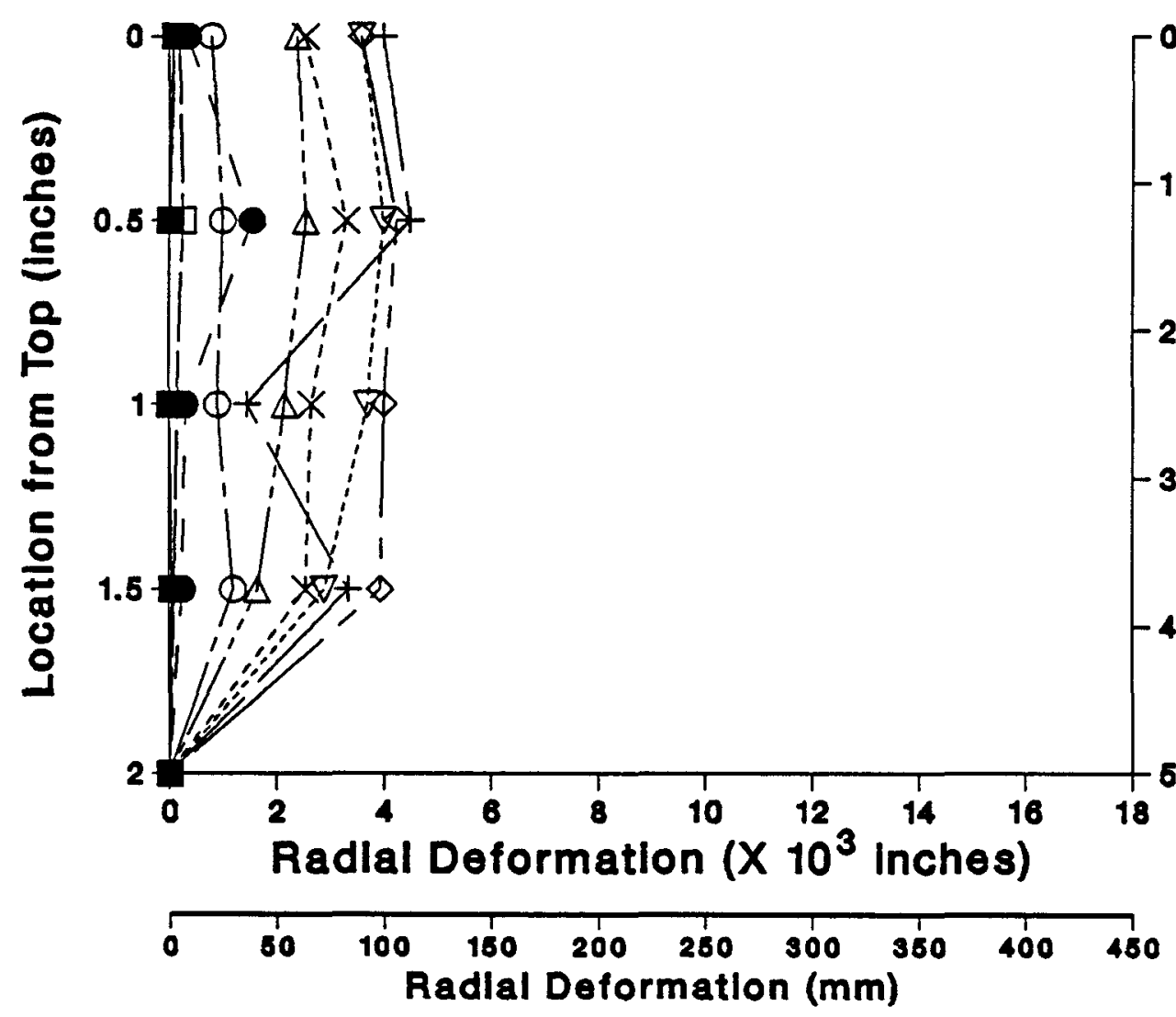


TRIGA Irradiation Testing

Capsule 3 Diode 1

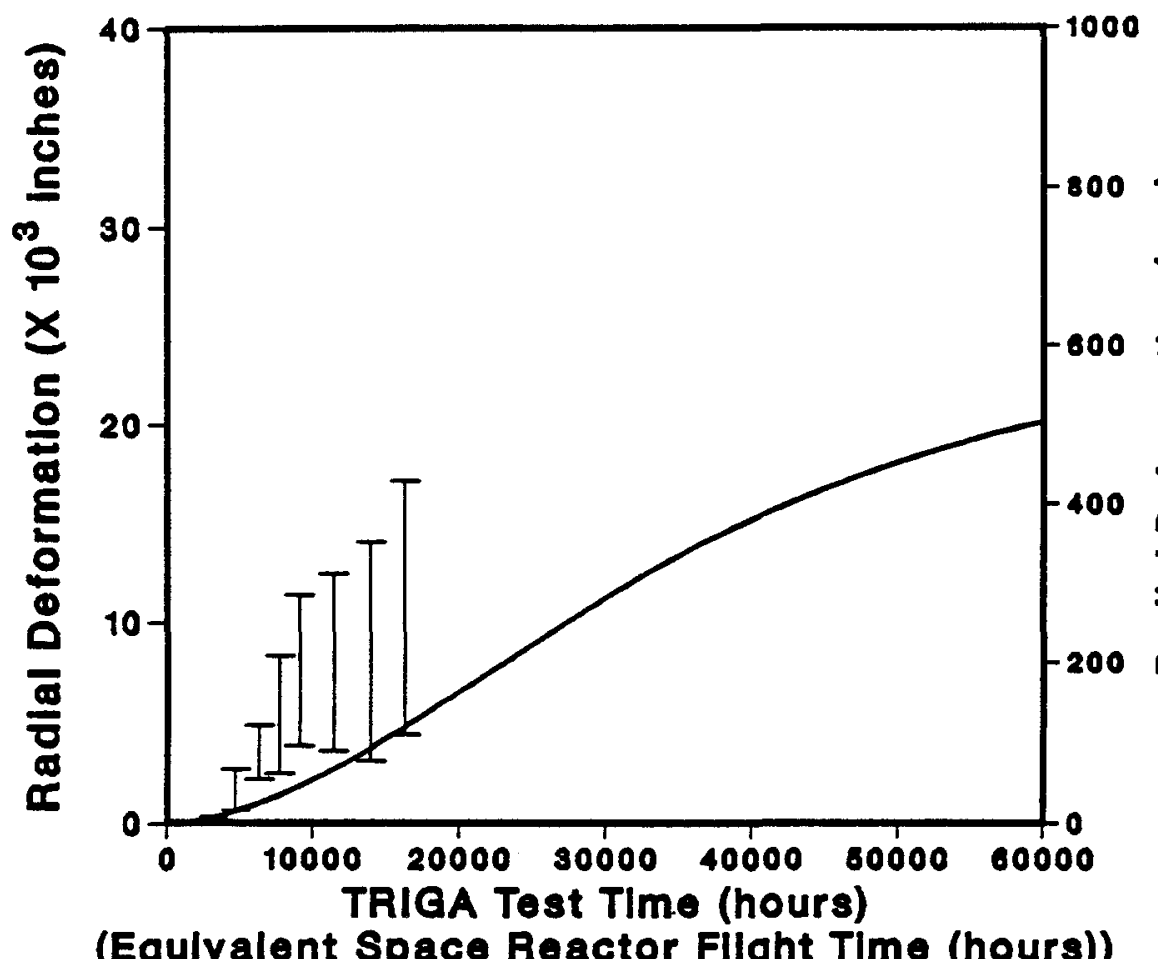

Emitter OD $\quad 1.100$ in Emltter Thlckness 0.040 in Irrad Time $16281 \mathrm{hr}$ Emltter Temp $1750 \mathrm{~K}$

\section{LIFE-IV Calculated}

- Measured Range

(Equlvalent Space Reactor Fllght Time (hours))

\section{Local Emitter Distortion}

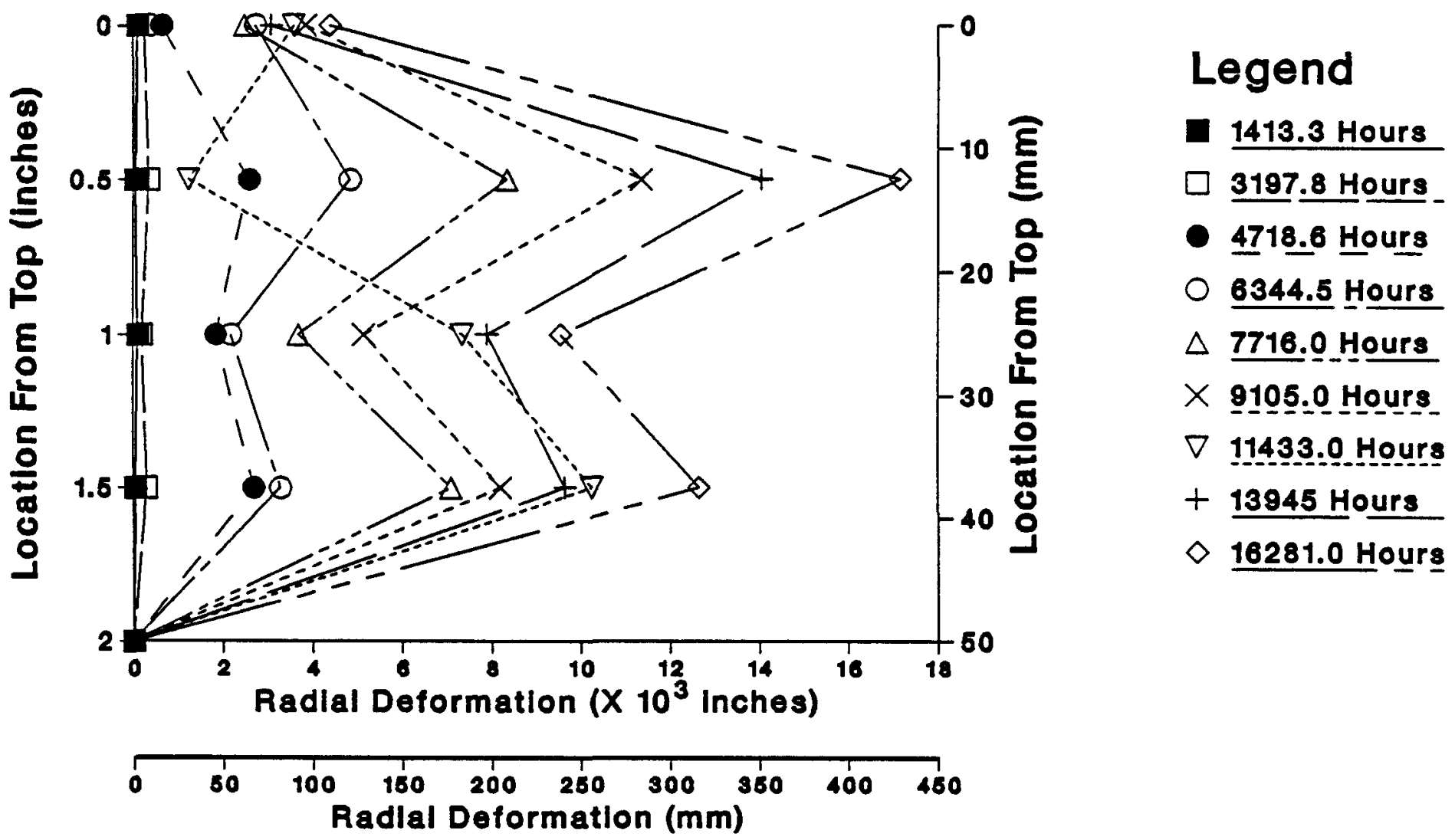




\section{TRIGA Irradiation Testing Capsule 3 Diode 2}

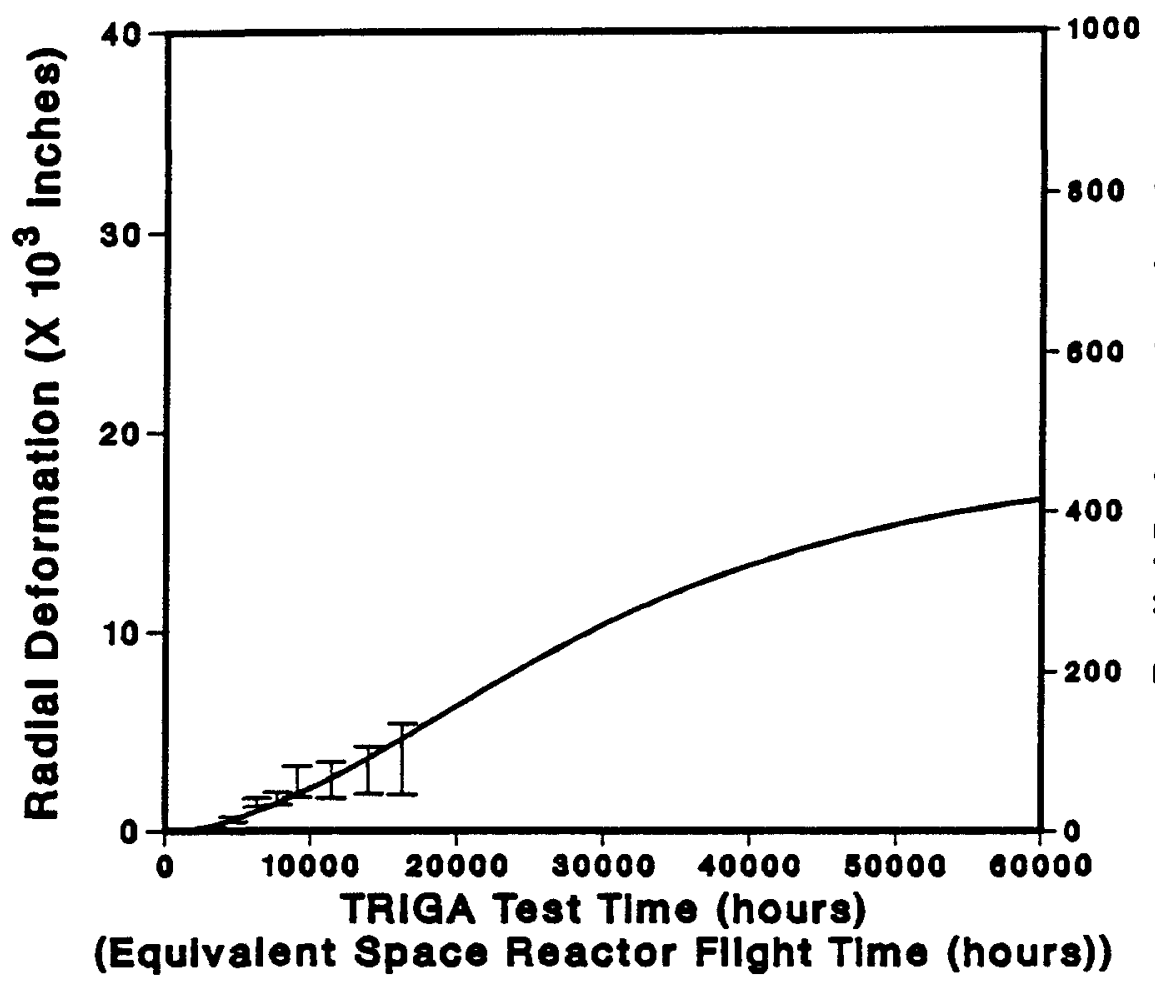

Emitter OD $\begin{array}{ll}\text { Emitter Thickness } & 0.070 \mathrm{in} \\ \text { E Irrad Time } & 16281 \mathrm{hr} \\ \text { Emitter Temp } & 1750 \mathrm{~K}\end{array}$

$\begin{array}{ll}\text { Emitter Thickness } & 0.070 \mathrm{in} \\ \text { E Irrad Time } & 16281 \mathrm{hr} \\ \text { E Emltter Temp } & 1750 \mathrm{~K}\end{array}$

$\begin{array}{ll}\text { Emitter Thickness } & 0.070 \mathrm{in} \\ \text { E Irrad Time } & 16281 \mathrm{hr} \\ \text { E Emltter Temp } & 1750 \mathrm{~K}\end{array}$

$1.100 \mathrm{ln}$

\section{Local Emitter Distortion}

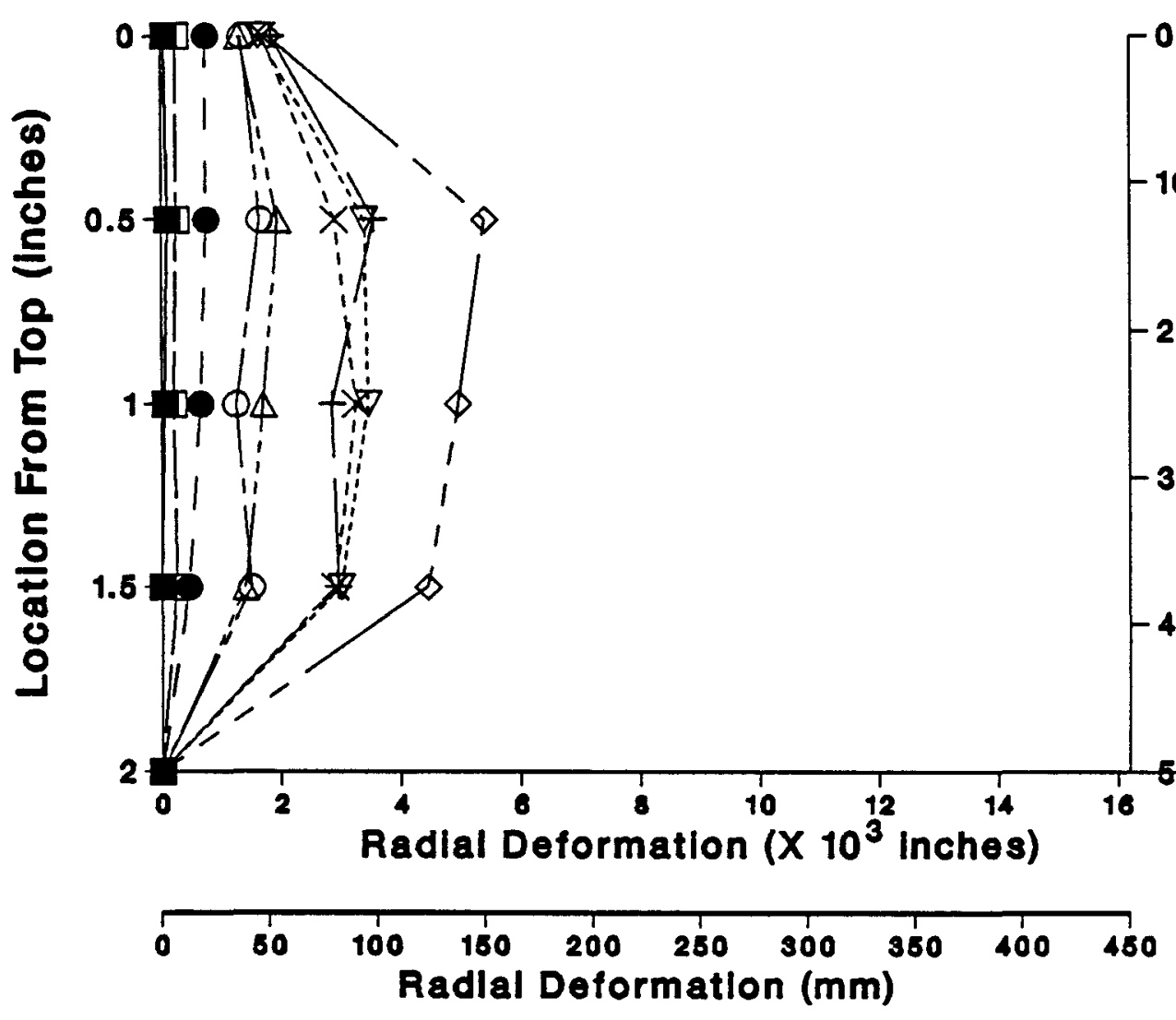


TRIGA Irradiation Testing

Capsule 3 Diode 3

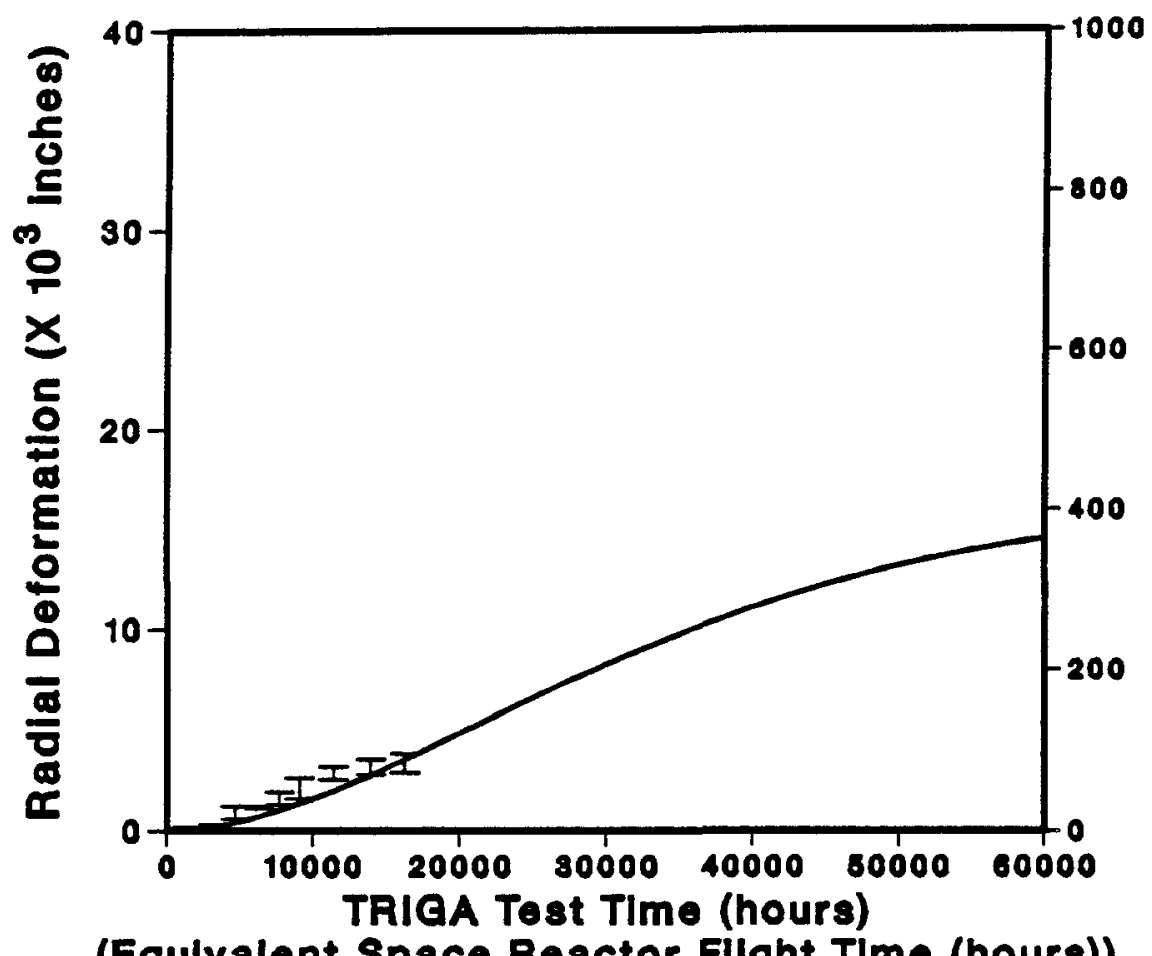

Emitter OD

1.100 in

Emitter Thickness 0.070 in Irrad Time $16281 \mathrm{hr}$

Emitter Temp $1750 \mathrm{~K}$

(Equlvalent Space Reactor Filght Time (hours))

\section{LIFE-IV Calculated}

- Measured Renge

\section{Local Emitter Distortion}

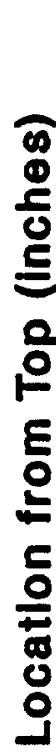

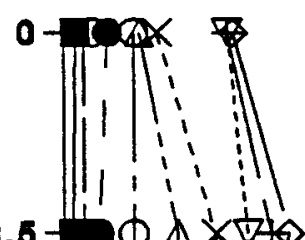

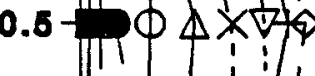
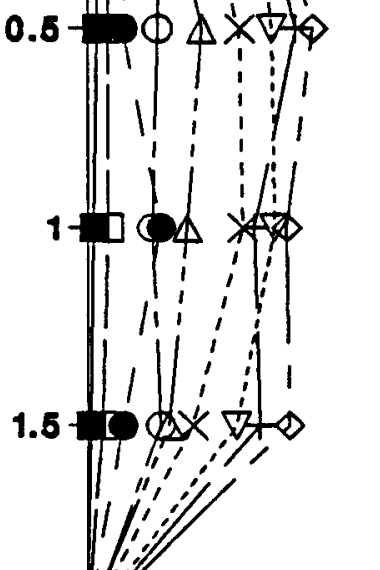


\section{CESIUM RESERVOIR AND INTERCONNECTIVE TFE COMPONENTS}

\subsection{OBJECTIVE}

The overall objective of the cesfum reservoir and interconnective TFE components task is to develop and validate the performance of cesium reservoirs and interconnective TFE components, such as intercell insulation, fission product vents and fission product traps. In particular, the objectives are:

1. Design integral cesium reservoirs and interconnective TFE components.

2. Develop required fabrication processes for integral cesium reservolrs and interconnective TFE components and document the process specifications.

3. Fabricate integral cesium reservoirs and interconnective TFE components for in-reactor and ex-reactor tests.

4. Verify the performance characteristics and lifetimes associated with integral cesium reservolrs and interconnective TFE components by means of in-reactor and ex-reactor testing.

5. Develop an analytical model of the performance and lifetime of the Cs reservoir and interconnective TFE components.

\subsection{TASK DESCRIPTION}

The integral cesium reservoir and interconnective TFE tasks consists of five subtasks:

1. Cesium Reservoir and Interconnective TFE Components Design. Design integral cesium reservoir test specimens consistent with the TFE design requirements. Design test specimens of intercell insulation and interconnective TFE components such as TFE end 
restraint and fission product traps, ports and tubes consistent with TFE design requirements.

2. Fabrication Development. Determine integral cesium reservoir materials with the capability for storing cesium either as intercalation compounds or as sorption reservoirs. Develop systems for containing the integral reservoir material in a TFE environment. Select insulator materials such as $\mathrm{Al}_{2} \mathrm{O}_{3}, \mathrm{Y}_{2} \mathrm{O}_{3}$ and YAG and develop processes for fabricating TFE end restraints and intercell insulation components. Develop materials for use as fission product traps and develop components for fission product vent and port tubes.

3. Ex-Reactor Testing. Perform ex-reactor tests to determine the cesium pressure of integral reservoir materials as a function of cesium loading and temperature. Examine the ability of intercell insulation coatings to reduce parasitic discharges. Determine the mechanical stability of TFE end restraints. Test fission product traps to determine efficiency for trapping previously determined fission products. Perform tests to determine conditions under which plugs may form in fission product port and vent tubes.

4. In-Reactor Testing. Determine the effect of fast neutron fluence on the stability of the pressure versus temperature characteristics of integral cesium reservoirs at a fixed cesium loading. Also examine the mechanical stability of the integral reservoir material. Examine the effect of fast neutron fluence on the mechanical stability of prototypical TFE end restraints and intercell insulation coatings.

\subsection{PROGRESS DURING PRESENT REPORTING PERIOD}

\subsubsection{Cesium Loading of HOPG}

Preliminary Cs pressure versus $C s$ loading ( $P-L$ ) data for HOPG-ZYH and 
POCO CZR-2 graphites were reported in Ref. 7-1. At that time it was noted that the Cs loading of the POCO specimen slightly exceeded that of the HOPG specimen. During the present reporting period the $\mathrm{P}-\mathrm{L}$ behavior of a second HOPG-ZYH specimen was examined in detail at a sample temperature of $1000^{\circ} \mathrm{K}$. The results are shown in Fig. 7-1. There are two distinct differences between the present result and the previous preliminary result: at a fixed Cs pressure, the present Cs loading exceeds that previously reported by as much as $50 \%$ to $80 \%$, showing evidence of intercalation of Cs into the graphite in the form of distinct discontinuities in the $P-L$ curve separated by plateau regions. The preliminary P-L curve for HOPG-ZYH was continuous over the Cs pressure range from 0.5 to 10 torr.

The major reason for the difference between the data of Fig. 7-1 and the $1000^{\circ} \mathrm{K}$ data of Ref. $7-1$ is the long equilibration time required for intercalation and deintercalation as demonstrated in Figs. 7-2a and 7-2b. In Fig. 7-2a the Cs pressure was increased from a very low value (Cs pool reservoir temperature $\sim 35^{\circ} \mathrm{C}$ ) to 3 torr and the loading was monitored as a function of time by observing the ${ }^{134} \mathrm{Cs}$ count rate as described previously. In Fig. 7-2b, the Cs pressure was decreased from 6 torr to 3.8 torr and, again, monitored. A time in excess of 2 hours is required to reach equilibrium in either case. Scheduling constraints did not permit the attainment of equilibrium loading in the case of the UCA-1 specimen reported in Ref. 7-1.

\subsubsection{POCO Outgassing}

A cesium reservoir assembly containing two discs of POCO DFP-1 graphite was used in this test. The total weight of the graphite was $0.6439 \mathrm{~g}$, total (geometrical) surface area was $\sim 5 \mathrm{~cm}^{2}$ and volume was $\sim 0.36$ $\mathrm{cm}^{3}$. The test apparatus was conductance limited to increase sensitivity and was instrumented for both total and partial pressure measurements. More details are given in Section 7.3.5, below. 


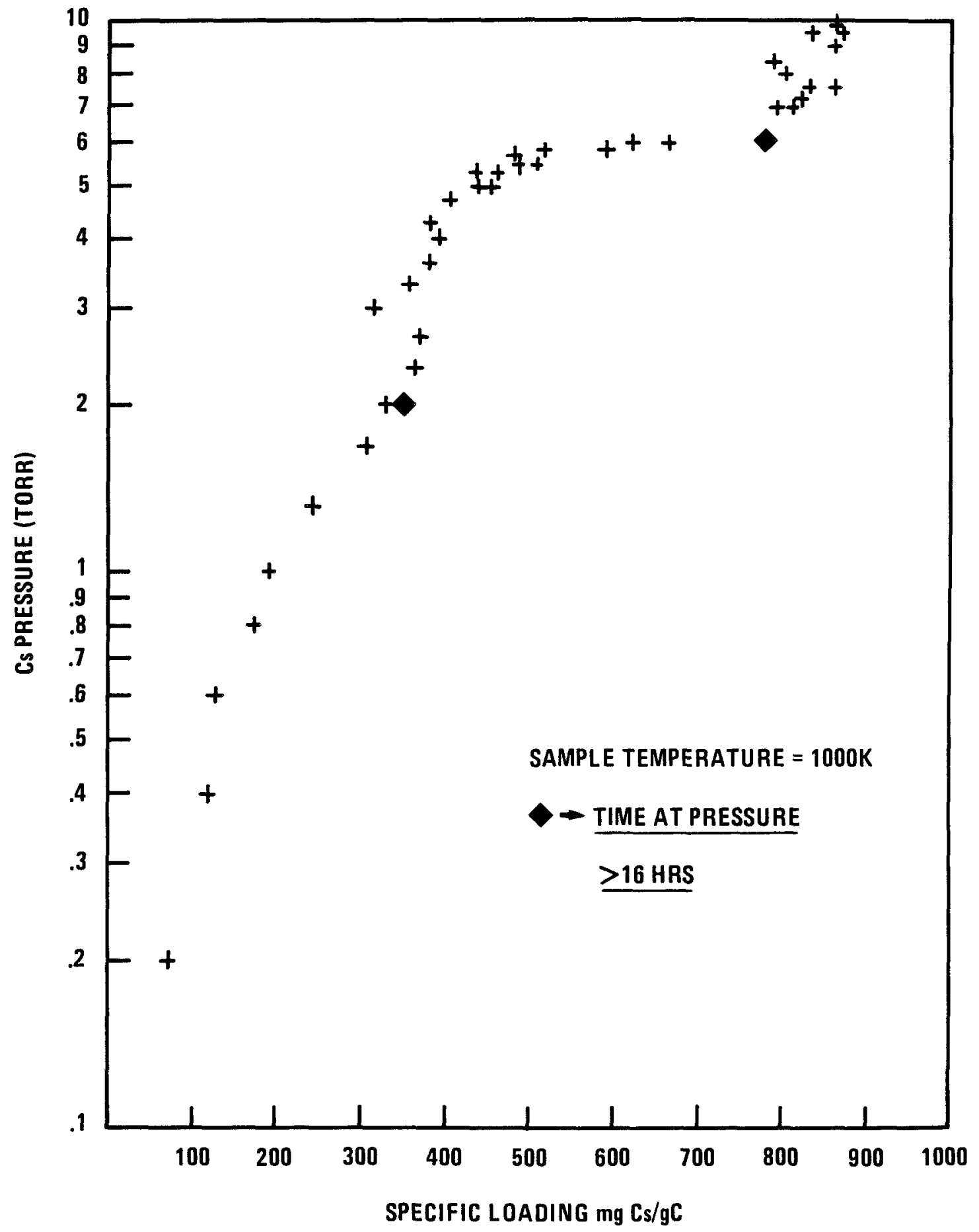

Figure 7-1 - Cs pressure vs. Cs loading for HOPG-ZYH at $1000^{\circ} \mathrm{K}$ 


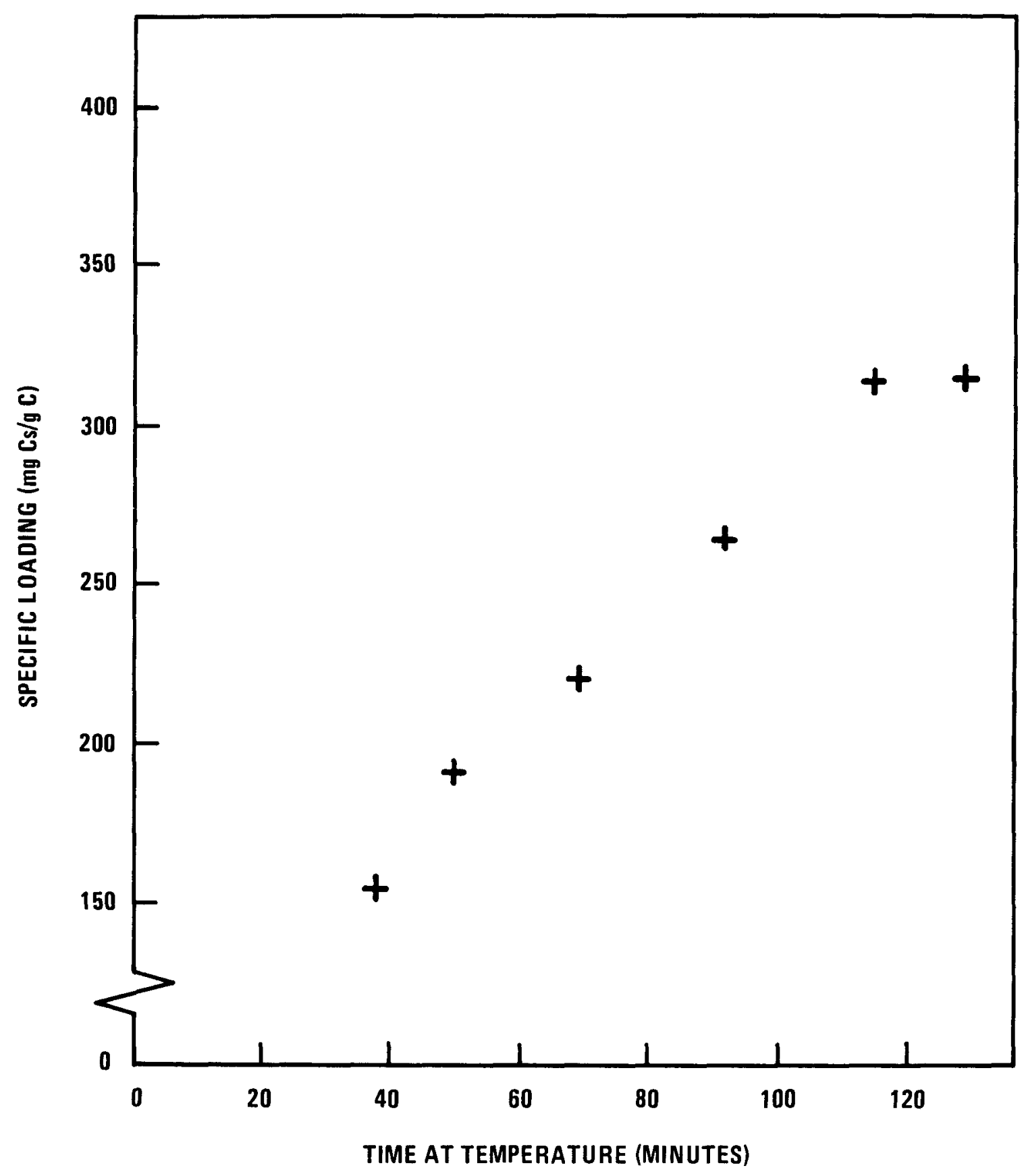

Figure 7-2a - Cs loading as a function of time at a Cs pressure of 3 torr (after equilibrium at 0.0 torr) and graphite temperature of $10000 \mathrm{~K}$ for HOPG-ZYH 


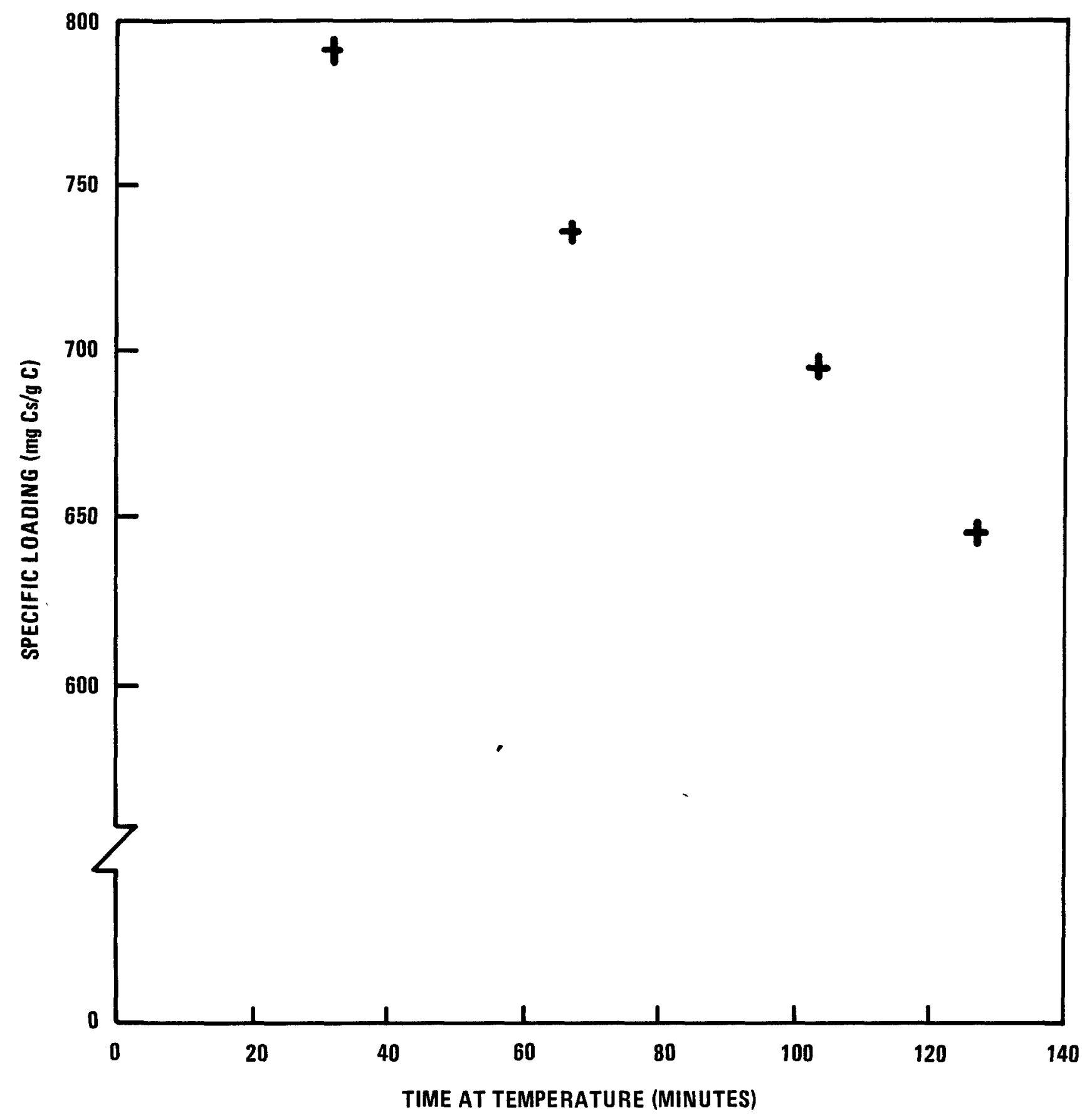

Figure 7-2b - Cs unloading as a function of time at a Cs pressure of 3.8 torr (after equilibrium at 6 torr) and graphite temperature of $1000^{\circ} \mathrm{K}$ for HOPG-ZYH 
The minimum detectable outgassing rate in the test apparatus was estimated to be slightly less than $10^{-7}$ torr-1/sec; the maximum outgassing rate allowed during the course of the measurements was $\sim 10^{-5}$ torr-1/sec. The graphite and the $\mathrm{Nb}$ containment can complete with $\mathrm{Ta}$ spacers was held at $\sim 250^{\circ} \mathrm{C}$ for several days before the outgassing test was run. The graphite (and can) were heated in $\sim 40^{\circ} \mathrm{C}$ steps from $250^{\circ} \mathrm{C}$ to $1200^{\circ} \mathrm{C}$ over a total interval of about 150 hours. The total amount of gas evolved was about $7 \times 10^{-2}$ torr-1, corresponding to $0.1 \mathrm{mg}$ if the average molecular weight was 28. About one-half of this gas was evolved at temperatures $<900^{\circ} \mathrm{C}$; the other half was evolved at temperatures between $900^{\circ} \mathrm{C}$ and $1200^{\circ} \mathrm{C}$. After degassing at $1200^{\circ} \mathrm{C}$, the subsequent outgassing rate at $900^{\circ} \mathrm{C}$ was below the detection limit $\left(\left\langle 10^{-7}\right.\right.$ torr-1/sec). Although the largest constituents of the background were generally 28,2 and 18 amu, the largest decreases as a result of the 150 hour degas were at 15 and $44 \mathrm{amu}$. These peaks can be attributed to $\mathrm{CH}_{4}, \mathrm{CO}_{2}$ and/or other hydrocarbons.

\subsubsection{Alternate Reservoir Materials}

A survey of available (non-graphite, non-carbon) materials yielded several that were thought to be worthy of further investigation. Six samples were obtained from vendors for measurement of BET surface areas and impurity analysis. To limit the amount of testing required at this stage, only generic samples were obtained. For example, sintered specimens of $\mathrm{T} i$, Mo and stainless steel were tested; from the same vendors, sintered $\mathrm{W}, \mathrm{Ta}$ and $\operatorname{Re}$ are also available. Table 7-1 lists the samples, the measured BET surface areas and the impurities detected by emission spectroscopy. For comparison, the BET surface area of POCO CZR-1 was measured as $.99 \mathrm{~m}^{2} / \mathrm{g}$ and POCO DFP-1 was $.44 \mathrm{~m}^{2} / \mathrm{g}$ (Ref. 7-1). Thus the sintered Mo sample had a BET area comparable with the POCO graphite while the $\mathrm{Al}_{2} \mathrm{O}_{3}$ pellet samples had very much larger areas. The other alternate reservoir samples had much smaller BET areas. 
TABLE 7-1

SURFACE AREA AND IMPURITY CONTENT OF ALTERNATE RESERVOIR MATERIALS

\begin{tabular}{|c|c|c|c|c|}
\hline Vendor & Material & Form & $\begin{array}{l}\text { BET } \\
\text { Surface } \\
\text { Area }\end{array}$ & Impurities \\
\hline VISTA Chemical & $\mathrm{Al}_{2} \mathrm{O}_{3}$ & $\begin{array}{l}\text { 3 mm dia. } \\
\text { pellets }\end{array}$ & $210 \mathrm{~m}^{2} / \mathrm{g}$ & $\begin{array}{l}\mathrm{Fe}(50-100 \mathrm{ppm}) \\
\mathrm{Mg}(10-30 \mathrm{ppm}) \\
\mathrm{Si}(50-100 \mathrm{ppm}) \\
\mathrm{T} i(300-500 \mathrm{ppm})\end{array}$ \\
\hline Hi-Tech Ceramics & $\begin{array}{l}\text { Partially } \\
\text { stab1lized } \\
\mathrm{ZrO}_{2}(\mathrm{Mg})\end{array}$ & $\begin{array}{l}\text { Reticulated, } \\
65 \text { pores per } \\
\text { linear Inch, } \\
80 \% \text { porous }\end{array}$ & .051 & $\begin{array}{l}\mathrm{S} i(300-500 \mathrm{ppm}) \\
\mathrm{T} 1(500-1000 \mathrm{ppm})\end{array}$ \\
\hline $\begin{array}{l}\text { Rhenium Alloys, } \\
\text { Inc. }\end{array}$ & Mo & $\begin{array}{l}\text { Sintered, } \\
50 \% \text { dense }\end{array}$ & .42 & $\begin{array}{l}\mathrm{Fe}(50-100 \mathrm{ppm}), \\
\mathrm{S} 1(100-300 \mathrm{ppm})\end{array}$ \\
\hline $\begin{array}{l}\text { Mott Metallurgical } \\
\text { Corp. }\end{array}$ & $\mathrm{T} 1$ & Sintered & .017 & $\begin{array}{l}\mathrm{Fe}(50-100 \mathrm{ppm}), \\
\mathrm{Si}(30-50 \mathrm{ppm})\end{array}$ \\
\hline $\begin{array}{l}\text { Mott Metallurgical } \\
\text { Corp. }\end{array}$ & $\begin{array}{l}\text { Stainless } \\
\text { Steel }\end{array}$ & Sintered & .0018 & $\begin{array}{l}\operatorname{Co}(500-1000 \mathrm{ppm}), \\
\operatorname{Cu}(500-1000 \mathrm{ppm}), \\
\operatorname{Mn}(5000-10000 \mathrm{ppm}), \\
\operatorname{Si}(3000-5000 \mathrm{ppm})\end{array}$ \\
\hline Alcan Chemicals & $\mathrm{Al}_{2} \mathrm{O}_{3}$ & $\begin{array}{l}\sim 6 \text { mia. } \\
\text { pellets }\end{array}$ & 426 & - \\
\hline
\end{tabular}




\subsubsection{Impurities in Bulk Graphite}

The bulk impurity levels in four as-received graphite samples were determined: HOPG-ZYH from Union Carbide, DFP-1 and CZR-2 from POCO Graphite Corporation and PC-113 from Stackpole Carbon Corporation. The General Atomics analysis was performed by spark emission spectroscopy, except for chlorine. Chlorine was analyzed by pyrohydrolysis followed by ion chromotography. The vendor analyses were also obtained for comparison. These data are compiled in Table 7-2. Possible significant discrepancies between the vendor specifications and GA measurement occurs only for DFP-1 in the case of $\mathrm{Al}, \mathrm{Ca}, \mathrm{S} i$ and $\mathrm{V}$. The $\mathrm{GA}$ analysis shows less $\mathrm{S} i$, but more of the other three elements. Chlorine was only detectable in POCO CZR-1 (2 ppm). Based on the $G A$ analysis, the overall level of impurities increase in the order HOPG-ZYH (none detected), POCO CZR-2, Stackpole PC113, POCO DFP-1 (450-950 ppm).

\subsubsection{Test Stand Modifications}

Cs Reservoir Ex-reactor Test Stand. The 1-1/2" various al1-metal valves mentioned as a redesign feature of this test stand in Ref. 7-1 proved not to be as reliable as desired. Nupro valves have been reinstalled, but in such a way that the temperature of the valve stem can be independently monitored and controlled. Prior problems with Nupro valves were caused by excessive heating of the valve stems. An additional reduction in the number of flange and gasket connections is also being incorporated into this latest modification.

\section{Outgassing Test Stand Modifications. The insulator seal test stand} has been modified for temporary use as an outgassing test stand for integral reservoir samples. A quadrupole mass analyzer (RGA) was installed to measure the gaseous species evolved from the samples as the outgassing proceeds. An ion gauge measures the total pressure as a function of time and temperature. A conductance-limiting aperture was located between this system and the turbomolecular pump to limit the pumping speed to 0.36 1/sec. This pumping speed, when divided into the measured system volume, yields a vacuum time constant of 8.3 seconds. This time constant was 
TABLE 7-2

IMPURITY LEVELS (IN PPM) OF AS-RECEIVED STARTING GRAPHITES

AS SPECIFIED BY VENDOR AND MEASURED BY GENERAL ATOMICS

\begin{tabular}{|c|c|c|c|c|c|c|c|c|}
\hline \multirow[t]{2}{*}{$\begin{array}{c}\text { Element (GA } \\
\text { Detection Limit) } \\
\end{array}$} & \multicolumn{2}{|c|}{ HOPG } & \multicolumn{4}{|c|}{$\begin{array}{c}\text { Graphite } \begin{array}{c}\text { Designation } \\
\text { POCO DFP-1 }\end{array} \\
\end{array}$} & \multicolumn{2}{|c|}{ Stackpole PC-113 } \\
\hline & Vendor $^{a}$ & $\mathrm{GA}^{\mathrm{b}}$ & Vendor & $\mathrm{GA}^{\mathrm{d}}$ & Vendor & $\underline{\mathrm{GA}}$ & Vendor $^{c}$ & $\underline{\mathrm{GA}}$ \\
\hline $\mathrm{A} 1(10)$ & $1-10$ & & $10-50$ & $100-300$ & $\leq 5$ & & & $30-50$ \\
\hline $\mathrm{B}(1)$ & 10 & & Trace & $3-5$ & & $1-3$ & & $1-3$ \\
\hline $\mathrm{Ca}(50)$ & 1 & & Trace & $50-100$ & & & & $50-100$ \\
\hline $\mathrm{Cu}(1)$ & 1 & & & & & & & \\
\hline $\mathrm{Fe}(1)$ & 1 & & $50-200$ & & $\leq 5$ & & & $50-100$ \\
\hline $\mathrm{Mg}(1)$ & 1 & & Trace & $1-3$ & $\leq 5$ & & & $10-30$ \\
\hline Mo(5) & & & & & & & & $1-3$ \\
\hline $\mathrm{N} 1(1)$ & & & Trace & $5-10$ & & & & $50-100$ \\
\hline Si(3) & $1-10$ & & $25-200$ & $5-10$ & $\leq 5$ & $3-5$ & & $10-30$ \\
\hline $\mathrm{V}(5)$ & & & $50-100$ & $300-500$ & & & & $30-50$ \\
\hline $\operatorname{Ti}(1)$ & 1 & & $1-5$ & & & & & \\
\hline Ash & $10-30$ & & $100-300$ & & 5 & & & \\
\hline $\mathrm{Cl}$ & & & & & & 2 & & \\
\hline
\end{tabular}

a) No entry in vendor column means either element not listed or not detected.

b) No impurities measured by $\mathrm{GA}$ above stated detection limits in HOPG-ZYH.

c) Impurity Information not provided by Stackpole.

d) No entry in GA column means element not detected. 
verified from experimental pumpdown curves with Argon using the expression

$$
p=p_{0} \exp (-t / \tau)
$$

where

$$
\tau=V / F=\text { volume of system/pumping speed. }
$$

Since the range of change of outgassing is slow compared with the time constant of 8.3 seconds, the outgassing rate, $Q$, can be estimated from the relation $Q=F P$ torr $-1 / \mathrm{sec}$, where $P$ is the system pressure increase due to Q. This system and method of analysis was used in the outgassing measurements described in Section 7.3 .2 above.

\subsubsection{PIE Test Stand}

A test stand is required for postirradiation examination of UCA series Cs reservoir test samples. This test stand must be able to perform the same type of Cs pressure vs. sample temperature ( $P-T)$ tests as were performed in the ex-reactor test stand.

The PIE test stand must be designed to function in a hot cell environment, in particular all operating functions must be performed with remote manipulators, and electromechanical or pneumatic actuators. The Nb encapsulated reservoir specimen must be inserted into the vacuum system, pump-down performed, the encapsulation punctured and P-T data obtained. Sample removal and system reuse are also required. A conceptual design for a PIE test stand that meets the above requirements has been completed and is currently under review prior to detailed design, construction and testing.

\subsection{CESIUM RESERVOIR MATERIALS SUMMARY}

At this stage in the TFE Verification Program, ex-reactor tests and other studies have resulted in considerable down-selection among the proposed candidate materials for integral Cs reservoirs. Attention is presently being focused on six candidates: four carbon/graphite, one refractory and one ceramic. These materials are as follows: 
a) Graphites

$$
\begin{array}{ll}
- & \text { HOPG-ZYH } \\
\text { - } & \text { POCO CZR-2 } \\
\text { - } & \text { POCO DFP-1 }
\end{array}
$$

b) Carbon

$$
\text { - Stackpole PC-113 }
$$

c) Refractory Meta1

- Sintered Mo

d) Ceramic

$$
\text { - Porous } \mathrm{Al}_{2} \mathrm{O}_{3} \text { (6 mm diameter pellets) }
$$

Table 7-3 lists several properties of these materials compiled both from experimental data obtained under the TFE Verffication Program and from other sources. From these data, an evaluation matrix is presented in Table 7-4 which ranks these materials from 1 (most desirable) to 6 (least desirable), based on the major critical areas of concern in an integral Cs reservoir application.

\section{References}

7-1 TFE Verification Program Semiannual Report for the Period Ending September 30, 1987, GA-A19115.

7-2 J. N. Smith, Jr., T. Heffernan and I. D. Woolf, Memo to Distribution 3450:324:JNS/TH:87, "Preirradiation Test Specifications of UCA-2 Graphite Integral Reservoir Specimens, Serial Numbers 0197 and 0199". 
TABLE 7-3

TECHNICAL DATA: CANDIDATE RESERVOIR MATERIALS

\begin{tabular}{|c|c|c|c|c|c|c|c|}
\hline Material & $\begin{array}{l}\text { Bulk } \\
\text { Impurities }\end{array}$ & $\begin{array}{l}\text { Impurities } \\
\text { Volatile } \\
\text { at } T \leq 1400^{\circ} \mathrm{K}\end{array}$ & $\begin{array}{l}\mathrm{BET}^{\mathrm{C}} \\
\text { A5ea } \\
\left(\mathrm{m}^{2} / \mathrm{gm}\right)\end{array}$ & $\begin{array}{c}\text { Cs Loading } \\
\text { e } 3 \text { torr } \\
10700_{K} \\
m g ~ C s / g)\end{array}$ & $\begin{array}{l}\text { Neut } \\
\text { C-axis } \\
\text { Elongation }\end{array}$ & $\begin{array}{l}\text { Volume } \\
\text { Swelling }\end{array}$ & $\begin{array}{l}\text { Change in } \\
\text { Cs Pressure } \\
\text { vs. } \\
\text { Temperature }\end{array}$ \\
\hline HOPG - 2YH & ND & $\mathrm{HC}, \mathrm{s}, \mathrm{CO}_{2}, \mathrm{CO}$ & - & 375 & $\begin{array}{c}<0.5 \% \text { at } \\
10^{21} \mathrm{n} / \mathrm{cm}^{2}\end{array}$ & - & $\mathrm{Nil}$ (inferred) \\
\hline POCO C2R-2 & $\mathrm{Nil}$ & TBD & 0.99 & $400($ prelim) & - & - & Nil (inferred) \\
\hline POCO DFP-1 & $\begin{array}{l}<900 \mathrm{ppm} \\
\mathrm{V}, \mathrm{Al}, \mathrm{Ca}\end{array}$ & $\mathrm{HC} \cdot \mathrm{s}, \mathrm{CO}_{2}$ & 0.44 & TBD & $4 \times 1$ & $\begin{array}{l}8 \% \text { at } \\
10^{22} \mathrm{n} / \mathrm{cm}^{2}\end{array}$ & $\mathrm{Nil}$ (inferred) \\
\hline $\begin{array}{l}\text { Stackpole } \\
\text { PC-113 }\end{array}$ & $\begin{array}{l}\leq 400 \mathrm{ppm} \\
\mathrm{Ni}, \mathrm{Fe}, \mathrm{Ca}\end{array}$ & TBD & 0.49 & TBD & - & - & $\mathrm{Nil}$ (inferred) \\
\hline $\begin{array}{l}\text { Sintered Mo } \\
\text { (Rhenium } \\
\text { Alloys, Inc.) }\end{array}$ & $\begin{array}{l}<400 \mathrm{ppm} \\
\mathrm{Si}, \mathrm{Fe}\end{array}$ & TBD & .42 & TBD & - & - & TBD \\
\hline $\begin{array}{l}\text { Porous } \mathrm{Al}_{2} \mathrm{O}_{3} \\
\text { (ALCAN) }\end{array}$ & ND & TBD & 426 & TBD & 10 & $\begin{array}{ll}<3 q & \text { at } \\
0^{22} & \mathrm{n} / \mathrm{cm}^{2}\end{array}$ & TBD \\
\hline
\end{tabular}

a) From vendor specs and GA emission spectroscopy.

b) From GA outgassing tests.

c) From GA BET measurements.

d) From GA loading measurements.

e) Inferred from HTGR studies on other graphites; verification awaits UCA series PIE.

TBD implies measurement underway or planned.

ND implies not detected. 
TABLE $7-4$

OVERALL EVALUATION OF CANDIDATE RESERVOIR MATERIALS AFTER DOWN SELECTION $\underline{O K}=$ MEETS DESIGN CRITERIA; $P=$ MEASUREMENT PLANNED; IP $=$ MEASUREMENT IN PROGRESS

\begin{tabular}{|c|c|c|c|c|c|c|c|c|c|c|}
\hline \multirow[b]{2}{*}{ Material } & \multirow[b]{2}{*}{$\begin{array}{l}\text { Interim } \\
\text { Rank, } \\
3 / 88\end{array}$} & \multicolumn{2}{|c|}{$\begin{array}{l}\text { Specific } \\
\text { Cs Loading }\end{array}$} & \multicolumn{2}{|c|}{$\begin{array}{c}\text { Cs } \mathrm{P}-\mathrm{T} \\
\text { Reproducibility/ } \\
\text { Stability }\end{array}$} & \multicolumn{2}{|c|}{$\begin{array}{l}\text { Stable Pressure } \\
\text { in Neutron Flux }\end{array}$} & \multicolumn{2}{|c|}{ Impurities } & \multirow[b]{2}{*}{$\begin{array}{c}\text { Chemical } \\
\text { Compati- } \\
\text { bility }\end{array}$} \\
\hline & & $\begin{array}{r}\text { From } \\
\text { BET } \\
\text { Area }\end{array}$ & $\begin{array}{l}\text { From } \\
\text { P-L } \\
\text { Test }\end{array}$ & $\begin{array}{c}\text { BOL } \\
\text { (Ex-reactor) }\end{array}$ & $\begin{array}{c}\text { EOL } \\
\text { (UCA PIE) }\end{array}$ & $\begin{array}{l}\text { Inferred } \\
\text { From } \\
\text { Data Base }\end{array}$ & $\begin{array}{l}\text { Measured } \\
\text { (UCA PIE) }\end{array}$ & $\begin{array}{c}\text { Bulk } \\
\text { Analys is }\end{array}$ & $\begin{array}{l}\text { Out- } \\
\text { gas- } \\
\text { sing } \\
\text { Test }\end{array}$ & \\
\hline \multicolumn{11}{|l|}{ Graphite: } \\
\hline HOPG-ZYH & 1 & $\mathrm{OK}$ & OK & OK & $\mathrm{P}$ & OK & $\mathbf{P}$ & OK & OK & OK \\
\hline POCO CZR-2 & 2 & OK & OK & OK & $P$ & OK & $\mathbf{P}$ & $\mathrm{OK}$ & $\mathbf{P}$ & OK \\
\hline POCO DFP-1 & 6 & OK & $\mathrm{P}$ & $\mathbf{P}$ & $\mathbf{P}$ & $\mathrm{OK}$ & $\mathbf{P}$ & OK & OK & OK \\
\hline $\begin{array}{l}\text { Carbon: } \\
\text { Stackpole } \\
\text { PC-113 }\end{array}$ & 5 & OK & $P$ & $\mathbf{P}$ & $\mathbf{P}$ & $\mathrm{OK}$ & $\mathbf{P}$ & OK & IP & OK \\
\hline $\begin{array}{l}\text { Ceramic: } \\
\text { Activated } \\
\text { Alumina, } \\
\text { AA-400 (ALCAN) }\end{array}$ & 3 & $\mathrm{OK}$ & $\mathrm{P}$ & $\mathbf{P}$ & $\mathbf{P}$ & $(\mathrm{OK})$ & $\mathrm{P}$ & OK & $\mathbf{P}$ & OK \\
\hline $\begin{array}{l}\text { Refractory: } \\
\text { Sintered Mo } \\
\text { (Rhenium } \\
\text { Alloys, Inc.) }\end{array}$ & 4 & OK & $\mathrm{P}$ & $\mathbf{P}$ & $\mathbf{P}$ & $(\mathrm{OK})$ & $\mathbf{P}$ & OK & $\mathrm{P}$ & OK \\
\hline
\end{tabular}




\section{THERMIONIC FUEL ELEMENT}

\subsection{OBJECTIVE}

The overall goal of the thermionic fuel element task is to demonstrate that TFEs prototypic of a $2 \mathrm{MW}(\mathrm{e})$ thermionic space nuclear power system of seven year life can be fabricated from well modeled components, and that their performance is as predicted when operated in a prototypic thermionic reactor environment. Derivative goals include:

1) Produce a TFE engineering design and specifications.

2) Develop required TFE assembly processes, process specifications, and demonstrate manufacturing capability.

3) Fabricate TFEs and test them to demonstrate the processes and the integrated performance of the components.

4) Develop and verify a TFE model that can predict TFE performance and lifetime.

Components with demonstrated performance and which are projected to meet lifetime requirements will be used in these TFEs. Most of the TFEs will undergo irradiation in the TRIGA reactor. The performance of one prototypic TFE will be demonstrated in the FFTF.

\subsection{TASK DESCRIPTION}

\subsubsection{Testing Logic}

All TFEs tested will be as close to the baseline TFE design in geometry and performance as practicable. This is illustrated on Table 8-1.

Six TFE tests are planned for the TRIGA reactor before a demonstration in the fast-neutron spectrum FFTF. These are outlined in Table 8-2. 
TABLE $8-1$

COMPARISON OF TFE TEST REQUIREMENTS WITH SYSTEM BASELINE DESIGN REQUIREMENTS

Test Requirements (BOL)

Baseline Design Requirements (BOL)

Cell power density average $\left(\mathrm{W} / \mathrm{cm}^{2}\right)$

Current density average $\left(\mathrm{A} / \mathrm{cm}^{2}\right)$

2.9

7

Emitter temperature average (K)

Collector temperature average $(\mathrm{K})$

Sheath-collector voltage maximum (V)

TFE geometry

TFE materials

Fuel enrichment ( $\%$ U-235)

Fast fluence: nominal ( $\mathrm{E}>0.1 \mathrm{MeV})$

Fuel burnup: nominal (a/o)

2.9
7
1800
1070
$< \pm 15$
Baseline
Baseline or variants for
performance/structural
improvements
Variable enrichment
Real time
4.1

2.9

7

1800

1070

$< \pm 15$

Baseline

Section 2.2

93; variable fuel volume fraction

$$
2.7 \times 10^{22}
$$

4.1 
TABLE 8-2

TFE IN-REACTOR TEST MATRIX

\begin{tabular}{|c|c|c|c|c|c|}
\hline TFE ID & $\begin{array}{l}\text { Fuel/Emitter } \\
\text { Collector }\end{array}$ & $\begin{array}{l}\text { Cs }^{*} \\
\text { Reservoir }\end{array}$ & Purpose & $\begin{array}{l}\text { Data Needed } \\
\text { For }\end{array}$ & Reactor \\
\hline $1 \mathrm{H} 1$ & $\mathrm{UO}_{2} / \mathrm{W} / \mathrm{Nb}$ & Pool & $\begin{array}{l}\text { Verification of reference cell design } \\
\text { performance and fabrication processes. } \\
\text { Sheath integration. }\end{array}$ & $\begin{array}{l}3 \mathrm{H} \text { and } 6 \mathrm{H} \text { TFEs } \\
\mathrm{UCA}-3 \text {, UFAC, } \\
\text { IFAC-SI }\end{array}$ & TRIGA \\
\hline $1 \mathrm{H} 2$ & $\mathrm{UO}_{2} / \mathrm{W} / \mathrm{Nb}$ & Integral & $\begin{array}{l}\text { Backup to } 1 \mathrm{H} 1 \text {. } \\
\text { Verification of integral cesium } \\
\text { reservoir design, performance. }\end{array}$ & $\begin{array}{l}3 \mathrm{H} \text { and } 6 \mathrm{H} \text { TFEs } \\
\text { UCA-3, UFAC, } \\
\text { IFAC-SI }\end{array}$ & TRIGA \\
\hline $1 \mathrm{H} 3$ & $\mathrm{UO}_{2} / \mathrm{W} / \mathrm{Nb}$ & Pool & $\begin{array}{l}\text { Study effect of fission products } \\
\text { mixing with cesium }\end{array}$ & & TRIGA \\
\hline $3 \mathrm{H} 1$ & $\mathrm{UO}_{2} / \mathrm{W} / \mathrm{Nb}$ & Integral & $\begin{array}{l}\text { Intercell process development. } \\
\text { Fission product control. }\end{array}$ & $\begin{array}{l}\text { 6H TFE } \\
\mathrm{UCA}-3, \text { IFAC-SI }\end{array}$ & TRIGA \\
\hline $3 \mathrm{H} 5$ & $\mathrm{UO}_{2} / \mathrm{TBD} / \mathrm{TBD}$ & Integral & $\begin{array}{l}\text { Backup to } 3 H 1 \text {. Consider oxygenated } \\
\text { collector. Consider fuel clad variants. }\end{array}$ & & TRIGA \\
\hline $6 \mathrm{H1}$ & $\mathrm{UO}_{2} / \mathrm{W} / \mathrm{Nb}$ & Integral & $\begin{array}{l}\text { Verification of long-TFE fabricability. } \\
\text { Consider evolutionary improvements. } \\
\text { Verification of fission gas ventings. } \\
\text { Increased voltages. }\end{array}$ & $6 \mathrm{H} 2,6 \mathrm{H} 3$ & TRIGA \\
\hline $6 \mathrm{H} 2$ & $\mathrm{UO}_{2} / \mathrm{W} / \mathrm{Nb}$ & Integral & Backup to $6 \mathrm{H} 1$. & $6 \mathrm{H} 3$ & TRIGA \\
\hline $6 \mathrm{H} 3$ & $\mathrm{UO}_{2} / \mathrm{W} / \mathrm{Nb}$ & Integral & $\begin{array}{l}\text { Verification of } \mathrm{TFE} \text { performance in } \\
\text { fast reactor environment. }\end{array}$ & & FFTF \\
\hline
\end{tabular}

\footnotetext{
* Graphite cesium reservoir is the current reference design. Alternative materials to contain the cesium will also be studied; e.g., porous ceramics or metals.
} 
The logic behind this test series is a step-by-step development of the fabrication processes, culminating in the fast reactor prototype. The first step is the development of the processes for a single cell, and the integration of the single cell into a TFE sheath tube with appropriate end fittings. These end fittings involve the cesium reservoir, fission gas venting and the conduction of electrical current produced. This single-cell TFE is designated " $1 \mathrm{H}$ ", where the $\mathrm{H}$ refers to the latest generation of thermionic cell in a megawatt class TFE, and the "1" refers to the number of cells in the TFE.

The second step is the development of the intercell region of the TFE. The test vehicle will be the 3 H-series TFE which will contain three of the H-series cells welded end-to-end in an electrical serles circuit. The center cell in the series is isolated from TFE end-fittings and is thereby typical of cells within the interior of a thermionic reactor. The testing of the three cell TFE also allows the study of fission gas venting in a representative multicell environment at a minimum expense.

As the last step in the TRIGA testing, 6H-series TFEs will be built to demonstrate the fabricability of a long TFE where axial alignment is critical. Testing of these TFEs will provide additional demonstration of fission product venting and the capability to maintain unobstructed fission gas passages.

Success in the process development will be evidenced by the observed in-reactor performance and stability. At the same time, TFE design features/options/evolutionary improvements can be tested:

1) Oxygenated electrodes

2) Cesfum sorption reservoir alternatives

3) High strength emitter alternatives

4) Sheath insulator electrical stability

5) Fission gas venting

6) Fuel hold-down device (launch capability). 


\subsubsection{TRIGA Facility}

The Mark F TRIGA reactor will be used for TFE testing. This includes a neutron radiography facility located within the reactor pool for periodic nondestructive diagnostic examinations of the TFE internals.

The TRIGA typically operates at about $1.4 \mathrm{MW}(t)$. At this power level, the fast fluence is about $1 \times 10^{21}$ nvt (E>.1 Mev) per year.

\subsubsection{Design Description}

Test article. The partial length and prototypic TFEs for incore testing are made up of a string of thermionic converters with additional portions above and below the string. The thermionic converter string, which is the portion of the TFE that constitutes the active core of the thermionic reactor, is designed and fabricated to the requirements of the system baseline design. The number of converters in the partial length string varies according to test defintion. The portions of the TFE above and below the converter string, which include the cesium reservoir for the TFE, have only been designed thus far for the partial length TFEs. These portions are not prototypic but instead designed for the requirements of the test. However, they are to be fabricated in the same manner as the reactor prototypic TFE, which has an essentially all electron-beam-welded refractory metal envelope.

The remainder of the test vehicle is designed to encapsulate the test article as necessary for irradiation in the test reactor, to provide appropriate boundary conditions to assure validity of the test and to accommodate desired instrumentation.

Converter string. The present thermionic converter design is designated as the H-series. (This terminology follows from the A-series through F-series converter designs fabricated under the NASA/AEC thermionic program from 1962 to 1973. The various series had different emitter diameters and employed differing fabrication techniques. The H-serfes most closely resembles the old $E$ - and F-series converters.) 
There are 12 H-series converters welded together axially and bonded into a common sheath tube in the reference thermionic reactor system design. All of the test articles in the current program plan have from one to six converters per TFE. Figure 8-1 illustrates a single H-series converter and identifies its parts according to the nomenclature used in the following text. The converters in a TFE string differ from each other only in the fuel enrichment and/or fuel pellet inside diameter.

Thermionic converter. The H-series emitter is $12.7 \mathrm{~mm}(0.5 \mathrm{in.})$ in diameter and $51 \mathrm{~mm}(2.0 \mathrm{in.})$ 1ong. The emitter cylindrical wall thickness is $1.0 \mathrm{~mm}(0.040 \mathrm{in.})$, and the emitter bottom thickness is $1.5 \mathrm{~mm}(0.060$ in.) with a $0.33(0.013 \mathrm{in.)}$ deep recess to accomodate a $7.6 \mathrm{~mm}(0.3 \mathrm{in.})$ diameter converter-to-converter alignment spring (which is discussed further below). At the top end of the emitter is the emitter stem, which serves as both electrical lead to the emitter and as thermal choke for the emitter. The stem is $0.51 \mathrm{~mm}(0.020 \mathrm{in.})$ thick and $12.2 \mathrm{~mm}$ (0.48 in.) long. The emitter is tungsten, and it is fabricated in two layers. The inner, thicker layer is chemically vapor deposited from $\mathrm{WF}_{6}{ }^{\circ}$. This is the structural layer of the emitter, and 1 t also makes up the emitter stem. The outer $0.30 \mathrm{~mm}(0.012 \mathrm{in.})$ of the emitter is deposited from $\mathrm{WCI}_{6}$, which provides the oriented emission surface. The emitter is diffusion bonded to a tantalum transition piece at the top end.

Inside the emitter is the nuclear fuel. Three annular pellets of $\mathrm{UO}_{2}$ total $46 \mathrm{~mm}(1.83 \mathrm{in.})$ in length. In the reference reactor all fuel pellets are made of fully enriched uranium, and the fuel pellet inside diameter varles depending on axial location of the converter in the TFE and the radial location of the TFE in the core in order to flatten power generation. In the test articles both enrichment and fuel volume are varied according to test goals. A tungsten-26\% rhenium pedestal holds the fuel off the emitter bottom for the purpose of maintaining lower and more uniform emitter bottom temperatures than if the fuel were in contact with the bottom. Above the fuel there are four tungsten-26\% rhenium discs alternating with formed wire spacers which serve as thermal radiation shields to reduce axial heat loss from the fuel and to inhibit fuel vapor transport. A tungsten-26\% rhenlum fuel holddown spring locates the fuel 


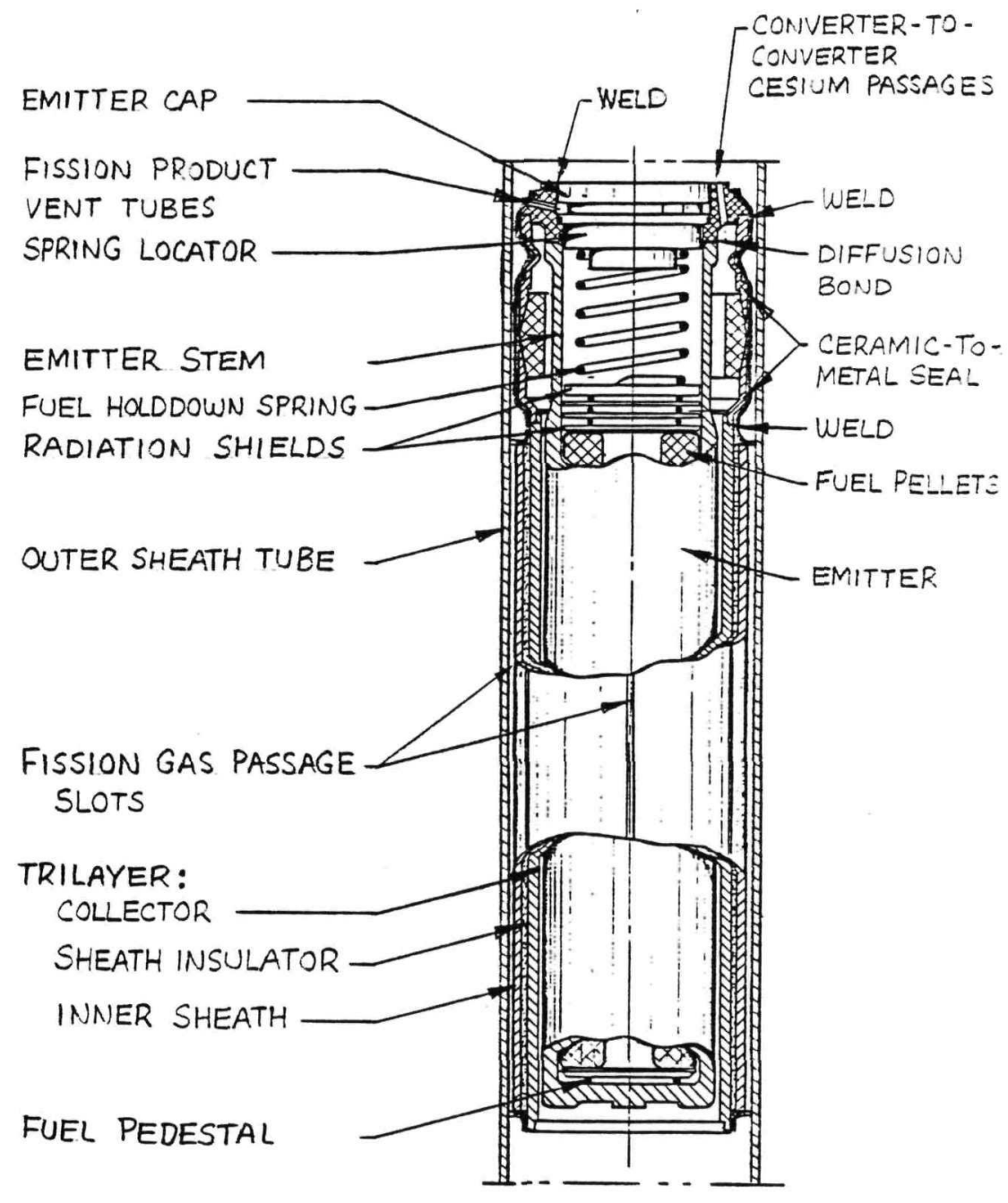

Figure 8-1. H-Series Thermionic Converter 
and internal parts in place during fabrication and encapsulation. (At this phase in the program the design of a flight qualifed fuel holddown has not been incorporated in the H-series TFEs.) Above the spring is a component to radially and axially locate the spring. This spring locator is made of tantalum.

The fuel space is closed with a tantalum cap welded into the transition piece. There are three $0.30 \mathrm{~mm}(0.012 \mathrm{in.})$ inside diameter fission product vent tubes located in the transition piece. The tubes are made of polycrystalline high purity alumina and pressed into radial holes $0.66 \mathrm{~mm}$ ( $0.026 \mathrm{in.})$ in diameter in the transition piece. These vent tubes provide a passage for fission product gases from the fuel cavity inside the emitter to the annular space outside of the ceramic-to-metal seal and the emitter transition piece.

Opposite the emitter is the collector, and between them is the interelectrode gap, which is filled with cesium vapor. The radial interelectrode gap is $0.25 \mathrm{~mm}(0.010 \mathrm{in.})$. Cesium is supplied to each converter through six $0.33 \mathrm{~mm}$ (0.026 in.) diameter axial holes in the transition piece which provide passages between the converters in the string.

The collector is part of a trilayer structure which is fabricated by gas pressure bonding. It is made up of a $0.76 \mathrm{~mm}(0.030 \mathrm{in.})$ thick niobium Inner layer, which is the current carrying collector, an intermediate sheath insulator layer $0.41 \mathrm{~mm}(0.016 \mathrm{in.})$ thick, and an outer niobium layer $0.48 \mathrm{~mm}$ (0.019 in.) thick, which is called the inner sheath. YAG, yttria and alumina are candidate materials for sheath insulator ceramic. The trilayer outside diameter is $16.5 \mathrm{~mm}(0.65 \mathrm{in.})$. The inner sheath is slotted parallel to its longitudinal axis at places around the outside diameter to a depth of $0.20 \mathrm{~mm}(0.008 \mathrm{in.}), 0.38 \mathrm{~mm}(0.015 \mathrm{in.})$ wide, to form axial fission product gas passages from one converter to the next. There would be no slots in the trilayer of the bottom converter in a string, since there is no converter below it to produce gas.

The converter ceramic-to-metal seal is a subassembly comprised of a 
$1.4 \mathrm{~mm}$ ( $0.054 \mathrm{in.})$ thick by $0.64 \mathrm{~mm}$ ( $0.025 \mathrm{in.})$ wide ceramic (insulator) ring with niobium skirts brazed to it. The upper niobium skirt is thinned to $0.38 \mathrm{~mm}(0.015 \mathrm{in}$ ) and formed into a convolution with a depth of $0.76 \mathrm{~mm}(0.030 \mathrm{in.})$ and a minimum radius of $0.25 \mathrm{~mm}(0.010 \mathrm{in.})$. This convolution compensates for the differential thermal expansion between the ceramic-to-metal seal and the unbonded section of the outer sheath tube. The ceramic-to-metal seal is welded between the fueled emitter subassembly and the trilayer to make up the converter unit, as shown in Fig. 8-1.

Intercell Region. The individual converters are welded end-to-end connecting the emitter transition of one converter to the collector of the converter above it and completing the electrical series conection. This weld also seals the interelectrode (cesium) space from the fission product space. Figure 8-2 shows the converter-to-converter region in detail. In between the welded converter units (fueled emitter, ceramic-to-metal seal and trilayer) are a conical tungsten-26\% rhenium alignment washer $0.25 \mathrm{~mm}$ ( 0.010 in.) thick, $7.6 \mathrm{~mm}(0.30 \mathrm{in.})$ outside diameter, $2.5 \mathrm{~mm}(0.10 \mathrm{in.})$ inside diameter, and a high purity polycrystalline alumina insulator 0.89 mo (0.035 in.) thick and $10.9 \mathrm{~mm}(0.43 \mathrm{in.})$ in diameter. The alignment washer locates on a $2.5 \mathrm{~mm}(0.10 \mathrm{in}$ ) ) diameter button on the bottom of the emitter, and the alignment insulator sits in a $10.9 \mathrm{~mm}$ ( $0.43 \mathrm{in.})$ diameter recess in the emitter cap of the converter below. These components provide support for the end of the emitter under mechanical loading and assure alignment of the interelectrode gap.

A $80 \mu(0.003$ in. $)$ thick plasma-sprayed alumina coating is applied over the outside of the ceramic-to-metal seals and transition pieces after the converter string is welded together. The string is then put into a $0.51 \mathrm{~mm}$ ( 0.020 in.) thick niobium-1\% zirconium outer sheath tube which has an inner coating of nickel. The radial clearance to the tube is 13 to $18(0.0005$ to $0.0007 \mathrm{in.)}$. The assembly is subsequently wrapped with tungsten wire and heated to $1500 \mathrm{~K}$, at which temperature the inner sheath and outer sheath tube are forced into contact by the differential expansion of the largely niobium TFE structure and the tungsten wrap. A nickel-niobium braze is accomplished which bonds the converter string into the outer sheath tube. The tungsten wire wrap is removed and the final TFE outside diameter is $17.5 \mathrm{~mm}(0.69 \mathrm{in.})$. 


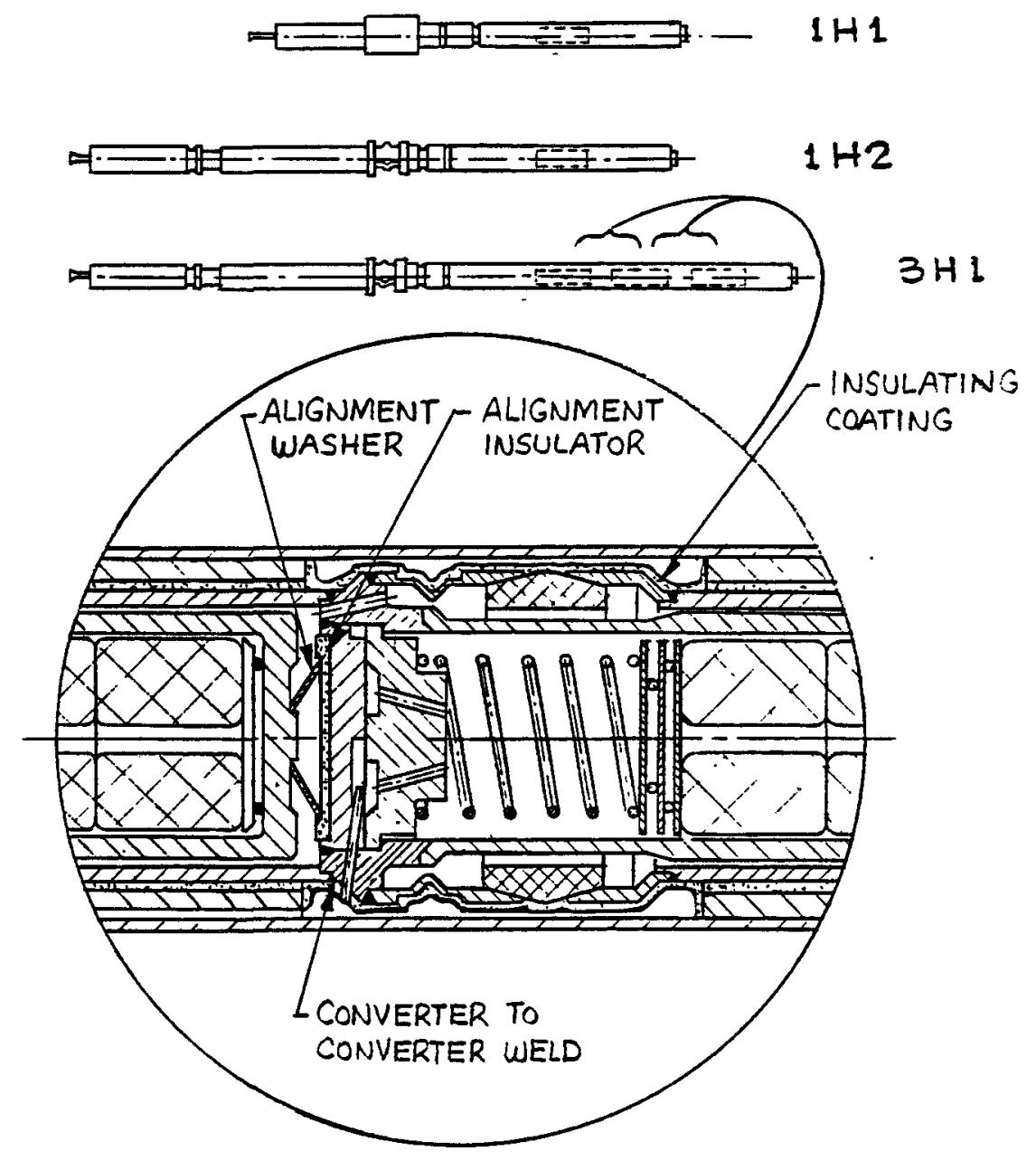

Figure 8-2. Converter to Converter Region 
Above and Below the Converter String. The description above applies to all of the partial length and prototypic TFEs for in-core testing in either TRIGA or FFTF. The description following applies only to the near term TRIGA irradiations, specifically test articles $1 \mathrm{H} 1,1 \mathrm{H} 2$ and $3 \mathrm{H} 1$.

Located below the bottom converter in the test articles is a "dummy cell". The dummy is welded to the collector of the bottom converter as another converter would be, and it is located within the outer sheath tube. The converter-to-dummy region is shown in Fig. 8-3. The dumy performs the following functions:

- seats the alignment washer and insulator for the bottom emitter,

- conducts the TFE current from the bottom collector,

- provides another ceramic-to-metal seal, which insulates the bottom converters collector potential from the outer sheath tube potential,

- seals the interelectrode (cesium) space at the bottom,

- provides a backup fission product space seal to the sheath tube bond of the bottom trilayer,

- provides a shoulder to which to weld the outer sheath tube.

Figure 8-4 illustrates the bottom of the TFE. A brazed niobium-copper lead end piece is welded to the dumm collector lead after TFE sheath tube bonding and final processing. To this is welded a copper bus tube that carries the TFE current back to beyond the top end of the test article.

Above the converter string is the TFE stem region. Above that is a liquid cesium reservoir in TFE 1H1. Figure 8-5 shows the complete TFE $1 \mathrm{H} 1$.

Not only is the cesium supplied to the converter string from above these test articles, but also the converter current and the fission product gases are led away from the string in the same direction. The electric current is drawn from the top of the emitter of the top most converter by a hollow niobium lead. The cesium communicates between the reservoir and the converter through the center of the lead. The region between the converter string and the cesium reservoir is referred to as the TFE stem. 


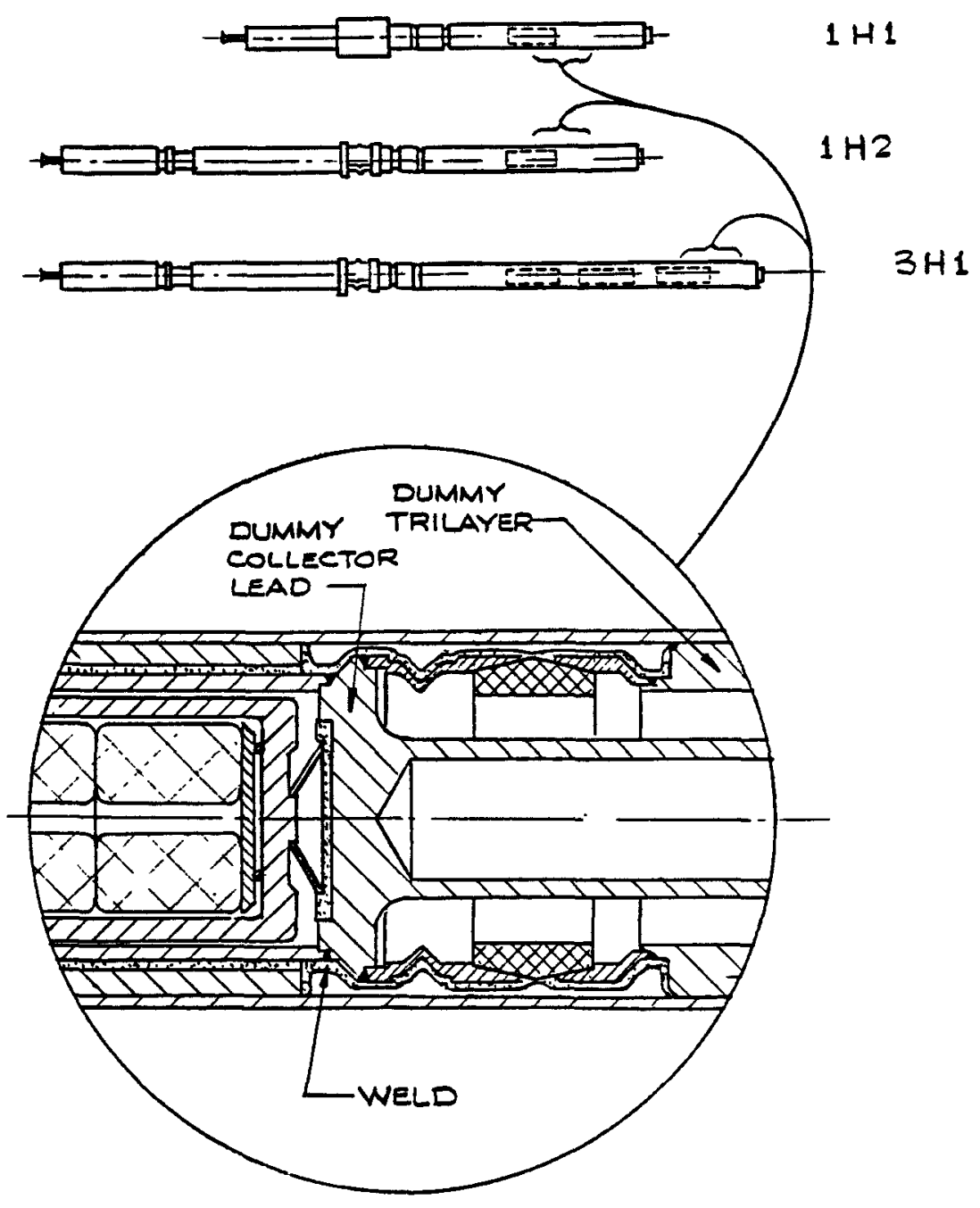

Figure 8-3. Converter-to-Dumny Region 


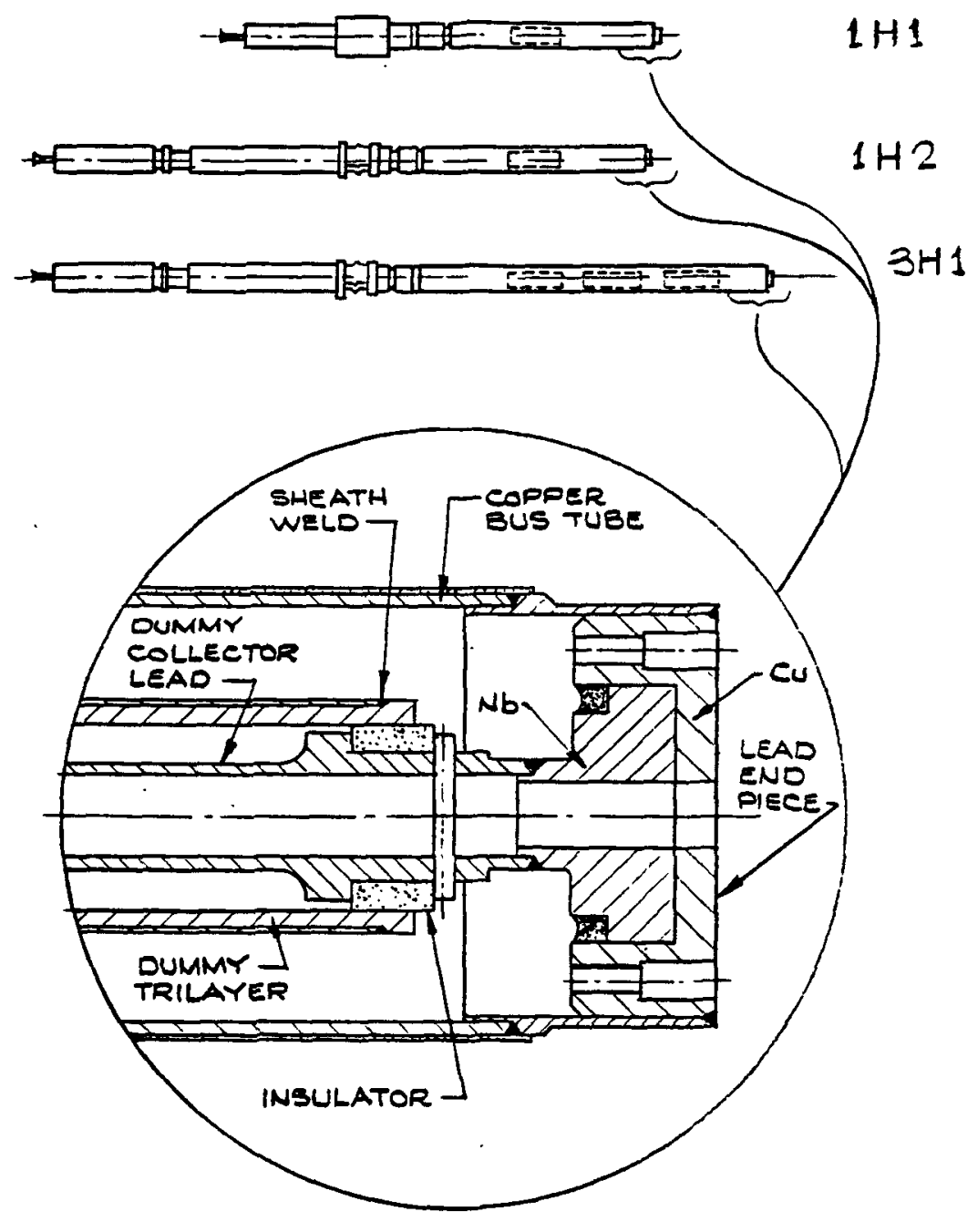

Figure 8-4. Bottom of TFE 


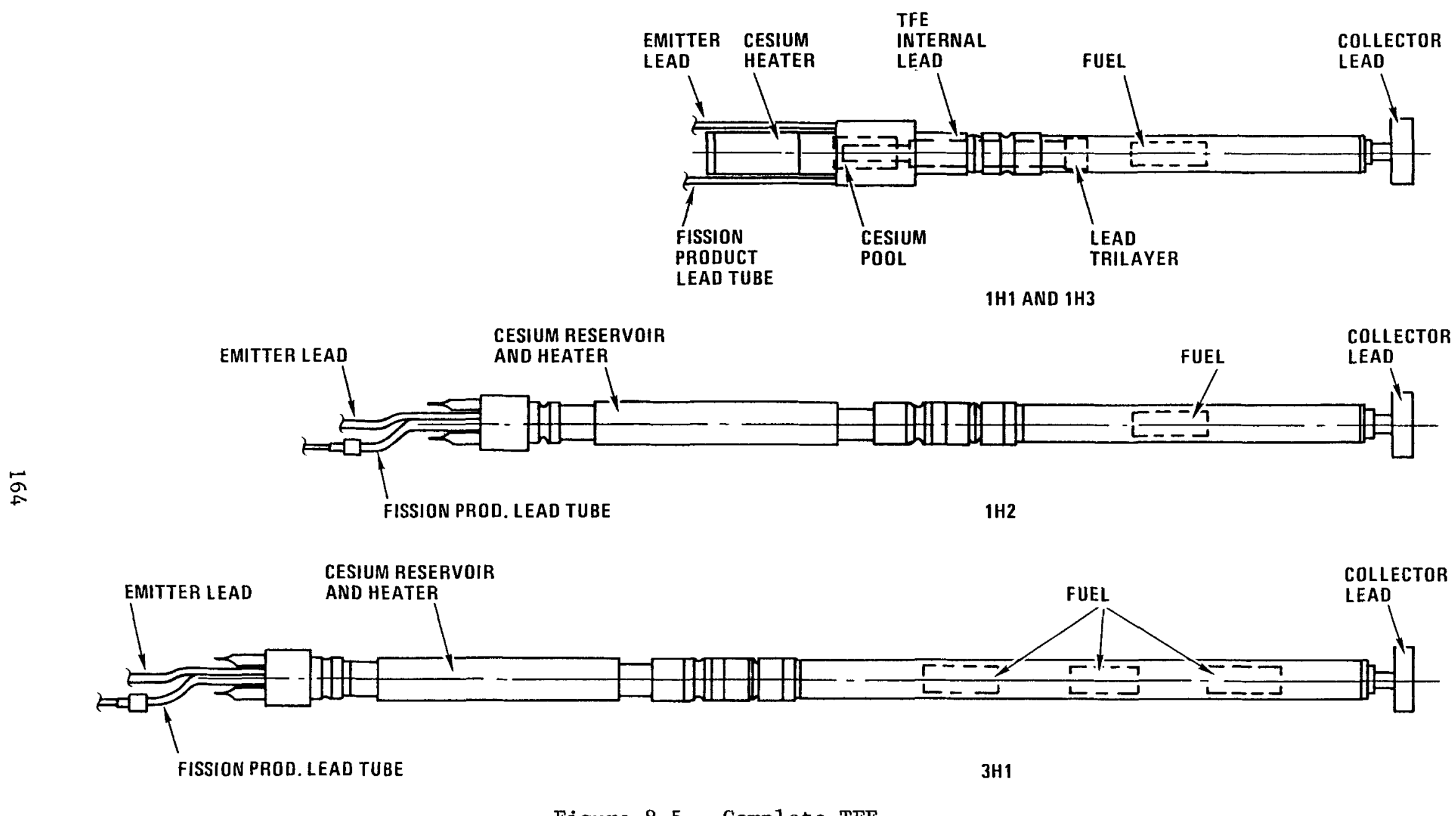

Figure 8-5 - Complete TFE 
Figure 8-6 shows the detail of the bottom of this stem region. Between the emitter lead and the top most emitter transition piece is the lead trilayer. This is a short piece of the same structure as the collector trilayer in the converters, and it is bonded to the outer sheath tube. This component is required in order to mechanically locate the top most emitter, which otherwise would be supported only on the convolution of its ceramic-to-metal seal.

Outside of the emitter lead the fission product space is enclosed by a stem sheath structure consisting of an expansion joint, to accomodate differential thermal growth, and a ceramic-to-metal insulator. This ceramic-to-metal seal is of the same high temperature brazed design as the converter seals. This stem sheath structure is welded at the bottom to the top of the TFE outer sheath and at the top to the cesium reservoir. The insulator separates the sheath potential from the reservoir structure which is electrically connected to the emitter potential.

Cesium Reservoir. Figure 8-7 shows the detail of the liquid cesium reservoir and Fig.8-8 shows the graphite reservoir. These assemblies are welded niobium, except where fission product tubing has been brazed in place. The heater wires are tantalum sheathed mineral-coated cable and are brazed in position. Leading away from the TFE at the top in each design are the solid niobium emitter current lead and a tube for fission products.

In the TFE, there is complete separation of the interelectrode (cesium) volume from the fission product space. In the event of a leak between the two volumes, the cesium would gradually flow into the fission product space and then out of the TFE and into the external fission gas collection chambers. (The design of the collection system external to the TFE is discussed below under the test vehicle topic.) To assure against such a loss of cesium, which would eventually terminate the test, the TFE design includes a port tube in the fission product system. The port tube passes the noble gas fission products with insignificant pressure drop but reduces cesium vapor leakage out of the TFE, if there should be a leak between the cesium volume and the fission product space. The port tube is located in TFE $1 \mathrm{H} 1$ as shown in Fig. 8-7, and for $1 \mathrm{H} 2$ and $3 \mathrm{H} 1$ it is illustrated in Fig. 8-8. 


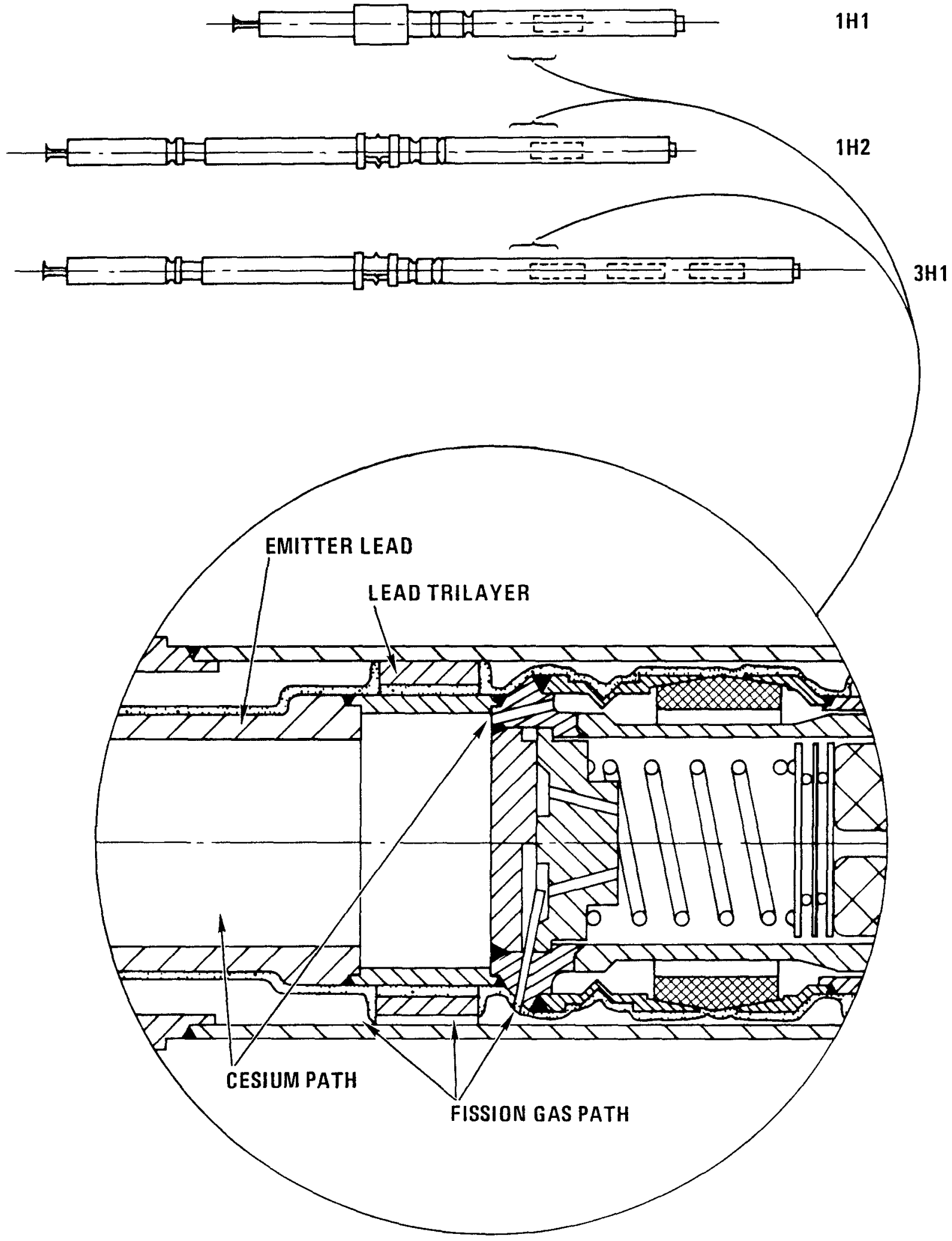

Figure 8-6 - Converter-to-TFE Lead Region 


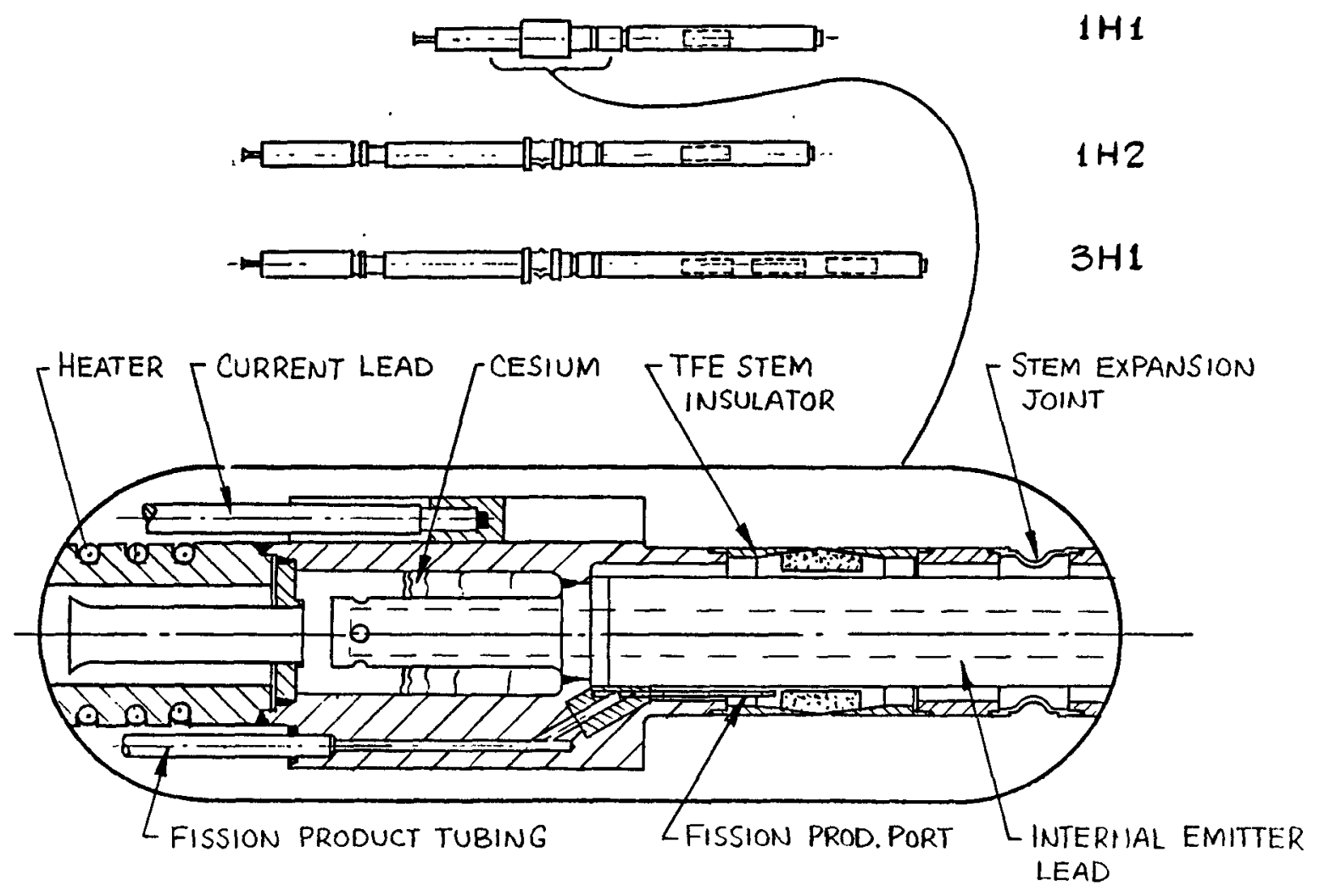

Figure 8-7. Liquid Cesium Reservoir 

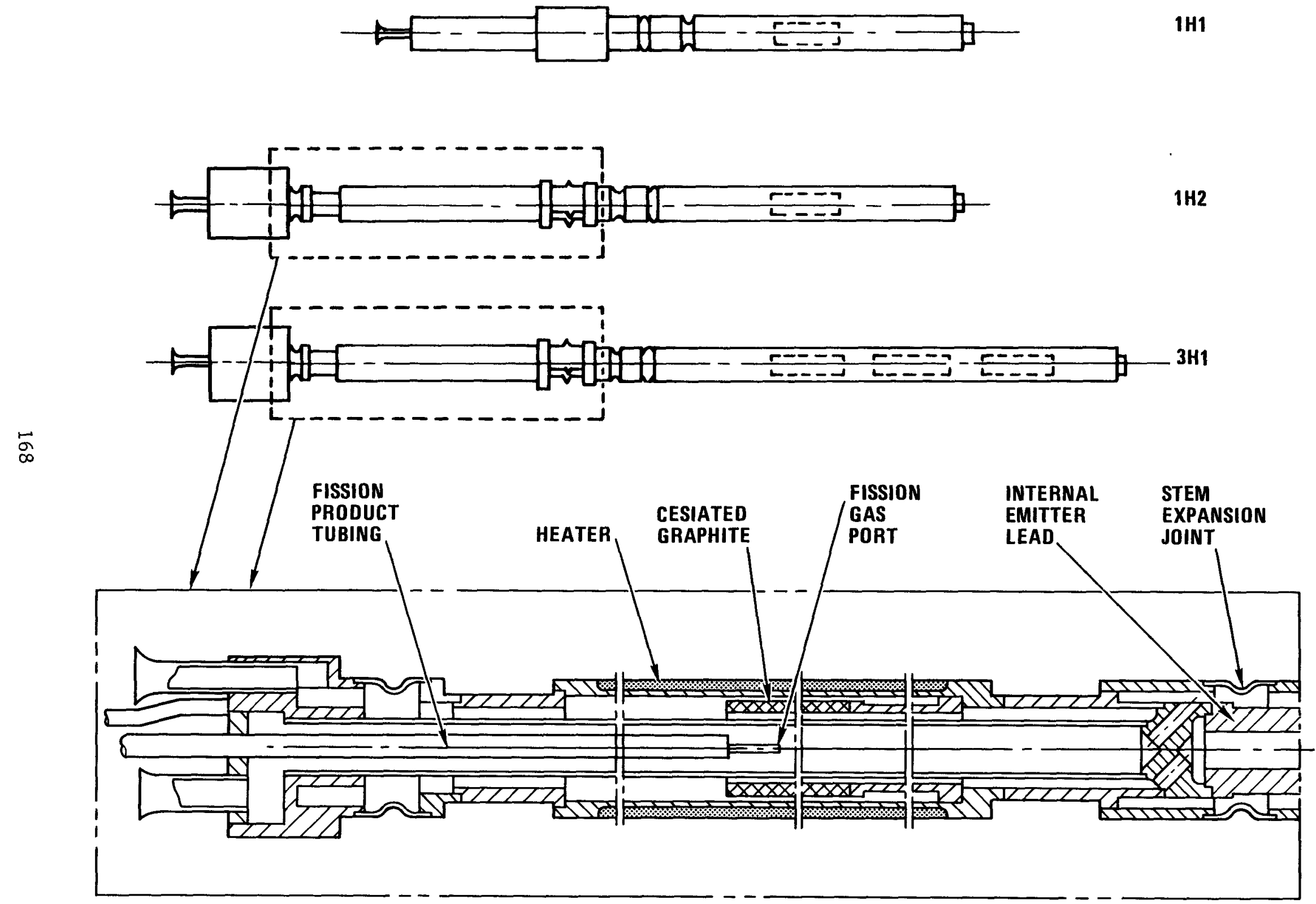

Figure 8-8, Latest Graphite Cesium Reservoir 
Figure 8-9 is a simplified diagram of the separate cesium and fission product plumbing within the TFE for both liquid and graphite reservoir designs. Shown in the figure are the tubing connecting the TFE to the pumpout and backfill systems at the final processing step. (This processing is discussed further in Section 8.4.) Also shown is the connection to the line leading to the fission gas collection chamber in the TRIGA test capsule configuration. (The schematic diagram of the capsule is shown in Fig.8-10.)

Above the TFE, the solid niobium emitter lead is welded to a solid copper bus, which passes through the primary containment hard seal. Outside of the converter string and TFE stem and reservoir assemblies is a copper bus tube connected to the bottom converter collector potential, as shown in Fig. 8-4. This bus tube continues upward to the hard seal where there is a transition to a copper bus, which passes through the seal.

Test Vehicle. The test vehicle described here is the irradiation capsule for testing TFEs 1H1, 1H2, 1H3, 3H1 in the Mark F TRIGA reactor. No significant engineering has yet begun on capsules for the other tests in the overall program.

In the TRIGA reactor, the test vehicle will be inserted in place of a TRIGA fuel element, which is $38 \mathrm{~mm}$ ( $1.5 \mathrm{in.}$ ) in diameter. The test vehicle must be dimensionally compatible with the reactor core. The test vehicle is required to meet the safety criteria and technical specification limits of the reactor 1 icense.

The test vehicle design must permit operation of the test article over the range of TFE thermal and electrical parameters desired to meet the test objectives. Instrumentation must also be provided in accordance with the test plan.

The test vehicle design incorporates a double austenitic stainlesssteel encapsulation of the test article with the primary (inner) containment leak tight to less than $2 \times 10^{-8} \mathrm{scc} / \mathrm{sec}$. All instrumentation penetrations of the primary containment must be leak tight to $1200 \mathrm{~K}$. Heat rejection to the TRIGA reactor coolant must not exceed the threshold for nucleate bolling. 


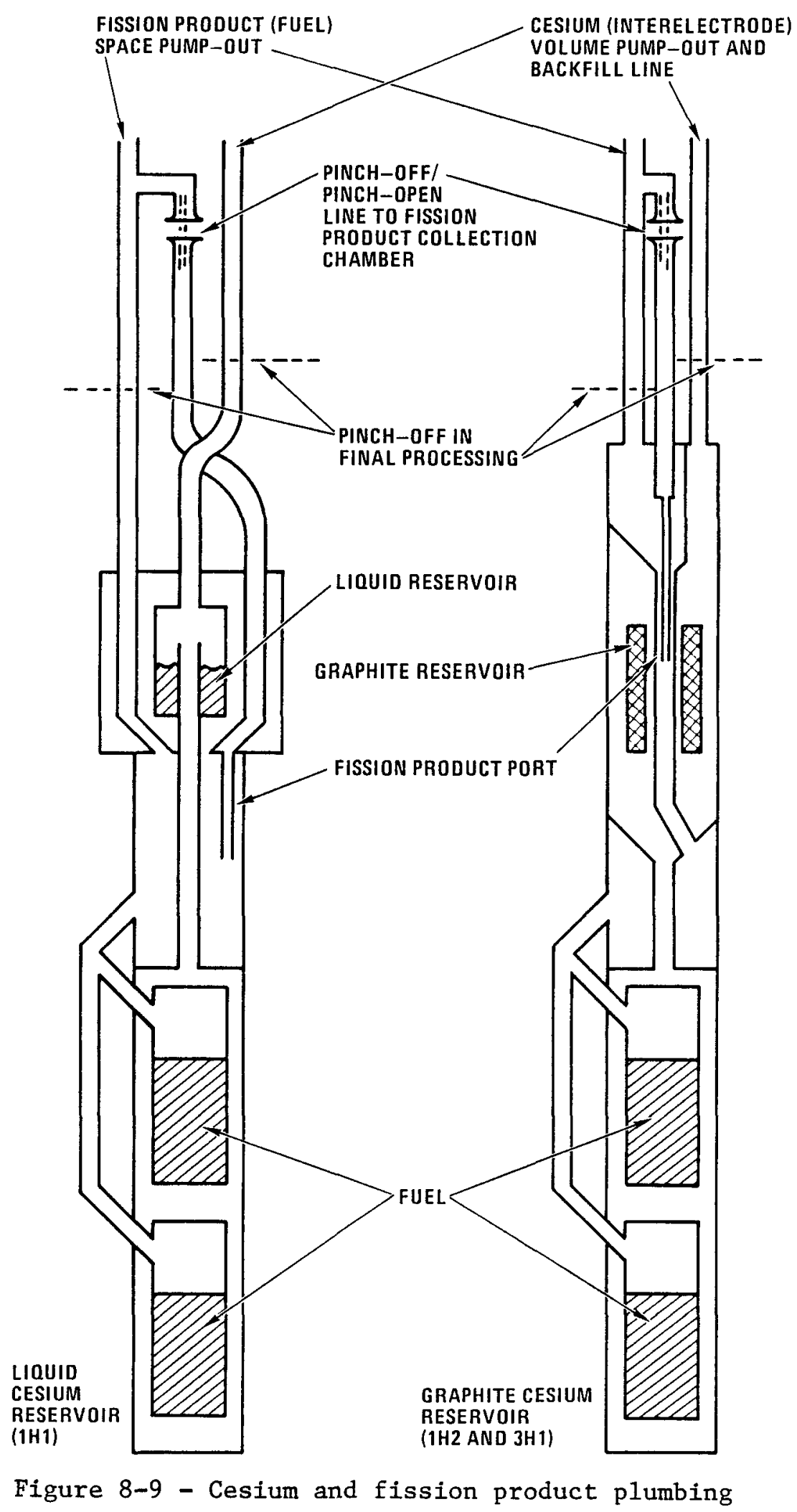




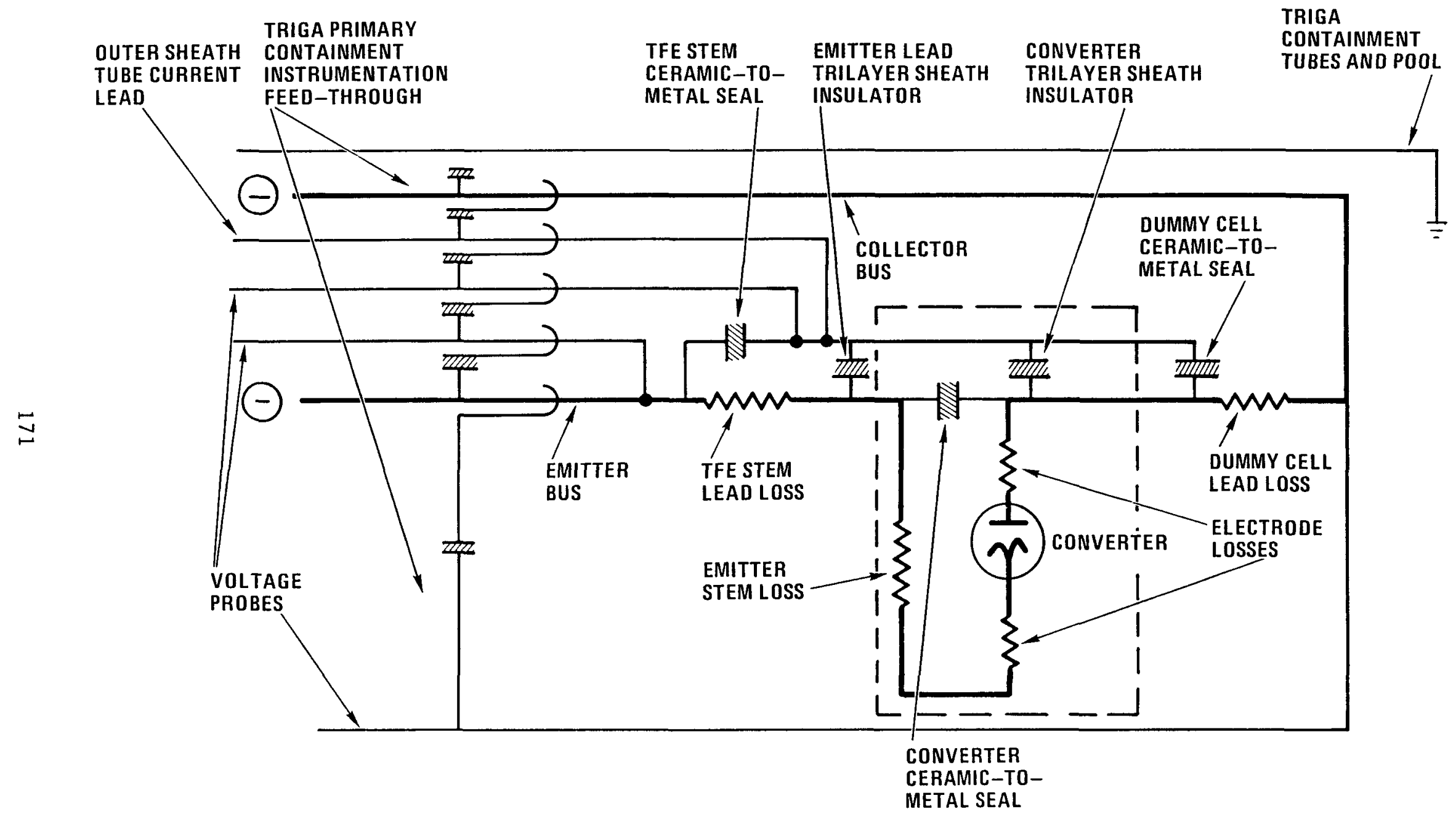

Figure 8-10 - 1H TFE Electrical Schematic 
The basic electrical arrangement and performance diagnostics are shown in the schematic diagram in Fig. 8-11.

Figure 8-10 is a schematic drawing of TFE 1H1 in its TRIGA irradiation capsule.

Surrounding the test article, the test vehicle for the $1 \mathrm{H}$ and $3 \mathrm{H}$ series of TFEs consists of concentric thin walled stainless steel containment envelopes. Above the TRIGA core there is a transition to a larger diameter, and there the primary containment is closed with a hard seal. The primary containment is permanently filled with one atmosphere of helium. The outer containment extends to above the top of the reactor pool, a distance of approximately $7.5 \mathrm{~m}$. It is closed $2.5 \mathrm{~m}$ above the core with a cast epoxy seal, but by means of a tube extending to the top of the pool the gas in the secondary containment volume can be changed during the test.

Between the TFE and the containment tubes there is a filler block which incorporates a pair of heater colls. The collector temperature of the TFE can thus be controlled by both adding heat to the redundant coils on the filler block and changing the gas mixture in the secondary containment. Two similar heaters are brazed to the cesium reservoir heater block for control of the reservoir temperature, and hence control of the cesium vapor pressure in the TFE and the thermionic performance. In TFE 1 H1 two stainless steel-clad heater cables will be wrapped around the cesium reservoir stem to trim the temperature of the top of the TFE. For $1 \mathrm{H} 2$ and $3 \mathrm{H} 1$ there will be heaters wrapped around the pinchoff tubes at the end of the TFE. A11 of these custom-made heater cables, are approximately $1.8 \mathrm{~mm}(0.070 \mathrm{in}$.) in diameter.

The dimensions of the various heat transfer gaps and other relevant thicknesses are shown in Fig. 8-12 for a TFE with a liquid cesium rservoir, like 1H1, and in Fig. 8-13 for a TFE with a graphite reservoir, like $1 \mathrm{H} 2$ and 3H1. Also shown are the general locations of the heaters.

Emitter temperature is dependent upon current density, cesium pressure (proportional to reservolr temperature), collector temperature and fuel heat 


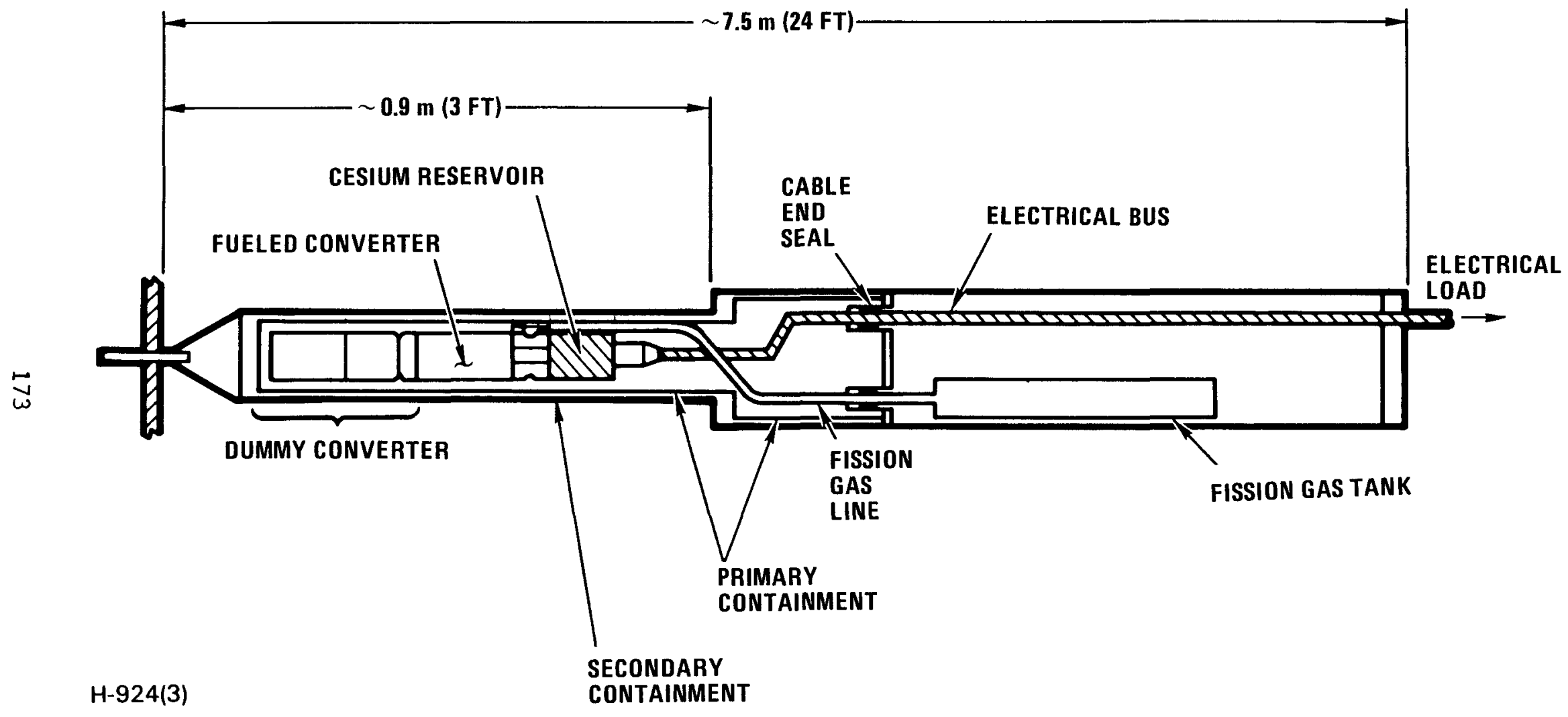

Figure 8-11 - TRIGA Test Capsule Schematic 


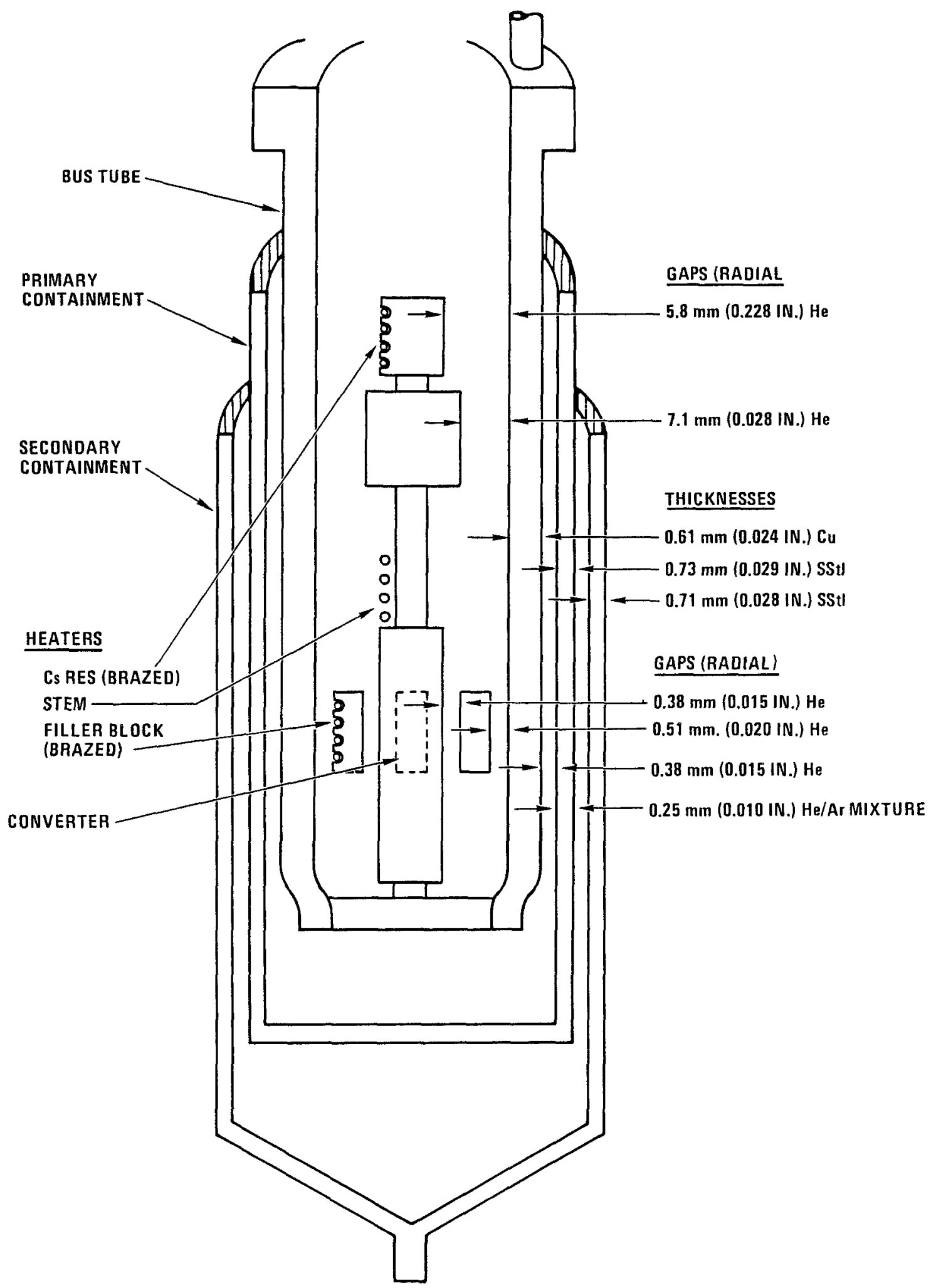

Figure 8-12 - TFE $1 \mathrm{H} 1$ Containment Details (all dimensions cold) 


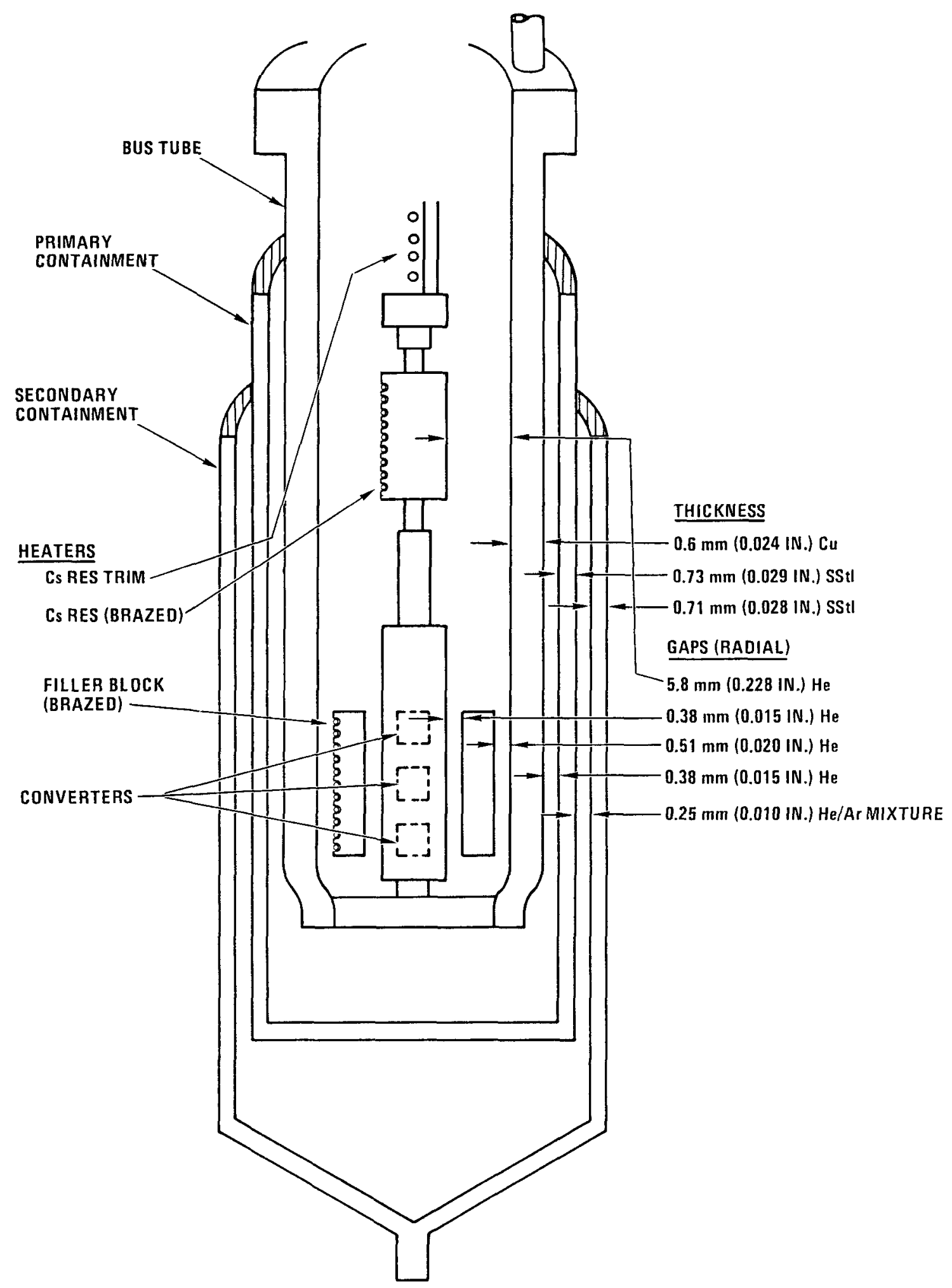

Figure 8-13 - TFE 1 H2 Containment Details (a11 dimensions cold) 
generation. Nuclear heating in the fuel can be reduced by lifting the entire test vehicle assembly above and away from the core centerplane. As a result, the principal parameters of emitter temperature, cesium pressure and collector temperature can be adjusted by changing elevation, collector (filler block) heater power, cesium reservoir heater power and secondary containment gas composition.

The $1 \mathrm{H} 1$ and $1 \mathrm{H} 2$ capsules for in-core TRIGA testing are instrumented with twelve thermocouples to monitor the TFE. These are ceramic-insulated, Inconel-clad, floating junction, chromel-alumel thermocouples of $1.0 \mathrm{~mm}$ (0.040 in.) diameter. Tables $8-3$ and $8-4$ describe the location and summarize the purpose of each thermocouple.

Current leads will link the TFE to the load, located outside the reactor. These bus bars are designed for 150 amps of continuous electric current. A third lead will be attached to the outer sheath potential to allow drawing current across the sheath insulators. Current in this lead will be only a few milliamperes. Three voltage probes will tap the cell emitter potential, the collector potential and the outer sheath potential. This arrangement is shown in the schematic diagram of Fig. 8-10.

The TFE fission product system consists of the passages within the converter region of the TFE which connect the fuel space to the volume between the converters and the sheath tube. This space communicates with the annular space in the cesium reservoir stem region outside the emitter lead and inside the enveloping sheath assembly. Through passages in the cesium reservoir block, tubes lead out of the TFE and into an external fission gas collection chamber. The collection chamber is a stainless vessel one liter in volume and initially a vacuum. Xenon and krypton are the major noncondensable fission product constituents, and based on their projected generation rate in a one-cell TFE, the chamber pressure would rise to $4.5 \mathrm{mbar}$ at the end of 20,000 hours.

\subsection{ENGINEERING AND HARDWARE DESIGN}

This subtask involves the preliminary engineering design of the test 
TABLE 8-3

LOCATIONS OF THERMOCOUPLES AND PROBES - TFE $1 \mathrm{HI}$

$\begin{array}{lll}\text { Thermocouple Number* Location } & \text { Purpose }\end{array}$

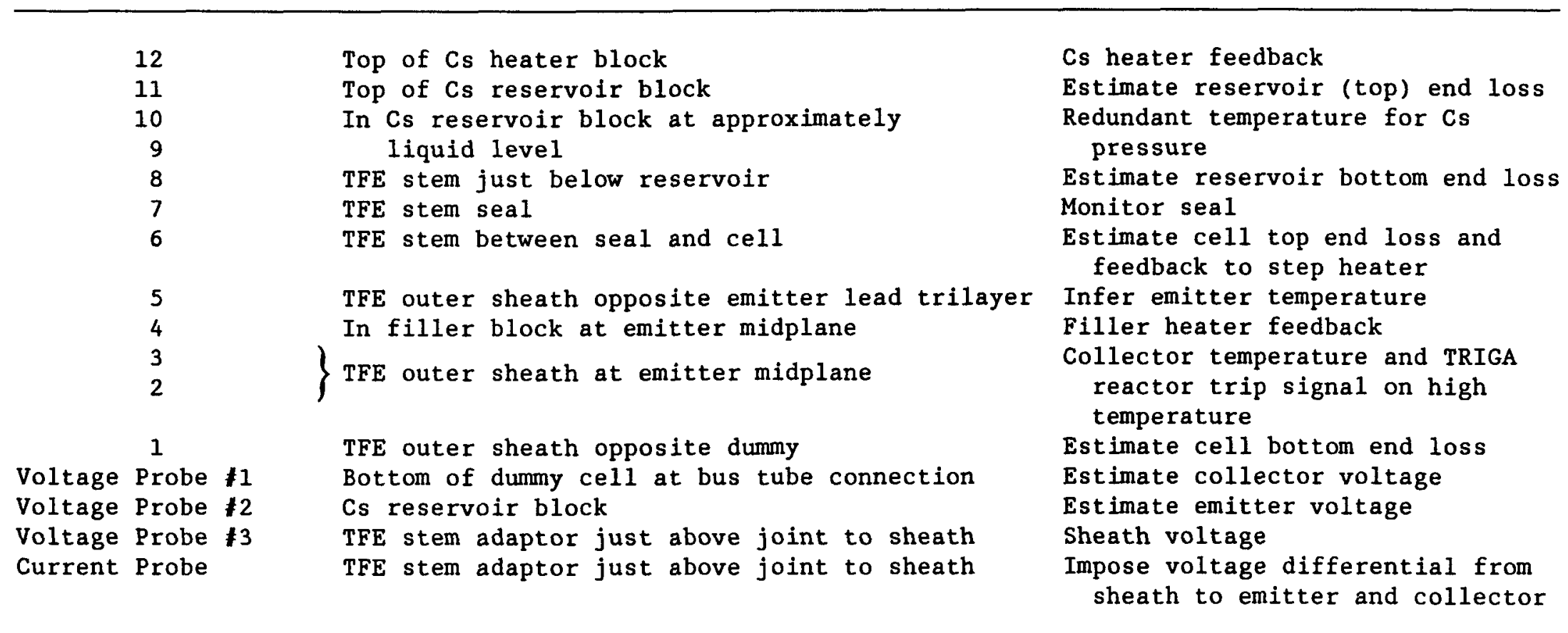

* Sheaths of T/Cs 1 thru 6 are at TFE sheath potential;

Sheaths of T/Cs 7 thru 12 are at emitter potential. 
TABLE $8-4$

LOCATIONS OF THERMOCOUPLES AND PROBES - TFE 1H2

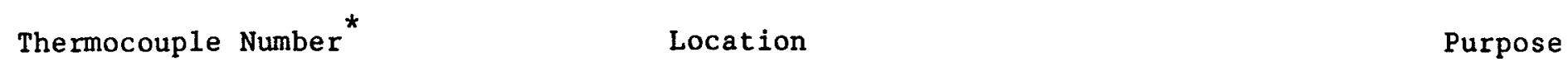

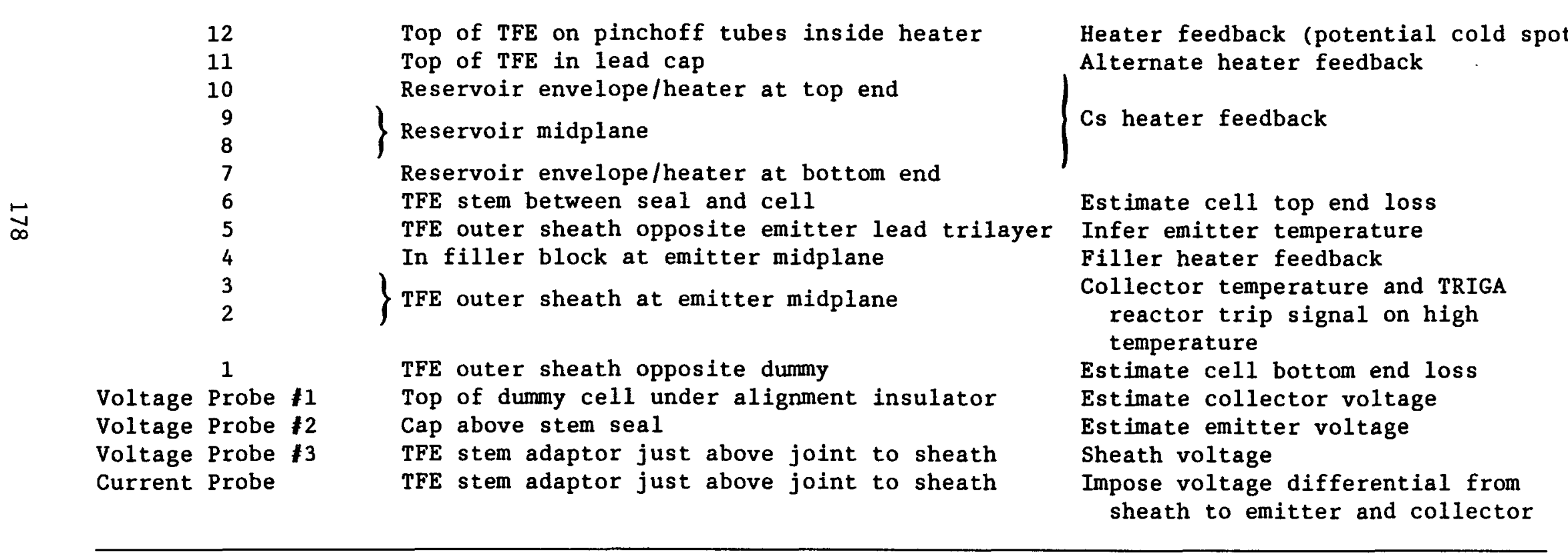

* Sheaths of T/Cs 1 thru 6 are at TFE sheath potential;

Sheaths of $\mathrm{T} / \mathrm{Cs} 7$ thru 12 are at emitter potential. 
article TFEs, as described in Section 8.2 .3 , and the test vehicles for real time TFE testing, as described in Section 8.3.3.

The test article serles is to progress toward more and more prototypic TFEs, to be tested in more realistic test environments. The progression of the design is also to be iterative during the course of the program, incorporating modifications, new methods and alternate materfals resulting from testing and modeling being conducted in parallel.

The detailed design begins with and improves upon the "flashlight" TFE technology developed under the 1962-1973 NASA/AEC thermionic reactor development program.

Analyses are done to confirm adherence to the specifications and requirements. These include thermionic performance calculations and oneand two-dimensfonal nuclear, thermal and stress analysis. The two-dimensional analyses employ varfous widely used, documented and verified computer programs. Stress analyses extend to calculations of static and dynamic responses and of thermoelastic, plastic and creep behavior. Analyses are done separately for various component parts of the TFE. Calculation files are maintained so that analytical support can be available in the subsequent testing and post-irradiation inspection phases.

Design of TFE fabrication tooling, fixtures and processing apparatus is included. Design support is also provided for weld qualification, for component mockup pieces and for general review of process specifications in support of fabrication development. In addition, the designers participate through the Materials Review Board, which is a part of the quality assurance function. During the actual fabrication, they will participate in the postirradiation examinations of test articles.

Technical results for the latest reporting period are reported as follows :

\footnotetext{
- Converter design

- Cesium reservoir design

- TFE assembly design

- Test capsule design.
} 


\subsubsection{Converter Design}

Summary of past work. Design drawings for TFE 1 H1 and associated tooling were completed. Conceptual design and initial detailed design of TFE 1 H2 was completed.

Thermal analyses were done for the converter in the $6 \mathrm{H}$ configuration and the liquid-metal-cooled reactor to verify that electrode profiles and converter end losses are insignificantly different. The converter in $1 \mathrm{HI}$ configuration was also analyzed to provide comparative end losses.

Converter design refinements. Design and assembly details for TFE $1 \mathrm{H} 2$ were completed. Preliminary designs of TFEs $1 \mathrm{H} 3$ and $3 \mathrm{H} 1$ were done. Differences in the basic converter design between these test articles are slight. Table 8-5 summarizes those differences.

TABLE $8-5$

DIFFERENCES BETWEEN CONVERTERS

\begin{tabular}{lccccc} 
Test Article Feature & $1 \mathrm{H} 1$ & $1 \mathrm{H} 2$ & $1 \mathrm{H} 3$ & $3 \mathrm{H} 1$ & $3 \mathrm{H} 5$ \\
\hline Number of converters & 1 & 1 & 1 & 3 & 3 \\
Alignment scheme & $01 \mathrm{~d}$ & $01 \mathrm{~d}$ & $01 \mathrm{~d}_{*}$ & $\mathrm{New}_{\star}$ & New \\
F.P. trap in emitter & No & No & $\mathrm{Yes}$ & Yes & Yes \\
Revised trilayer ends & No & No & No & Yes & Yes \\
$\begin{array}{l}\text { Mixed Cs and f.p. space } \\
\text { No }\end{array}$ & No & $\mathrm{Yes}_{2}$ & No & No \\
Converter trilayer & $\mathrm{Y}_{2} \mathrm{O}_{3}$ & $\mathrm{Al}_{2} \mathrm{O}_{3}$ & $\mathrm{Al}_{2} \mathrm{O}_{3}$ & $\mathrm{Al}_{2} \mathrm{O}_{3}$ & TBD \\
\hline
\end{tabular}

* $1 \mathrm{H} 3$ and $3 \mathrm{H} 1$ will have interim fission product trap design, similar to traps in 6F5; $3 \mathrm{H} 5$ will have f.p. trap design from Task 7.

The one piece fuel pedestal is a change from that used in $1 \mathrm{H} 1$ and $1 \mathrm{H} 2$ and is a modification of that used for the UFAC test articles. The revised alignment scheme is preliminary as described and 1llustrated in the last semiannual report in Section 7.3.5. The alignment scheme, emitter fission product trap and revised trilayer ends all are designed initially for $3 \mathrm{H} 1$. 


\subsubsection{Cesium Reservoir Design}

Summary of Past Work. Two separate designs have been concluded for the region of the TFE above the converters. One incorporates the liquid ceslum reservoir for $1 \mathrm{H} 1$ and $1 \mathrm{H} 3$, and the other has the graphite cesium reservoir planned for all the other TFEs, starting with $1 \mathrm{H} 2$. Design details and thermal analyses for both have been previously documented.

\section{Cesium Reservoir Design Refinements. The $1 \mathrm{H} 2$ cesium reservoir} reference materlal was changed to POCO-CZR2. Section 7.0 contains a discussion of reservoir materials options. The reservoir is an annular stack of graphite rings $12.9 \mathrm{~mm}(0.51 \mathrm{in.})$ outside diameter by $1.3 \mathrm{~mm}$ $(0.050 \mathrm{in.})$ thick and $50 \mathrm{~mm}$ high. This is a volume of $2.4 \mathrm{cc}$ which will hold $1.5 \mathrm{~g}$ of cesium based upon a conservative graphite specific loading factor for the CZR2 material of $300 \mathrm{mg} / \mathrm{g}$ for $3 \mathrm{H} 1$. The TFE stem region and reservoir was redesigned to improve gas flow conductance for TFE fabrication final outgassing and cesium loading steps. The design configuration of Fig. 8-8 shows the new arrangement.

As shown in Fig. 8-8, the fission gas port is located concentrically within the cesium reservoir in the $1 \mathrm{H} 2$ design. This configuration is chosen so that the port runs as hot as possible to minimize plugging by condensable fission products. In the 1 H1 design (Fig. 8-7) the port was located just below the liquid cesium reservoir where it would run approximately $50 \mathrm{~K}$ above the reservoir temperature of from 500 to $580 \mathrm{~K}$. The resulting design for $1 \mathrm{H} 1$ was a port $50 \mu$ (0.002 in.) in diameter and 28 $\mathrm{mm}$ ( $1.12 \mathrm{in.)} \mathrm{long,} \mathrm{which} \mathrm{would} \mathrm{limit} \mathrm{cesium} \mathrm{loss} \mathrm{from} \mathrm{the} \mathrm{TFE} \mathrm{in} \mathrm{the} \mathrm{event}$ of an internal TFE leak to at most $1.0 \mathrm{~g}$ per 30,000 hours. Inside the $1 \mathrm{H} 2$ reservoir the port tube will run at a minimum of $950 \mathrm{~K}$. For a slightly less conservative design leak rate of 1.0 gram per 20,000 hours the same diameter port tube is $12.6 \mathrm{~mm}$ ( $0.5 \mathrm{in.}$ ) long.

\subsubsection{TFE Assembly Design}

Summary of Past Work. Design details of TFEs $1 \mathrm{H} 1$ and $1 \mathrm{H} 2$ have been previously documented. 
TFE assembly design refinements. A shorter dummy converter was designed for incorporation in TFEs $1 \mathrm{H} 3$ and $3 \mathrm{H} 1$. Figure 8-14 shows the two configurations. The shorter dummy reduces the TFE length by $38 \mathrm{~mm}(1.5$ in.). This configurational change reduces electrical loss in the dummy. The change has no significant effect on the thermal end losses of the converter above and raises the minimum collector temperature, opposite the end of the emitter by approximately $5 \mathrm{~K}$. The temperature at that location in the end converter of a TFE is $125 \mathrm{~K}$ lower than the same location in a converter connected at that end to another converter, and so this temperature rise is not significant.

A calculation was completed of the temperatures in a converter trilayer for the case of an unbonded spot between the trilayer and the TFE outer sheath. U1trasonic inspection after the 1 H1 bonding showed unbonded spots of up to 25 (0.1 in.) across. Figure 8-15 shows the resulting temperatures for a $25 \mathrm{~mm}(0.1 \mathrm{in}$.) disbond starting at the center of the disbonded spot moving circumferentially around the trilayer and outer sheath structure. The collector surface temperature rise at the spot is $3 \mathrm{~K}$ and the maximum temperature difference across the unbonded gap is $17 \mathrm{~K}$. Figure 8-16 shows the temperatures for a $50 \mathrm{~mm}(0.2 \mathrm{in.})$ disbond, where the collector temperature rise is $10 \mathrm{~K}$ and the difference across the gap $45 \mathrm{~K}$. Figure 8-17 shows the effects out to $75 \mathrm{~mm}(0.3 \mathrm{in.})$ disbond size. The analysis demonstrates that although the converter design imposes a high radial heat flux on the trilayer and sheath structure, the structure has a sufficient circumferential thermal conductivity to accommodate less than perfect sheath tube bonding.

\subsubsection{Test Vehicle Design}

Summary of past work. The TRIGA test capsule design details have been committed to fabrication for $1 \mathrm{H} 1$. Previous work included an instrumentation arrangement for the $1 \mathrm{H} 1$ and $1 \mathrm{H} 2$ test vehicles.

Test vehicle design refinements. Preliminary design of capsules and assemblies for $1 \mathrm{H} 2$ and $3 \mathrm{H} 1$ were done. Differences are shown in Table 8-6. 


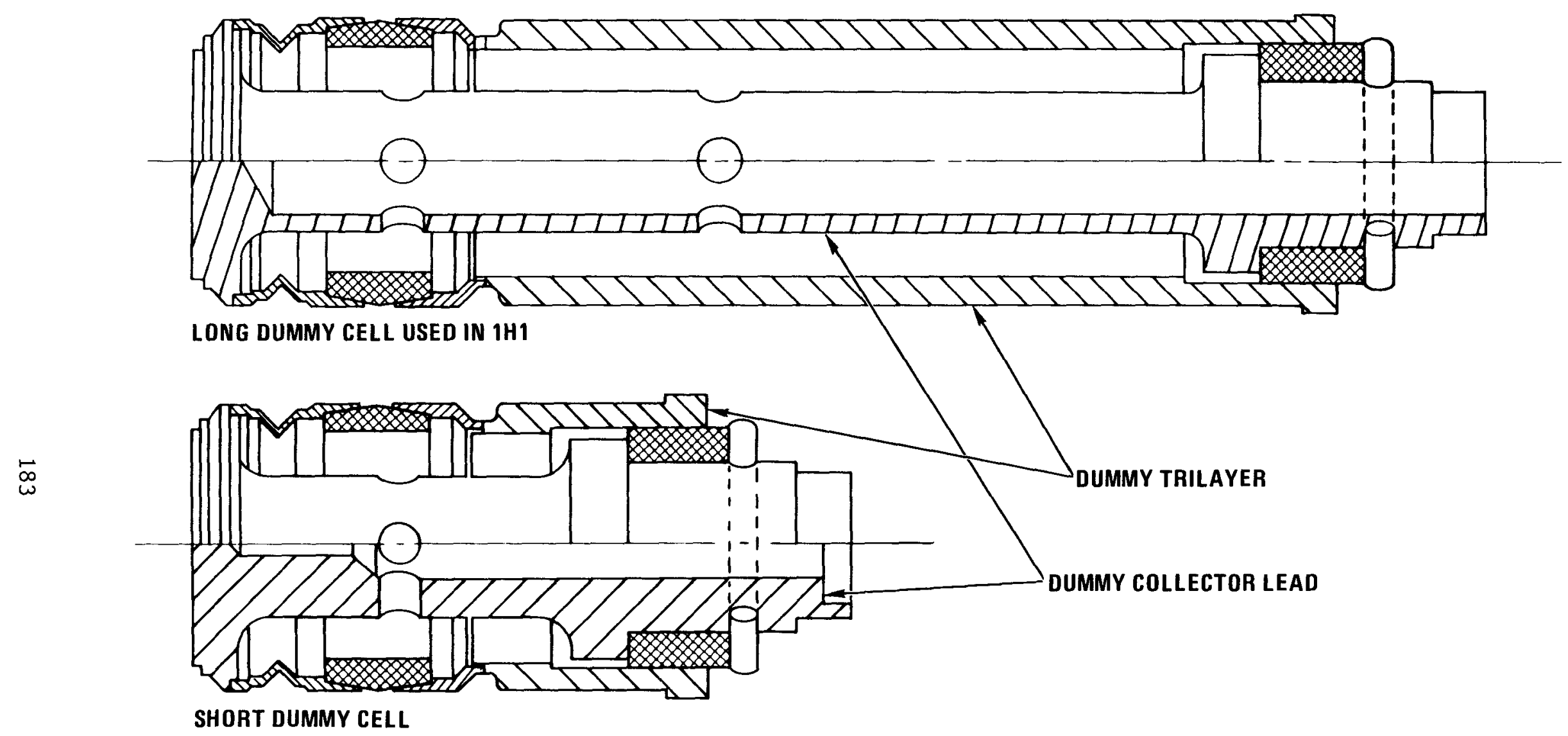

Figure 8-14 - Dummy Converter Changes 


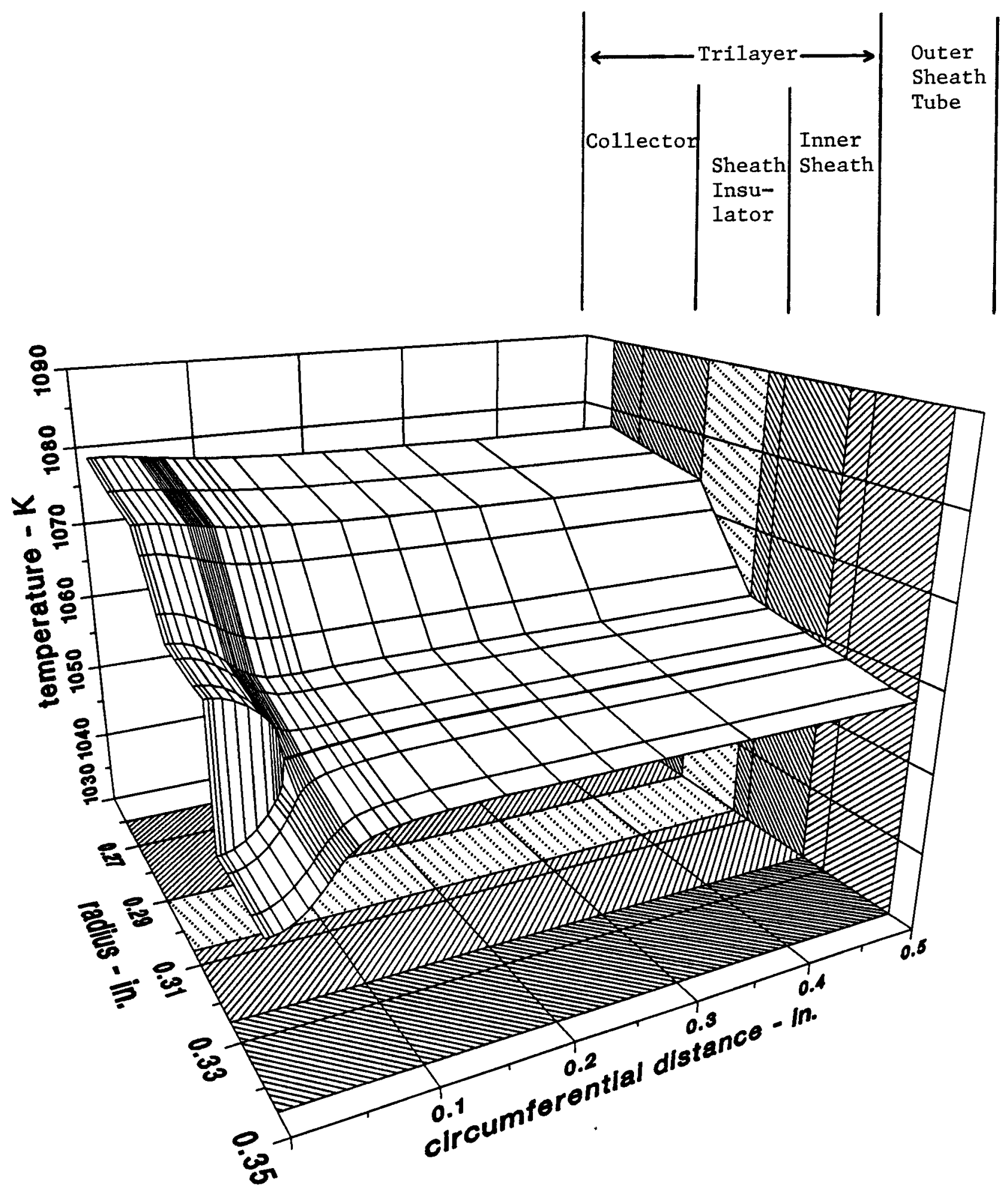

Figure 8-15 - Temperatures resulting from 0.1 in. disbond spot 


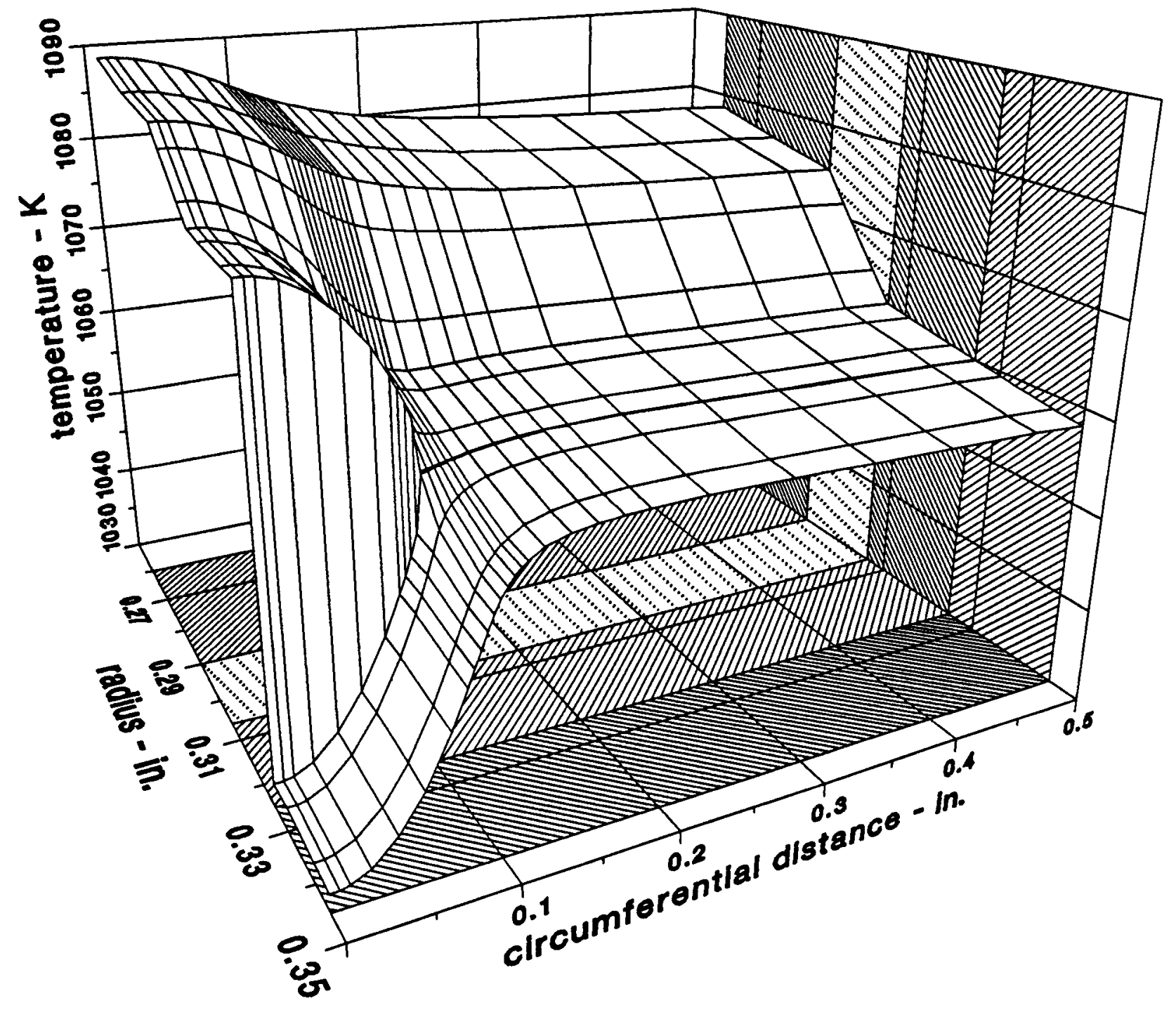

Figure 8-16 - Temperatures resulting from 0.2 in. disbond spot 


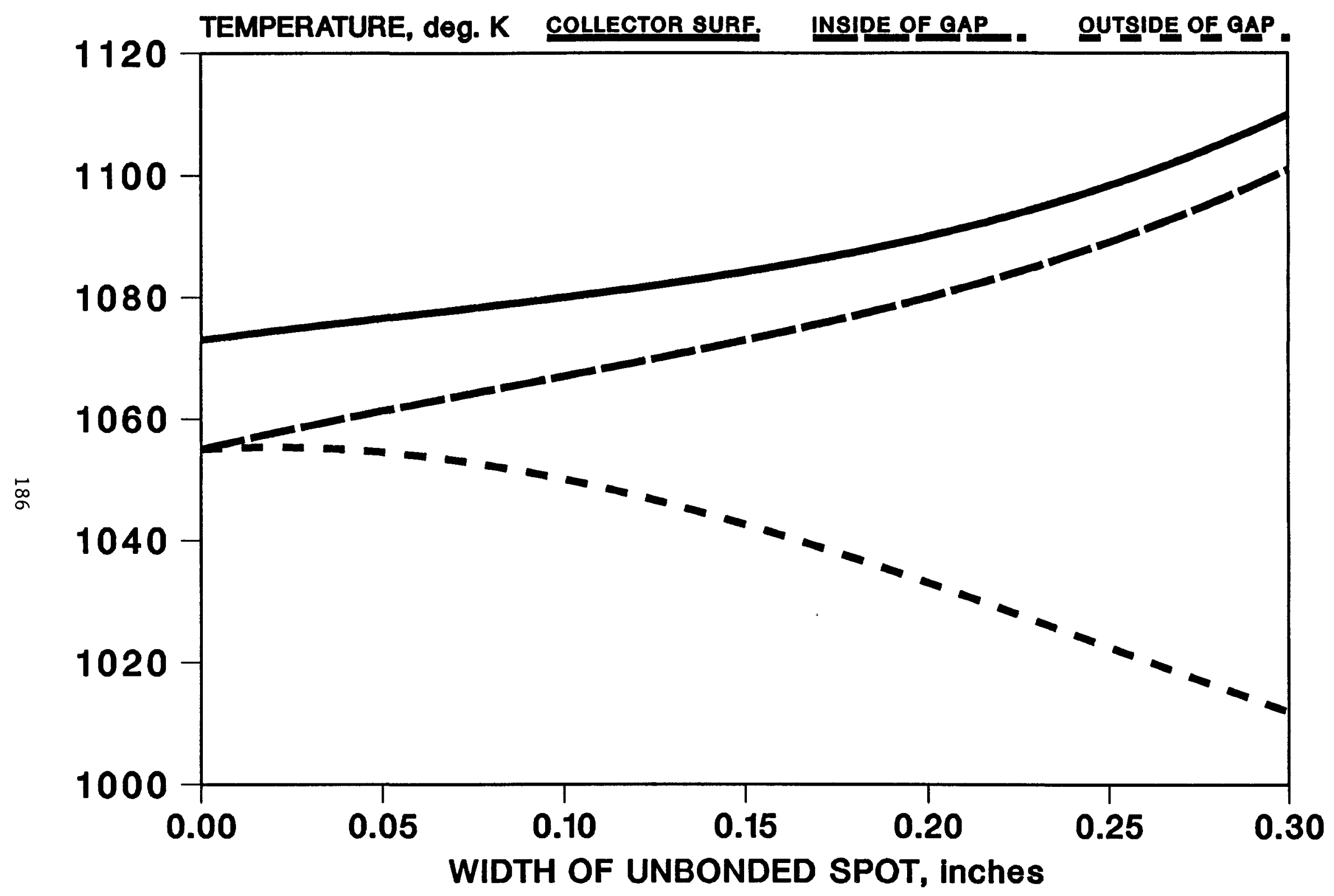

Figure 8-17 - Effects of disbond spot size on trilayer and sheath temperatures 
TABLE 8-6

TEST VEHICLE DIFFERENCES

Test Article Feature

Number of thermocouples

Modified f.p. pichopen

F.P. collection chamber gauge
1H1

$1 \mathrm{H} 2$

1H3

3H1

3H5

$\begin{array}{rrrrr}12 & 12 & 12 & 16 & 16 \\ \text { No } & \text { No } & \text { Yes } & \text { No } & \text { No } \\ \text { No } & \text { No } & \text { No } & \text { Yes } & \text { Yes }\end{array}$

\subsection{TFE FABRICATION}

TFE fabrication is based on an all welded TFE assembly to improve reliability and fabrication economy. Assembly of converters and TFEs in a clean room atmosphere is necessary to ensure that contamination of electrodes is minimized, and the effect of particulate contamination on subsequent fuel element degassing operations is eliminated. In order to provide for stable long term converter operation, bulk degassing is performed for machined components and subassemblies to remove sources of gas that could degrade TFE performance. Accurate rotary weld fixturing and electron beam welding techniques are specified for converter and TFE assembly operation to help control and minimize welding distortion from weld shrinkage. The electron beam welder chamber is installed as part of the clean room so that the benefits of clean room assembly extend to the assembly welding operations.

Final degassing and cesium loading of TFEs must be performed within an ultra high vacuum chamber utilizing all metal-to-metal seals and ion pumping to provide sensitive leak checking methods and vacuum safety should a power failure occur with the TFE at degassing temperature $\left(\sim 1250^{\circ} \mathrm{C}\right)$.

Impurities in test environments have contributed to fast embrittlement and failure of TFE envelopes. An appropriate test environment for TFEs is within a static envelope filled with high purity inert gas. The test containment must be sealed by welding, with ceramic-to-metal seals for power and instrumentation lead feedthroughs. It must be vacuum degassed to remove residual impurities before inert gas backfilling to provide the test environment. 
Reproducible converter and TFE performance requires use of a consistent set of speciflcations and procedures for TFE material procurement, and component machining assembly and processing.

A system of manufacturing controls incorporating detailed machine shop and assembly processing travelers is used. Materials, component and assembly procurement and processing specifications, and detailed scheduling methods are necessary to guide the fabrication effort. These systems were designed to comply with the Quality Assurance program applied to the overall program activity.

Summary of past work. TFE fabrication and development facilities and equipment were setup and development and fabrication tasks were performed during the past reporting periods. The facilities included processing laboratorles for chemical cleaning, tungsten vapor deposition, vacuum processing and brazing, clean room assembly and electron beam welding.

Three rotary welding fixtures were fabricated, tested and used to complete welding parameter development for the ten H-series TFEs (with liquid cesium reservoir) weld joint geometries. Processes and equipment were setup or developed for sheath tube fabrication, sheath tube nickel electroplating and bonding, tungsten emitter electropolishing, emitter final machining, final processing (final degassing, sheath tube bonding and cesium loading) of TFEs, and ultrasonic testing of bonded trilayers and sheath tube bonds. An H-series TFE mockup was fabricated to demonstrate all TFE assembly processes through final processing operations. The mockup confirmed that the selected assembly processes and tooling were approprlate, with only minor changes, for H-series TFE fabrication.

Fabrication of H-series TFE components and subassemblies during earlier reporting periods included preparation of sintered, machined and degassed $\mathrm{UO}_{2}$ fuel pellets for $1 \mathrm{H} 1$ and $1 \mathrm{H} 2$, isostatically processed graded alumina trilayers, and tungsten tantalum emitter assemblies. Batches of ceramic-to-metal seals were prepared through component machining, metallizing and brazing, and finish machining steps. 
1H1 TFE fabrication progressed to completion of the plasma sprayed emitter electric lead-to-cell and dummy cell subassembly in the last reporting period. The sheath tube was completed and electroplated with nickel in preparation for installation over the TFE cells and electric lead. Other major subassemblies completed included the cesium reservoir, cesium reservoir heater and the emitter electric lead sheath.

Travelers and fabrication process and product specifications covering all of the TFE fabrication work were prepared and formally published within the GA document control system.

\subsubsection{Fabrication Process Development}

Fabrication process development tasks were completed to define the exact process parameters required for TFE fabrication, and to investigate and resolve unanticipated problems arising during TFE assembly steps.

Final processing station. Bonding of the 1 H1 mockup, performed last reporting period in part to test the final processing station, illustrated a weakness in the bonding station hot zone heater system design. The final processing system functional characteristics are illustrated in Fig. 8-18. The heater subassembly was damaged because tight assembly tolerances within a spring loading system caused binding of an alumina insulating plate that supports the .040 inch diameter tantalum wire heating element. The spring loading system was rebuilt to incorporate boron nitride bearings to provide more uniform preload.

Electron beam welding. Welding parameters required to join the $1 \mathrm{H} 1$ primary containment electric lead to the cesium reservoir block were developed and qualified with a sertes of five weld samples. Similar qualification was performed for pumpout tube weld backs and for the cesium reservoir to cesium reservoir heater subassembly weld. Computer control features of the electron beam welder were used to precisely locate the welds by turning the beam on and off to prevent damage to structures adjacent to the welds, such as heater wires and pumpout tubulation. 


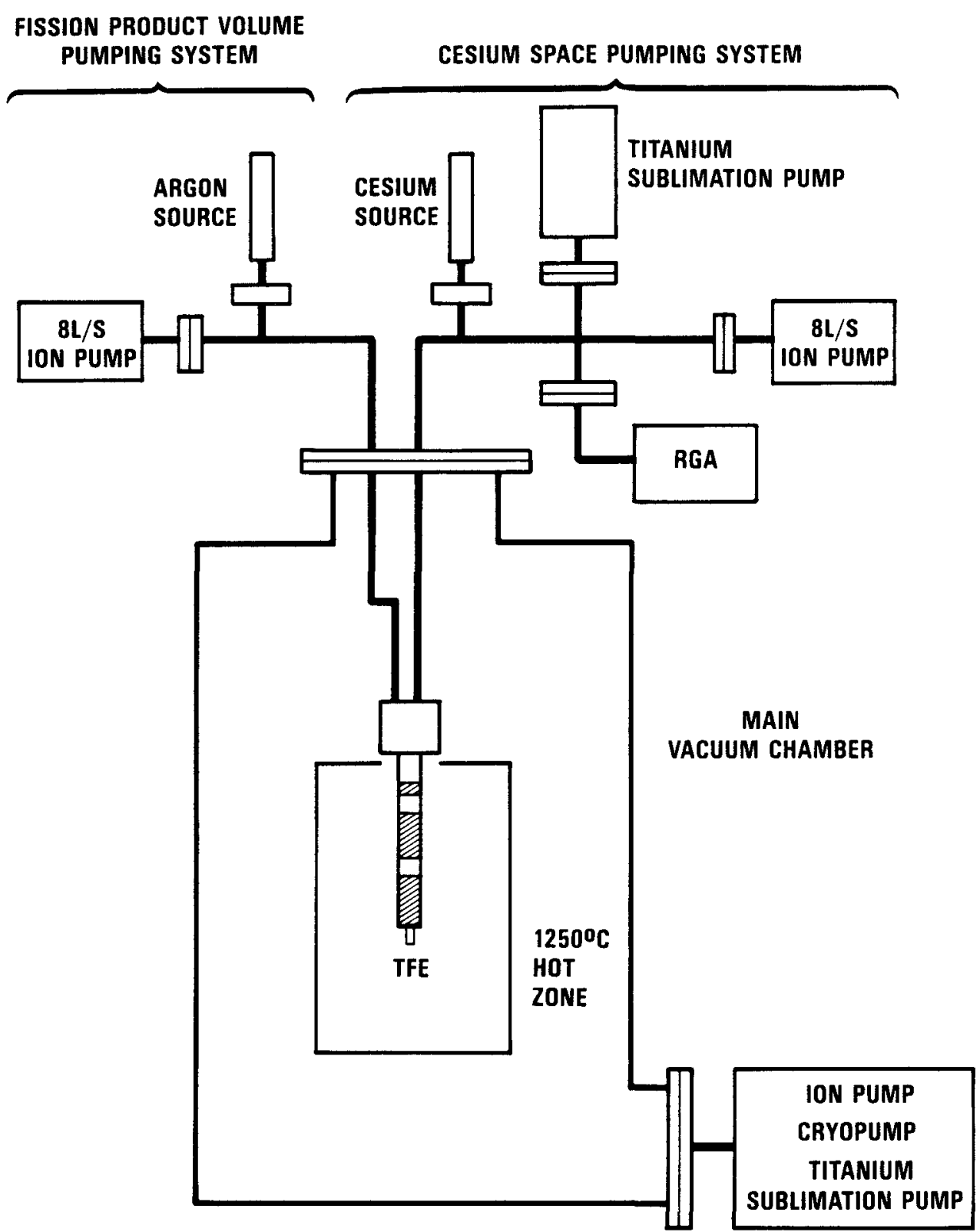

$1-468(18)$

Figure 8-18 - Fina1 Processing Station 
Chloride tungsten deposition apparatus. Deposition of tungsten by hydrogen reduction of tungsten hexachloride is used to provide a high work function emitter surface $(0=5.0 \mathrm{eV})$ of $\langle 110\rangle$ orfented tungsten. The yield of this process was improved through changes to the equipment and raw materials. Perlodic air inleakage or chlorine outleakage during a few deposition runs at connections of flexible tubing to the glass system caused early termination of the process. More frequent replacement of polymer gas transfer tubing and improved tubing connection methods improved system reliability in terms of leaks. A further improvement to flexible metal bellows tubing with teflon sealed fittings as replacement for polymer tubing is planned. Commercially available feedstock (fluoride tungsten deposition scrap) for the chloride process was contaminated with pieces of copper, stainless steel and other metals requiring extensive etching and degassing to prepare suitable material for the chlorination chip bed in the deposition apparatus. A large diameter reusable mandrel was prepared and is presently used to produce fluoride tungsten chips for the chloride process. A fluoride deposit of suitable thickness is prepared, cleaned and broken into chips. The chips are vacuum degassed at $2073^{\circ} \mathrm{K}$ prior to use.

Alumina raw stock material quality. Failure of the lead sheath ceramic-to-metal seal during assembly of the 1 H1 TFE cesium reservoir to electric lead (see Section 8.4.2) and subsequent failure analyses stimulated development of a test for alumina raw material quality. The seal, which failed through development of a slight leak after a series of adjacent welds, was removed from the TFE for examination at the site of the leak.

Metallographic and scanning microscopic examination of the failed seal revealed the flaw that caused the leak was a small region of second phase silica contamination in the nominally pure Coors AD999 alumina ceramic. The flaw, shown in Fig. 8-19, contained microcracks through the silica phase and extended as a line of particulate contamination from the internal diameter of the ceramic to near the outside diameter in the section examined. It is thought that welding stresses induced a crack already present in the ceramic second phase to penetrate through the outside diameter of the seal. No other flaws were found. An inspection technique 


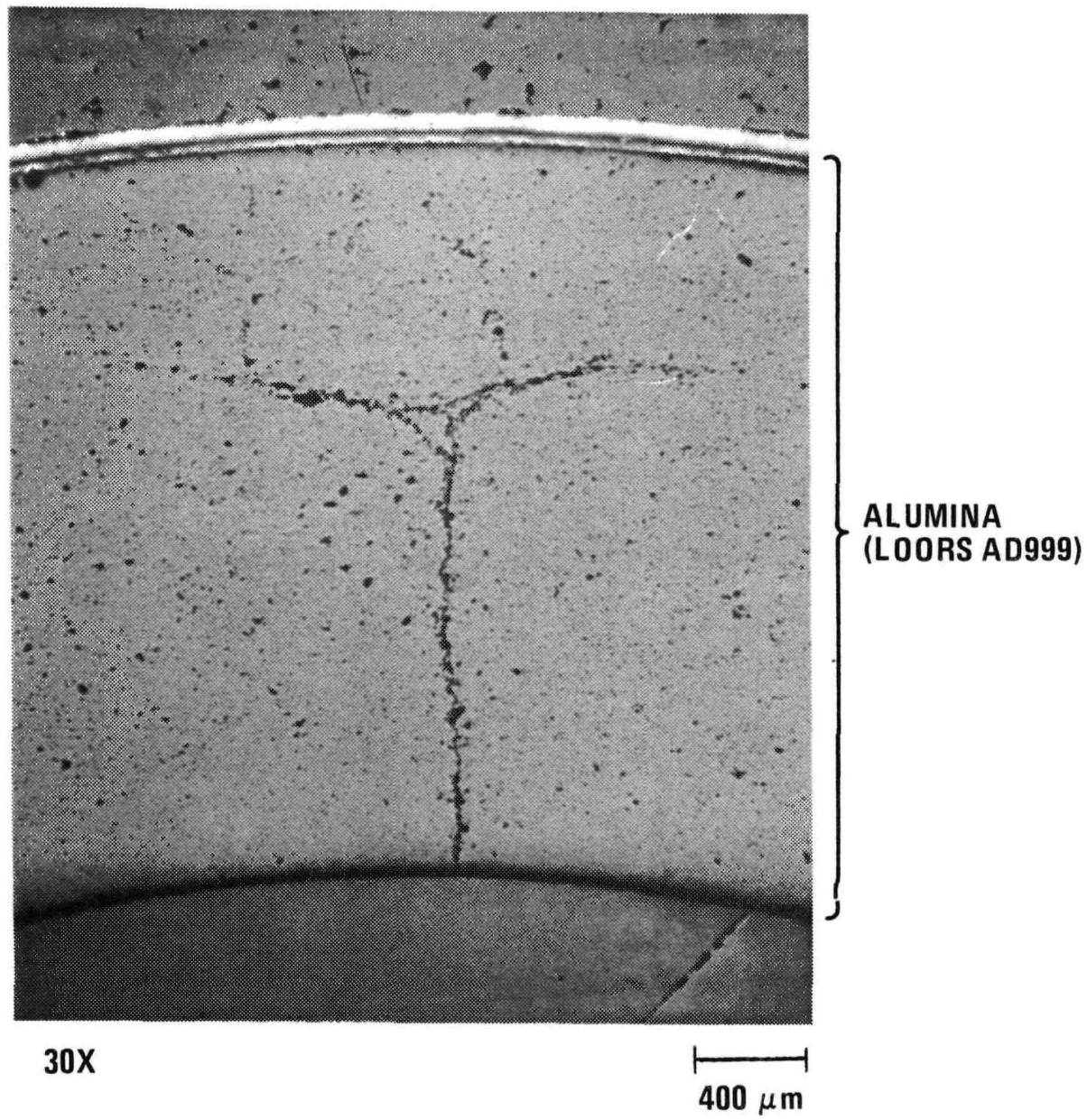

\footnotetext{
Figure 8-19 - Microstructure of flaw found at 1 H1 stem seal leak site. The dark grains delineating the defect are silica that contains many microcracks.
} 
and specification, based on "candling" methods, were derived for examination of ceramic tubing used as raw stock for ceramic-to-metal seal fabrication. With an intense lamp illuminating the tubing internal diameter, the material is examined for linear indications and dark spots with a 7 power microscope. Such indications cause rejection of the material. Approximately half of the tubing inspected to-date was rejected for flaw indications.

Primary containment. Installation of a TFE into a contamination free primary containment envelope requires that the TFE and instrumentation leads be degassed to remove contaminants within the envelope at temperatures above those expected during operation before the containment is backfilled with purified inert gas (helium) and sealed. Preparation for this process was completed this period. An exhaust system was designed and constructed for the envelope degassing process. The system as installed in a vacuum chamber for processing is shown schematically in Fig. 8-20. The current plan for $1 \mathrm{H} 1$ is to degas the containment by heating zones $\mathrm{H}_{1}$ and $\mathrm{H}_{2}$ to raise zone $\mathrm{H}_{2}$ to $\sim 500^{\circ} \mathrm{C}$ with other portions of the containment $\left(\mathrm{H}_{1}\right.$ and pinchoff tubulation) at around $300^{\circ} \mathrm{C}$. Subsequent to degassing and leak checking, the containment will be backfilled to $200 \mathrm{~mm} \mathrm{Hg}$ of helium $\left(<.1 \mathrm{ppm} \mathrm{O}_{2}\right)$ and pinched off.

To assure a leak tight assembly for $1 \mathrm{H} 1$, a fixture for qualification leak checking of the hard seal was fabricated. Electron bombardment brazing of tantalum sheathed heater wire leads through the hard seal was successfully demonstrated with copper-10\% $\mathrm{N}$ braze using the heating filaments and holders planned for the primary encapsulation.

\subsubsection{H-Series Fabrication}

Assembly of TFE $1 \mathrm{HI}$ was completed through final processing and lead attachment, and installation into the primary containment was initiated. Several impediments to progress were experienced in the process and are discussed in the paragraphs below.

Once plasma spraying of the TFE $1 H 1$ intercell and lead regions was 


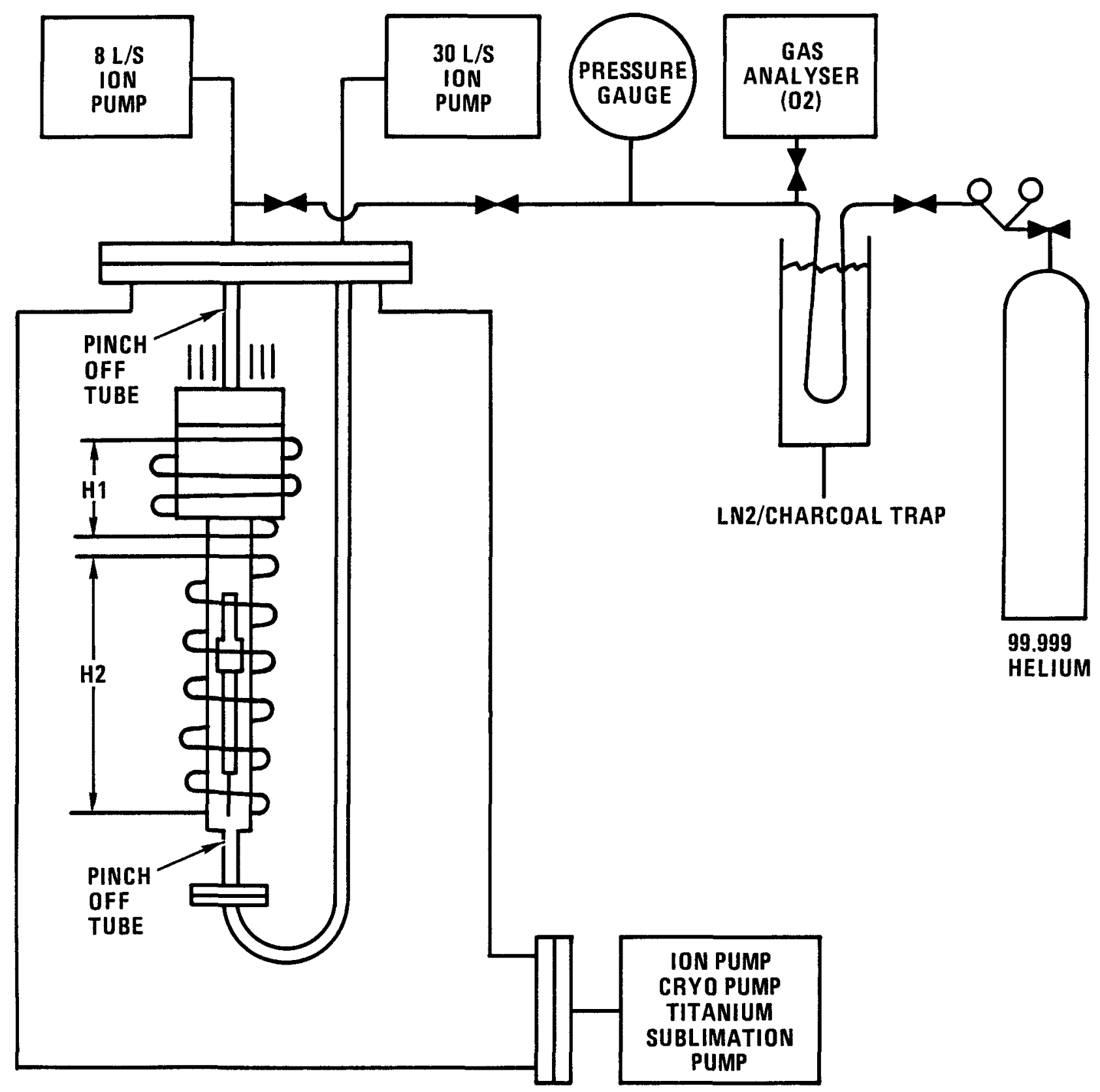

Figure 8-20 - Primary containment degassing setup 
completed, the sheath tube was sized for installation and nickel plated at the end of the last reporting period. Both the sheath tube and TFE exhibited a slight bow (.005 in.) and, based upon successful past experience, it was planned to install the TFE into the sheath tube with bow directions aligned. The sheath tube was left in its holder and was successfully placed over the emitter electric lead and cell. However, it galled as it passed onto the dummy cell collector. The sheath tube holder, which held the tube in an unbowed condition, should have been removed from the tube at the point the tube was slid onto the dumny cell. It was determined that a prudent course of action without technical drawbacks was to leave the sheath tube in this position, weld it to the dummy collector and machine away material at the other end to regain the originally intended configuration. This work was successfully performed and the lead sheath and cesium reservoir subassemblies were welded to the sheath tube and emitter lead. It was determined that the lead sheath ceramic-to-metal seal had developed a small leak after this weld sequence. Rework and repair was accomplished to cut away the damaged seal and to rebuild the TFE structure. The reasons for the seal leakage were covered in Section 8.4.1. Figure 8-21 shows the TFE setup in the rotary weld fixture for welding the lead sheath (hand held) to the TFE sheath tube (on the left) and the cesium reservoir subassembly (on the right).

Once the leaking seal was replaced exhaust tubulation was welded to the fission gas and cesium space tubulation, the TFE appeared as shown in Fig. 8-22.

The TFE was wire wrapped with $.020 \mathrm{in}$. diameter tungsten wire over the trilayer segments, installed into the final processing station and degassed. The sheath tube was bonded to the trilayer segments (collector and lead) by heating to $1225^{\circ} \mathrm{C}$ for four hours.

Repetition of cesium space and fission product space degassing operations were required because vacuum system leaks external to the TFE resulted from the system bakeout procedures. For example, compression ports attaching the TFE to fission product volume and cesium space pumping systems (see Fig. 8-18) leaked after the degassing sequence when tightened 


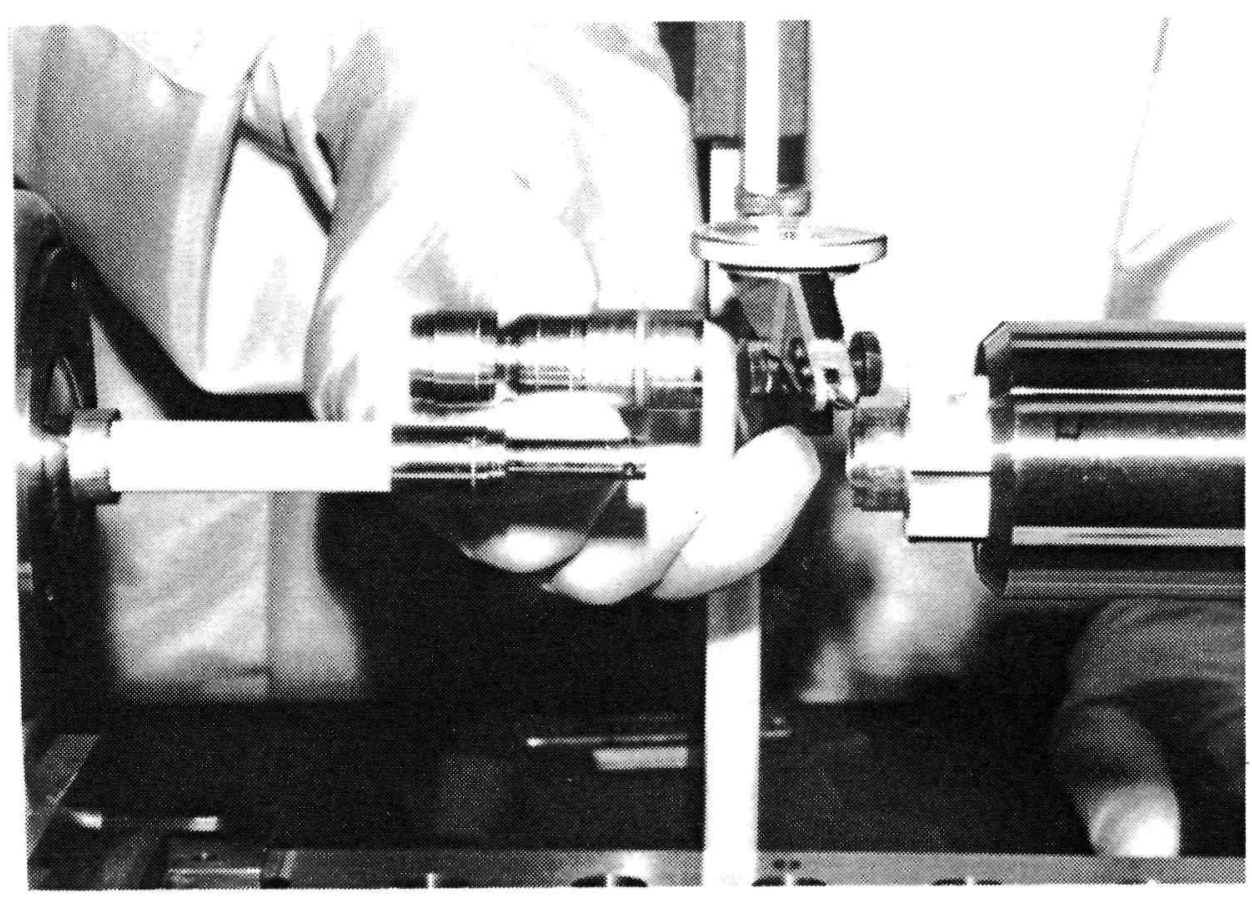

Figure 8-21 - Cesium reservoir lead sheath and sheath tube weld setup for TFE $1 \mathrm{H} 1$ 


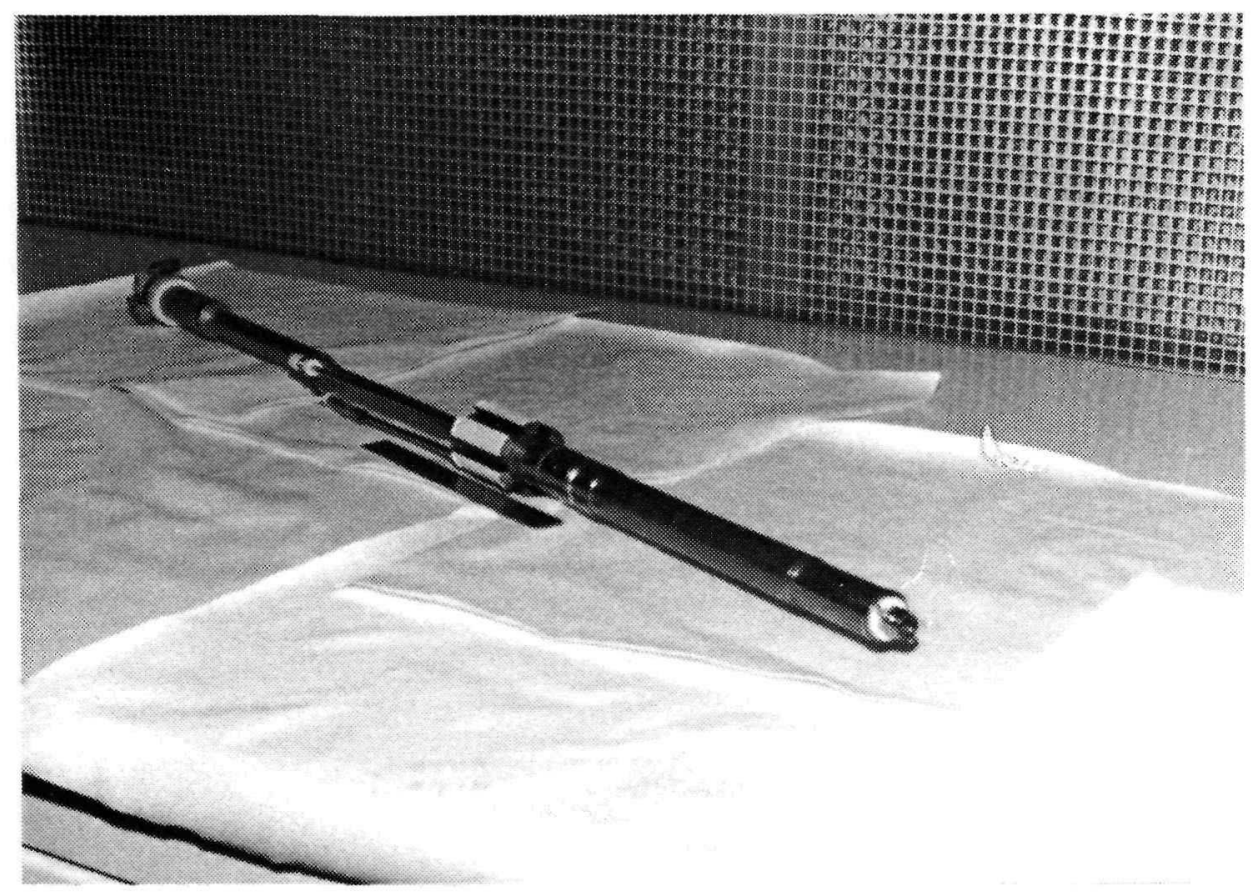

Figure 8-22 (a) - View showing dummy ce11 insulator Note: Instrumentation slots in the cesium reservoir

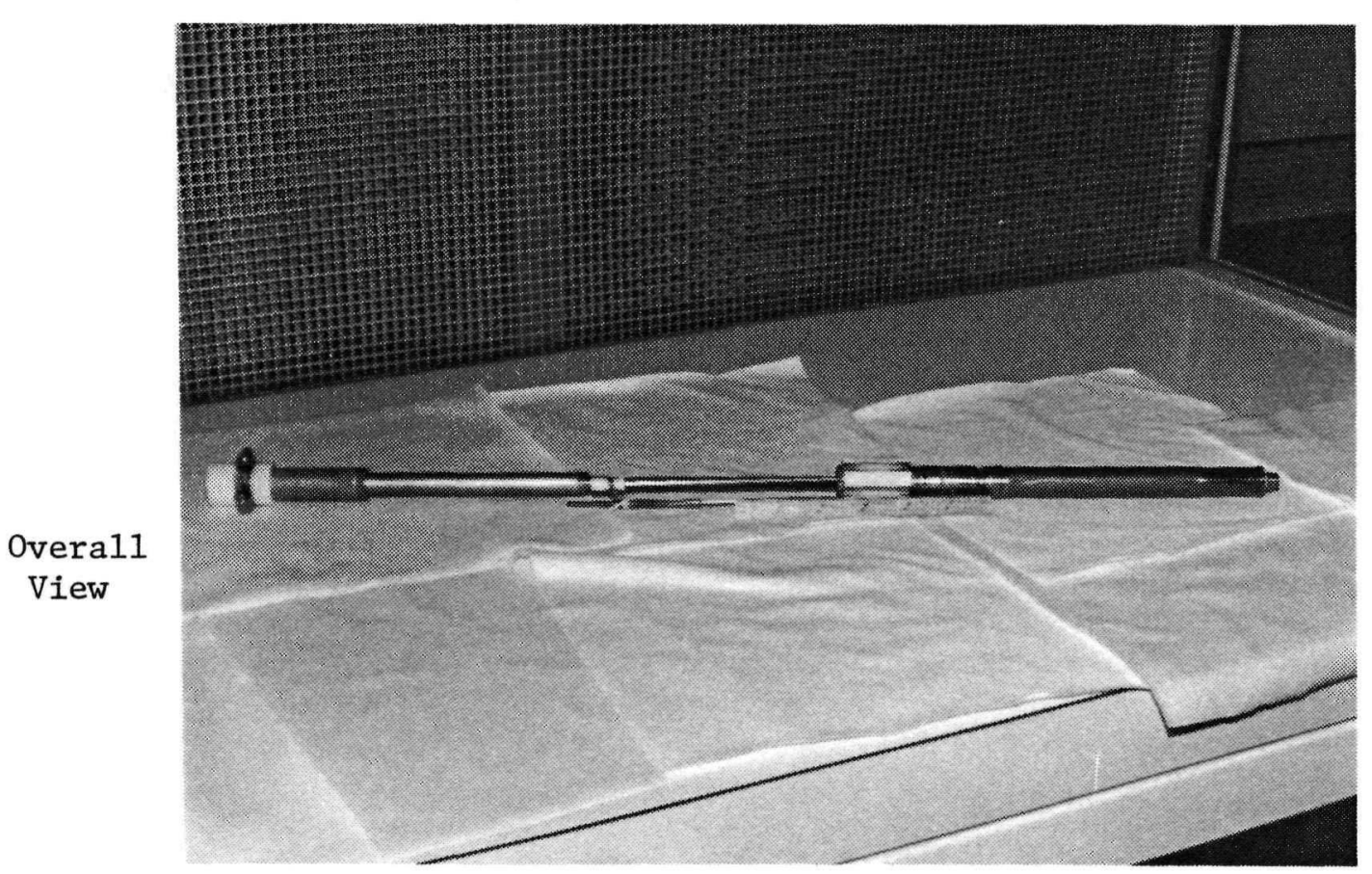

Figure 8-22 (b) - TFE 1 H1 prepared for final processing. The white teflon caps protect the cesium and fission gas volumes from contaminants. 
to the manufacturer's recommended torque. Higher torques resolved the problem, but the degassing steps were repeated.

Cesium distillation into the TFE was accomplished and subsequent inspection of the sheath tube bonding by ultrasonic testing showed the bond to be generally free from defects and fully acceptable for TRIGA reactor testing.

Electrical leads were welded to the ceslum reservoir (emitter potential) and dumy cell (collector potential) with the collector heater installed, and the cesium reservoir heater was welded to the cesium reservoir. Figure 8-23 shows the emitter potential lead and cesium reservoir heater attached to the cesium reservoir.

By the end of the reporting period, the TFE was set up on fixtures for encapsulation into its primary containment and attachment of leads and thermocouples was inftiated.

The emitter-transition piece for TFE 1 H2 was completed, electropolished, degassed and loaded with $\mathrm{UO}_{2}$ fuel. The subassembly was machined at the transition piece for electrical lead attachment to prepare for cell assembly welding. Table 8-7 shows a summary of the cell and TFE fabrication status.

Component fabrication included completion of a trilayer and lead trilayer segment for TFE 1H2, fabrication of emitters through the bond to transition piece for TFEs through $3 \mathrm{H} 1$ and preparation of ceramic-to-metal seals for TFEs through $1 \mathrm{H} 3$.

All primary and secondary containment components for TFE encapsulation were completed for TFEs $1 \mathrm{H} 1$ and $1 \mathrm{H} 2$. Electric leads (collector potential) were plasma sprayed with alumina to prepare for installation. A primary containment alignment fixture to support and align the TFEs at the required final containment position while leads and insulators are attached to the TFE and hard seal was fabricated and setup for the TFE 1H1. The fixture will also be used for electron bombardment heater wire brazing to the hard seal feedthroughs. 


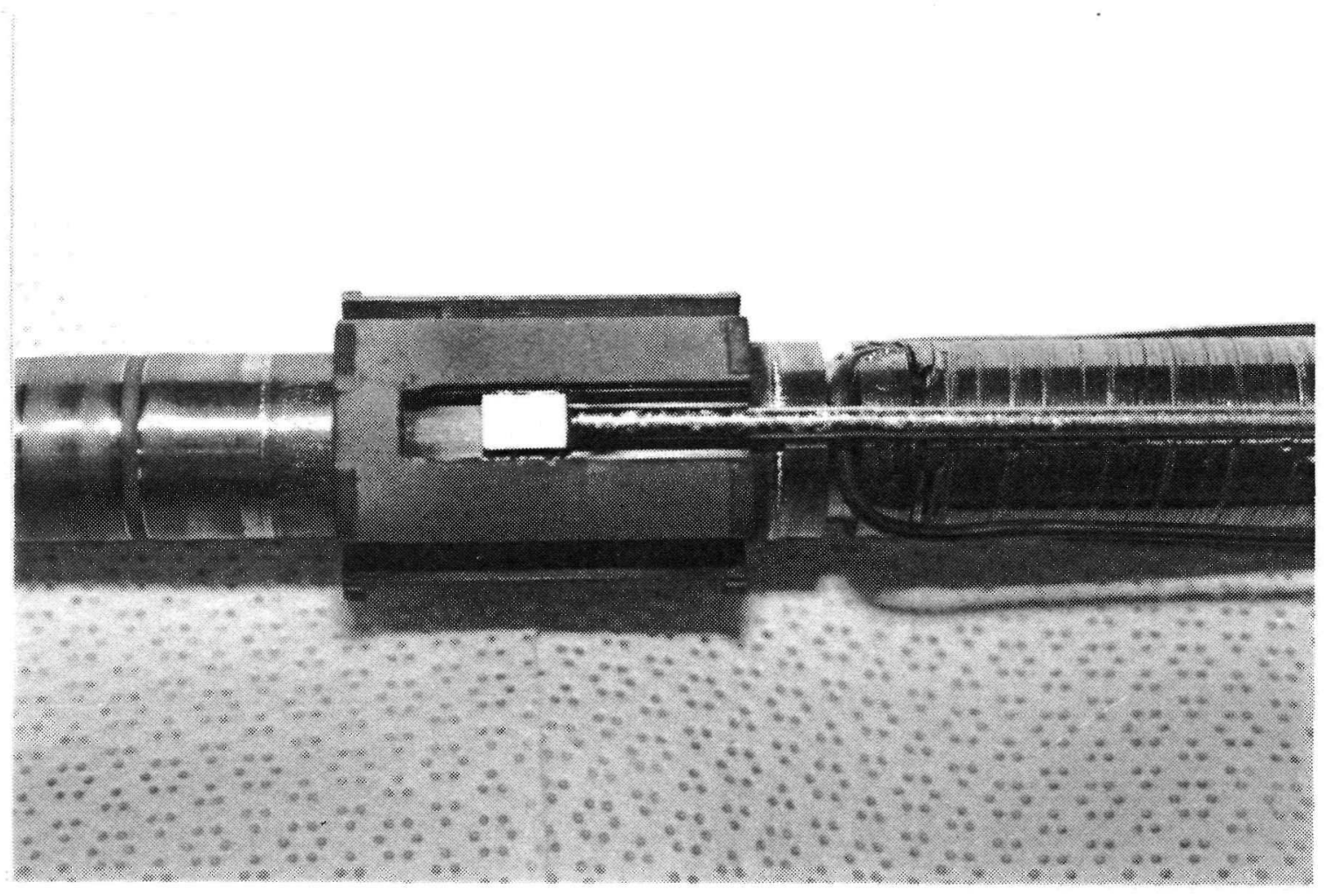

Figure 18-23 - View of 1 H1 emitter potential lead welded into a cesium reservoir slot with the cesium reservoir heater joined to the reservoir on the right. The cesium reservoir diameter is $\sim 1.2$ inches. 
TABLE $8-7$

CELL AND TFE FABRICATION STATUS SUMMARY THROUGH FEBRUARY 29. 1988

Major Cell Components

Fluoride deposited emitter

Chloride deposited emitter

Emitter transition

Fue 1

Trilayer

Ceramic-to-metal seals

Subassemblies

Fueled emitter

Cell assembly

TFE :

CELLS :

Emitter lead assembly

Cesium reservoir assembly

TFE Assemb1y

Cells welded

Sheath tube welded

TFE Final Processing

Instrumentation

Bonding complete

Test Containment

Primary penetration

Containment housings

Primary encapsulation complete

Secondary encapsulation complete

Begin Testing

$7 / 88$ 11/88 $12 / 88$

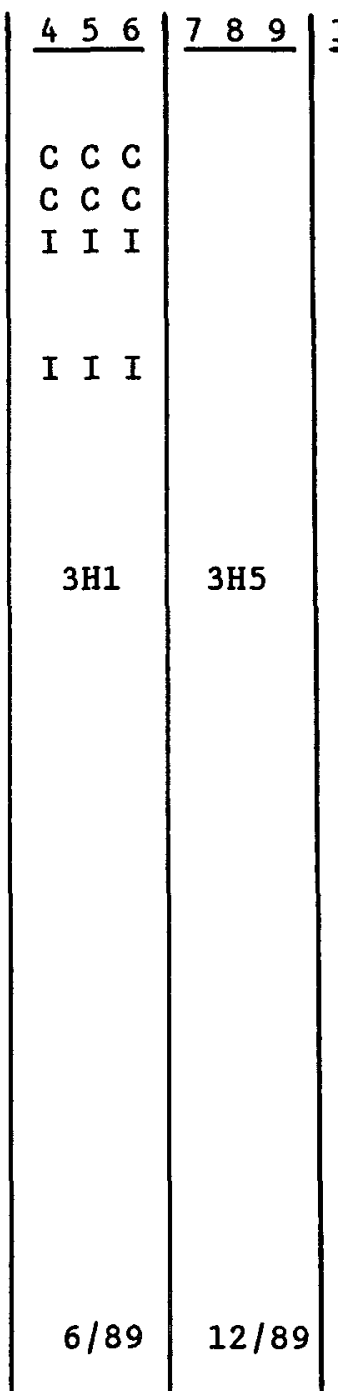

$\begin{array}{llllll}10 & 11 & 12 & 13 & 14 & 15\end{array}$

$\begin{array}{llllll}16 & 17 & 18 & 19 & 20 & 21\end{array}$

$\begin{array}{llllll}22 & 23 & 24 & 25 & 26 & 27\end{array}$

Legend: C - Complete

I - In Process 